\title{
WestVirginiaUniversity
}

THE RESEARCH REPOSITORY @ WVU

Graduate Theses, Dissertations, and Problem Reports

2007

\section{Modeling the effect of a spray on a liquid film on a heated surface}

\author{
Rageey M. Youssef \\ West Virginia University
}

Follow this and additional works at: https://researchrepository.wvu.edu/etd

\section{Recommended Citation}

Youssef, Rageey M., "Modeling the effect of a spray on a liquid film on a heated surface" (2007). Graduate Theses, Dissertations, and Problem Reports. 2784.

https://researchrepository.wvu.edu/etd/2784

This Dissertation is protected by copyright and/or related rights. It has been brought to you by the The Research Repository @ WVU with permission from the rights-holder(s). You are free to use this Dissertation in any way that is permitted by the copyright and related rights legislation that applies to your use. For other uses you must obtain permission from the rights-holder(s) directly, unless additional rights are indicated by a Creative Commons license in the record and/ or on the work itself. This Dissertation has been accepted for inclusion in WVU Graduate Theses, Dissertations, and Problem Reports collection by an authorized administrator of The Research Repository @ WVU.

For more information, please contact researchrepository@mail.wvu.edu. 
Modeling the Effect of a Spray on a Liquid Film on a Heated Surface

Rageey M. Youssef

Dissertation submitted to

The College of Engineering and Mineral Resources

\author{
At \\ West Virginia University \\ In partial fulfillment of the requirements \\ for the degree of \\ Doctor of Philosophy \\ In \\ Civil and Environmental Engineering \\ Donald Gray, Ph.D., P.E., Chair \\ John Kuhlman, Ph.D., P.E. \\ Robert Eli, Ph.D., P.E. \\ Wade Huebsch, Ph.D. \\ Manfred Boehm, Ph.D.
}

Morgantown, West Virginia

2007

Keywords; Spray Cooling, Source Term, CFD-ACE+ 


\begin{abstract}
Modeling the Effect of a Spray on a Liquid Film on a Heated Surface
\end{abstract}

\title{
Rageey M. Youssef
}

Thermal management is considered one of the most challenging problems in practical and industrial applications such as space and satellite research. Among the most widely used techniques are spray and jet cooling. However it was found that spray cooling is the most efficient and complex technique. It was not possible to simulate the spray cooling in detail; this was due to a formation of a liquid layer above the heater surface. The interaction between the spray droplets and the liquid layer was studied in the present work indirectly by assuming a pre-existing liquid layer moving in the horizontal direction and modeling the flux of liquid spray as mass and momentum source terms in the continuity and momentum equations respectively for the layer flow. However, the energy equation was not altered because it was assumed that initially the spray and the surrounding are at the same temperature due to the small scale of the model and from the available experimental data. Even though this is not an exact representation of the interaction between the spray and the liquid layer, it gives a very good indication of how to improve the heat transfer.

The influence of adding source terms to the liquid layer on the heat transfer for a laminar flow moving parallel to a horizontal heated flat plate has been simulated. A commercial multiphysics code, CFD-ACE+, was used and verified for Heat, Flow and VOF modules. Three subroutines were written for the mass and momentum source terms, which run as part of the code. Many parameters were changed by using these subroutines, for example, the mass flow rate, the nozzle spacing, the velocity magnitude, the layer thickness and velocity. It was found that the momentum of the spray has a major effect on the heat transfer. The simulations results showed promising results due to adding the source terms on improving the heat transfer. 


\section{Table of Contents}

Abstract............................................................................

List of Figures................................................................

List of Tables......................................................................

Nomenclature..............................................................

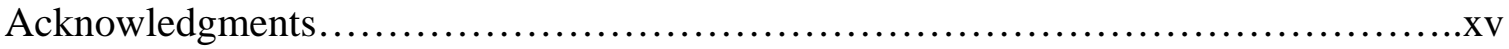

\section{Chapter 1}

Introduction.................................................................

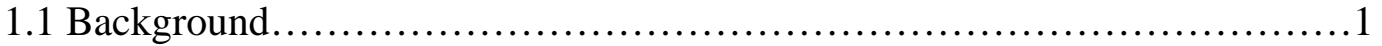

1.2 Objectives.........................................................

1.3 Overview............................................................

\section{Chapter 2}

Literature Review.......................................................... 10

\section{Chapter 3}

Numerical Methods and Techniques.....................................19

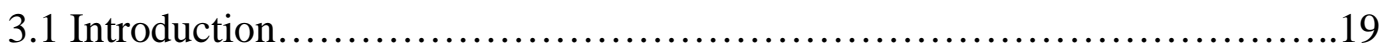

3.2 Numerical Methods....................................................20

3.2.1 Finite Volume Method...................................20

3.2.2 Source Term Linearization....................................24

3.2.3 Finite Difference Equations.................................25

3.3 Velocity-Pressure Coupling .......................................25

3.4 Solution Procedure.................................................26

\section{Chapter 4}

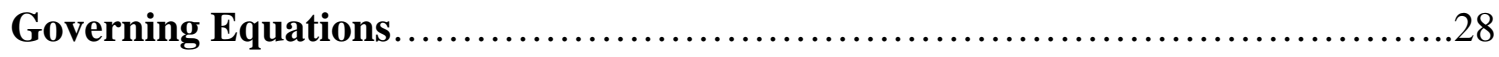

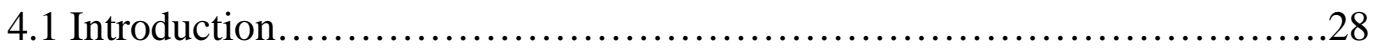

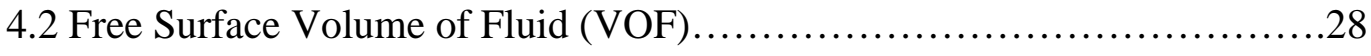


4.2.1 Mixture Properties.........................................29

4.2.2 Theory of Surface Reconstruction.............................30

4.3 Mass Conservation....................................................31

4.4 Momentum Conservation.............................................32

4.5 Navier-Stokes Equations.............................................33

4.6 Energy Equation..................................................

\section{Chapter 5}

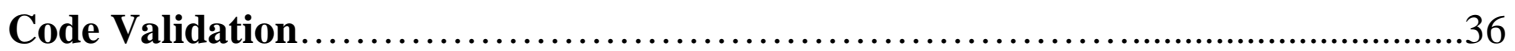

5.1 Introduction........................................................

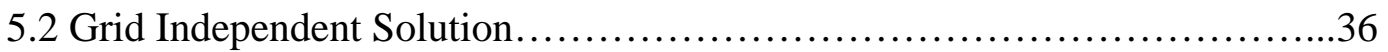

5.3 Flow on Inclined Plane.................................................40

5.4 Laminar Boundary Layer Validation.................................42

5.5 Flat Plate Boundary Layer Validation against Blasius Solution..............44

5.6 Source Term Validation...............................................46

5.7 Thermal Laminar Boundary Layer Validation for Uniform Heat Flux Wall..48

\section{Chapter 6}

Model Setup and Results................................................. 52

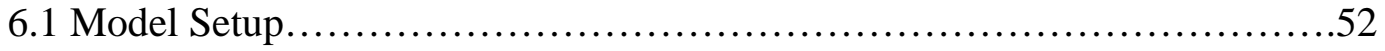

6.2 Results of Numerical Simulations....................................54

6.2.1 Introduction..............................................54

6.2.2 Distribution of Mass and Momentum in Two Dimensional

Planar Spray..............................................56

6.2.3 Effect of Adding Mass and Momentum Source Terms on

Temperature.............................................61

6.2.3.1 Effect of Spray Velocity....................................61

6.2.3.2 Effect of Spray Nozzle Spacing.................................74

6.2.3.3 Effect of Spray Mass Flow Rate.......................85

6.2.4 Effect of Adding Mass and Momentum Source Terms

on Liquid Layer Thickness and Velocity........................92 


\section{Chapter 7}

Conclusions and Recommendations for Future Work...........................96

7.1 Summary and Conclusions..............................................96

7.2 Recommendations for Future Work....................................99

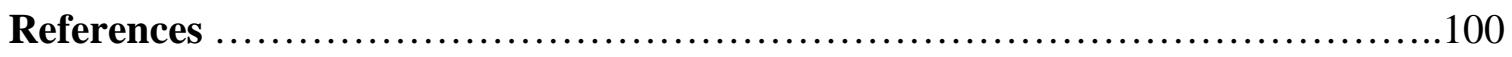

Appendices

A-1 Parabolic Initial Condition Subroutine..................................106

A-2 Parabolic Inlet Profile Subroutine..........................................110

A-3 Mass Source Term Subroutine...........................................114

A-4 U Momentum Source Term Subroutine.....................................121

A-5 V Momentum Source Term Subroutine................................129

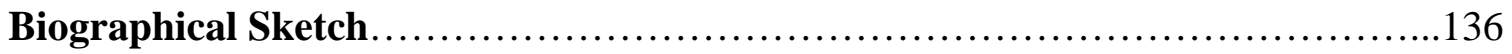




\section{List of Figures}

Figure 1.1 Comparison of Heat Transfer Coefficient for Different Cooling Techniques...2

Figure 1.2 Numerical Model Setup....................................................

Figure 1.3 Spray Cooling Device, Adopted from LPS (The Laboratory for Physical Sciences), University of Maryland ......................................

Figure 1.4 Momentum Driven Spray Cooling........................................6

Figure 1.5 Spray Impinging a Heated Surface........................................ 8

Figure 2.1 Schematic View of Droplet and Film Flow adapted from Kim et al............16

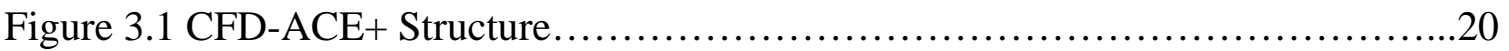

Figure 3.2 Three Dimensional Control Volume.......................................21

Figure 3.3 Numerical Solution Procedures..........................................27

Figure 5.1 Grid Resolution for Two Dimensional Planar 7500 Node Domain.............38

Figure 5.2 Grid Resolution for Two Dimensional Planar 8680 Node Domain............38

Figure 5.3 Grid Resolution for Two Dimensional Planar 12000 Node Domain............39

Figure 5.4 Grid Resolution for Two Dimensional Planar 22000 Node Domain............39

Figure 5.5 Grid Independent Solution with Source Term..............................40

Figure 5.6 Flow on Inclined Plane..................................................

Figure 5.7 Flat Plate Boundary Layer Model Setup and Grid............................43

Figure 5.8 Laminar Boundary Layer Velocity Profile at $\mathrm{x}=1 \mathrm{~m} \ldots \ldots \ldots \ldots \ldots \ldots \ldots \ldots . . .44$

Figure 5.9 Blasius Solution Model Solution.............................................. 45

Figure 5.10 Flat Plate Boundary Validation against Blasius Solution......................46

Figure 5.11 Source Term Validation Initial Condition.................................47

Figure 5.12 Source Term Validation............................................... 48

Figure 5.13 Thermal Boundary Layer Validation Model Results for Water...............50

Figure 5.14 Thermal Boundary Layer Comparison between Numerical Solution and

Integral Solution for Water...........................................50

Figure 5.15 Thermal Boundary Layer Validation Model Results for Air..................51

Figure 5.16 Thermal Boundary Layer Comparison between Numerical Solution and Integral Solution for Air...............................................51

Figure 6.1 Model Setup and Grid..................................................... 


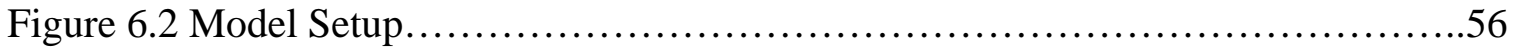

Figure 6.3 Distributions of Mass and Momentum in Two Dimensional Planar Spray.....59 Figure 6.4 Effect of Spray Velocity on Wall Temperature Profile

(Water, $d=200$ microns, $U=1.0 \mathrm{~m} / \mathrm{s}, q^{\prime \prime}=150 \mathrm{~kW} / \mathrm{m}^{2}$ ).............63

Figure 6.5 Effect of Spray Velocity on Nusselt Number

(Water, $d=200$ microns, $U=1.0 \mathrm{~m} / \mathrm{s}, q^{\prime \prime}=150 \mathrm{~kW} / \mathrm{m}^{2}$ )

Figure 6.6 Effect of Spray Velocity on Maximum Temperature Difference

(Water, $d=200$ microns, $U=1.0 \mathrm{~m} / \mathrm{s}, q^{\prime \prime}=150 \mathrm{~kW} / \mathrm{m}^{2}$ )

Figure 6.7 Effect of Spray Velocity on Wall Temperature Profile

(Water, $d=200$ microns, $U=0.5 \mathrm{~m} / \mathrm{s}, q^{\prime \prime}=150 \mathrm{~kW} / \mathrm{m}^{2}$ )

Figure 6.8 Effect of Spray Velocity on Nusselt Number

(Water, $d=200$ microns, $U=0.5 \mathrm{~m} / \mathrm{s}, q^{\prime \prime}=150 \mathrm{~kW} / \mathrm{m}^{2}$ )

Figure 6.9 Effect of Spray Velocity on Maximum Temperature Difference

(Water, $d=200$ microns, $U=0.5 \mathrm{~m} / \mathrm{s}, q^{\prime \prime}=150 \mathrm{~kW} / \mathrm{m}^{2}$ ).............66

Figure 6.10 Effect of Spray Velocity on Wall Temperature Profile

(Water, $d=100$ microns, $U=0.5 \mathrm{~m} / \mathrm{s}, q^{\prime \prime}=150 \mathrm{~kW} / \mathrm{m}^{2}$ )

Figure 6.11 Effect of Spray Velocity on Nusselt Number

(Water, $d=100$ microns, $U=0.5 \mathrm{~m} / \mathrm{s}, q^{\prime \prime}=150 \mathrm{~kW} / \mathrm{m}^{2}$ )

Figure 6.12 Effect of Spray Velocity on Maximum Temperature Difference

(Water, $d=100$ microns, $U=0.5 \mathrm{~m} / \mathrm{s}, q^{\prime \prime}=150 \mathrm{~kW} / \mathrm{m}^{2}$ )..............68

Figure 6.13 Effect of Spray Velocity on Wall Temperature Profile

(FC-72, $d=100$ microns, $U=0.5 \mathrm{~m} / \mathrm{s}, q^{\prime \prime}=25 \mathrm{~kW} / \mathrm{m}^{2}$ )

Figure 6.14 Effect of Spray Velocity on Nusselt Number

$$
\text { (FC-72, } d=100 \text { microns, } U=0.5 \mathrm{~m} / \mathrm{s}, q^{\prime \prime}=25 \mathrm{~kW} / \mathrm{m}^{2} \text { ) }
$$

Figure 6.15 Effect of Spray Velocity on Maximum Temperature Difference

(FC-72, $d=100$ microns, $U=0.5 \mathrm{~m} / \mathrm{s}, q^{\prime \prime}=25 \mathrm{~kW} / \mathrm{m}^{2}$ ).

Figure 6.16 Effect of Spray Velocity on Wall Temperature Profile 
(HFE-7000, $d=100$ microns, $\left.U=0.5 \mathrm{~m} / \mathrm{s}, q^{\prime \prime}=10 \mathrm{~kW} / \mathrm{m}^{2}\right) \ldots \ldots \ldots \ldots . .71$

Figure 6.17 Effect of Spray Velocity on Nusselt Number

(HFE-7000, $d=100$ microns, $\left.U=0.5 \mathrm{~m} / \mathrm{s}, q^{\prime \prime}=10 \mathrm{~kW} / \mathrm{m}^{2}\right) \ldots \ldots \ldots \ldots . . .71$

Figure 6.18 Effect of Spray Velocity on Maximum Temperature Difference

(HFE- 7000, $d=100$ microns, $U=0.5 \mathrm{~m} / \mathrm{s}, q^{\prime \prime}=10 \mathrm{~kW} / \mathrm{m}^{2}$ ).........72

Figure 6.19 Effect of Spray Velocity on Wall Temperature Profile

(Hypothetical Fluid, $d=100$ microns, $U=0.5 \mathrm{~m} / \mathrm{s}, q^{\prime \prime}=50 \mathrm{~kW} / \mathrm{m}^{2}$ ).....73

Figure 6.20 Effect of Spray Velocity on Nusselt Number

(Hypothetical Fluid, $d=100$ microns, $U=0.5 \mathrm{~m} / \mathrm{s}, q^{\prime \prime}=50 \mathrm{~kW} / \mathrm{m}^{2}$ ).....73

Figure 6.21 Effect of Spray Velocity on Maximum Temperature Difference

(Hypothetical Fluid, $d=100$ microns, $U=0.5 \mathrm{~m} / \mathrm{s}, q^{\prime \prime}=50 \mathrm{~kW} / \mathrm{m}^{2}$ ).....74

Figure 6.22 Effect of Nozzle Spacing on Wall Temperature Profile

(Water, $d=200$ microns, $U=0.5 \mathrm{~m} / \mathrm{s}, q^{\prime \prime}=150 \mathrm{~kW} / \mathrm{m}^{2}$ )..............75

Figure 6.23 Effect of Nozzle Spacing on Nusselt Number

(Water, $d=200$ microns, $U=0.5 \mathrm{~m} / \mathrm{s}, q^{\prime \prime}=150 \mathrm{~kW} / \mathrm{m}^{2}$ )..............76

Figure 6.24 Effect of Nozzle Spacing on Maximum Temperature Difference

(Water, $d=200$ microns, $U=0.5 \mathrm{~m} / \mathrm{s}, q^{\prime \prime}=150 \mathrm{~kW} / \mathrm{m}^{2}$ ).............76

Figure 6.25 Effect of Nozzle Spacing on Wall Temperature Profile

(Water, $d=100$ microns, $U=0.5 \mathrm{~m} / \mathrm{s}, q^{\prime \prime}=150 \mathrm{~kW} / \mathrm{m}^{2}$ )

Figure 6.26 Effect of Nozzle Spacing on Nusselt Number

(Water, $d=100$ microns, $U=0.5 \mathrm{~m} / \mathrm{s}, q^{\prime \prime}=150 \mathrm{~kW} / \mathrm{m}^{2}$ ).............78

Figure 6.27 Effect of Nozzle Spacing on Maximum Temperature Difference

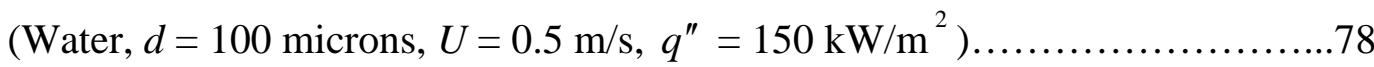

Figure 6.28 Effect of Nozzle Spacing on Wall Temperature Profile

(FC-72, $d=100$ microns, $U=0.5 \mathrm{~m} / \mathrm{s}, q^{\prime \prime}=25 \mathrm{~kW} / \mathrm{m}^{2}$ )

Figure 6.29 Effect of Nozzle Spacing on Nusselt Number

(FC-72, $d=100$ microns, $U=0.5 \mathrm{~m} / \mathrm{s}, q^{\prime \prime}=25 \mathrm{~kW} / \mathrm{m}^{2}$ ) 
Figure 6.30 Effect of Nozzle Spacing on Maximum Temperature Difference

$$
\text { (FC-72, } d=100 \text { microns, } U=0.5 \mathrm{~m} / \mathrm{s}, q^{\prime \prime}=25 \mathrm{~kW} / \mathrm{m}^{2} \text { ) }
$$

Figure 6.31 Effect of Nozzle Spacing on Wall Temperature Profile

(HFE-7000, $d=100$ microns, $U=0.5 \mathrm{~m} / \mathrm{s}, q^{\prime \prime}=10 \mathrm{~kW} / \mathrm{m}^{2}$ )

Figure 6.32 Effect of Nozzle Spacing on Nusselt Number

(HFE-7000, $d=100$ microns, $U=0.5 \mathrm{~m} / \mathrm{s}, q^{\prime \prime}=10 \mathrm{~kW} / \mathrm{m}^{2}$ )

Figure 6.33 Effect of Nozzle Spacing on Maximum Temperature Difference

(HFE- 7000, $d=100$ microns, $U=0.5 \mathrm{~m} / \mathrm{s}, q^{\prime \prime}=10 \mathrm{~kW} / \mathrm{m}^{2}$ )

Figure 6.34 Effect of Nozzle Spacing on Wall Temperature Profile

(Hypothetical Fluid, $d=100$ microns, $U=0.5 \mathrm{~m} / \mathrm{s}, q^{\prime \prime}=50 \mathrm{~kW} / \mathrm{m}^{2}$ )....83

Figure 6.35 Effect of Nozzle Spacing on Nusselt Number

(Hypothetical Fluid, $d=100$ microns, $U=0.5 \mathrm{~m} / \mathrm{s}, q^{\prime \prime}=50 \mathrm{~kW} / \mathrm{m}^{2}$ )....84

Figure 6.36 Effect of Nozzle Spacing on Maximum Temperature Difference

(Hypothetical Fluid, $d=100$ microns, $U=0.5 \mathrm{~m} / \mathrm{s}, q^{\prime \prime}=50 \mathrm{~kW} / \mathrm{m}^{2}$ )....84

Figure 6.37 Effect of Spray Mass Flow Rate on Wall Temperature Profile

(Water, $d=200$ microns, $U=0.5 \mathrm{~m} / \mathrm{s}, q^{\prime \prime}=150 \mathrm{~kW} / \mathrm{m}^{2}$ )

Figure 6.38 Effect of Spray Mass Flow Rate on Nusselt Number

(Water, $d=200$ microns, $U=0.5 \mathrm{~m} / \mathrm{s}, q^{\prime \prime}=150 \mathrm{~kW} / \mathrm{m}^{2}$ ).

Figure 6.39 Effect of Spray Mass Flow Rate on Maximum Temperature Difference

(Water, $d=200$ microns, $U=0.5 \mathrm{~m} / \mathrm{s}, q^{\prime \prime}=150 \mathrm{~kW} / \mathrm{m}^{2}$ ).............87

Figure 6.40 Effect of Spray Mass Flow Rate on Wall Temperature Profile

(Water, $d=100$ microns, $U=0.5 \mathrm{~m} / \mathrm{s}, q^{\prime \prime}=150 \mathrm{~kW} / \mathrm{m}^{2}$ )

Figure 6.41 Effect of Spray Mass Flow Rate on Nusselt Number

(Water, $d=100$ microns, $U=0.5 \mathrm{~m} / \mathrm{s}, q^{\prime \prime}=150 \mathrm{~kW} / \mathrm{m}^{2}$ )

Figure 6.42 Effect of Spray Mass Flow Rate on Maximum Temperature Difference

(Water, $d=100$ microns, $U=0.5 \mathrm{~m} / \mathrm{s}, q^{\prime \prime}=150 \mathrm{~kW} / \mathrm{m}^{2}$ )

Figure 6.43 Effect of Spray Mass Flow Rate on Wall Temperature Profile 
(FC-72, $d=100$ microns, $\left.U=0.5 \mathrm{~m} / \mathrm{s}, q^{\prime \prime}=25 \mathrm{~kW} / \mathrm{m}^{2}\right) \ldots \ldots \ldots \ldots \ldots . . . . .90$

Figure 6.44 Effect of Spray Mass Flow Rate on Nusselt Number

(FC-72, $d=100$ microns, $U=0.5 \mathrm{~m} / \mathrm{s}, q^{\prime \prime}=25 \mathrm{~kW} / \mathrm{m}^{2}$ )

Figure 6.45 Effect of Spray Mass Flow Rate on Maximum Temperature Difference

(FC-72, $d=100$ microns, $U=0.5 \mathrm{~m} / \mathrm{s}, q^{\prime \prime}=25 \mathrm{~kW} / \mathrm{m}^{2}$ )

Figure 6.46 Effect of Spray Velocity on Layer Thickness

(Water, $d=100$ microns, $U=0.5 \mathrm{~m} / \mathrm{s}, q^{\prime \prime}=150 \mathrm{~kW} / \mathrm{m}^{2}$ )

Figure 6.47 Effect of Spray Velocity on Layer Surface Velocity

(Water, $d=100$ microns, $U=0.5 \mathrm{~m} / \mathrm{s}, q^{\prime \prime}=150 \mathrm{~kW} / \mathrm{m}^{2}$ ).

Figure 6.48 Effect of Nozzle Spacing on Layer Thickness

(Water, $d=100$ microns, $U=0.5 \mathrm{~m} / \mathrm{s}, q^{\prime \prime}=150 \mathrm{~kW} / \mathrm{m}^{2}$ ).

Figure 6.49 Effect of Nozzle Spacing on Layer Surface Velocity

(Water, $d=100$ microns, $U=0.5 \mathrm{~m} / \mathrm{s}, q^{\prime \prime}=150 \mathrm{~kW} / \mathrm{m}^{2}$ )

Figure 6.50 Effect of Spray Mass Flow Rate on Layer Thickness

(Water, $d=100$ microns, $U=0.5 \mathrm{~m} / \mathrm{s}, q^{\prime \prime}=150 \mathrm{~kW} / \mathrm{m}^{2}$ )

Figure 6.51 Effect of Spray Mass Flow Rate on Layer Surface Velocity

(Water, $d=100$ microns, $U=0.5 \mathrm{~m} / \mathrm{s}, q^{\prime \prime}=150 \mathrm{~kW} / \mathrm{m}^{2}$ ) 


\section{List of Tables}

Table 6.1 Working Fluid Properties...........................................59

Table 6.2 Simulation Parameters of Water..........................................60

Table 6.3 Simulation Parameters of FC-72.........................................60

Table 6.4 Simulation Parameters of HFE-7000....................................61

Table 6.5 Simulation Parameters of Hypothetical Fluid................................61 


\section{Nomenclature}

\section{Roman Symbols}

$$
\begin{aligned}
& A_{i}=\text { area of the face } i \\
& a_{n b} \quad=\quad \text { values at neighboring cells } \\
& \mathrm{B}=\text { bottom cell, node } \\
& C_{i} \quad=\quad \text { mass flux across the phase } \\
& \mathrm{E}=\text { east cell, node } \\
& F \quad=\quad \text { fluid } \\
& g=\text { gravitational acceleration }\left[\mathrm{m} / \mathrm{s}^{2}\right] \\
& h_{o}=\text { total enthalpy }[\mathrm{J}] \\
& I \quad=\quad \text { internal energy }[\mathrm{J}] \\
& K=\text { thermal conductivity }[\mathrm{W} / \mathrm{m} \mathrm{K}] \\
& \mathrm{m}^{\bullet} \quad=\quad \text { mass flow rate }[\mathrm{kg} / \mathrm{s}] \\
& \mathrm{N}=\text { north cell, node } \\
& \mathrm{N} \quad=\quad \text { number of cells } \\
& n=\text { number of spray drops } \\
& \mathrm{P} \quad=\quad \text { cell center } \\
& p \quad=\quad \text { pressure }[\mathrm{Pa}] \\
& Q \quad=\quad \text { heat flux }\left[\mathrm{W} / \mathrm{m}^{2}\right] \\
& q^{\prime \prime} \quad=\quad \text { heat flux }\left[\mathrm{kW} / \mathrm{m}^{2}\right] \\
& q_{s}^{\prime} \quad=\quad \text { Volume of spray }\left[\mathrm{m}^{3} / \mathrm{s} . \mathrm{rad}\right] \\
& \mathrm{S} \quad=\quad \text { south cell, node } \\
& S_{M x}=\text { momentum source term in } x \text { direction }\left[\mathrm{N} / \mathrm{m}^{3}\right] \\
& S_{M y}=\text { momentum source term in } y \text { direction }\left[\mathrm{N} / \mathrm{m}^{3}\right] \\
& S_{M z}=\text { momentum source term in } z \text { direction }\left[\mathrm{N} / \mathrm{m}^{3}\right] \\
& S_{h} \quad=\quad \text { energy source term }[\mathrm{W} / \mathrm{m}] \\
& S_{m}=\quad \text { mass source term }\left[\mathrm{kg} \mathrm{m}^{-3} / \mathrm{s}\right]
\end{aligned}
$$




$$
\begin{aligned}
& T \quad=\quad \text { temperature }[\mathrm{K}] \\
& \mathrm{T}=\text { top cell, node } \\
& t=\text { time }[\mathrm{s}] \\
& \mathrm{U}=\text { horizontal velocity in the } x \text { direction }[\mathrm{m} / \mathrm{s}] \\
& u=\text { horizontal velocity in the } x \text { direction }[\mathrm{m} / \mathrm{s}] \\
& V_{i}^{n}=\text { velocity component in the direction that is normal to the face } \\
& V_{\text {cut }}=\quad \text { volume of the cell truncated by the cutting plane } \\
& V_{C} \quad=\quad \text { volume of the whole cell } \\
& v_{d} \quad=\quad \text { spray droplet volume }\left[\mathrm{m}^{3}\right] \\
& v_{s} \quad=\quad \text { spray droplet speed }[\mathrm{m} / \mathrm{s}] \\
& v \quad=\quad \text { cell volume }\left[\mathrm{m}^{3}\right] \\
& v=\text { horizontal velocity in the } y \text { direction }[\mathrm{m} / \mathrm{s}] \\
& \mathrm{W}=\text { west cell } \\
& w \quad=\quad \text { horizontal velocity in the } z \text { direction }[\mathrm{m} / \mathrm{s}] \\
& X=\text { cartesian coordinate } \\
& \mathrm{xc}=\quad \text { cell horizontal distance measured from the plate edge [m] } \\
& Y=\text { cartesian coordinate } \\
& \mathrm{y} \quad=\quad \text { layer thickness }[\mathrm{m}] \\
& \text { yc }=\quad \text { cell vertical distance between the injector and the plate }[\mathrm{m}] \\
& Z=\text { cartesian coordinate } \\
& Z_{s} \quad=\quad \text { nozzle spacing }[\mathrm{m}]
\end{aligned}
$$

\section{Greek Symbols}

$$
\begin{array}{lll}
\delta & = & \text { boundary layer thickness }[\mathrm{m}] \\
\delta_{P, E} & = & \text { distance between } \mathrm{E} \text { and } \mathrm{P} \\
\delta_{C 2, C 1} & = & \text { distance between } \mathrm{C} 2 \text { and } \mathrm{C} 1 \\
\eta & = & \text { dimensionless similarity variable } \\
\mu & = & \text { dynamic viscosity }[\mathrm{kg} / \mathrm{ms}] \\
v & = & \text { kinematic viscosity }\left[\mathrm{m}^{2} / \mathrm{s}\right]
\end{array}
$$




$$
\begin{array}{lll}
\rho & = & \text { density }\left[\mathrm{kg} / \mathrm{m}^{3}\right] \\
\tau & = & \text { shear stress }\left[\mathrm{kg} / \mathrm{m} \mathrm{s}^{2}\right] \\
\phi & = & \text { variable } \\
\langle\phi\rangle & = & \text { volume-averaged quantity } \\
\phi_{2} & = & \text { value of the property for fluid two } \\
\phi_{1} & = & \text { value of the property for fluid one }
\end{array}
$$

\section{Subscripts}

$$
\begin{array}{lll}
W & = & \text { wall } \\
\infty & = & \text { infinite away from the domain } \\
\max & = & \text { maximum } \\
i, j, k & = & \text { components in three dimensions } \\
\mathrm{e} & = & \text { cell faces }
\end{array}
$$

\section{Superscripts}

$\begin{array}{lll}\mathrm{o} & = & \text { older time step } \\ \mathrm{n} & = & \text { normal direction }\end{array}$

\footnotetext{
Abbreviations

$\mathrm{CHF}=$ critical heat flux

Pr = Prandtl number

Re $=$ Reynolds number

$\mathrm{Nu}=$ Nusselt Number

$\mathrm{PDE}=$ Partial Differential Equation

$\mathrm{FDE}=$ Finite Difference Equation

SIMPLEC $=$ Semi-Implicit Method for Pressure-Linked Equations Consistent

CGS = Conjugate Gradient Squared

AMG = Algebraic MultiGrid

VOF $=$ Volume of Fluid
} 


\section{Acknowledgements}

I would like to take this opportunity to thank my advisor Professor Donald Gray for giving me the chance to continue my study in West Virginia University. Dr. Gray guided me throughout my dissertation and helped me through his valuable knowledge and expertise. Also, I would like to thank Dr. John Kuhlman for his advice and comments. I would like also to thank my committee members, Dr. Robert Eli, Dr. Wade Huebsch and Dr. Manfred Boehm for their help and giving me the chance to learn from their comments.

I would like to thank the Air Force Office of Scientific Research, USAF, for supporting my graduate studies under grant number F49620-03-1-0276. The views and conclusions contained herein are my own and should not be interpreted as necessarily representing the official polices or endorsements, either expressed or implied, of the Air Force Office of Scientific Research or U.S. Government.

I would like to thank Dr. Kirk Yerkes and his team at the Air Force Research Laboratory for their support throughout the entire project. I would like to thank Dr. Samuel Lowry and Dr. Vernon Cole of CFD Research Corporation for helping me in using and modifying the CFD-ACE+ code. I thank Mr. Deepak Mehra, Mr. Paul Krietzer, Ms. Shannon Glaspell, and Mr. Andy Hunnell for their help in the project.

I thank my parents and my family for helping me to become what I am now. I would like also to thank my wife Sozan Kras for standing beside me. Also, I would like to thank my little angels Jessica and Andrew Youssef who gave me the reason to work hard. 


\section{Chapter 1}

\section{Introduction}

\subsection{Background}

Due to the enormous increase in heat flux required to cool smaller, more powerful electronic components, thermal management becomes critical to system performance. Required heat fluxes are expected to exceed $10 \mathrm{MW} / \mathrm{m}^{2}$ by the end of the decade. The conventional air cooled system is not sufficient for removing this heat flux. Different techniques have been used for this purpose. The most widely used techniques are impinging jets and spray cooling. In both techniques liquid-vapor phase change may occur. However, in liquid-vapor phase change a much higher heat flux can be removed. The main objective of thermal management techniques is the critical heat flux (CHF) that can be achieved. The ideal thermal management technique is one which provides high heat removal rates uniformly over a large area, with a high CHF.

Jets can be classified into submerged jets in which the jet flows within the same fluid in the same state (i.e. gas into gas or liquid into liquid) and free surface jets in which the liquid jet is injected into gas. Spray cooling occurs when liquid is forced through a small orifice, shattering into a dispersion of fine droplets that then impinge onto the heated surface. After the droplets hit the surface they spread and if the spreading area is small enough, a continuous thin liquid film covering the surface is formed. The advantage of spray cooling over jet cooling is that it more uniformly cools a large surface

and removes large amounts of heat, while in jet cooling the surface temperature will be highly non-uniform.

A comparison of the heat transfer coefficients for different cooling techniques is shown in Figure 1.1 as found in [1]. These techniques include free convection, forced convection, boiling convection, and jet and spray cooling using different working fluids. It can be seen that the highest heat transfer coefficients occur in spray cooling. 
Heat Transfer Coefficient $\mathrm{W} / \mathrm{cm}^{2} .{ }^{\circ} \mathrm{C}$

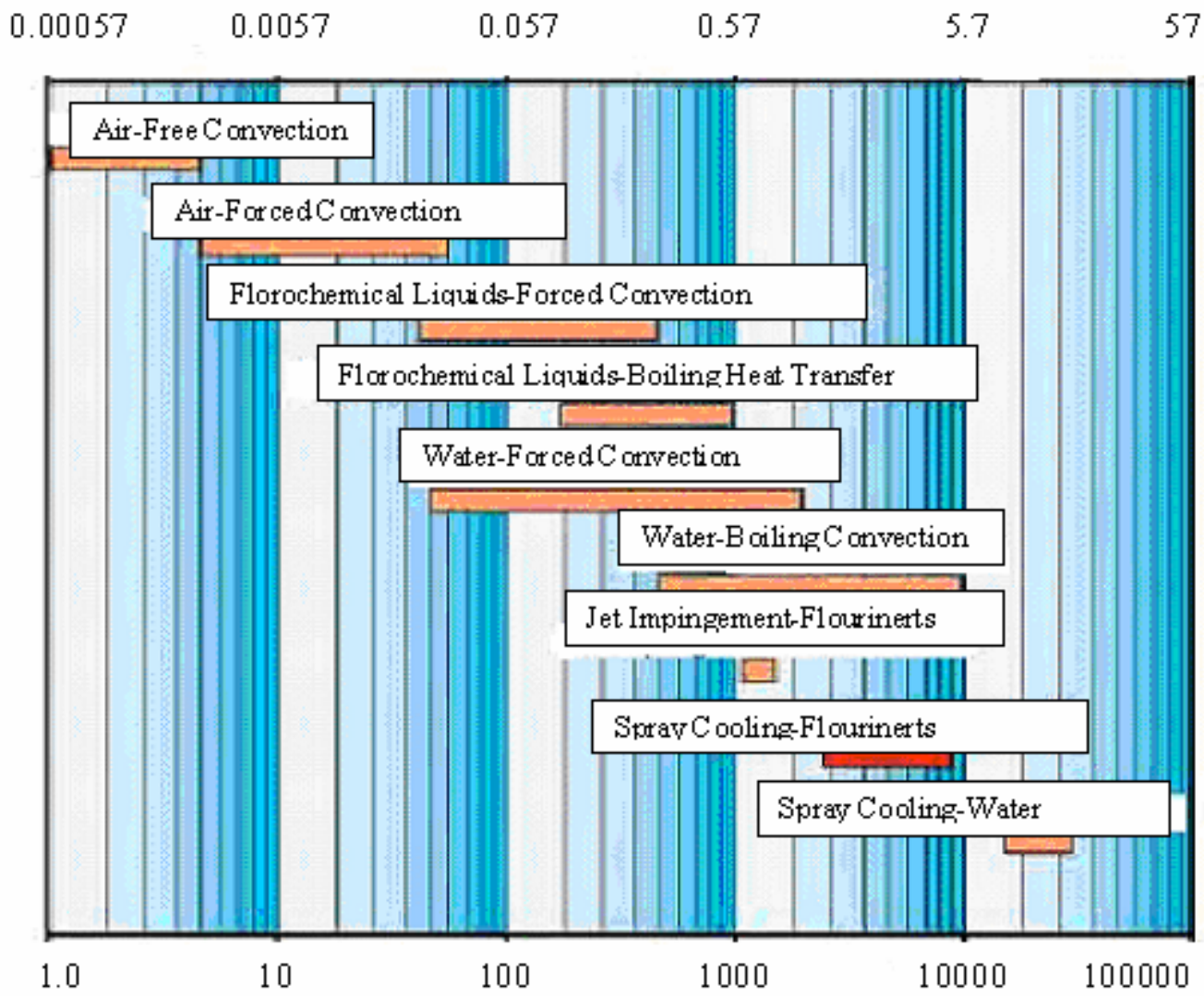

Heat Transfer Coefficient B.T.U./ Hr.Ft. ${ }^{2}{ }^{\circ} \mathrm{F}$

Figure 1.1 Comparison of Heat Transfer Coefficient for Different Cooling Techniques. [1] 


\subsection{Objectives}

To improve spray cooling, it was necessary to simulate the effect of spray velocity, nozzle spacing and spray mass flow rate on heat transfer. In order to simulate the spray impinging on a heated flat plate a new technique was developed by writing a series of user subroutines which run as a part of the commercial code CFD-ACE+. From the review of the previous research done in this area it was found that as the droplets impinge onto the heated surface, a thin layer is formed on the heater surface. As a result of the literature survey and computations it was concluded that the best way to investigate spray cooling is to specify the existence of a thin layer and then study the interaction between the layer and the impinging spray droplets.

A two dimensional planar numerical model was built as shown in Figure 1.2. The dimensions are $0.005^{*} 0.003 \mathrm{~m}^{2}$. The model has four boundaries; the bottom boundary is the heater, the left boundary is an inlet, the right and top boundaries are outlets. The spray nozzle is located in the top left corner of the computational domain. The nozzle spacing and the layer thickness are shown in the figure. The model was built to resemble some practical spray cooling applications. Figure 1.3 shows an actual spray cooling device adapted from the Laboratory for Physical Sciences, University of Maryland [2]. In this figure one can see Integrated Circuit (IC) chips, while the spray is injected onto the surface at an angle. A second application for this model is supercomputer cooling. Figure 1.4 shows a concept presented by G. Pautsch [3] which is known as momentum driven spray cooling. In this cooling technique the spray momentum forces the liquid layer to move horizontally. In the top of the figure one can see an elevation and side view where the grey color is the tube in which the liquid is supplied to the nozzles. The blue color represents the spray and the liquid layer. The heated surface is represented by the orange color. The left of the figure shows the tube and the nozzles while the right of the figure is another view of the top one.

To investigate the effect of the interaction between the spray droplets and the liquid layer on the temperature profile, three subroutines were written to add mass and 
momentum source terms to the continuity and momentum equations respectively. However no change was made to the energy equation because it was assumed that due to the small scale of the model and based on the available experimental data the spray and the surrounding were both initially at the same temperature. However the spray and film temperatures were not the same.

The mass source term was added to the upper cells in the liquid layer and specifically to half the layer thickness. The mass added to each cell in the upper layer was calculated by dividing the total spray mass flow rate $(\mathrm{kg} / \mathrm{s})$ by the number of cells in the

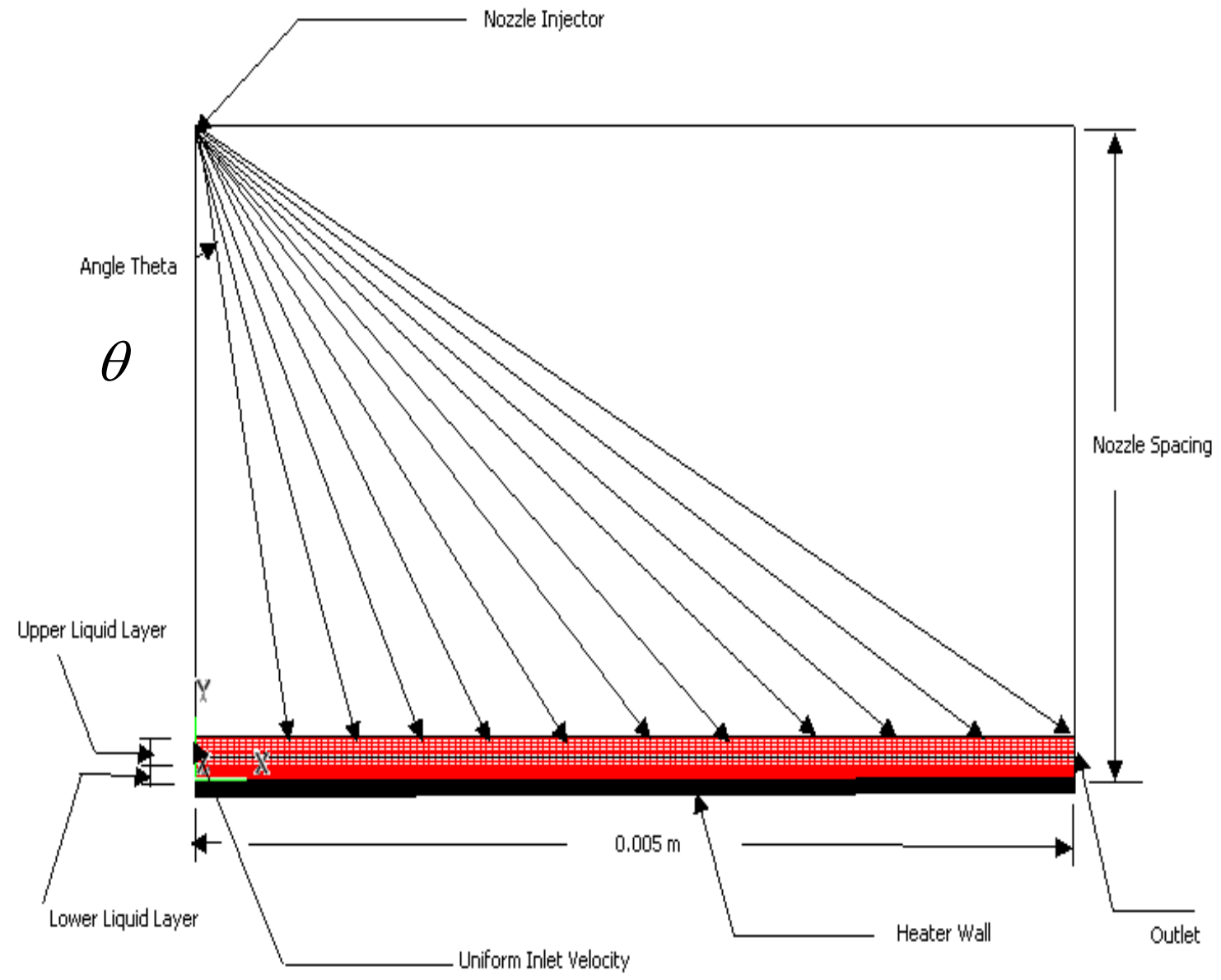

Figure 1.2 Numerical Model Setup. 


\section{Spray Cooling Deviee Coneept}

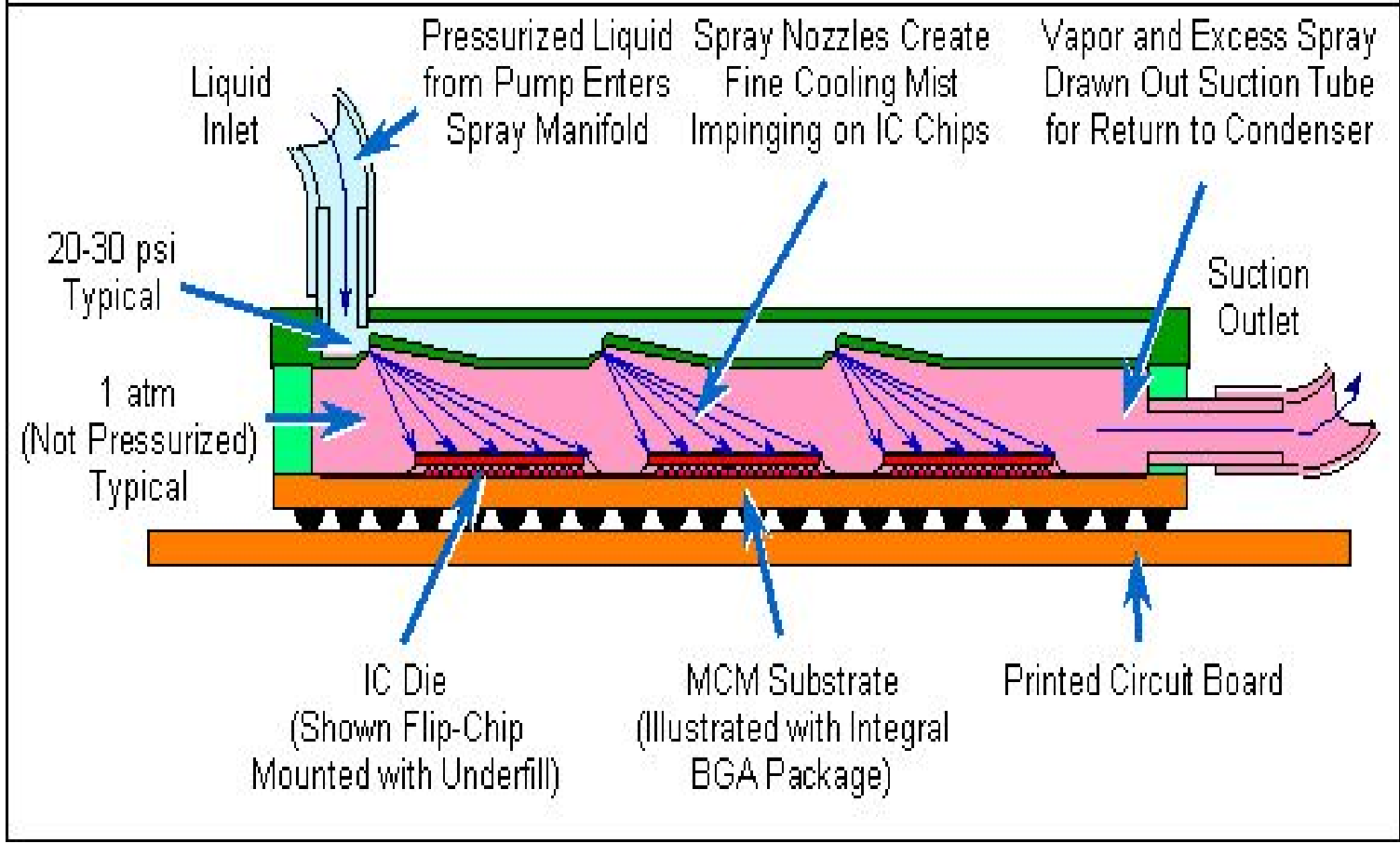

Figure 1.3 Spray Cooling Device, Adopted from LPS (The Laboratory for Physical Sciences), University of Maryland. [2] 

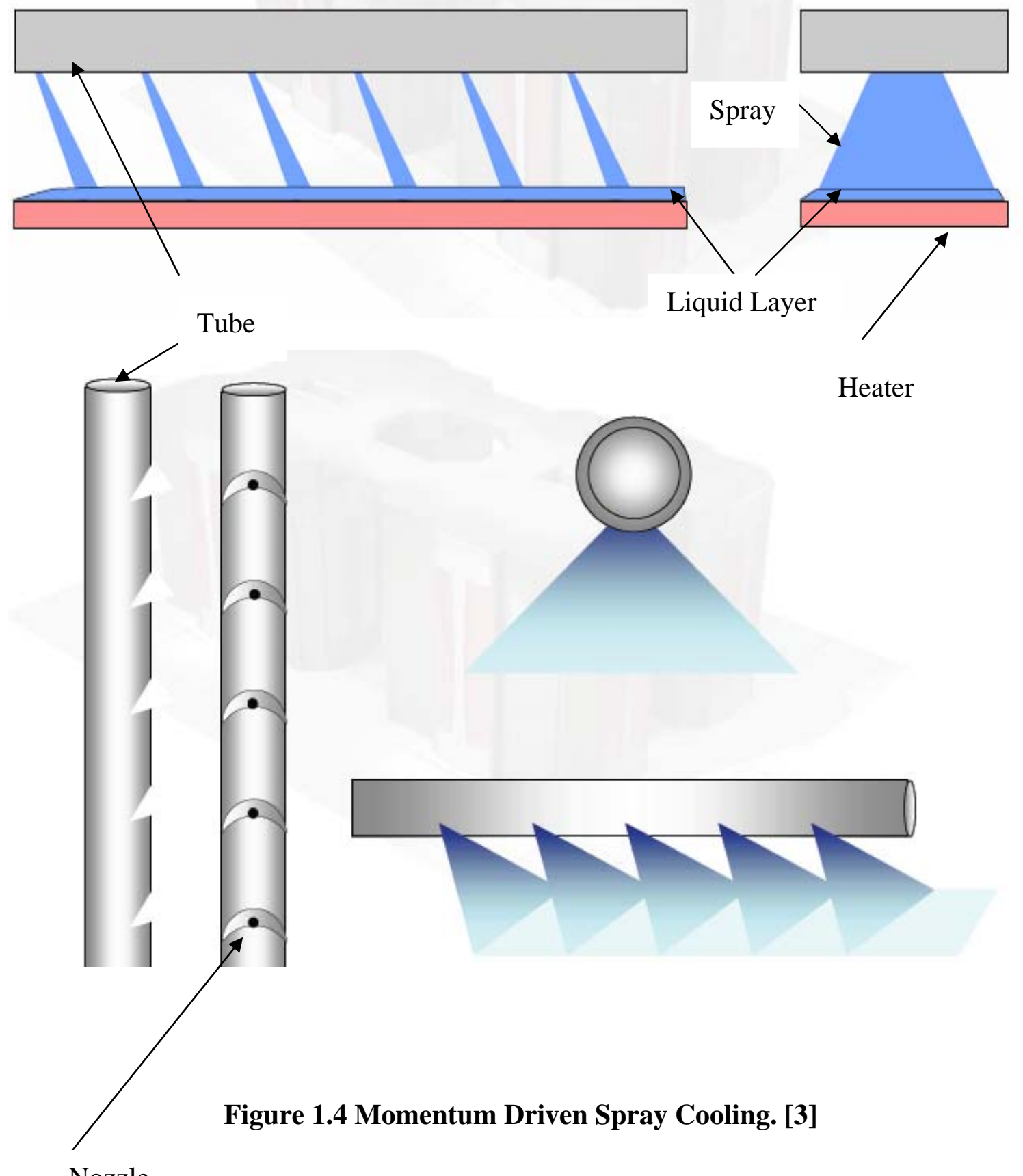

Heater

Nozzle 
liquid layer multiplied by the cosine of the droplet trajectory angle. The reason for this is that the spray comes out from the nozzle at different angles. Based on this angle the spray added to the liquid layer will be different, which means that closer from the nozzle center more mass will be added and further from the nozzle center less mass will be added and the factor governing this is the cosine of the angle from the nozzle to the point of impingement. In this model the spray droplets were assumed to follow straight line trajectories. Figure 1.5 shows a nozzle which produces a very fine spray impinging on a heated surface [4]. The spray pattern could have different shapes depending on the application in which it's used.

The momentum source term was also added to all of the cells in the upper half of the liquid layer through the momentum equation. In order to do this the mass of the droplets was multiplied by the velocity of each droplet. More details of how the spray was added to the continuity and momentum equations of the liquid layer as a source term are explained in Chapter 6.

The module is a part of the CFD-ACE+ code which can be used separately or with other modules. To gain confidence in the numerical results it was important to validate the results for both Flow and Heat modules. Because the main concern is the heater surface temperature, the laminar boundary layer profile was validated for both velocity and temperature profiles. The results were found to be in a good agreement with the integral solution. Also flow over a flat plate was validated against the Blasius solution. Uniform heat flux was used as a wall heat boundary condition. It was found that there is a constant difference between the numerical solution and the integral solution; this difference was found to be reasonable. This difference was a result of the origin offset. One more case used to validate the code is the fully developed flow on an inclined plane. The purpose of this was to see if there is a proper balance between the friction force and the gravity force. The simulation results showed a perfect balance between them.

The source term subroutines enable one to change many parameters in order to study their effects on the temperature distribution. These parameters are the flow rate of 
the mass source and momentum source terms, the velocity magnitude of the momentum source term, the nozzle spacing, the liquid layer thickness, the liquid layer velocity magnitude in the horizontal direction, the heater (wall) heat flux, the heater (wall) temperature, and the liquid.

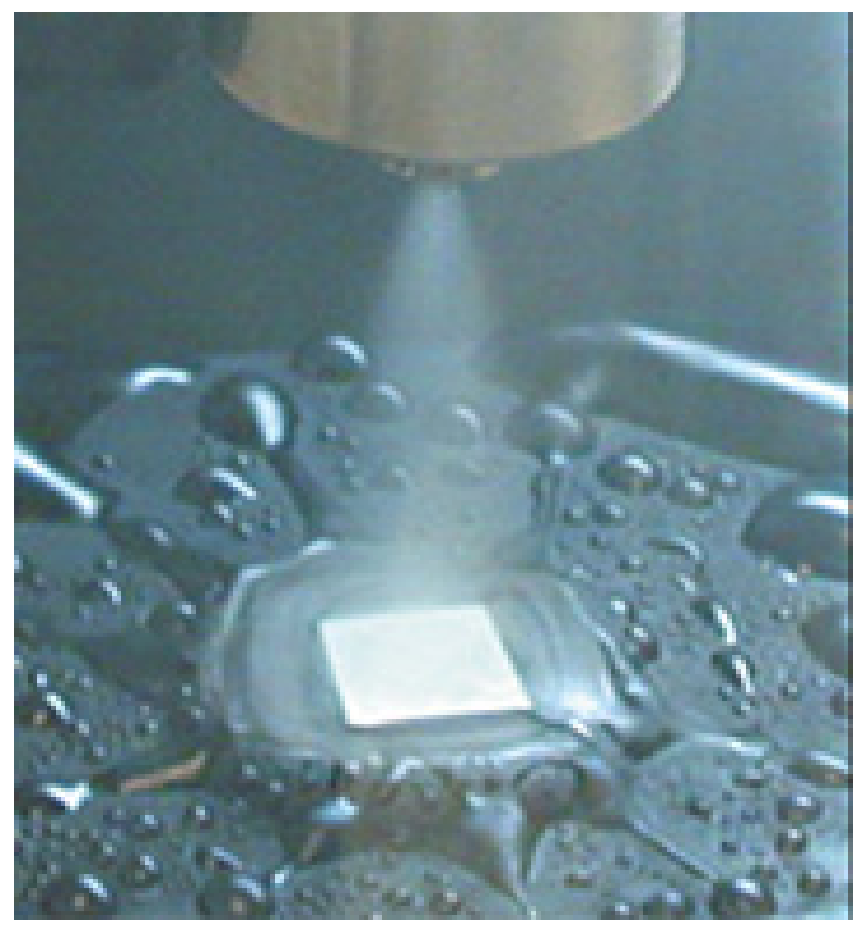

Figure 1.5 Spray Impinging a Heated Surface. [4]

\subsection{Overview}

This dissertation consists of seven chapters. This chapter contains the introduction. The second chapter is the literature review. What is covered in the review is both previous experimental and numerical work in the area of spray cooling. However, most of the work is experimental work, as it was found in the most recent review that there is a lack of understanding of the mechanisms of spray cooling because it is very complicated. So, it was found that there is a need for development of numerical models to cover this 
gap. The third chapter describes the numerical methods and techniques used by the solver. The finite volume approach was the technique which was used. In this chapter also it was explained what is meant by the VOF (Volume of Fluid) module and how it works. The fourth chapter covers the governing equations that are used by the solver; these equations are the continuity, momentum and energy equations. The fifth chapter covers the validation of the code. This was done by comparing the numerical results against the analytical solutions for both flow and heat transfer equations. Chapter 6 covers the results of adding the source terms on the temperature profile and Nusselt number. Four working fluids were used: water, FC-72, HFE-7000 and a hypothetical fluid. The effects of spray velocity, nozzle spacing and spray mass flow rate on the temperature profile were studied. Different values of layer thicknesses, layer velocities and wall heat fluxes were used. Chapter 7 presents the conclusions and recommendations for the future work. 


\section{Chapter 2}

\section{Literature Review}

This chapter summerizes the most recent experimental and numerical research that has done in spray cooling. The following topics will be covered in this review: comparison between spray cooling and jet cooling, the effect of spray characteristics (spray mass flux, spray volume flux, droplet number, droplet velocity and cone angle) on cooling performance (CHF and heat transfer coefficient), liquid layer thickness formed by the spray, the interaction between the spray and a liquid layer moving horizontally, proposed heat transfer mechanisms, and a survey of numerical solutions of spray cooling.

Liquid jet and spray impingement cooling were investigated experimentally and compared in the non-boiling regime by Oliphant et al. [5]. They classified the jets into submerged jets and free jets. Free liquid jets impinging on a flat plate were used. They reported that jet heat transfer is dependent on the number and velocity of the impinging jets, while spray heat transfer is dependent on both mass flux and droplet velocity. In their experiment the impingement surface temperature was maintained below the saturation temperature of the spray liquid. It was concluded in their comparison that the spray cooling can provide the same heat transfer as jets at a significantly lower liquid mass flux. They also proposed that the better cooling of sprays was due to the combined effect of evaporative cooling from the film along the impingement surface, and the unsteady thermal boundary layer expected in spray impingement. It was mentioned that spray cooling shows promise because of the large surface area that is formed when a liquid is atomized into many droplets by the spray nozzle.

The performance of arrays of sprays was studied by Pereira et al. [6] and Lin and Ponappan [7] as reported by Pautsch and Shedd [8]. It was found that similar trends for the heat transfer performance were obtained in comparison with single nozzle spray data from Estes and Mudawar [9], as reported by [8]. Estes and Mudawar [9] also did not see any spray interaction effect. Lin et al. [10], as reported by [8], found that as the number of spray nozzles increases, the CHF can increase up to $30 \%$. 
It was reported by Horacek et al. [11], that for spray cooling at lower wall superheats, the heat transfer occurs primarily through single-phase convection. It was found also that the droplet impingement onto the liquid film can provide significant disturbance, increasing the amount of heat transfer. Two mechanisms were proposed for the heat transfer through the liquid film; liquid film formation and secondary nucleation. They suggested that uncertainty regarding the spray cooling heat transfer mechanism is mainly due to the difficulties in obtaining local measurements of heat transfer and observing the state of the liquid on the surface. Pais et al. [12], as reported by [11], found that one mechanism is that the spray forms a thin liquid layer on the heated surface through which the heat is conducted. They found that a thinner film results in higher heat transfer due to the increased thermal gradient across the layer. Another mechanism is secondary nucleation according to Rini et al. [13], and Yang et al. [14], as reported by [11]. They believed that the impacting droplets entrain vapor and/or gas into the liquid film creating nucleation sites and causing boiling within the film.

It was reported by Pautsch [15], that spray cooling has often been misrepresented by the term spray evaporative cooling. He pointed that some spray cooling system designs rely very little on the evaporation of fluid to remove heat. Furthermore he suggested that spray cooling designs with higher values of CHF have less evaporation than designs with lower values of CHF. As a result, in order to show the difference between them he proposed a new name if there is phase change which is "spray with phase change".

A set of experiments were performed by Estes and Mudawar [16] to understand nucleate boiling and CHF for full cone sprays. They investigated the effect of spray nozzle, volumetric flux, (flow rate impacting an infinitesimal portion of the surface divided by the area of the same portion), subcooling, and working fluids. They reported that the CHF increases with increasing flow rate and increasing subcooling. They found also that the CHF is greater for smaller drops. The Sauter mean diameter, the diameter of a drop that has the same volume/ surface area as the entire spray, for full cone sprays is 
dependent upon orifice diameter and the Weber and Reynolds number based on the orifice flow conditions before liquid breakup. They reported that investigators have suggested different boiling and CHF trends, which were sometimes contradictory to one another and limited to a particular nozzle and single working fluid.

Peterson [17], as reported by Fabbri et al. [18], found that heat fluxes as high as $15 \mathrm{MW} / \mathrm{m}^{2}$ could be removed from a spray cooled surface. At a relatively low surface temperature of $130^{\circ} \mathrm{C}$ heat fluxes on the order of $2.2 \mathrm{MW} / \mathrm{m}^{2}$ were removed by Bonacina et al. [19], as reported by [17].

The rewetting of a hot surface by droplet impingement was studied experimentally by Celata et al. [20]. They indicated that one of the most important applications of their study is safety of tanks containing dangerous and toxic materials in the event of a fire accident. In order to avoid mechanical failure of the tank material due to high temperature, spray cooling should be applied. In their investigation spray droplets having a uniform constant diameter impinged on a vertical heated plate made from stainless steel. They reported that for large droplet diameters and higher wall temperature, no influence of the spray characteristics was observed. Bonacina et al. [21], as reported by [20], found that if the wall is fully wetted, the heat transfer rate is higher. Kim et al. [22], as reported by [20], found that the efficiency of the spray diminishes in the presence of the film. Kim also reported that the higher the film thickness the lower the heat transfer.

The effect of spray characteristics for non critical heat flux in subcooled water spray cooling was investigated experimentally by Chen et al. [23]. It was concluded that the droplet velocity $\mathrm{V}$ had the most dominant effect on $\mathrm{CHF}$ and the heat transfer coefficient followed by the droplet flux $(\mathrm{N})$, while the Sauter mean diameter had no definite effect. The CHF and the heat transfer coefficient were increased when $\mathrm{V}$ increased. Increasing $\mathrm{N}$ also resulted in an increase in CHF and heat transfer coefficient when other parameters were kept in narrow ranges. They also reported that to increase the CHF for a given $\mathrm{N}$, a dilute spray with large droplet velocity is more effective than a 
dense spray with low velocities. Toda [24], as reported by [23], using water as a working fluid, found that the CHF was increased approximately $50 \%$ as the droplet diameter increased from 88 to 120 microns. But Pais et al. [12], and Estes and Mudawar [25], as reported by [23], suggested that CHF could be increased by decreasing the droplet diameter. Sehmbey et al. [26], as reported by [23], found that the smaller droplets can produce the same values of CHF at smaller flow rates as larger droplets at larger flow rates.

Yang et al. [14], as reported by Hsieh et al. [27], recognized that spray cooling with phase change is a powerful method to remove high heat flux (> $\left.10 \mathrm{MW} / \mathrm{m}^{2}\right)$ from surfaces with a low wall superheat. Choi and Yao [28], as reported by [27], experimentally studied the effect of heater orientation on droplet impingement. It was found that a higher heat transfer happened in film boiling for a downward vertical spray jet; while for a horizontal spray jet, a higher heat transfer occurred in transition boiling. Most recently, Yoshida et al. [29], as reported by [27], experimentally studied the effect of microgravity for spray cooling using water and FC-72 as the working fluids. They reported that the gravity dependency of the spray cooling characteristics varies with the spray volume flux and the droplet Weber number. A set of experiments using water and R-134a as working fluids were performed by [27]. The effect of the working fluid, degree of subcooling, and spray mass fluxes on the cooling characteristics of a hot surface were investigated. They found that the spray mass flux has a strong effect on spray cooling performance. It was found that the effect of the degree of subcooling was not noticed especially for R-134a because of the low degree of subcooling used. They also reported that water shows a much higher cooling performance than R-134a.

The heat transfer distribution for an isothermal surface under one and two spray nozzles was investigated by Horacek et al. [30]. FC-72 was used as the working fluid and the spacing between the nozzle and the heater surface was varied from 7 to $17 \mathrm{~mm}$. In their experiments the maximum heat flux was $6.6 \mathrm{E}+05 \mathrm{~W} / \mathrm{m}^{2}$ at a superheat of $28{ }^{\circ} \mathrm{C}$. For a given nozzle-to-surface distance, the maximum heat flux occurred directly under the spray nozzle assuming that the spray distribution is the same. They also reported that 
the heat flux became more uniform across the heater surface as the nozzle-to-surface distance increased. They reported that an optimum spacing for the distance between the nozzle and the heated surface exists in order to achieve a uniform heat flux distribution. For a certain nozzle-to-surface distance, the average heat flux within the region covered by the spray is the same for both single and two spray cases at $5 \%$ uncertainty of the measurements. They concluded that the magnitude of the heat flux can be improved. Yang et al. [14] and Chow et al. [31], as reported by [30], observed that heat flux as high as $10 \mathrm{MW} / \mathrm{m}^{2}$ in gas-assisted spray cooling with water can be obtained. Using FC-72 as working fluid a $1 \mathrm{MW} / \mathrm{m}^{2}$ heat flux was obtained by Estes and Mudawar [32], as reported by [30].

The cooling characteristics of the sprays impacting a square heated test surface were investigated by Rybicki and Mudawar [33]. PF-5052 was used as a working fluid with three upward-oriented full-cone spray nozzles subject to variation in both flow rate and subcooling. They concluded that the volumetric flux and Sauter mean diameter are the key hydrodynamic parameters that influence spray cooling performance. They also proved that nozzle orientation has no effect on spray cooling performance, provided the cooling system does not promote liquid build-up upon the test surface.

Toda [24], as reported by [33], found that subcooling had a minor effect on single-phase and nucleate boiling heat transfer and did not have a dominant effect on CHF. Monda [34], as reported by [33], observed that the nucleate boiling gradient in spray cooling is nearly half that of pool boiling. Toda and Monda both found that the cooling performance is enhanced by increasing the spray volumetric flux in every cooling regime. Mudawar and Valentine [35], as reported by [33], also showed that the volumetric flux had the most dominant effect on CHF compared to other hydrodynamic properties of the spray.

Spray cooling heat transfer was surveyed by Kim [36]. He reported that the heat removal mechanisms are poorly understood due to their dependency on many parameters which include the unique droplet size distribution, droplet number density and droplet 
velocity. Other parameters which affect spray cooling heat transfer are impact angle, surface roughness, gas content, number of nozzles and heater surface orientation. Kim reported that after the droplets impact the heated surface they spread on the surface and evaporate or form a thin liquid film, removing large amounts of energy. Kim also found that significant disturbances occur due to the droplet impact onto the liquid film, increasing the amount of heat transferred. Kim found that the heat transfer increases with increasing flow rate. Kim reported that this is due to the increase of the liquid velocity over the surface and the thinner thermal boundary layer. It was also reported that the mechanisms by which the critical heat flux is triggered during spray cooling are currently unknown. Two mechanisms were suggested; homogenous nucleation within the film and liftoff of the thin liquid layer due to nucleation within the film. It was mentioned that spray cooling is not expected to be affected by the heater orientation relative to the gravity vector or by low gravity conditions due to the large momentum of the spray. Kim reported that it was not possible to model the spray cooling process from first principles due to enormous number of droplets. Kim concluded that further advances in understanding spray cooling will require the development and application of new experimental techniques.

Spray cooling is a well known technique in steel plate manufacturing. It is used to control the steel temperature and hence the steel properties as described by Kim et al. [37]. Arrays of nozzles are placed in multiple stages in the plate direction for spray cooling. A liquid film flow is formed on the steel plate by an upstream side nozzle cluster that interacts with the spray flow on the downstream side as shown in Figure 2.1. Kim et al. reported that at that time no information was available concerning spray cooling which interacts with liquid film flow. They pointed out that it was not clear if the spray cooling heat transfer was enhanced by the liquid film flow on the steel plates. They concluded that in the presence of the liquid film flow the heat transfer rate directly below the spray center is decreased, and this decrease increases as the liquid film thickness increases. They also found that the spray cooling heat transfer that interacts with the liquid film flow is significantly enhanced as the spray droplet flux increases. 


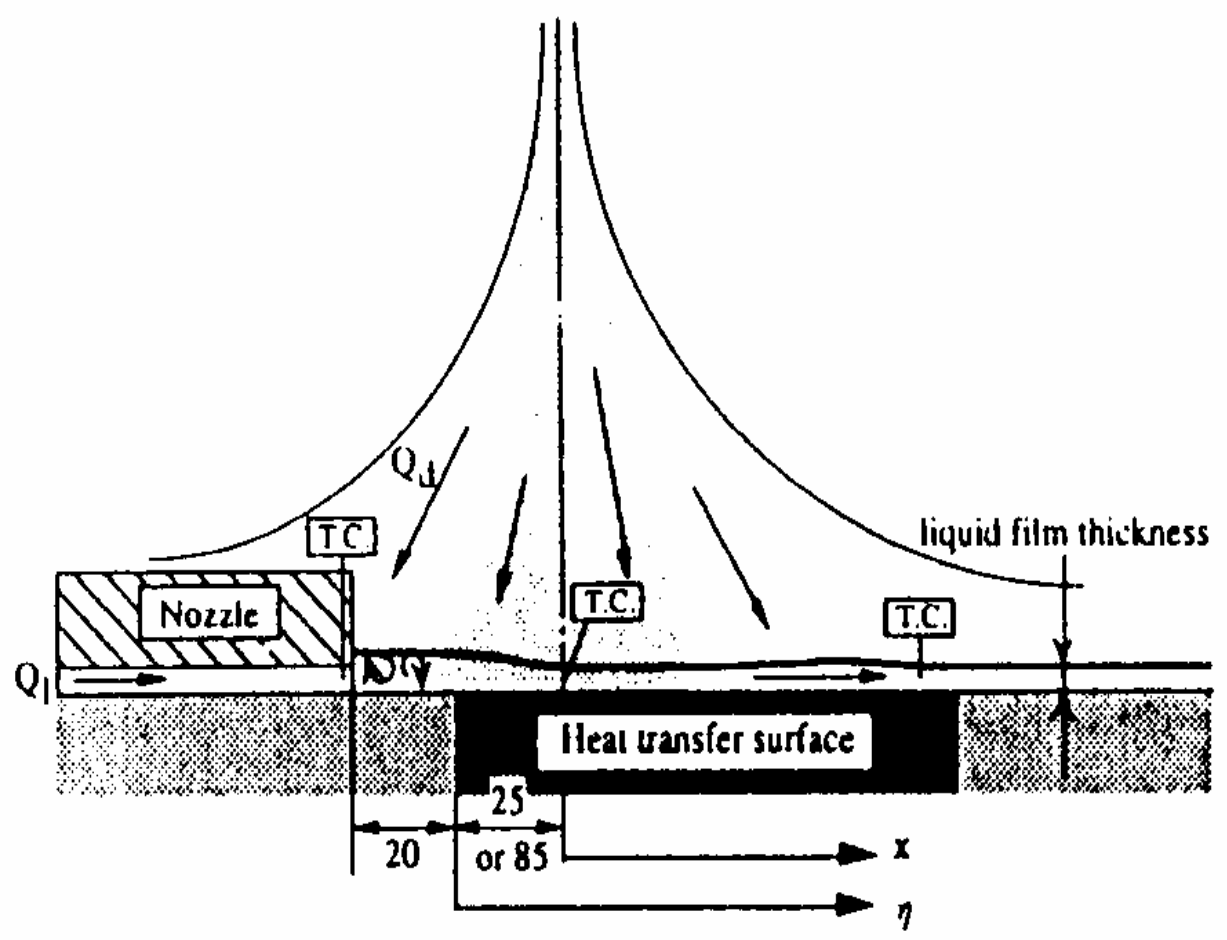

Figure 2.1 Schematic View of Droplet and Film Flow adapted from Kim et al. [37] 
Different attempts have been made to measure the thickness of the film in spray cooling. Yang et al. [38], as reported by Pautsch [15], used water as the test fluid with an airatomizing nozzle. It was found that with a constant air pressure the film thickness can be increased from between 85 and 235 microns by increasing the flow rate of water. They considered spray cooling involving the deposition of a large number of liquid droplets onto a surface with a temperature greater than the saturation temperature of the droplets. Toda [24], as reported by [15], explained how these droplets contact the heated surface and spread out over the surface which becomes fully wetted by a thin liquid film. Under the effect of the momentum added by the incoming fluid the film is passed along the surface. The new droplets arrive at a temperature lower than the film temperature near the surface. The droplets which impact the surface of the film become part of the film and their kinetic energy maintains the flow.

The liquid film thickness created by both a low flow rate single nozzle and a high flow rate four-nozzle array spray was measured by Pautsch et al. [39], using FC-72 as a working fluid. A non-intrusive optical technique based on total internal reflection was used. The reflected light rings that formed on a test die were photographed. An automated program measured and recorded the radii, from which the thickness of the film was calculated using the fundamental equations of geometric optics. It was found that for the four-nozzle array the regions which had previously shown the poorest heat transfer performance are the ones which have the thickest film. While using the single-nozzle spray, it was found that adding a heat load did not affect the film thickness. They also reported that the most important and the least studied parameter of spray cooling is the thickness of the liquid film layer which exists on the heated surface. The values of the film thickness were 0 to 75 microns. They also explained that once the droplets hit the surface they are swept off by the flow of subsequent droplets, the surface is continually wetted, and a thin liquid film forms. They explained different mechanisms of heat transfer in this film; conduction, convection, bubble nucleation, and gas bubbles entrained by impacting droplets. They concluded that each of these components contributes to the total heat removal process and that this contribution is unknown, but all are related to the thickness of the film. 
In a recent survey done by Selvam et al. [40], regarding the computational modeling of spray cooling, they conclude that the best way to model the spray cooling is to have the spray impinge on a preexisting thin liquid film on a hot surface. They stated that this will help to understand and improve the performance of spray cooling. As a result of their survey they found that theoretical understanding of spray cooling is still in its infancy and a focused effort to develop a comprehensive numerical model is of prime importance to this field. They also reported that the liquid film thickness can not exceed 2 mm. For spray cooling designed for high heat flux, the liquid film thickness on the hot surface is less than 200 microns. It was reported that numerical modeling of nucleate boiling of thin films has never been attempted before.

From this survey it is concluded that the spray cooling heat transfer mechanism is quite complicated and there are a lot of contradictions in the experimental results. It was found that a numerical study is needed to cover the gap in this area. As suggested by Selvam et al. [40], the best way to study spray cooling is to model a spray onto a preexisting liquid film. 


\section{Chapter 3}

\section{Numerical Methods and Techniques}

\subsection{Introduction}

Numerical techniques are used when the solution of a problem depends on complex interaction of different physical phenomena, within complex geometrical domains. The resulting equations are not analytically solvable, and hence only numerical methods can be used. Numerical simulations save time in comparison with experimental study and can help to understand the physics.

Numerical methods yield a discrete solution which is comprised of the values of the variables at the grid points. The partial differential equations (PDE) governing the physics are discretized on the computational grid. The discretization of the differential equations is introduced to produce a set of algebraic equations which can be solved numerically. To do this three methods could be used which are finite difference, finite element and finite volume approaches. Specifically, in CFD-ACE+, the finite volume approach is used because of its capability of conserving solution quantities.

CFD-ACE+ is a software package originally developed by the CFD Research Corporation (CFDRC). In 2004 the code was purchased by ESI, Inc. The package consists of three main applications, as follows:

CFD-GEOM Pre-processing, geometry and grid generation, CFD-ACE (GUI) Processing, model preparation and numerical solver, and CFD-VIEW Post-processing, visualization and results analysis. 
Figure 3.1 shows a diagram of these different modules of the program and how they interact together [41]. The governing equations are found in the CFD-ACE+ Manual [42].

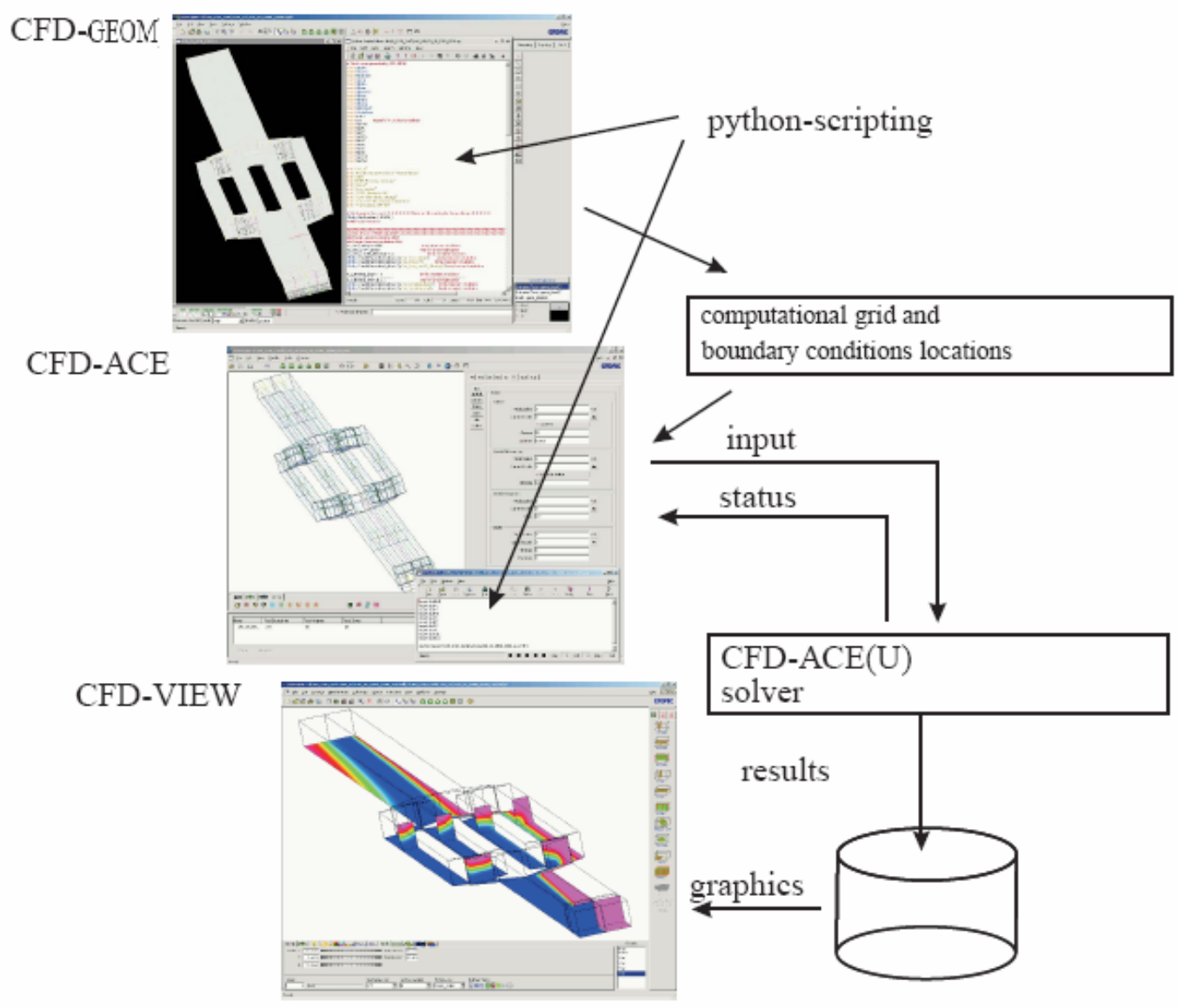

Figure 3.1 CFD-ACE+ Structure. [41]

\subsection{Numerical Methods}

\subsubsection{Finite Volume Method}

In this technique the solution domain is divided into a number of cells known as control volumes, and then the governing equations are numerically integrated over each 
of these computational cells or control volumes. The solver uses the cell-centered variables arrangement in which all dependent variables and material properties are stored at the cell center. Figure 3.2 shows a three dimensional control volume, in which the cell center is defined by P. There are six neighboring nodes called by W, E, S, N, T, B and they represent the west, east, south, north, top and bottom nodes respectively. The lower case letters represent the cell face centroids. For two dimensional geometry only four neighboring nodes are used: N, S, E, and W. More details are found in Patankar [43].

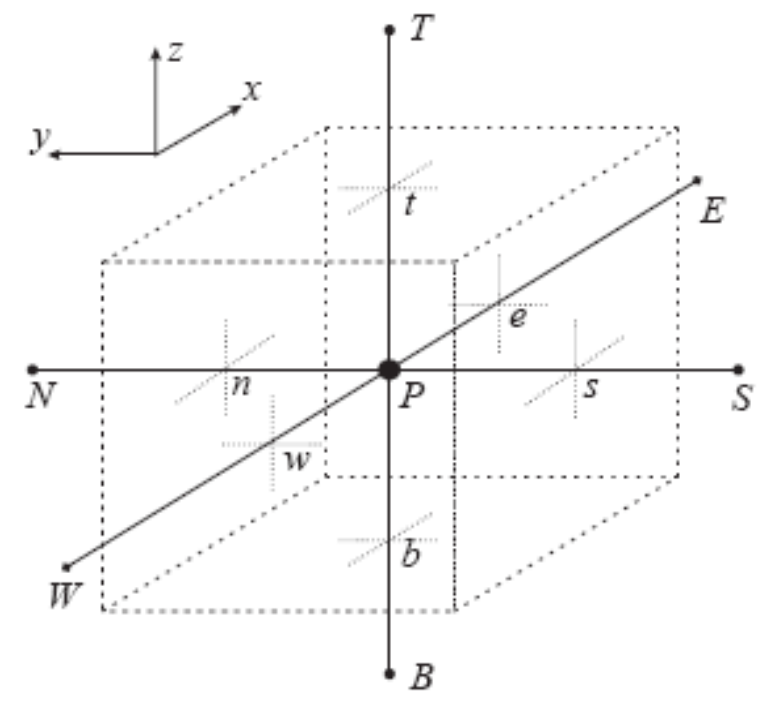

Figure 3.2 Three Dimensional Control Volume. [41]

The governing equations are generalized in the form of the transport equation:

$$
\frac{\partial(\rho \phi)}{\partial t}+\nabla \cdot(\rho \vec{V} \phi)=\nabla \cdot(\Gamma \nabla \phi)+S_{\phi}
$$

where

$$
\begin{array}{rll}
\rho & = & \text { density }\left[\mathrm{kg} / \mathrm{m}^{3}\right] \\
\phi & = & \text { dependent variable } \\
t & = & \text { time }[\mathrm{s}]
\end{array}
$$




$$
\begin{array}{lll}
\Gamma & = & \text { diffusion coefficient }\left[\mathrm{kg} \mathrm{m}^{-1} \mathrm{~s}^{-1}\right] \\
\mathrm{S}_{\phi} & = & \text { source term } \\
\vec{V} & = & \text { velocity vector }[\mathrm{m} / \mathrm{s}]
\end{array}
$$

The first term in the above equation represent the transient term, the second term is the convection term, the third term is the diffusion term and the last term is the source term.

By integrating this equation over a control volume cell one have;

$$
\int_{v} \frac{\partial(\rho \phi)}{\partial t} d v+\int_{v} \nabla \cdot(\rho \vec{V} \phi) d v=\int_{v} \nabla \cdot(\Gamma \nabla \phi) d v+\int_{v} S_{\phi} d v
$$

where

$$
v \quad=\quad \text { volume }\left[\mathrm{m}^{3}\right]
$$

The transient term in the above equation will be integrated as follows:

$\int_{v} \frac{\partial(\rho \phi)}{\partial t} d v=\frac{\rho \phi v-\rho^{o} \phi^{o} v^{o}}{\Delta t}$

where the superscript o denotes an older time, and no superscript denotes the current or new time.

The convection term is evaluated as flows;

$$
\int_{v} \nabla \cdot(\rho \vec{V} \phi) d v=\oint_{A} \rho \phi \vec{V} \cdot \vec{n} d A=\sum_{i}\left(\rho_{i} \phi_{i} V_{i}^{n}\right) A_{i}=\sum_{i} C_{i} \phi_{i} A_{i}
$$

where

$$
\begin{aligned}
& A_{i}=\quad \text { the area of the face } i \\
& V_{i}^{n}=\quad \text { the velocity component in the direction that is normal to face }
\end{aligned}
$$




$$
\begin{array}{rll}
C_{i} & = & \text { the mass flux across the face } \\
\vec{n} & = & \text { normal vector } \\
i & = & \text { sum index }
\end{array}
$$

Since the geometry in the current study is two dimensional and the variable $\phi$ is available only at the cell-centers, the cell-face values of $\phi, \rho$ and $\vec{V}$ need to be interpolated. Various interpolation schemes are available with different levels of numerical accuracy and stability. However the first order upwind scheme is the default scheme used by the solver for its faster convergence. In this scheme, $\phi_{i}$ is taken to be the value of $\phi$ at the upstream grid point. This means that the value of $\phi_{i}$ will equal either $\phi_{E}$ or $\phi_{P}$ depending on the flow direction at cell face e and can be written as

$$
\phi_{i}^{U P}=\phi_{P} \text { if } V_{i}^{n}>0
$$

$\phi_{i}^{U P}=\phi_{E}$ if $V_{i}^{n}<0$

Similar considerations apply for other cell faces.

The diffusion term is approximated as follows:

$$
\int_{v} \nabla \cdot(\Gamma \nabla \phi) d v=\int_{A} \Gamma \nabla \phi \cdot \vec{n} d A=\sum_{i} \Gamma_{i}\left(\frac{\partial \phi}{\partial n}\right)_{i} A_{i}
$$

where

$$
\begin{aligned}
& \frac{\partial \phi}{\partial n}=\frac{1}{\vec{n} \cdot \vec{e}}\left(\frac{\partial \phi}{\partial e}-\vec{e} \cdot \vec{\tau} \frac{\partial \phi}{\partial \tau}\right) \\
& \vec{\tau} \quad=\quad \text { unit vector parallel to face e }
\end{aligned}
$$

So the diffusion term will become 


$$
\int_{v} \nabla \cdot(\Gamma \nabla \phi) d v=\sum_{i} \frac{\Gamma_{i}}{\vec{n} \cdot \vec{e}}\left(\frac{\partial \phi}{\partial e}\right)_{i} A_{i}-\sum_{i} \frac{\vec{\tau} \cdot \vec{e} \Gamma_{i}}{\vec{n} \cdot \vec{e}}\left(\frac{\partial \phi}{\partial \tau}\right)_{i} A_{i}
$$

where

$$
\begin{aligned}
& \left(\frac{\partial \phi}{\partial e}\right)_{i}=\frac{\phi_{E}-\phi_{P}}{\delta_{P, E}} \\
& \left(\frac{\partial \phi}{\partial \tau}\right)_{i}=\frac{\phi_{C 2}-\phi_{C 1}}{\delta_{C 2, C 1}} \\
& \delta_{P, E}=\quad \text { the distance between } \mathrm{E} \text { and } \mathrm{P} \\
& \delta_{C 2, C 1}=\quad \text { the distance between the cell corners C2 and C1 } \\
& \mathrm{C} 1, \mathrm{C} 2=\quad \text { cell corners }
\end{aligned}
$$

\subsubsection{Source Term Linearization}

If the source term is a function of $\phi$ itself (for example it could be mass as in the continuity equation or temperature as in the energy equation) it is linearized as

$$
S_{\phi}=S^{U}+S^{P} \phi
$$

where

$$
\begin{aligned}
& S^{U}=\text { the constant part of the source term } S \\
& S^{P} \quad=\quad \text { the coefficient of } \phi
\end{aligned}
$$

where $S^{P}$ is negative and both $S^{P}$ and $S^{U}$ can be functions of $\phi$. They are evaluated using the latest available value of $\phi$, which is generally taken to be the values of $\phi$ at the end of the previous iteration. The linerized source term is integrated over the control volume which results in 


$$
\begin{aligned}
& \int_{v} S_{\phi} d v=S_{U}+S_{P} \phi_{P} \\
& S_{P}=S^{P} v \\
& S_{U}=S^{U} v
\end{aligned}
$$

\subsubsection{Finite Difference Equations}

The final form of the integrated, discretized, transport equation is the following linear equation

$\left(a_{P}-S_{P}\right) \phi_{P}=\sum_{n b} a_{n b} \phi_{n b}+S_{U}$

The subscripts $n b$ denote values at neighboring cells, and $a_{n b}$ are known as the link coefficients. The finite difference equation (FDE) is the discrete equivalent of the continous flow transport equation. When a FDE is formulated for each computational cell, it results in a set of coupled nonlinear algebraic equations. There is no direct matrix inversion method available to solve a set of nonlinear algebraic equations. So an iterative procedure is used in CFD-ACE + in which at every time step, linear FDE are formed by evaluating the link coefficients with the values of $\phi$ available at the end of the previous iteration.

\subsection{Velocity-Pressure Coupling}

The continuity equation, which governs mass conservation, is used to determine the pressure field in the pressure-based method which is employed in CFD-ACE+.

Solving the momentum equations results in three Cartesian components of velocity at each cell center in the solution domain. No governing PDE for pressure is presented. The Pressure-based method utilizes the continuity equation to formulate an 
equation for the pressure. In CFD-ACE+, the SIMPLEC scheme is used. SIMPLEC stands for Semi-Implicit Method for Pressure-Linked Equations Consistent. Further details are available in Patankar [43].

\subsection{Solution Procedure}

Once the equation set for a variable has been assembled it must be solved. The iterative equation solvers are used because they are more economical in terms of memory requirements than are direct solvers. Two solvers can be used in CFD-ACE+ which are the Conjugate Gradient Squared (CGS) +Preconditioning Solver and the Algebraic MultiGrid (AMG) solver. However, in the current study the CGS solver is used because it requires no user-specified parameters.

The parameters that control how many times the procedure is repeated can be specified by the user. In the case of a transient simulation the number of iterations (NITER) is repeated at each time step until the convergence criterion is satisfied. This number is dictated by overall residual reduction desired; at each iteration the program calculates a residual for each variable. This residual is the sum of the residuals for that variable at each computational cell. The problem is converged if one has a five order of magnitude reduction in the residual. The solution procedure is shown in Figure 3.3. In this figure $\mathrm{p}^{\prime}$ is defined as the pressure correction and is given by $\mathrm{p}=\mathrm{p}^{*}+\mathrm{p}^{\prime}$ where $\mathrm{p}^{*}$ is the guessed pressure. The enthalpy is defined by $h$ and $t_{f}$ is the initial time. 


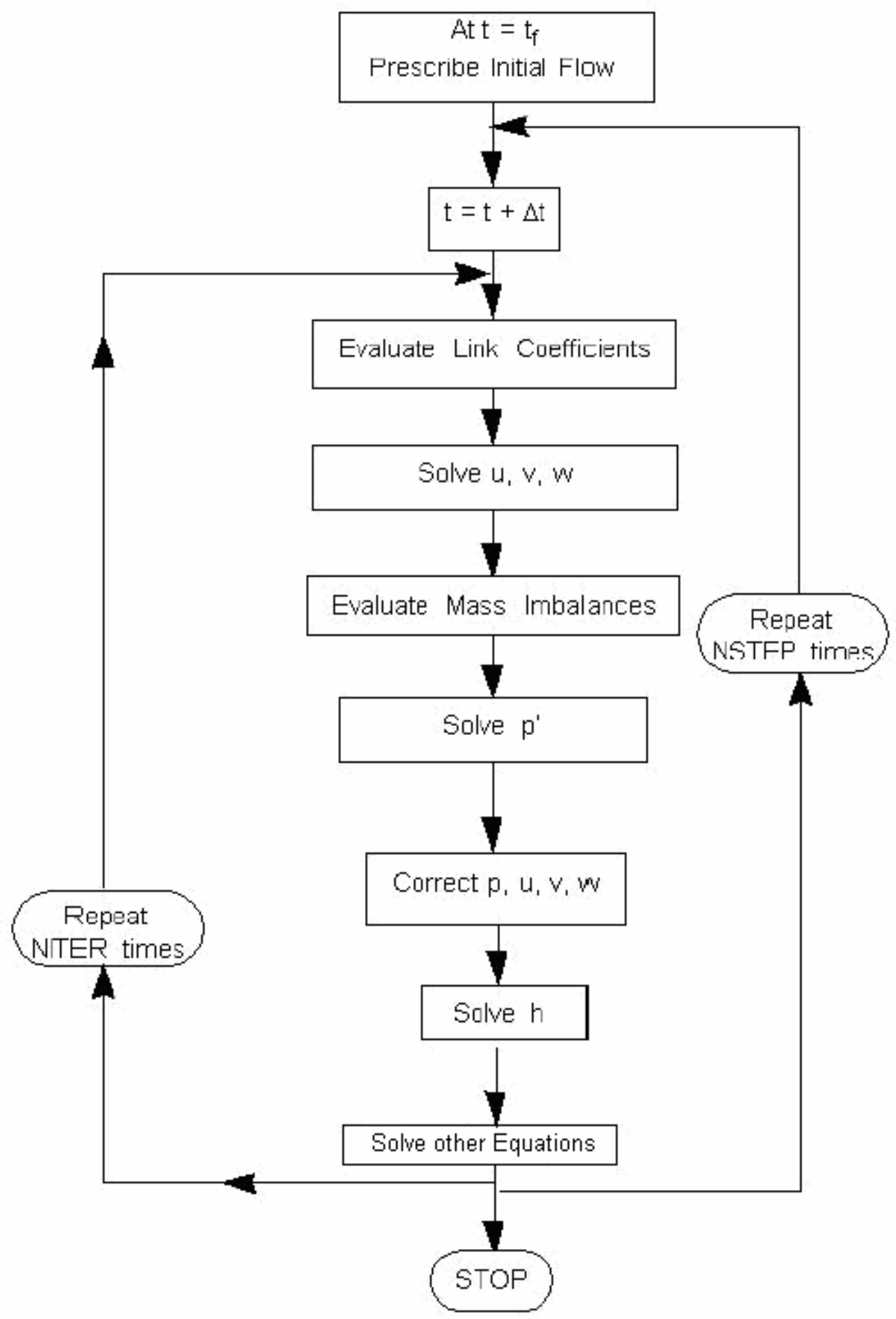

Figure 3.3 Numerical Solution Procedures. [42] 


\section{Chapter 4}

\section{Governing Equations}

\subsection{Introduction}

To study the spray interaction with the liquid layer requires solving the heat transfer for a laminar flow parallel to a heated plate. CFD-ACE+ [42] is commercial software which was used in the current study. This is a multiphysics code which contains 14 modules. In the present simulations three modules were used: Flow, VOF (Volume of Fluid), and Heat. The code enables one to add or modify the source code by writing user subroutines which can run as part of the code. The heart of the code is the Flow module which solves the continuity equation and the momentum equations. If the fluid is a liquid and has a free surface the Volume of Fluid module (VOF) should be used. Because of the importance of this module it has been explained in detail; the governing equations are found in the CFD-ACE manual [42].

\subsection{Free Surface Volume of Fluid (VOF)}

The free surface module is named as Volume of Fluid. This module accommodates any two fluids which are incompressible and immiscible where the mixture of the two fluids is tracked in terms of the volume fraction of one of the two fluids. Fluid 1 represents the gas phase and fluid 2 represents the liquid phase.

The VOF methodology is that the distribution of the second fluid (for example FC-72 or water in the present application) in the computational grid is accounted for using a single scalar field variable, $F$, that specifies the fraction of the volume of each computational cell in the grid occupied by fluid two (FC-72 or water in this case). So, $F$ takes the value 1 in cells that contain only fluid two (FC-72 or water) and the value 0 in cells that contain only fluid one (air). A cell that contains an interface would have a value of $F$ between 0 and 1 . 
For a given flow field with an initial distribution of $F$ on a grid, the fluid distribution is determined by solving the passive transport equation.

$$
\frac{\partial F}{\partial t}+\nabla \cdot(\vec{V} F)=0
$$

where

$$
\begin{array}{lll}
F & = & \text { liquid volume fraction } \\
t & = & \text { time }[\mathrm{s}] \\
\vec{V} & = & \text { velocity vector }
\end{array}
$$

This equation is solved together with the fundamental equations of conservation of mass, momentum and energy as follows;

1-The mixture properties are computed.

2-The fluid-fluid interface is reconstructed in each cell.

3-The contribution of the secondary fluid flux to the conservation of mass, momentum, energy, and volume fraction equations is determined.

\subsubsection{Mixture Properties}

The average value of any volume-specific quantity $\phi$ in a computational cell can be computed from the value of $F$ as follows:

$$
\langle\phi\rangle=F \phi_{2}+(1-F) \phi_{1}
$$

where

$$
\begin{array}{lll}
\langle\phi\rangle & = & \text { the volume-averaged quantity } \\
\phi_{2} & = & \text { the value of the property for fluid two } \\
\phi_{1} & = & \text { the value of the property for fluid one }
\end{array}
$$


For a mass-specific value, the above equation can be extended to include the effect of density

$$
\langle\phi\rangle=\left[F \rho_{2} \phi_{2}+(1-F) \rho_{1} \phi_{1}\right] / \rho_{\text {mix }}
$$

where

$$
\rho_{\text {mix }}=\text { mixture density }\left[\mathrm{kg} / \mathrm{m}^{3}\right]
$$

\subsubsection{Theory of surface reconstruction}

The classification of the VOF method as a volume tracking method follows from the use of single scalar variable $F$ to describe the liquid distribution and to solve for the liquid volume evolution. Because of the volumetric representation of the phase distribution there is no unique definition of the interface between the two phases. So if the location of the interface is needed it must be dynamically reconstructed from the $F$ distribution. Three different methods for the surface reconstruction could be used by the CFD-ACE+ solver.

1- A zero order upwind scheme.

2- An upwind scheme with the single line interface construction (SLIC)

3- An upwind scheme with the piecewise linear interface construction (PLIC)

However in the current study the PLIC method was used because it is the most accurate. In this scheme the liquid-gas interface is assumed to be flat and is allowed to take any orientation within the cell. The interface will generally have the shape of an arbitrary polygonal face. The facet, any polygon whose corners are vertices of the polyhedron, in a cell is defined by:

i- $\quad$ The spatial orientation of the infinite plane that contains the facet.

ii- $\quad$ The location of a point within the cell through which the infinite plane passes.

The orientation is specified by the unit normal of the infinite plane which points out of the liquid phase and into the gas phase. The unit normal of the plane is determined 
by assuming that it is parallel to the gradient of $F$. The gradient of $F$ is determined from the local distribution of $F$ in a set of cells which includes the target cell and all its immediate neighbors. The location of the anchor point through which the infinite plane passes is determined by finding the infinite cutting plane perpendicular to the unit normal of the infinite plane that truncates the liquid volume from the cell. It satisfies the condition

$v_{c u t}=F^{*} v_{C}$

where

$$
\begin{aligned}
& v_{c u t}=\quad \text { the volume of the cell truncated by the cutting plane. } \\
& v_{C}=\quad \text { the volume of the whole cell. }
\end{aligned}
$$

In the PLIC scheme, each cell has a unique surface normal that can be used to compute the surface curvature from cell to cell. After computing the surface curvature the surface tension forces are calculated for the free surfaces.

\subsection{Mass Conservation}

The time rate of change of mass in a control volume is balanced by the net mass flow into the control volume and the generation of the mass within the control volume. As the control volume shrinks to a point one can write

$$
\frac{\partial \rho}{\partial t}+\nabla \cdot(\rho \vec{V})=S_{m}
$$

where

$$
\begin{array}{lll}
\rho & = & \text { density }\left[\mathrm{kg} / \mathrm{m}^{3}\right] \\
S_{m} & = & \text { mass source term }\left[\mathrm{kg} \mathrm{m}^{-3} / \mathrm{s}\right]
\end{array}
$$

For incompressible fluids with no source, equation (4.5) simplifies to $\nabla \cdot \vec{V}=0$ 


\subsection{Momentum Conservation}

The momentum equation is derived by setting the rate of change of the momentum of a fluid particle equal to the total force in the same direction on the particle due to the surface stresses and body forces.

The momentum equations in the $\mathrm{x}, \mathrm{y}$ and $\mathrm{z}$ directions are given by (4-6), (4-7) and (4-8) respectively. The governing equations (4-6, 4-7, and 4-8) are found in the CFDACE+ manual [42]

$$
\begin{aligned}
& \frac{\partial(\rho u)}{\partial t}+\nabla \cdot(\rho \vec{V} u)=\frac{\partial\left(-p+\tau_{x x}\right)}{\partial x}+\frac{\partial \tau_{y x}}{\partial y}+\frac{\partial \tau_{z x}}{\partial z}+S_{M x} \\
& \frac{\partial(\rho v)}{\partial t}+\nabla \cdot(\rho \vec{V} v)=\frac{\partial \tau_{x y}}{\partial x}+\frac{\partial\left(-p+\tau_{y y}\right)}{\partial y}+\frac{\partial \tau_{z y}}{\partial z}+S_{M y} \\
& \frac{\partial(\rho w)}{\partial t}+\nabla \cdot(\rho \vec{V} w)=\frac{\partial \tau_{x z}}{\partial x}+\frac{\partial \tau_{y z}}{\partial y}+\frac{\partial\left(-p+\tau_{z z}\right)}{\partial z}+S_{M z}
\end{aligned}
$$

where

$$
\begin{array}{lll}
p & = & \text { static pressure }[\mathrm{Pa}] \\
\tau_{x x} & = & \text { xx component of the viscous stress tensor }\left[\mathrm{kg} / \mathrm{m} \mathrm{s}^{2}\right] \\
S_{M_{x}}= & \mathrm{x} \text { - momentum source term }\left[\mathrm{N} / \mathrm{m}^{3}\right] \\
u, v, w= & \text { velocity components in } x, y, z \text { directions respectively }[\mathrm{m} / \mathrm{s}]
\end{array}
$$




\subsection{Navier-Stokes Equations}

To define the viscous stress components $\tau_{i j}$, a Newtonian fluid is assumed in which the viscous stress is linearly proportional to the rate of deformation of the fluid element. The nine viscous stress components are related to the velocity gradients according to equations (4-9 to 4-14). By substituting these terms into the momentum equations the Navier-Stokes equations are obtained (4-15 to 4-17). The details of this derivation can be found in White [44].

$$
\begin{aligned}
& \tau_{x x}=2 \mu \frac{\partial u}{\partial x}-\frac{2}{3} \mu(\nabla \cdot \vec{V}) \\
& \tau_{y y}=2 \mu \frac{\partial v}{\partial y}-\frac{2}{3} \mu(\nabla \cdot \vec{V}) \\
& \tau_{z z}=2 \mu \frac{\partial w}{\partial z}-\frac{2}{3} \mu(\nabla \cdot \vec{V}) \\
& \tau_{x y}=\tau_{y x}=\mu\left(\frac{\partial u}{\partial y}+\frac{\partial v}{\partial x}\right) \\
& \tau_{x z}=\tau_{z x}=\mu\left(\frac{\partial u}{\partial z}+\frac{\partial w}{\partial x}\right) \\
& \tau_{y z}=\tau_{z y}=\mu\left(\frac{\partial v}{\partial z}+\frac{\partial w}{\partial y}\right)
\end{aligned}
$$




$$
\begin{aligned}
\frac{\partial(\rho u)}{\partial t}+\nabla \cdot(\rho \vec{V} u)=- & \frac{\partial p}{\partial x}+\frac{\partial}{\partial x}\left[2 \mu \frac{\partial u}{\partial x}-\frac{2}{3} \mu(\nabla \cdot \vec{V})\right]+\frac{\partial}{\partial y}\left[\mu\left(\frac{\partial u}{\partial y}+\frac{\partial v}{\partial x}\right)\right] \\
& +\frac{\partial}{\partial z}\left[\mu\left(\frac{\partial u}{\partial z}+\frac{\partial w}{\partial x}\right)\right]+S_{M x} \\
\frac{\partial(\rho v)}{\partial t}+\nabla \cdot(\rho \vec{V} v)=-\frac{\partial p}{\partial y}+ & \frac{\partial}{\partial x}\left[\mu\left(\frac{\partial u}{\partial y}+\frac{\partial v}{\partial x}\right)\right]+\frac{\partial}{\partial y}\left[2 \mu \frac{\partial v}{\partial y}-\frac{2}{3} \mu(\nabla \cdot \vec{V})\right] \\
& +\frac{\partial}{\partial z}\left[\mu\left(\frac{\partial v}{\partial z}+\frac{\partial w}{\partial y}\right)\right]+S_{M y} \\
\frac{\partial(\rho w)}{\partial t}+\nabla \cdot(\rho \vec{V} w)=- & \frac{\partial p}{\partial z}+\frac{\partial}{\partial x}\left[\mu\left(\frac{\partial u}{\partial z}+\frac{\partial w}{\partial x}\right)\right]+\frac{\partial}{\partial y}\left[\mu\left(\frac{\partial v}{\partial z}+\frac{\partial w}{\partial x}\right)\right] \\
& +\frac{\partial}{\partial z}\left[2 \mu \frac{\partial w}{\partial y}-\frac{2}{3} \mu(\nabla \cdot \vec{V})\right]+S_{M z}
\end{aligned}
$$

where

$$
\mu \quad=\quad \text { dynamic viscosity }[\mathrm{kg} / \mathrm{ms}]
$$

For an incompressible fluid with constant viscosity, equations (4-15 to 4-17) simplify to (4-18 to 4-20)

$$
\begin{aligned}
& \rho \frac{\partial(u)}{\partial t}+\rho \nabla \cdot(\vec{V} u)=-\frac{\partial p}{\partial x}+\mu \nabla \cdot(\nabla u)+S_{M x} \\
& \rho \frac{\partial(v)}{\partial t}+\rho \nabla \cdot(\vec{V} v)=-\frac{\partial p}{\partial y}+\mu \nabla \cdot(\nabla v)+S_{M y} \\
& \rho \frac{\partial(w)}{\partial t}+\rho \nabla \cdot(\vec{V} w)=-\frac{\partial p}{\partial z}+\mu \nabla \cdot(\nabla w)+S_{M z}
\end{aligned}
$$




\subsection{Energy Equation}

Heat transfer is computed by solving the conservation of energy equation. Several forms can be used for the energy equation. However CFD-ACE+ solves this equation numerically in the form known as the total enthalpy equation (4-21).

$$
\begin{aligned}
\frac{\partial\left(\rho h_{o}\right)}{\partial t}+\nabla \cdot\left(\rho \vec{V} h_{o}\right)= & \nabla \cdot(k \nabla T)+\frac{\partial p}{\partial t}+\left[\frac{\partial\left(u \tau_{x x}\right)}{\partial x}+\frac{\partial\left(u \tau_{y x}\right)}{\partial y}+\frac{\partial\left(u \tau_{z x}\right)}{\partial z}\right] \\
& +\left[\frac{\partial\left(v \tau_{x y}\right)}{\partial x}+\frac{\partial\left(v \tau_{y y}\right)}{\partial y}+\frac{\partial\left(v \tau_{z y}\right)}{\partial z}\right]+\left[\frac{\partial\left(w \tau_{x z}\right)}{\partial x}+\frac{\partial\left(w \tau_{y z}\right)}{\partial y}+\frac{\partial\left(w \tau_{z z}\right)}{\partial z}\right]+S_{h}
\end{aligned}
$$

where

$h_{o}=\quad$ the total enthalpy and is given by $[\mathrm{J} / \mathrm{kg}]$

$h_{o}=i+\frac{p}{\rho}+\frac{1}{2}\left(u^{2}+v^{2}+w^{2}\right)$

where

$$
\begin{array}{lll}
i & = & \text { the internal energy }[\mathrm{J} / \mathrm{kg}] \\
k & = & \text { the thermal conductivity }[\mathrm{W} / \mathrm{m} \mathrm{K}] \\
S_{h} & = & \text { represents the energy source term }\left[\mathrm{W} / \mathrm{m}^{3}\right]
\end{array}
$$




\section{Chapter 5}

\section{Code Validation}

\subsection{Introduction}

In order to use any commercial software one has to make sure that the results are correct by matching with appropriate analytical or experimental solutions. In this chapter the validation of Flow, Heat transfer and VOF modules is discussed. A module is a part of the program or the code which can run separately or with other modules. For example the Flow module solves the continuity and momentum equations, while the Heat module solves the energy equation.

The results were tested to make sure that they were not grid dependent before the code was validated. The following cases were validated; flow on inclined plate, laminar boundary layer thickness, source term and thermal boundary layer. The Flow module was validated by calculating the boundary layer thickness analytically, and the results were compared against the numerical solution. The thermal boundary layer solution was validated for a uniform wall heat flux.

\subsection{Grid Independent Solution}

A two dimensional model was built to investigate the effect of the grid resolution on the computed results. The actual model which was used in all simulations is used here, in which one have a layer moving horizontally with a uniform velocity parallel to a constant heat flux wall. The spray mass and momentum were added to the continuity and momentum equations of the upper surface of the liquid layer as source terms through the user subroutines. Four boundary conditions were defined in this model. The left boundary was defined as uniform inlet velocity boundary, the top and right boundaries were defined as constant pressure outlets and the bottom boundary was a constant heat flux 
wall which represents the heater surface. More details of the model and the boundary conditions are shown in section 6.1 under model setup.

A separate study was made for grid resolution and its effect on the results. It was necessary to check before proceeding further into the investigation if the solution was grid dependent or not. It is well known from the fundamentals of numerical analysis that the finer the grid the more accurate the results will be. However, after a certain point there is no point in refining the grid more, if the change in the results can be ignored. Another practical limitation on grid refinement is that the computational time increases. Four different grids were tested with the source term subroutines added. The number of nodes starting from the coarse grid to the fine were 7500, 8680, 12000 and 22000 nodes. The number of nodes was increased inside the liquid layer and in the vertical direction. The grid resolutions are shown in Figures 5.1, 5.2, 5.3 and 5.4 for the 7500, 8680, 12000 and 22000 node cases respectively. A $150 \mathrm{~kW} / \mathrm{m}^{2}$ uniform heat flux was applied at the bottom wall.

Since the region of concern is the heater surface, the grid was built in such a way that close to the heater surface there is a very fine grid followed by a medium grid and ending with a coarse grid at the top boundary.

The wall temperature profiles for the above meshes are shown in Figure 5.5. The results show that there was almost no difference between the 8680, 12000 and 22000 node grids. However there was only a $0.2 \mathrm{~K}$ difference with the 7500 node which is used in the current study due to the time concern. 


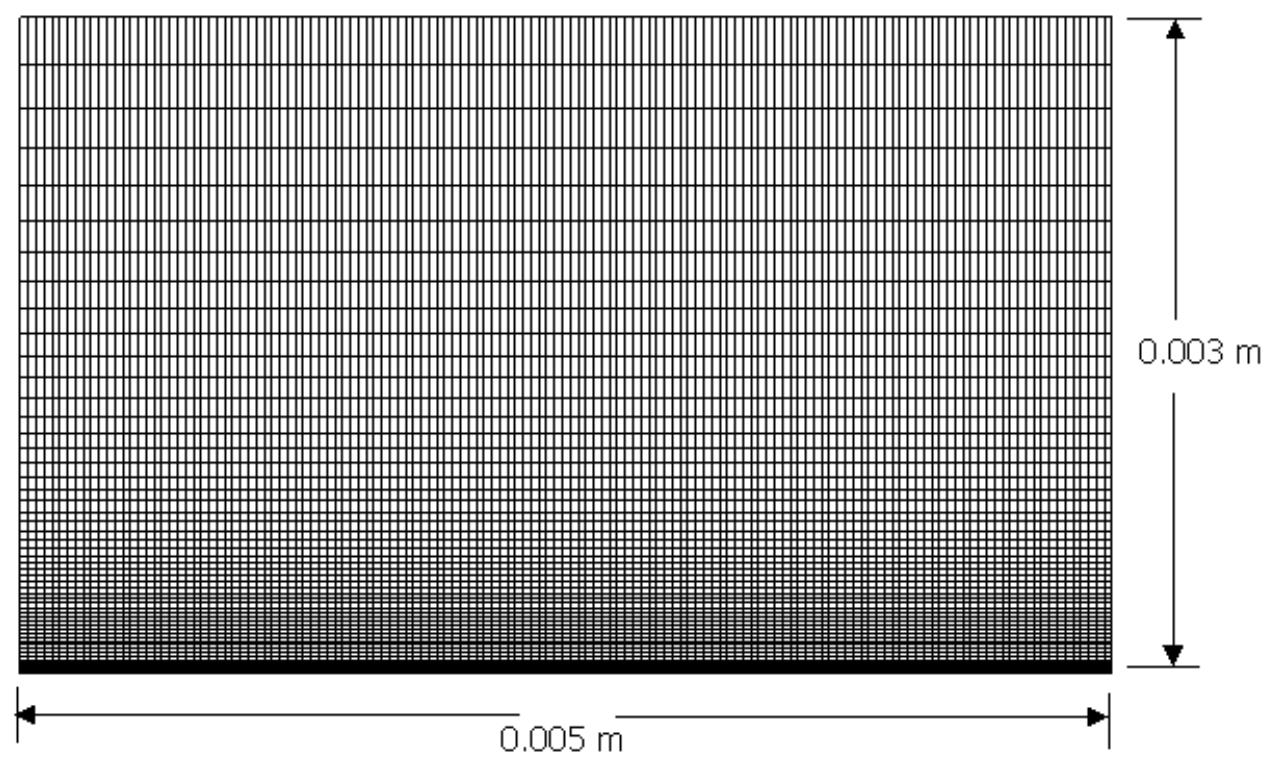

Figure 5.1 Grid Resolution for Two Dimensional Planar 7500 Node Domain.

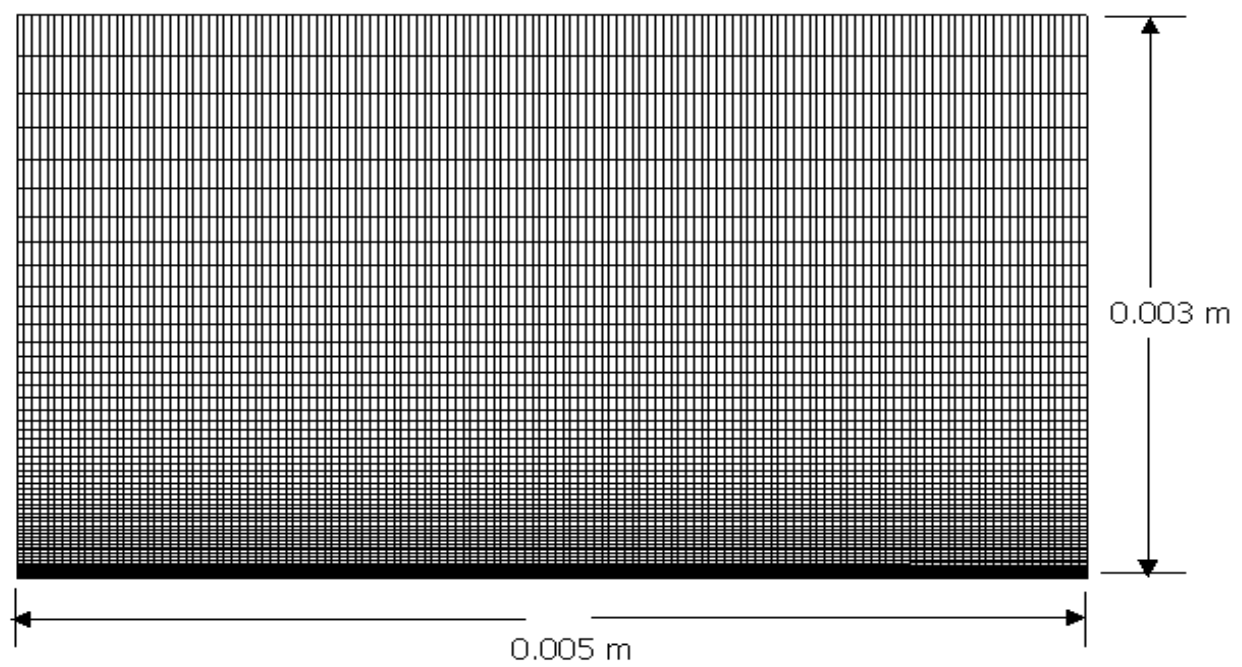

Figure 5.2 Grid Resolution for Two Dimensional Planar 8680 Node Domain. 


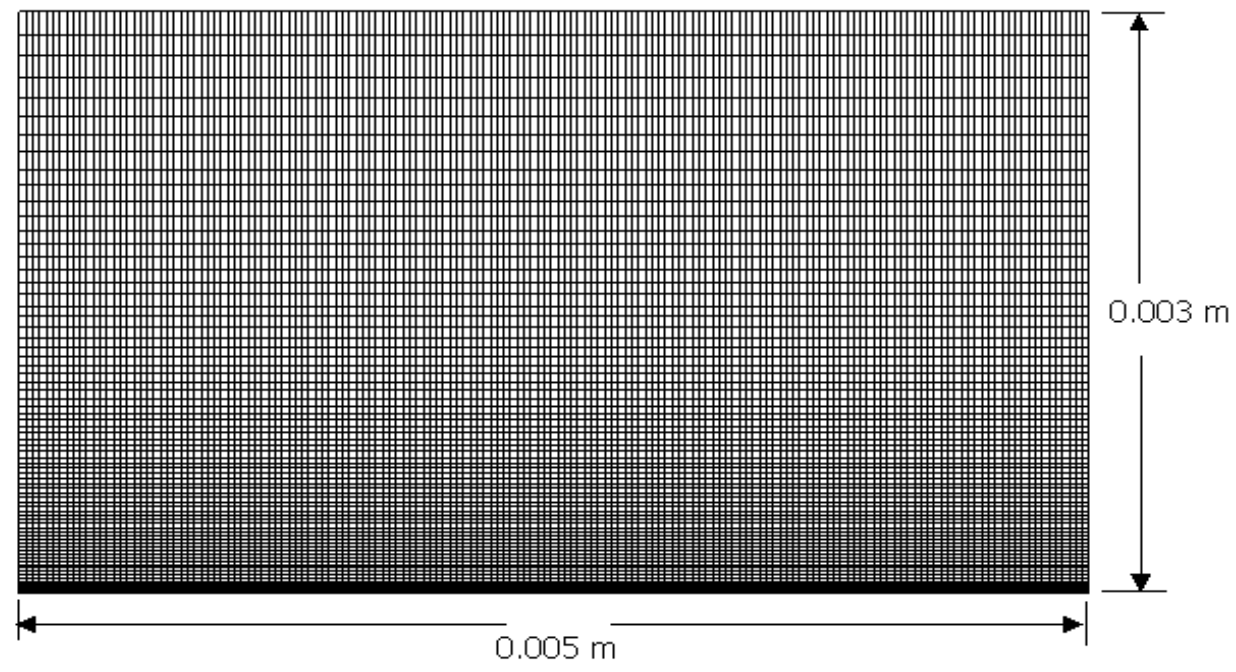

Figure 5.3 Grid Resolution for Two Dimensional Planar 12000 Node Domain.

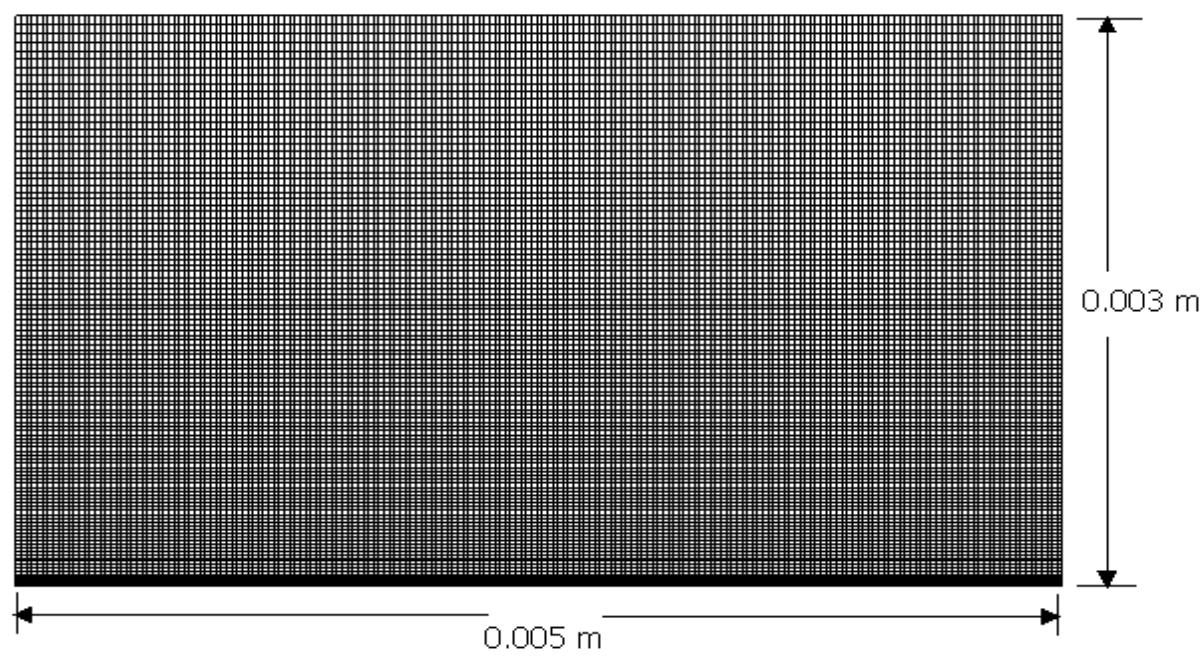

Figure 5.4 Grid Resolution for Two Dimensional Planar 22000 Node Domain. 


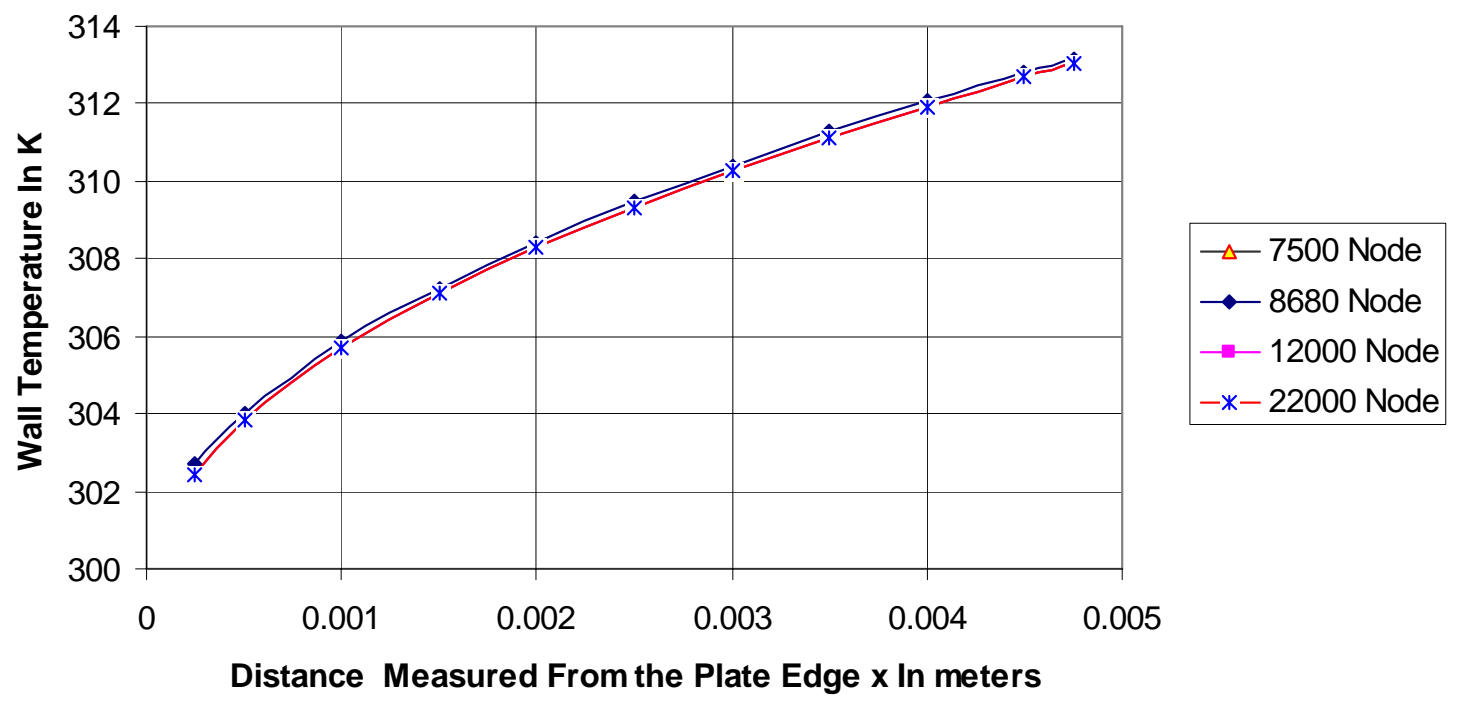

Figure 5.5 Grid Independent Solution with Source Term.

\subsection{Flow on Inclined Plane}

The balance between the gravity force and the friction force of a laminar layer flowing on an inclined plane was tested by using the following formula from White. [44]. Two user subroutines were written for the parabolic inlet profile velocity and the parabolic initial velocity profile as shown in appendices A-1 and A-2 respectively.

$U_{\max }=\frac{\rho g \sin (\theta) d^{2}}{2 \mu}$

where

$$
\begin{array}{lll}
\theta & = & \text { the angle measured from the horizontal } \\
d & = & \text { the layer thickness }[\mathrm{m}] \\
\mu & = & \text { dynamic viscosity }[\mathrm{kg} / \mathrm{m} \mathrm{s}] \\
g & = & \text { gravitational acceleration }\left[\mathrm{m} / \mathrm{s}^{2}\right]
\end{array}
$$


The value of $U_{\max }$ from equation (5-1) is substituted in the parabolic velocity profile subroutine using equation (5-2) which is found in White [44].

$U(N)=U_{\text {max }} *\left(2\left(y_{f c} / y_{\text {max }}\right)-\left(y_{f c} / y_{\text {max }}\right)^{2}\right)$

where

$$
\begin{array}{lll}
U_{\max } & = & \text { the maximum velocity }[\mathrm{m} / \mathrm{s}] \\
N & = & \text { cell number }[-] \\
y_{f_{c}} & = & \text { y coordinate at the cell face center }[\mathrm{m}] \\
y_{\max } & = & \text { maximum layer thickness }[\mathrm{m}]
\end{array}
$$

Figure 5.6 shows the model setup for this case. The simulation results showed a perfect balance between the gravity force and the friction force. 


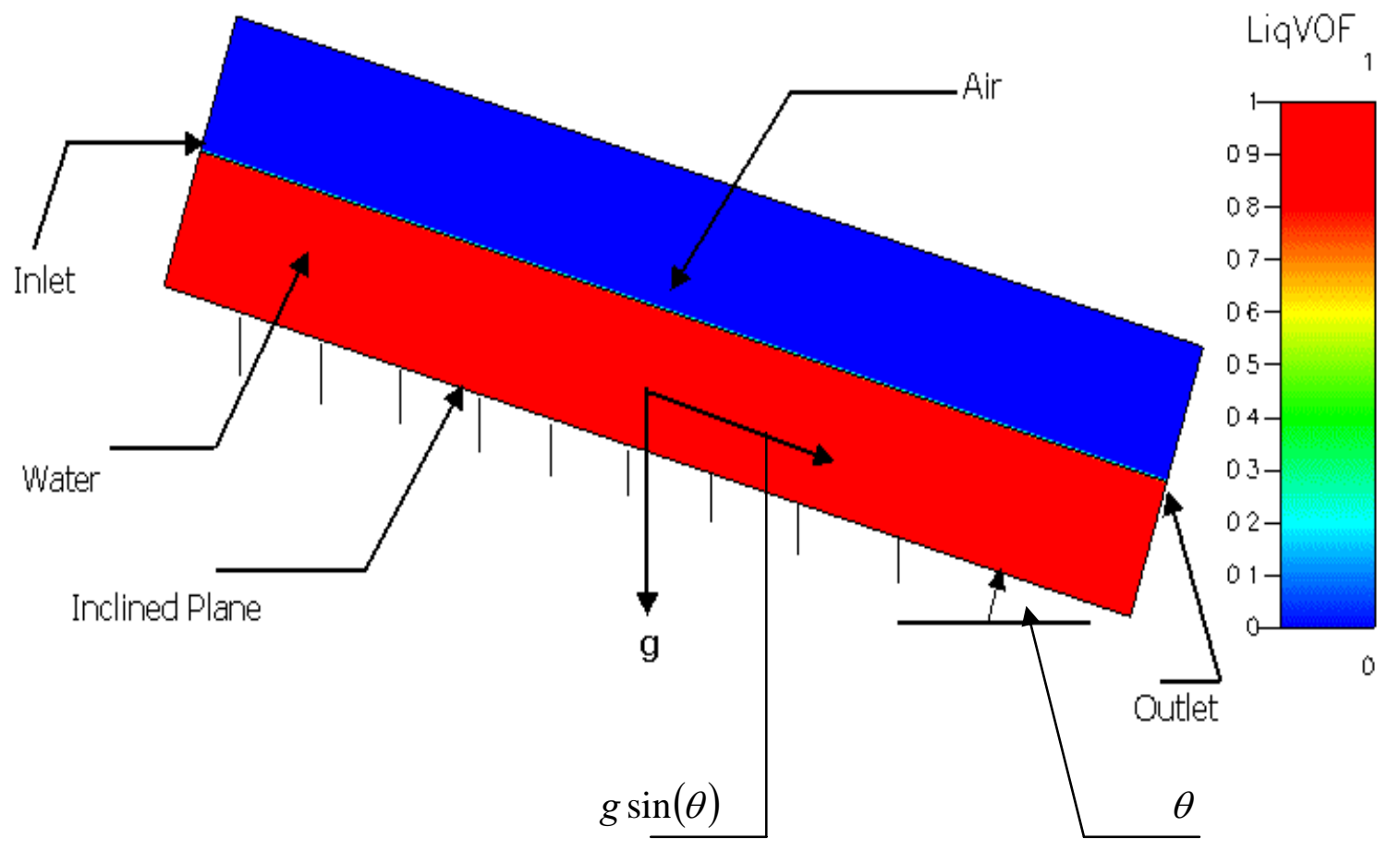

Figure 5.6 Flow on Inclined Plane.

\subsection{Laminar Boundary Layer Validation}

The boundary layer thickness, where the horizontal velocity is $99 \%$ of the free stream velocity, for laminar flow on a flat plate for a fluid with constant fluid properties is given by equation (84) in the Handbook of Heat Transfer by Rohsenow and Hartnett [45].

$$
\delta=\frac{5 x}{\sqrt{\operatorname{Re}_{x}}}
$$

where

$$
\begin{array}{lll}
\delta & = & \text { the boundary layer thickness [m] } \\
x & = & \text { distance measured from the plate edge [m] } \\
\operatorname{Re}_{x} & = & \text { Reynolds number at distance } x \text { from the plate edge [-] }
\end{array}
$$


A two dimensional test case was run to validate the code. The model setup is shown in Figure 5.7 in which one have only one working fluid (air). No user subroutine was used in this case. The flow has a uniform velocity distribution at the inlet and there is no heat transfer. The inlet velocity was $0.1 \mathrm{~m} / \mathrm{s}$ and Reynolds number is 6290 at 1 meter length from the plate edge. The condition for using equation (5-3) is that $x$ has to be long enough in comparison with $\delta$, where $\delta$ is the distance measured in the vertical direction $y$ and $x$ is the distance measured in the horizontal direction. The domain was chosen to be $2.0 * 0.5 \mathrm{~m}^{2}$. The boundary layer thickness for the steady state solution was calculated using equation (5-3) at different positions $x$ from the plate edge. The profile of velocity at $x=1 \mathrm{~m}$ is plotted in Figure 5.8. The results from equation (5-3) and the numerical solution were found to be the same and agree with Blasius profile.

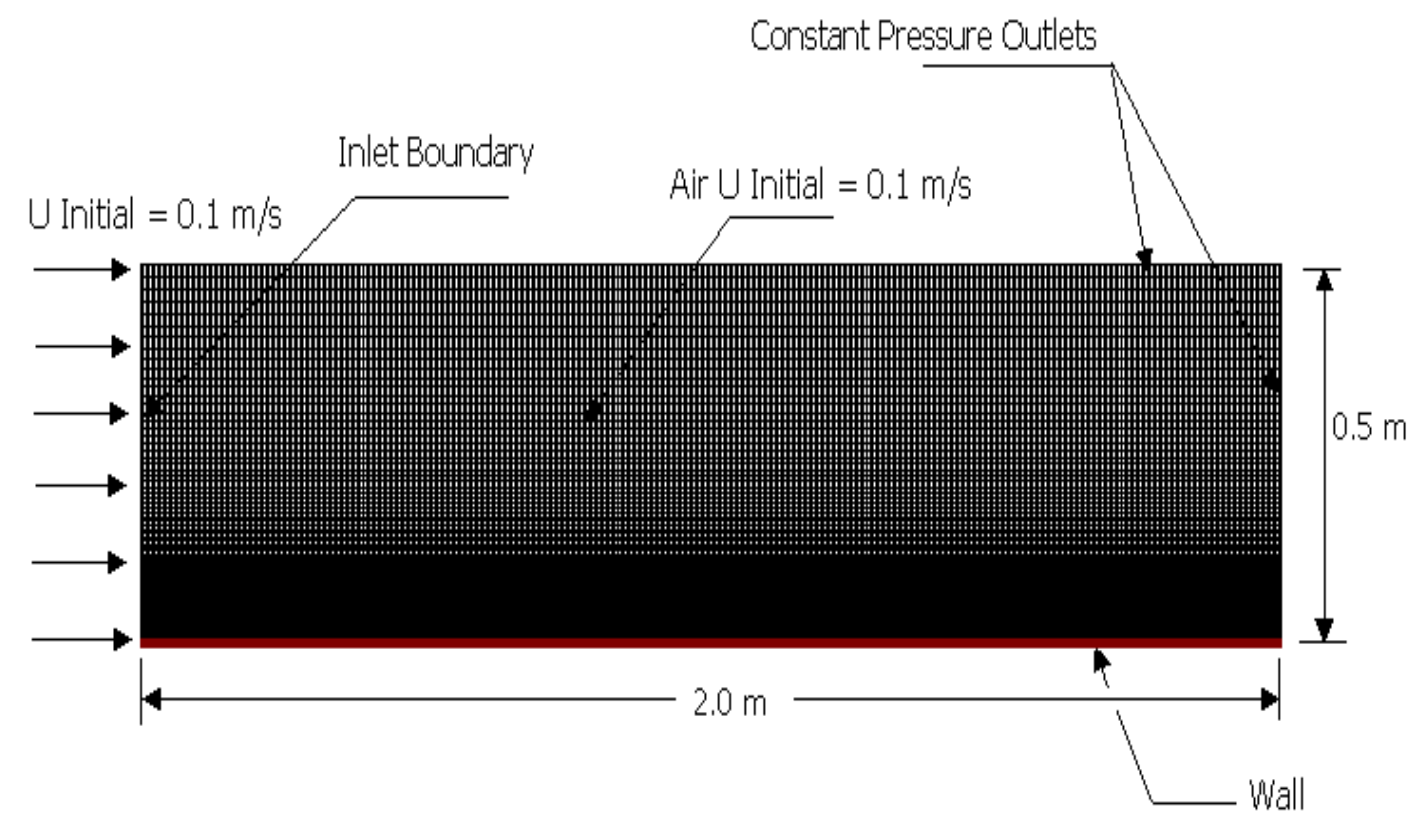

Figure 5.7 Flat Plate Boundary Layer Model Setup and Grid. 


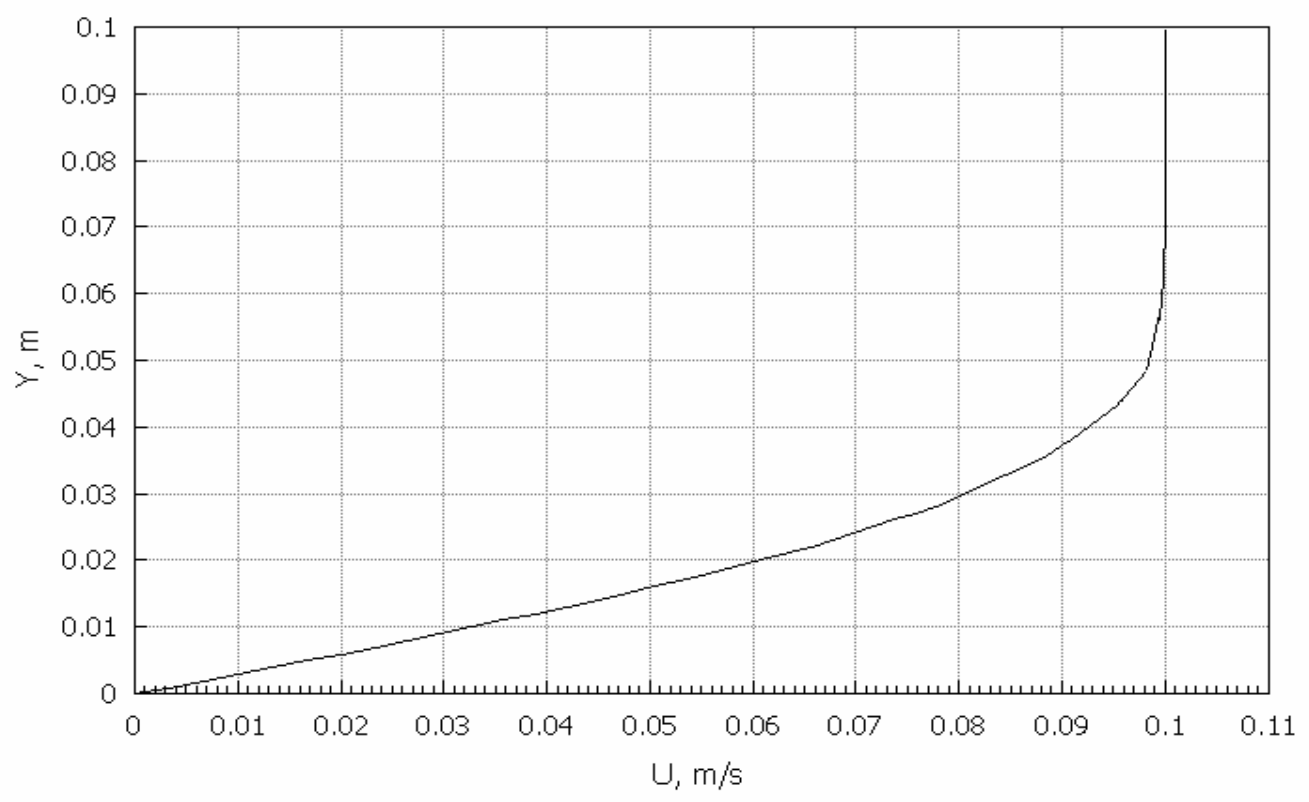

Figure 5.8 Laminar Boundary Layer Velocity Profile at $x=1 \mathrm{~m}$.

\subsection{Flat Plate Boundary Layer Validation against Blasius Solution}

The similarity variable for the Blasius solution is given by White [44] as formula (5-4).

$\eta=y \sqrt{\frac{U}{2 v x}}$

where

$$
\begin{array}{lll}
\eta & = & \text { dimensionless similarity variable }[-] \\
y & = & \text { distance measured in the vertical direction }[\mathrm{m}] \\
U & = & \text { free stream velocity }[\mathrm{m} / \mathrm{s}] \\
v & = & \text { kinematic viscosity }\left[\mathrm{m}^{2} / \mathrm{s}\right] \\
x & = & \text { distance from leading edge measured in the horizontal direction }[\mathrm{m}]
\end{array}
$$


A two dimensional model was built to compare against the Blasius solution for flat plate boundary layer. Results are shown in Figure 5.9 where the plot is not to scale. The value of $\eta$ was calculated from the numerical solution. At each distance $x$ from the plate edge different values of $u$ at different values of the corresponding vertical distance $y$ were measured using the code probe. Figure 5.10 shows a plot of $\mathrm{u} / U$ vs. $\sqrt{2} \eta$. The Blasius solution was plotted using data from White [44]. The results show a good match between the numerical and the Blasius solutions.

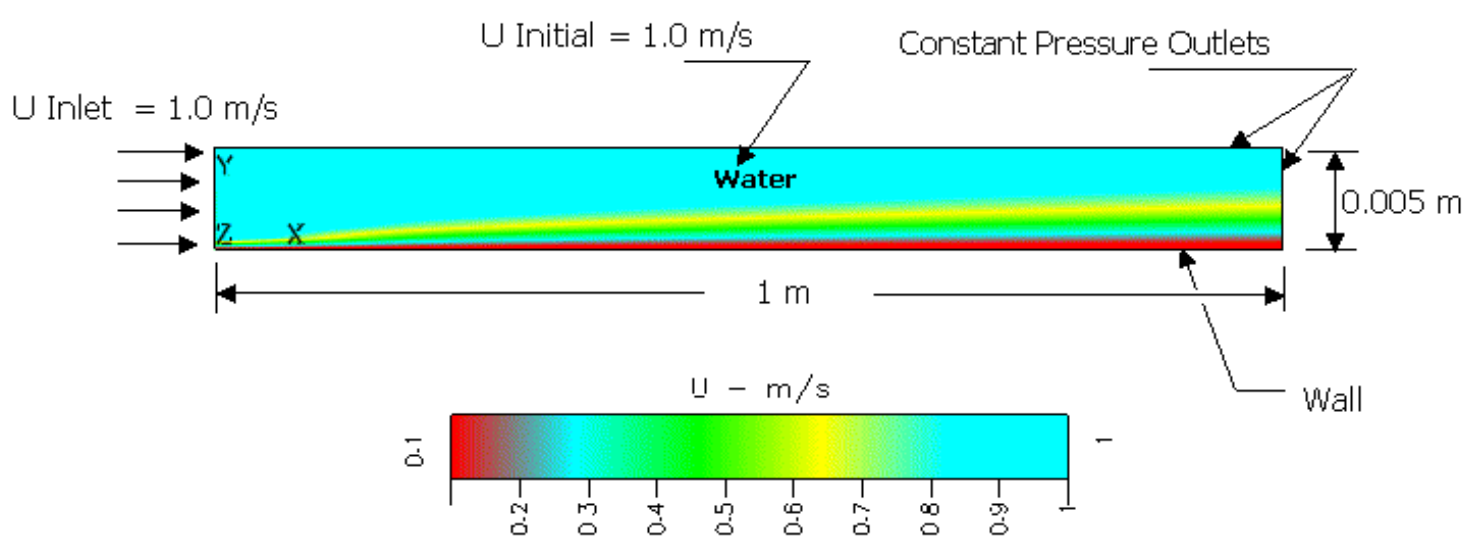

Figure 5.9 Blasius Solution Model Solution. 


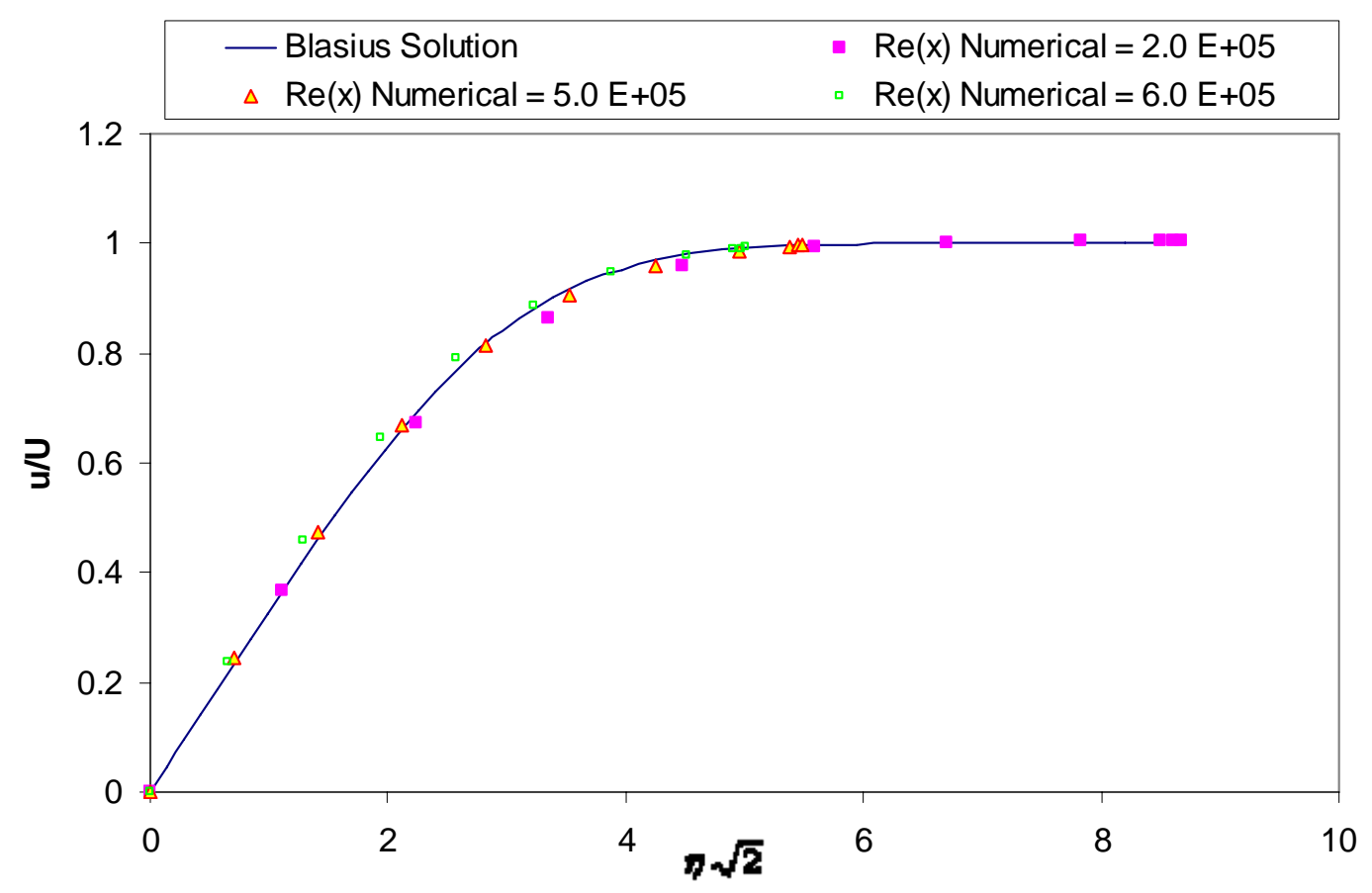

Figure 5.10 Flat Plate Boundary Validation against Blasius Solution.

\subsection{Source Term Validation}

One of the major advantages of the currently used software, CFD-ACE+, is the ability to change the source code itself through what are called user subroutines. User subroutines are written by the user to fit any particular application. Three subroutines were written by the current investigator. These subroutines were used to simulate the spray cooling by adding the spray mass and momentum as source terms to the continuity and momentum equations of a liquid layer moving parallel to a constant heat flux wall.

A simple two dimensional geometry was built to verify that the mass source term was added properly. The dimensions are $1.0 * 1.0 \mathrm{~m}^{2}$. Three boundaries were defined as walls as shown in Figure 5.11. The upper boundary was defined as an outlet. An initial liquid layer of known volume was defined. The mass source term was added uniformly to all the cells which contain liquid at a constant rate sufficient to fill the tank in 1 second. At different periods of time the total mass was calculated and compared with the rate of 
mass addition. The mass was calculated by multiplying the density of the water times the volume of water in the tank. After 1 second the tank was full as shown in Figure 5.12. The numerical results were found to be the same as the calculation results.

Two more source terms were added which were the horizontal and vertical momentum source terms. A two dimensional model was built to validate the momentum source term subroutines. The details of the model are shown in Chapter 6 under model setup. The value of the momentum source term is defined by the mass times the velocity. Both the mass and the velocity were defined and an output file was created by using the source term subroutine. The momentum values were calculated by hand and compared to those obtained from the subroutine at each cell, and the results were found to be the same. The source term subroutines are shown in Appendices A-3 to A-5.

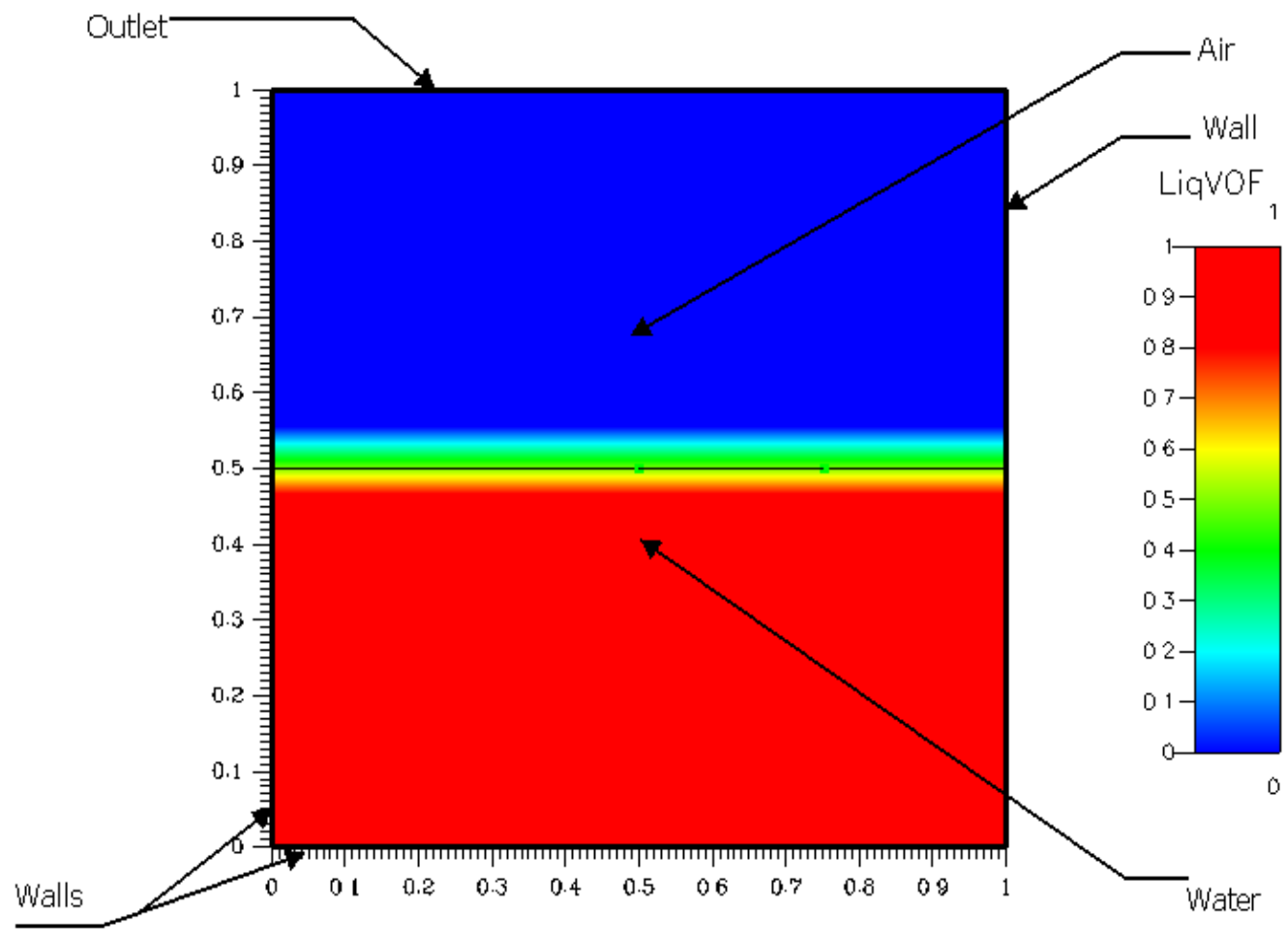

Figure 5.11 Source Term Validation Initial Condition. 


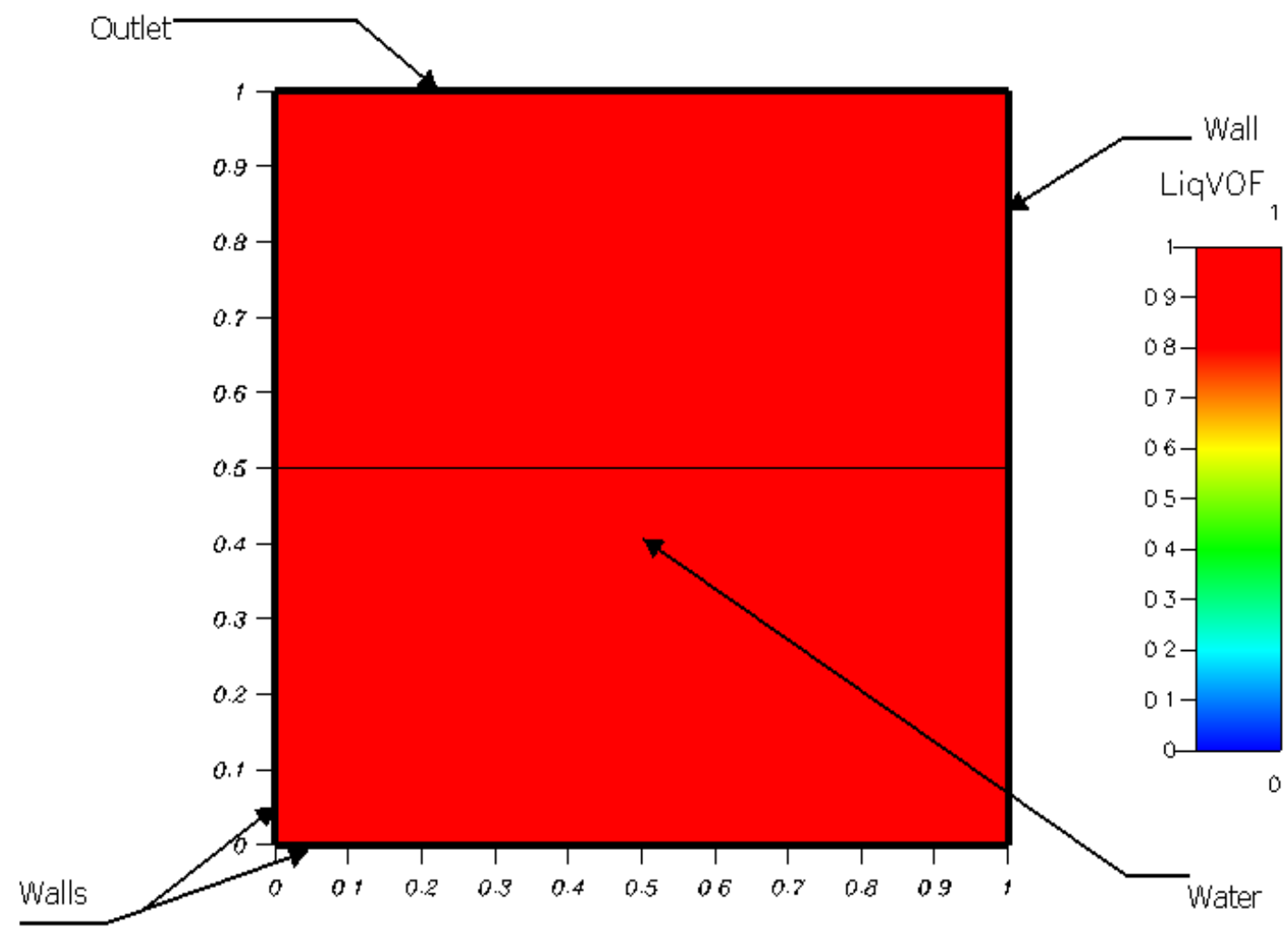

Figure 5.12 Source Term Validation.

\subsection{Thermal Laminar Boundary Layer Validation for Uniform Heat Flux Wall}

The integral solution for laminar boundary layer flow near a wall with uniform heat flux $(\operatorname{Pr}>0.5)$ is given by equation (5-5) as shown in Bejan [46]:

$$
T_{w}(x)-T_{\infty}=\frac{q_{w} x}{0.453 k \operatorname{Pr}^{1 / 3} \operatorname{Re}_{x}^{1 / 2}}
$$

where

$$
\begin{array}{lll}
T_{w}(x)= & \text { wall temperature measured from plate edge }[\mathrm{K}] \\
T_{\infty} & = & \text { ambient temperature }[\mathrm{K}] \\
q_{w} & = & \text { wall heat flux }\left[\mathrm{W} / \mathrm{m}^{2}\right]
\end{array}
$$




$$
\begin{array}{lll}
x & = & \text { distance from plate edge }[\mathrm{m}] \\
k & = & \text { fluid thermal conductivity }[\mathrm{W} / \mathrm{m} \mathrm{K}] \\
\operatorname{Pr} & = & \text { Prandtl number [-] } \\
\operatorname{Re}_{x} & = & \text { Reynolds number based on distance } x \text { from the plate edge [-] }
\end{array}
$$

A two dimensional model was build to validate equation (5-5). The model setup is shown in Figure 5.13. The integral solution for thermal laminar boundary layer with a uniform heat flux wall was obtained using water as working fluid where $\operatorname{Pr}=7.0$. The temperature at the wall surface was calculated at different distances $x$ from the plate edge. These values were plotted in Figure 5.14 and compared with the numerical solution. The figure shows that both the numerical and the integral solution have the same trend. However a shift between the two solutions was found. To make sure that this shift is repeatable the same case was run using air as a working fluid where $\operatorname{Pr}=0.7$. Figure 5.15 shows the model setup and the temperature distribution. The comparison between the numerical and the integral solution is shown in Figure 5.16. The same trend was obtained as before. However the temperature of the air is much higher that that of the liquid because of the liquid's higher specific heat. The domain of the air was shorter than that of the liquid because the air temperature would be much higher for a longer domain. 


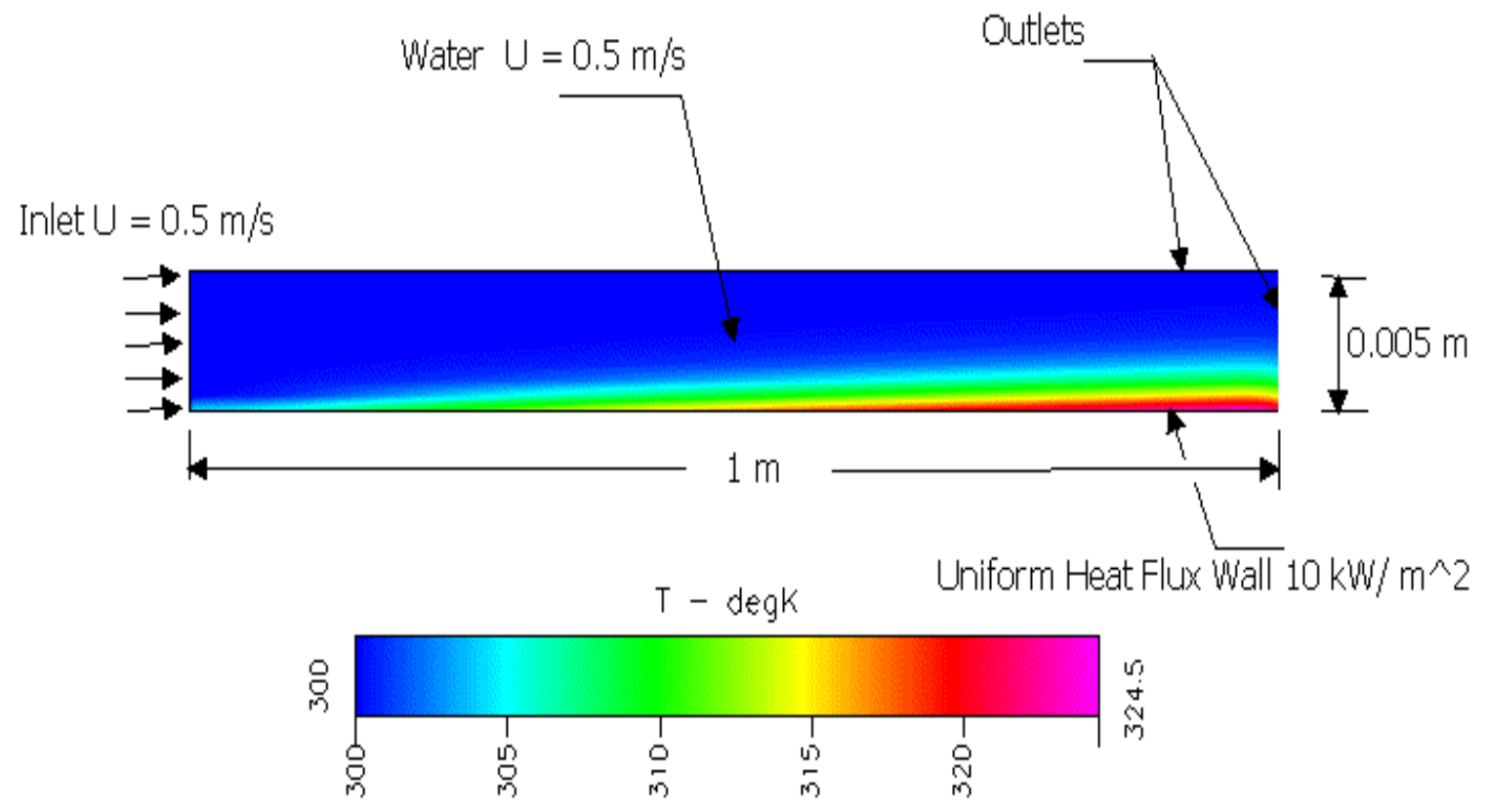

Figure 5.13 Thermal Boundary Layer Validation Model Results for Water.

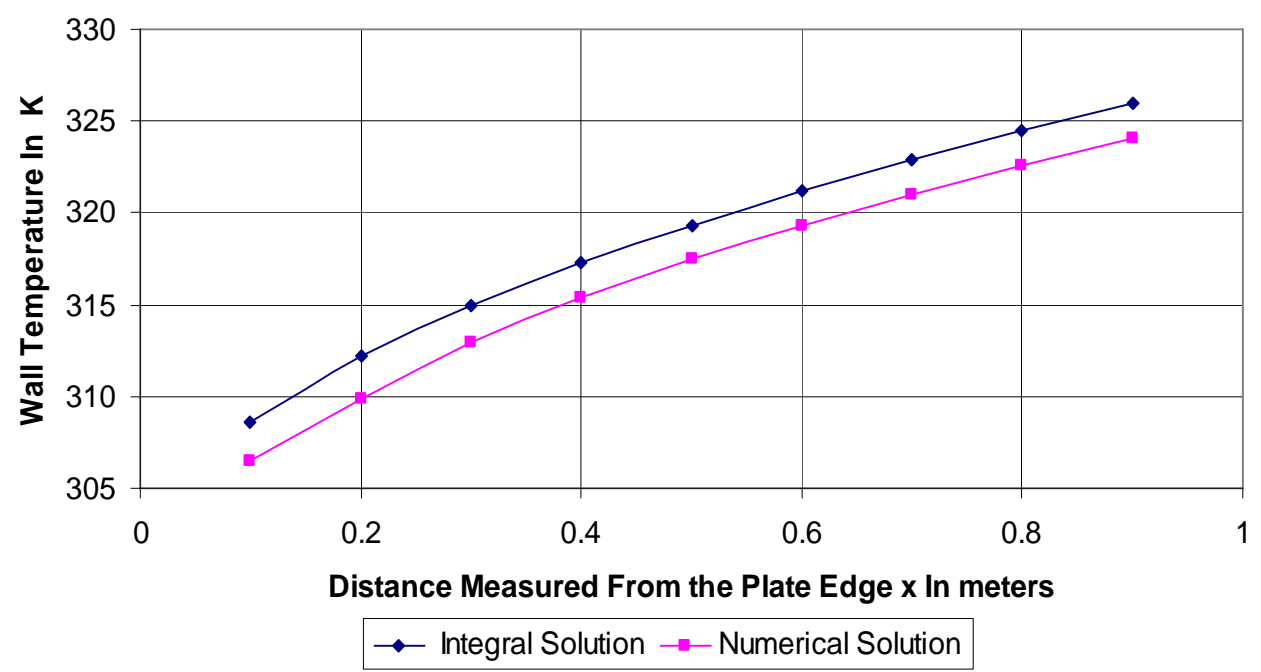

Figure 5.14 Thermal Boundary Layer Comparison between Numerical Solution and Integral Solution for Water. 


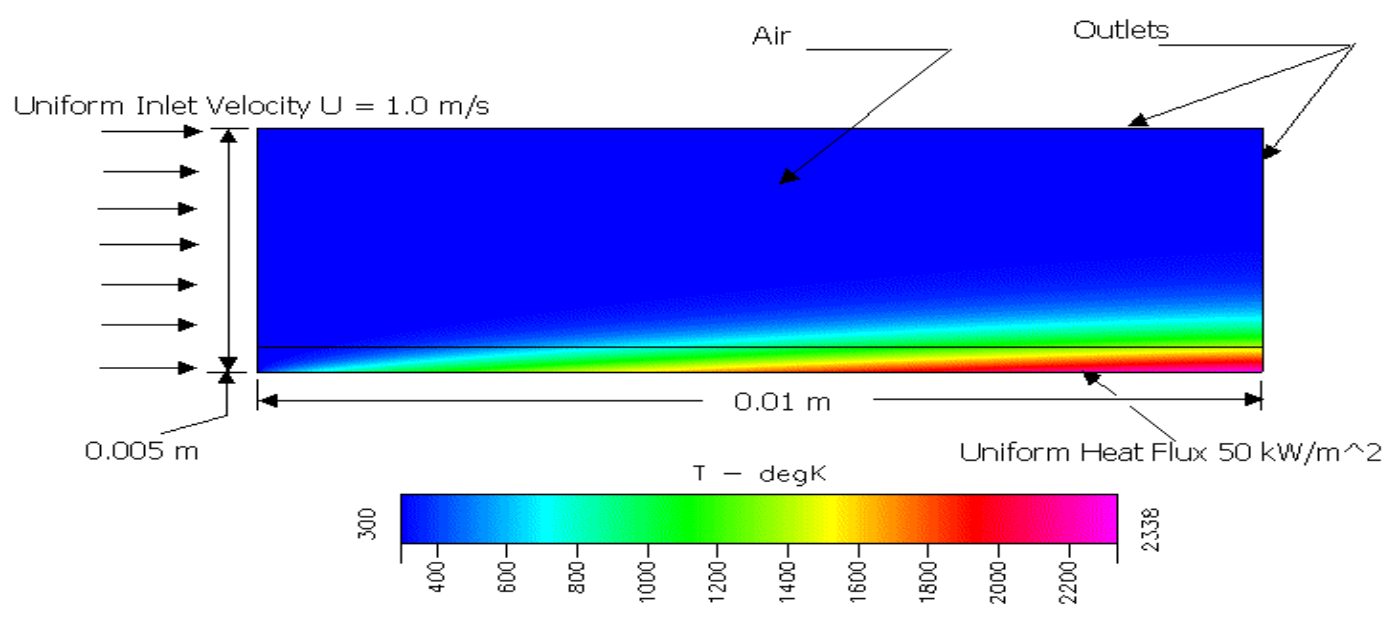

Figure 5.15 Thermal Boundary Layer Validation Model Results for Air.

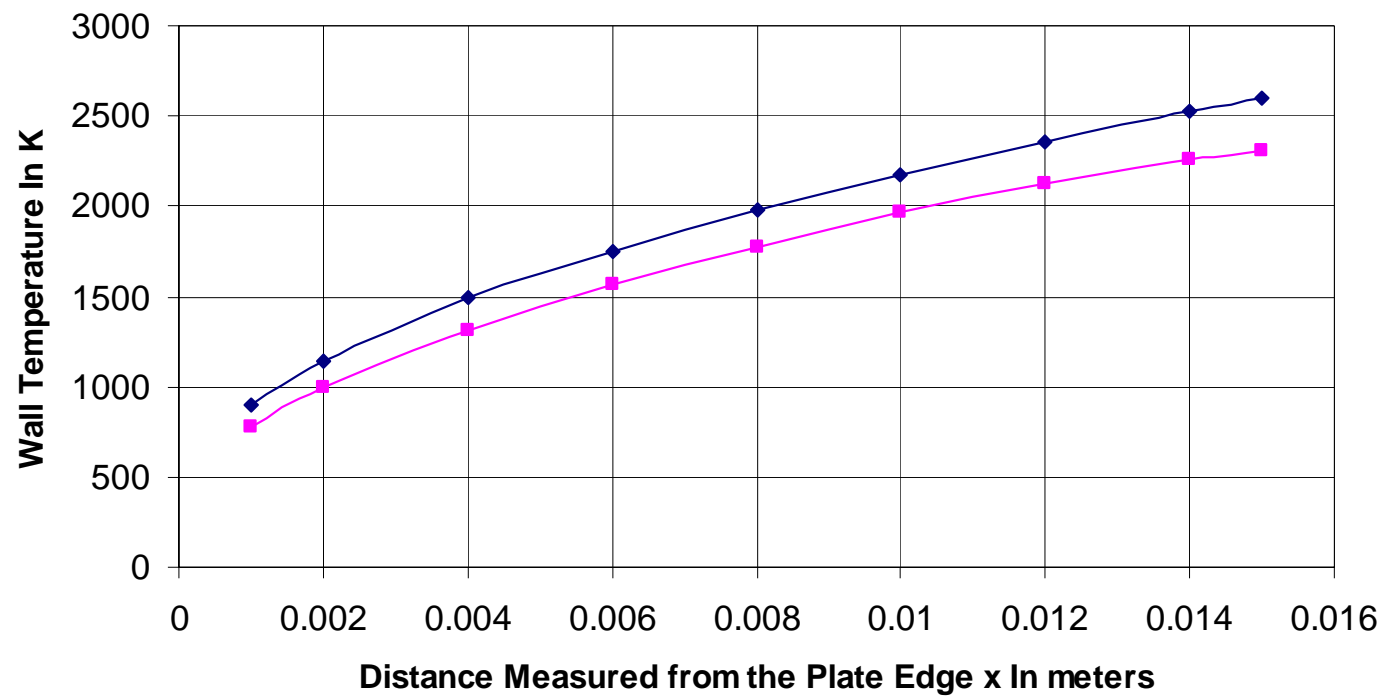

$\rightarrow-$ Integral Solution $\rightarrow-$ Numerical Solution

Figure 5.16 Thermal Boundary Layer Comparison between Numerical Solution and Integral Solution for Air. 


\section{Chapter 6 \\ Model Setup and Results}

\subsection{Model Setup}

Spray cooling is a widely used technique for heat removal from a heated surface in many industrial applications. Due the formation of the liquid layer on the heated surface by the injected spray, it was not possible to study or simulate the spray cooling without the consideration of the existence of this liquid layer. A new approach was developed in the present work to investigate this. In this approach a two dimensional numerical model was built and a liquid layer was defined initially above the heated surface. The liquid layer was given a uniform initial velocity. The spray was added to the liquid layer as a source term through the continuity and momentum equations. This source term was implemented into the code by the current investigator through the user subroutines which give flexibility in modifying the source code. The spray mass and velocity were varied as functions of the nozzle angle.

The user defined source terms enable one to modify the general equation for any of the solved variables by adding the source terms to the equation on a cell by cell basis. A volume condition is any part of the geometry defined by the user which has four boundaries in the two dimensional structured grid. The user source subroutine is called by volume condition basis for each variable that is requested. In order to add the source term to a particular volume condition it has to be defined first. For example for the mass source term, the user requests the variable which represents the mass in a particular volume condition, which is the second volume condition in the present case. If this variable index matches the variable index of the mass source term subroutine then the mass source will be added to that volume condition. The user source term subroutines are shown in Appendices A-3 to A-5.

A two dimensional grid was built to demonstrate the effect of adding the source term on the heat transfer of a liquid layer moving in the horizontal direction parallel to a 
uniform heat flux wall. The Reynolds number was calculated based on the domain length to make sure that the flow would be laminar. The domain was divided into three volume conditions as shown in Figure 6.1. The two bottom volume conditions contain the liquid layer which was given a uniform velocity for both initial and boundary conditions. The upper volume condition (2) in the liquid layer is the one to which the source term was added. Volume condition (3) is the bottom half of the liquid layer with the same uniform inlet velocity. The upper volume condition (1) contains air which was given a uniform velocity profile for both initial and boundary conditions. The lower boundary represents the wall to which a uniform heat flux was applied. The left boundary represents the inlet. The right and top boundaries are fixed pressure outlets. Different dimensions for the domain size were tested and showed a difference; however as the main objective of these simulations is to see the effect of adding the source term on the heat transfer between the wall and liquid layer, the smaller size was selected to save some simulation time. For this set of simulations the domain size was $0.005^{*} 0.003 \mathrm{~m}^{2}$ and the number of cells was varied based on the liquid layer thickness, which means that different grids were used for different layer thickness.

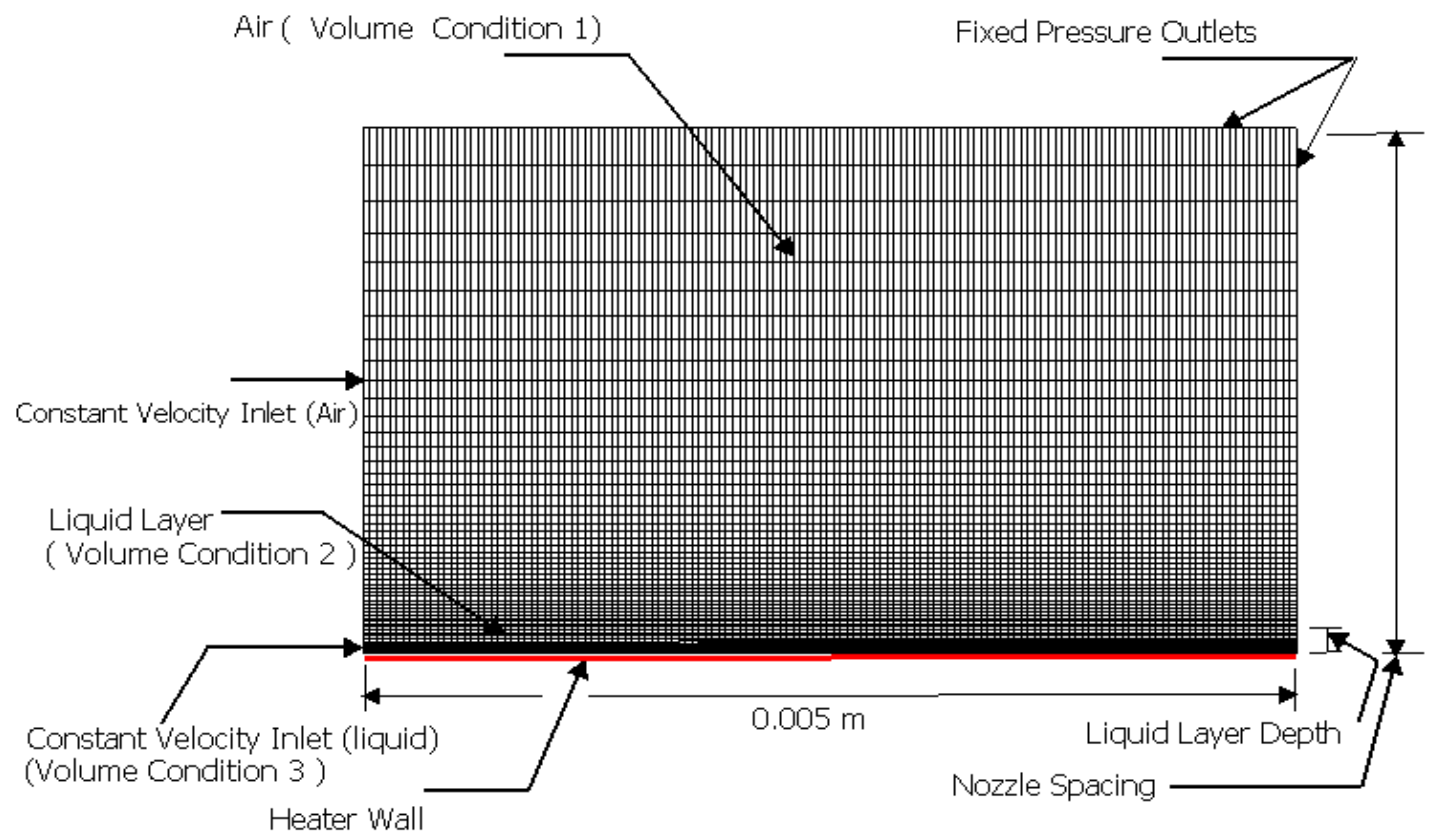

Figure 6.1 Model Setup and Grid. 


\subsection{Results of Numerical Simulations}

\subsubsection{Introduction}

Four working fluids were used to simulate the effect of adding the spray mass and momentum source terms to a liquid layer moving horizontally parallel to constant heat flux wall which represents the heater surface. These fluids were water, FC-72, HFE-7000 and a hypothetical fluid. The different properties of the working fluids are shown in Table 6.1. A two dimensional geometry was chosen. The heat flux was varied from 10 to $150 \mathrm{~kW} / \mathrm{m}^{2}$ for different fluids because the boiling temperature at atmospheric pressure was different for these fluids. The heat flux was chosen to avoid boiling because the focus of this investigation is on single phase heat transfer. In all simulations the initial temperature was set equal to $300 \mathrm{~K}$. Because the temperature profile along the heater surface was smooth, the temperature was plotted at only 11 different locations along the heater surface.

The model dimension was $0.005 \mathrm{~m}$ in the horizontal direction and $0.003 \mathrm{~m}$ in the vertical direction. The values of the flow rate and nozzle spacing used in this study were taken from Hunnell [47]. Three values were used for the nozzle vertical spacing from the heater surface $0.01,0.013$ and $0.015 \mathrm{~m}$. The spray mass flow rate was varied between 4.8 E-03 and $9.8 \mathrm{E}-03 \mathrm{~kg} / \mathrm{s}$. The spray velocity in the momentum source term was varied between 5 to $9 \mathrm{~m} / \mathrm{s}$. The layer thickness was varied between 50 to 300 microns. However it was found that the most efficient thickness which improves the cooling efficiently was 100 microns. Different values were chosen for the liquid layer initial horizontal velocities which were 0.5 to $5 \mathrm{~m} / \mathrm{s}$. The simulation parameters are shown in Tables 6.2 to 6.5 for different working fluids.

The spray mass and momentum are functions of spray velocity, nozzle spacing

and spray mass flow rate. So, in order to study the effect of adding the spray mass and momentum source terms into the liquid layer these parameters were allowed to change. 
The other parameters which are wall heat flux and layer horizontal velocity are defined through CFD-ACE+-GUI which is the software user interface.

The distribution of the spray mass and momentum fluxes was a function of the drop trajectory angle. It was also assumed that each spray drop trajectory is a straight line. Two momentum source terms were added by resolving the droplet velocity magnitude into horizontal and vertical components which were functions of the cell location in the domain. These two components were calculated using the following formulas. The parameters used in these formulas are defined in Figure 6.2.

$$
\begin{aligned}
& \theta=\arctan (\mathrm{xc} / \mathrm{yc}) \\
& \mathrm{v}(\mathrm{yc})=-|\mathrm{V}|^{*} \cos \theta \\
& \mathrm{u}(\mathrm{xc})=|\mathrm{V}|^{*} \sin \theta
\end{aligned}
$$

where

$$
\begin{aligned}
& \theta=\text { drop trajectory angle } \\
& \mathrm{xc}=\quad \text { cell horizontal distance measured from the plate edge }[\mathrm{m}] \\
& \mathrm{yc}=\quad \text { cell vertical distance between the injector and the plate }[\mathrm{m}] \\
& \mathrm{v}(\mathrm{yc})=\quad \text { vertical component of droplet velocity }[\mathrm{m} / \mathrm{s}] \\
& |\mathrm{V}|=\text { droplet velocity magnitude }[\mathrm{m} / \mathrm{s}] \\
& \mathrm{u}(\mathrm{xc})=\quad \text { horizontal component of droplet velocity }[\mathrm{m} / \mathrm{s}]
\end{aligned}
$$

From these equations the spray mass is added to the liquid layer as a function of $\mathrm{x}$. As in reality the spray is injected into the liquid layer at an angle $\theta$ (theta), so the spray mass will be a function of the injecting angle. 


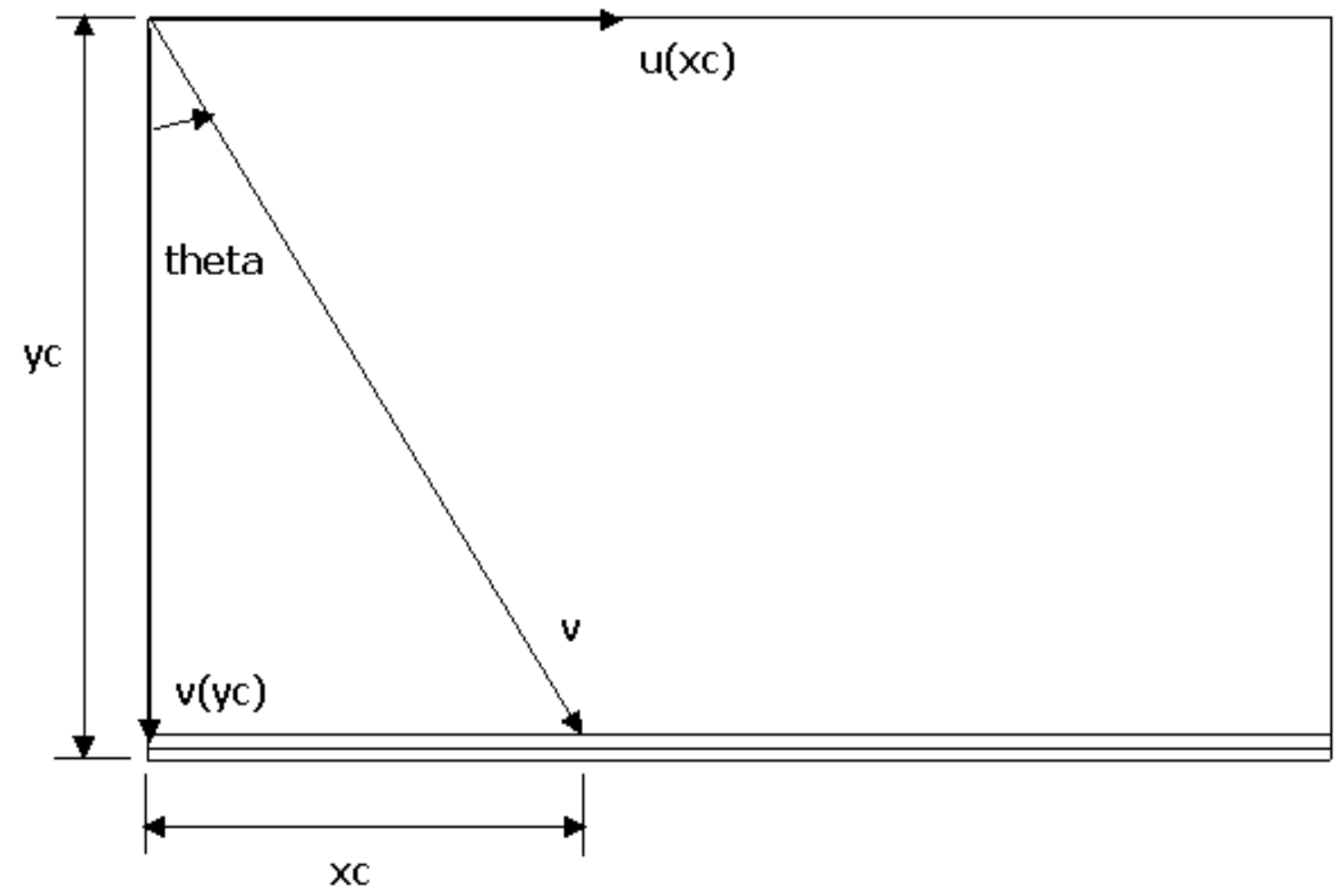

Figure 6.2 Model Setup.

\subsubsection{Distribution of Mass and Momentum in Two Dimensional Planar Spray:}

The following derivation was done by Professor Donald Gray, where the model setup is shown in Figure 6.3.

$q_{s}^{\prime}(\theta) d \theta=$ Volume of spray/ time in $d \theta$ around $\theta$

where

$q_{s}^{\prime} \quad=\mathrm{m}^{3} / \mathrm{s} \cdot \mathrm{rad}$

$Q_{S}^{\prime}(\theta)=\int_{0}^{\theta} q_{s}^{\prime} \mathrm{d} \theta=$ Volume of spray/ time added to the layer up to $\theta$ 


\section{Continuity equation:}

Assuming $y<<z_{s}$ ( $y$ is the layer thickness and $z_{s}$ is the nozzle spacing)

$Q(x)+q_{s}^{\prime}(\theta) d \theta=Q(x+d x)$

$q_{s}^{\prime}(\theta) d \theta=(d Q / d x) d x$

$d Q / d x=q_{s}^{\prime}(\theta) \frac{d \theta}{d x}$

For $\frac{x}{z_{S}}=\tan \theta \quad$ as shown in Figure (6.3)

$\therefore \quad \theta=\arctan \left(\frac{\mathrm{x}}{\mathrm{z}_{\mathrm{s}}}\right)$

$\frac{d \theta}{d x}=\frac{d}{d x}\left[\arctan \left(\frac{x}{z_{S}}\right)\right]=\frac{1}{1+\left(\frac{x}{z_{s}}\right)^{2}} \frac{1}{z_{s}}$

$\frac{d Q}{d x}=q_{s}^{\prime}(\theta) \frac{1}{\left(1+\left(\frac{x}{z_{s}}\right)^{2}\right)} \frac{1}{z_{s}}$

The mass source term added to the continuity equation (4.5) was

$$
\frac{d Q}{d x}=\frac{Q_{s}}{x_{m}} \cos \theta
$$

where

$$
\begin{array}{ll}
Q_{s} & =\quad \text { nominal spray volumetric flow rate } \\
x_{m} & =\quad \text { maximum } x \text { distance (length of surface) }
\end{array}
$$

Requiring that these results be consistent gives.

$$
\begin{aligned}
& \frac{d Q}{d x}=q_{s}^{\prime}(\theta) \frac{1}{\left(1+\left(\frac{x}{z_{s}}\right)^{2}\right)} \frac{1}{z_{s}}=\frac{Q_{s}}{x_{m}} \cos \theta \\
& q_{s}^{\prime}=\frac{Q_{s}}{x_{m}} z_{s}\left[1+\left(\frac{x}{z_{s}}\right)^{2}\right] \cos \theta=\frac{Q_{s}}{x_{m}} z_{s}\left[1+\tan ^{2} \theta\right] \cos \theta=\frac{Q_{s}}{\tan \left(\theta_{m}\right)} \sec ^{2} \theta \cos \theta
\end{aligned}
$$


$q_{s}^{\prime}(\theta)=\frac{Q_{s}}{\tan \theta_{m} \cos \theta}$

where $\tan \theta_{m}=\frac{x_{m}}{z_{s}}$

Total volume flowrate of spray that hits the surface is $Q_{s}^{\prime}\left(\theta_{m}\right)=Q_{s_{m}}^{\prime}$

$Q_{s_{m}}^{\prime}=\int_{0}^{\theta_{m}} q_{s}^{\prime}(\theta) d \theta=\frac{Q_{s}}{\tan \theta_{m}} \int_{0}^{\theta_{m}} \frac{d \theta}{\cos \theta}$

$Q_{s_{m}}^{\prime}=\frac{Q_{s}}{\tan \theta_{m}} \ln \left[\tan \left(\frac{\pi}{4}+\frac{\theta_{m}}{2}\right)\right]$

With the geometry of Figure (6.1)

$\theta_{\mathrm{m}}=\arctan \left(\frac{0.005 \mathrm{~m}}{0.01 \mathrm{~m}}\right)=26.6^{\circ}$
$Q_{s_{m}}^{\prime}=\frac{Q_{s}}{\tan \left(26.6^{\circ}\right)} \ln \left[\tan \left(45^{\circ}+\frac{26.6^{\circ}}{2}\right)\right]=0.962 Q_{s}$

This represents how much volume was actually added to the film.

To consider the streamwise momentum, one must know the velocity of a droplet

$q_{s}^{\prime}(\theta) d \theta=\frac{Q_{s}}{\tan \left(\theta_{m}\right)} \frac{d \theta}{\cos \theta}$

If it's assumed that the spray consists of identical drops of volume $V_{d}$ all with same speed $v_{\mathrm{s}}$

$q_{s}^{\prime}(\theta) d \theta=\dot{n}(\theta) d \theta \mathrm{V}_{\mathrm{d}}$

$\dot{n}(\theta)=\frac{q_{s}^{\prime}(\theta)}{\mathrm{V}_{d}}$

where $\mathrm{n}$ is the number of drops per second in the spray Assume all drops move at constant speed $v_{\mathrm{s}}$ 
$\mathrm{X}$-momentum of one drop $=\rho \mathrm{V}_{\mathrm{d}} v_{\mathrm{s}} \sin \theta$

X-momentum of $n d \theta$ drops $=\mathrm{n}(\theta) \mathrm{d} \theta \rho \mathrm{V}_{\mathrm{d}} \nu_{\mathrm{s}} \sin \theta$

$$
=q_{s}^{\prime}(\theta) d \theta \rho v_{s} \sin \theta=\left(\frac{d Q}{d x} d x\right) \rho v_{s} \sin \theta=\frac{Q_{s}}{x_{m}} \cos \theta \rho v_{s} \sin \theta d x
$$

Therefore the $\mathrm{x}$-momentum source term added to the $\mathrm{x}$-momentum equation (4.6) was $\frac{Q_{s}}{x_{m}} \cos \theta \rho v_{s} \sin \theta d x$ which was used in the code.

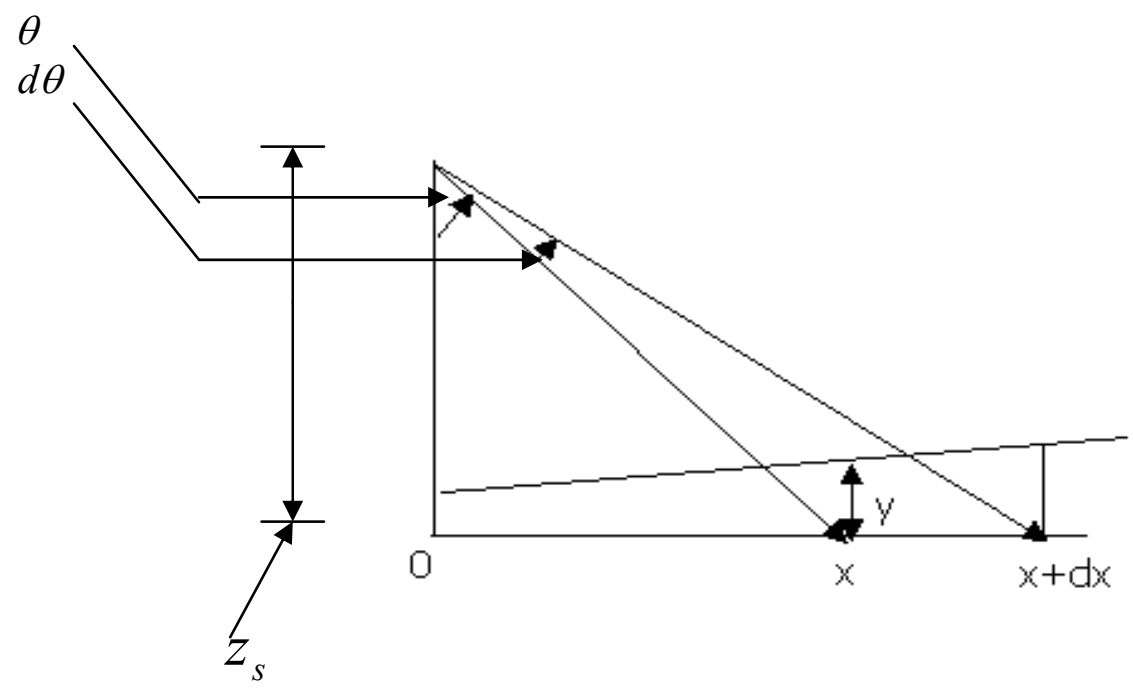

Figure 6.3 Distributions of Mass and Momentum in Two Dimensional Planar Spray.

Table 6-1 Working Fluid Properties.

\begin{tabular}{|c|c|c|c|c|}
\hline & Water & FC-72 & HFE-700 & $\begin{array}{l}\text { Hypothetical } \\
\text { Fluid }\end{array}$ \\
\hline Density $\left[\mathrm{kg} / \mathrm{m}^{3}\right]$ & 1000 & 1680 & 1400 & 1680 \\
\hline Kinematic Viscosity $\left[\mathrm{m}^{2} / \mathrm{s}\right]$ & 1.00E-06 & 3.80E-07 & $3.20 \mathrm{E}-07$ & 3.80E-07 \\
\hline Specific Heat [J/kg K] & 4179 & 1100 & 1300 & 1100 \\
\hline Thermal Conductivity [W/m.K] & 0.597 & 0.057 & 0.075 & 0.057 \\
\hline Boiling Temperature $\left[{ }^{\circ} \mathrm{C}\right]$ & 100 & 56 & 34 & 90 \\
\hline Surface Tension $[\mathrm{N} / \mathrm{m}]$ & 0.0725 & 0.01 & 0.0124 & 0.01 \\
\hline Prandtl Number [-] & 7 & 12.32 & 7.76 & 12.32 \\
\hline
\end{tabular}


Table 6.2 Simulation Parameters for Water.

\begin{tabular}{|c|c|c|c|c|c|c|c|c|}
\hline Run \# & $\begin{array}{l}\text { Wall Heat } \\
\text { Flux } \\
{\left[\mathrm{kW} / \mathrm{m}^{2}\right]}\end{array}$ & $\begin{array}{l}\text { Layer } \\
\text { Thickness } \\
\text { [microns] }\end{array}$ & $\begin{array}{l}\text { Layer } \\
\text { Horizontal } \\
\text { Velocity }[\mathrm{m} / \mathrm{s}]\end{array}$ & $\begin{array}{l}\text { Spray } \\
\text { velocity } \\
{[\mathrm{m} / \mathrm{s}]}\end{array}$ & $\begin{array}{l}\text { Nozzle } \\
\text { Spacing } \\
\text { [m] }\end{array}$ & $\begin{array}{l}\text { Spray Mass } \\
\text { Flow Rate } \\
{[\mathrm{kg} / \mathrm{s}]}\end{array}$ & $\frac{\dot{m} \text { Spray }}{\dot{m} \text { Layer }}$ & $\begin{array}{l}\mathrm{Re} \\
\text { (Inlet) }\end{array}$ \\
\hline $7-w$ & 150 & 200 & 1 & - & - & 0 & 0 & 200 \\
\hline 6-w & 150 & 200 & 1 & 8 & 0.013 & 9.78E-03 & 0.0489 & 200 \\
\hline 8-w & 150 & 200 & 1 & 6 & 0.013 & $9.78 \mathrm{E}-03$ & 0.0489 & 200 \\
\hline 9-w & 150 & 200 & 1 & 9 & 0.013 & 9.78E-03 & 0.0489 & 200 \\
\hline $31-w$ & 150 & 200 & 0.5 & - & - & - & 0 & 100 \\
\hline $32-w$ & 150 & 200 & 0.5 & 8 & 0.013 & 9.78E-03 & 0.0978 & 100 \\
\hline 34-w & 150 & 200 & 0.5 & 5 & 0.013 & 9.78E-03 & 0.0978 & 100 \\
\hline $35-w$ & 150 & 200 & 0.5 & 6 & 0.013 & 9.78E-03 & 0.0978 & 100 \\
\hline $36-w$ & 150 & 200 & 0.5 & 8 & 0.01 & 9.78E-03 & 0.0978 & 100 \\
\hline $37-w$ & 150 & 200 & 0.5 & 8 & 0.015 & 9.78E-03 & 0.0978 & 100 \\
\hline 38-w & 150 & 200 & 0.5 & 8 & 0.013 & 7.00E-03 & 0.07 & 100 \\
\hline 39-w & 150 & 200 & 0.5 & 8 & 0.013 & $4.80 \mathrm{E}-03$ & 0.048 & 100 \\
\hline $11-w$ & 150 & 100 & 0.5 & - & - & 0 & 0 & 50 \\
\hline $10-w$ & 150 & 100 & 0.5 & 8 & 0.013 & 9.78E-03 & 0.1956 & 50 \\
\hline $12-w$ & 150 & 100 & 0.5 & 5 & 0.013 & 9.78E-03 & 0.1956 & 50 \\
\hline 13-w & 150 & 100 & 0.5 & 6 & 0.013 & 9.78E-03 & 0.1956 & 50 \\
\hline $25-w$ & 150 & 100 & 0.5 & 8 & 0.01 & 9.78E-03 & 0.1956 & 50 \\
\hline $30-w$ & 150 & 100 & 0.5 & 8 & 0.015 & 9.78E-03 & 0.1956 & 50 \\
\hline $26-w$ & 150 & 100 & 0.5 & 8 & 0.013 & 4.84E-03 & 0.0968 & 50 \\
\hline 29-w & 150 & 100 & 0.5 & 8 & 0.013 & 7.00E-03 & 0.14 & 50 \\
\hline
\end{tabular}

Table 6.3 Simulation Parameters for FC-72.

\begin{tabular}{|c|c|c|c|c|c|c|c|c|}
\hline Run \# & $\begin{array}{l}\text { Wall } \\
\text { Heat } \\
\text { Flux } \\
{\left[\mathrm{kW} / \mathrm{m}^{2}\right]}\end{array}$ & $\begin{array}{l}\text { Layer } \\
\text { Thickness } \\
\text { [microns] }\end{array}$ & $\begin{array}{l}\text { Layer } \\
\text { Horizontal } \\
\text { Velocity } \\
{[\mathrm{m} / \mathrm{s}]}\end{array}$ & $\begin{array}{l}\text { Spray } \\
\text { velocity } \\
{[\mathrm{m} / \mathrm{s}]}\end{array}$ & $\begin{array}{l}\text { Nozzle } \\
\text { Spacing } \\
\text { [m] }\end{array}$ & $\begin{array}{l}\text { Spray Mass } \\
\text { Flow Rate } \\
{[\mathrm{kg} / \mathrm{s}]}\end{array}$ & $\frac{m \text { Spray }}{\dot{m} \text { Layer }}$ & $\operatorname{Re}($ Inlet $)$ \\
\hline $1-\mathrm{F}$ & 25 & 100 & 0.5 & - & - & 0 & 0 & 131.6 \\
\hline $8-\mathrm{F}$ & 25 & 100 & 0.5 & 5 & 0.013 & 9.78E-03 & 0.1165 & 131.6 \\
\hline $6-F$ & 25 & 100 & 0.5 & 6 & 0.013 & 9.78E-03 & 0.1165 & 131.6 \\
\hline $5-F$ & 25 & 100 & 0.5 & 8 & 0.013 & $9.78 \mathrm{E}-03$ & 0.1165 & 131.6 \\
\hline $9-\mathrm{F}$ & 25 & 100 & 0.5 & 8 & 0.015 & $9.78 \mathrm{E}-03$ & 0.1165 & 131.6 \\
\hline $7-\mathrm{F}$ & 25 & 100 & 0.5 & 8 & 0.01 & $9.78 \mathrm{E}-03$ & 0.1165 & 131.6 \\
\hline $12-\mathrm{F}$ & 25 & 100 & 0.5 & 8 & 0.013 & 4.84E-03 & 0.0576 & 131.6 \\
\hline $11-\mathrm{F}$ & 25 & 100 & 0.5 & 8 & 0.013 & 7.00E-03 & 0.0833 & 131.6 \\
\hline
\end{tabular}


Table 6.4 Simulation Parameters for HFE-7000.

\begin{tabular}{|c|c|c|c|c|c|c|c|c|}
\hline $\begin{array}{l}\text { Run } \\
\#\end{array}$ & $\begin{array}{l}\text { Wall Heat } \\
\text { Flux } \\
{\left[\mathrm{kW} / \mathrm{m}^{2}\right]}\end{array}$ & $\begin{array}{l}\text { Layer } \\
\text { Thickness } \\
\text { [microns] }\end{array}$ & $\begin{array}{l}\text { Layer Horizontal } \\
\text { Velocity }[\mathrm{m} / \mathrm{s}]\end{array}$ & $\begin{array}{l}\text { Spray } \\
\text { velocity } \\
{[\mathrm{m} / \mathrm{s}]}\end{array}$ & $\begin{array}{l}\text { Nozzle } \\
\text { Spacing } \\
{[\mathrm{m}]}\end{array}$ & $\begin{array}{l}\text { Mass Flow } \\
\text { Rate }[\mathrm{kg} / \mathrm{s}]\end{array}$ & $\begin{array}{l}\dot{\dot{m}} \text { Spray } \\
\dot{\dot{m}} \text { Layer }\end{array}$ & $\operatorname{Re}($ Inlet $)$ \\
\hline 1-H & 10 & 100 & 0.5 & - & - & 0 & 0 & 156.3 \\
\hline $2-\mathrm{H}$ & 10 & 100 & 0.5 & 8 & 0.013 & 9.78E-03 & 0.1397 & 156.3 \\
\hline $3-\mathrm{H}$ & 10 & 100 & 0.5 & 6 & 0.013 & 9.78E-03 & 0.1397 & 156.3 \\
\hline $4-\mathrm{H}$ & 10 & 100 & 0.5 & 5 & 0.013 & 9.78E-03 & 0.1397 & 156.3 \\
\hline $5-\mathrm{H}$ & 10 & 100 & 0.5 & 8 & 0.01 & 9.78E-03 & 0.1397 & 156.3 \\
\hline $6-\mathrm{H}$ & 10 & 100 & 0.5 & 8 & 0.015 & 9.78E-03 & 0.1397 & 156.3 \\
\hline
\end{tabular}

Table 6.5 Simulation Parameters for Hypothetical Fluid.

\begin{tabular}{|c|c|c|c|c|c|c|c|c|}
\hline Run \# & $\begin{array}{l}\text { Wall Heat } \\
\text { Flux } \\
{\left[\mathrm{kW} / \mathrm{m}^{2}\right]}\end{array}$ & $\begin{array}{l}\text { Layer } \\
\text { Thickness } \\
\text { [microns] }\end{array}$ & $\begin{array}{l}\text { Layer } \\
\text { Horizontal } \\
\text { Velocity } \\
{[\mathrm{m} / \mathrm{s}]}\end{array}$ & $\begin{array}{l}\text { Spray } \\
\text { velocity } \\
{[\mathrm{m} / \mathrm{s}]}\end{array}$ & $\begin{array}{l}\text { Nozzle } \\
\text { Spacing } \\
\text { [m] }\end{array}$ & $\begin{array}{l}\text { Spray Mass } \\
\text { Flow Rate } \\
{[\mathrm{kg} / \mathrm{s}]}\end{array}$ & $\begin{array}{l}\dot{m} \text { Spray } \\
\dot{m} \text { Layer }\end{array}$ & $\operatorname{Re}($ Inlet$)$ \\
\hline $2-A$ & 50 & 100 & 0.5 & - & - & 0 & 0 & 131.6 \\
\hline $3-A$ & 50 & 100 & 0.5 & 8 & 0.013 & 9.78E-03 & 0.1165 & 131.6 \\
\hline $4-A$ & 50 & 100 & 0.5 & 6 & 0.013 & 9.78E-03 & 0.1165 & 131.6 \\
\hline $5-A$ & 50 & 100 & 0.5 & 5 & 0.013 & 9.78E-03 & 0.1165 & 131.6 \\
\hline $6-A$ & 50 & 100 & 0.5 & 8 & 0.01 & 9.78E-03 & 0.1165 & 131.6 \\
\hline $7-A$ & 50 & 100 & 0.5 & 8 & 0.015 & 9.78E-03 & 0.1165 & 131.6 \\
\hline
\end{tabular}

\subsubsection{Effect of Adding Mass and Momentum Source Terms on Temperature}

\subsubsection{Effect of Spray Velocity}

The effects of the spray velocity on the temperature profile as well as Nusselt $\mathrm{(Nu)} \mathrm{number} \mathrm{were} \mathrm{studied} \mathrm{for} \mathrm{the} \mathrm{four} \mathrm{working} \mathrm{fluids.} \mathrm{The} \mathrm{simulation} \mathrm{parameters} \mathrm{for}$ water, FC-72, HFE-7000 and the hypothetical fluids are shown in Tables 6.2, 6.3, 6.4 and 6.5 respectively.

Equation (6-4) was used to calculate Nusselt number as shown in Bejan [46].

$$
\mathrm{Nu}=\frac{q^{\prime \prime}}{T(x)-T_{\infty}} \frac{x}{k}=0.453 \operatorname{Pr}^{1 / 3} \operatorname{Re}_{\mathrm{x}}^{1 / 2}
$$


where

$$
\begin{array}{lll}
\mathrm{Nu} & = & \text { Nusselt number }[-] \\
q^{\prime \prime} & = & \text { wall heat flux }\left[\mathrm{kW} / \mathrm{m}^{2}\right] \\
x & = & \text { horizontal distance measured from the plate edge }[\mathrm{m}] \\
T & = & \text { wall temperature at x position }[\mathrm{K}] \\
T_{\infty} & = & \text { ambient temperature }[\mathrm{K}] \\
k & = & \text { fluid thermal conductivity }[\mathrm{W} / \mathrm{m} \mathrm{K}] \\
\operatorname{Pr} & = & \text { Prandtl number }[-] \\
\operatorname{Re}_{x} & = & \text { Reynolds number }[-]
\end{array}
$$

Figure 6.4 shows the effect of the inlet spray velocity on the computed wall temperature profile using water as the working fluid. The layer thickness at the inlet was 200 microns while the layer horizontal velocity at the inlet was $1 \mathrm{~m} / \mathrm{s}$, and a constant heat flux $=150 \mathrm{~kW} / \mathrm{m}^{2}$ was applied to the heater. It was found that the effect of the spray velocity was not significant with these particular flow parameters. So, different values of the layer velocity were tested. It was found that the higher the layer velocity the less the effect of the spray velocity on the temperature profile. There was no measurable effect at all for $3 \mathrm{~m} / \mathrm{s}$ layer velocity. The same flow parameters were used to plot the relation between $\mathrm{Nu}$ and $x / L$ which showed the same effect as shown in Figure 6.5. It is shown in this figure that by increasing the spray velocity from 6 to $9 \mathrm{~m} / \mathrm{s}$, the Nusselt number increases. The maximum difference in temperature as a function of spray velocity for the same flow parameters is shown in Figure 6.6. It was found that the cooling is higher for the higher spray velocity. 


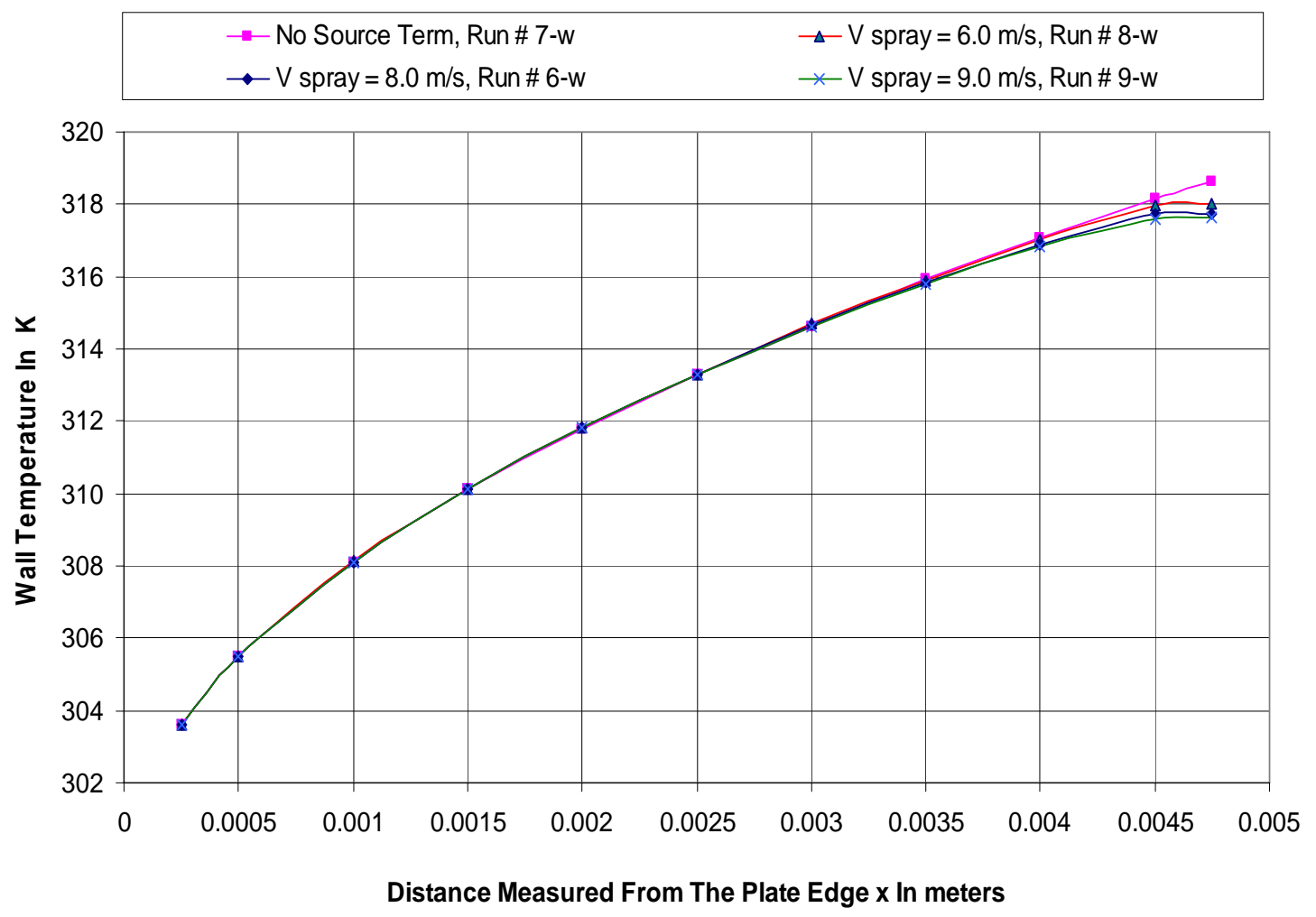

Figure 6.4 Effect of Spray Velocity on Wall Temperature Profile (Water, $d=200$ microns, $U=1.0 \mathrm{~m} / \mathrm{s}, q^{\prime \prime}=150 \mathrm{~kW} / \mathrm{m}^{2}$ ).

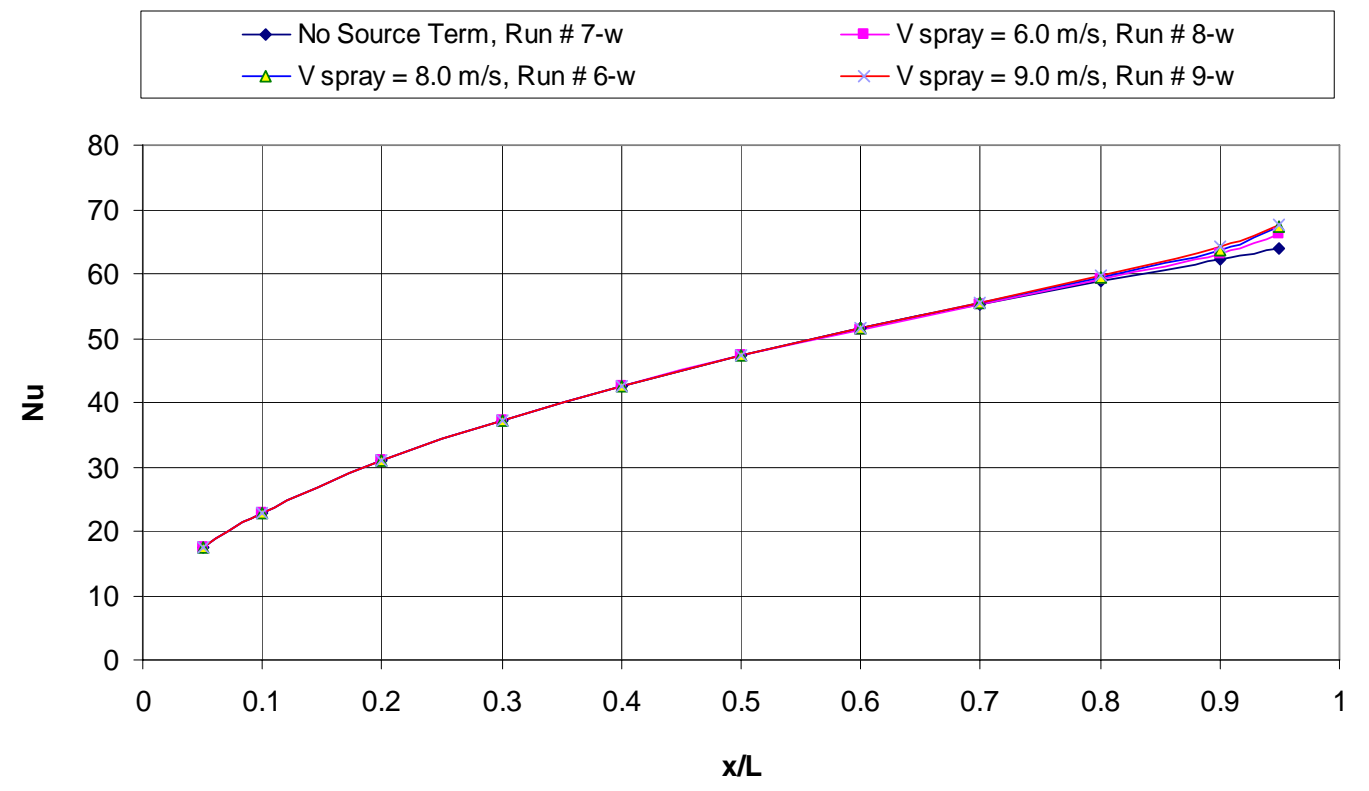

Figure 6.5 Effect of Spray Velocity on Nusselt Number (Water, $d=200$ microns, $U=1.0 \mathrm{~m} / \mathrm{s}, q^{\prime \prime}=150 \mathrm{~kW} / \mathrm{m}^{2}$ ). 


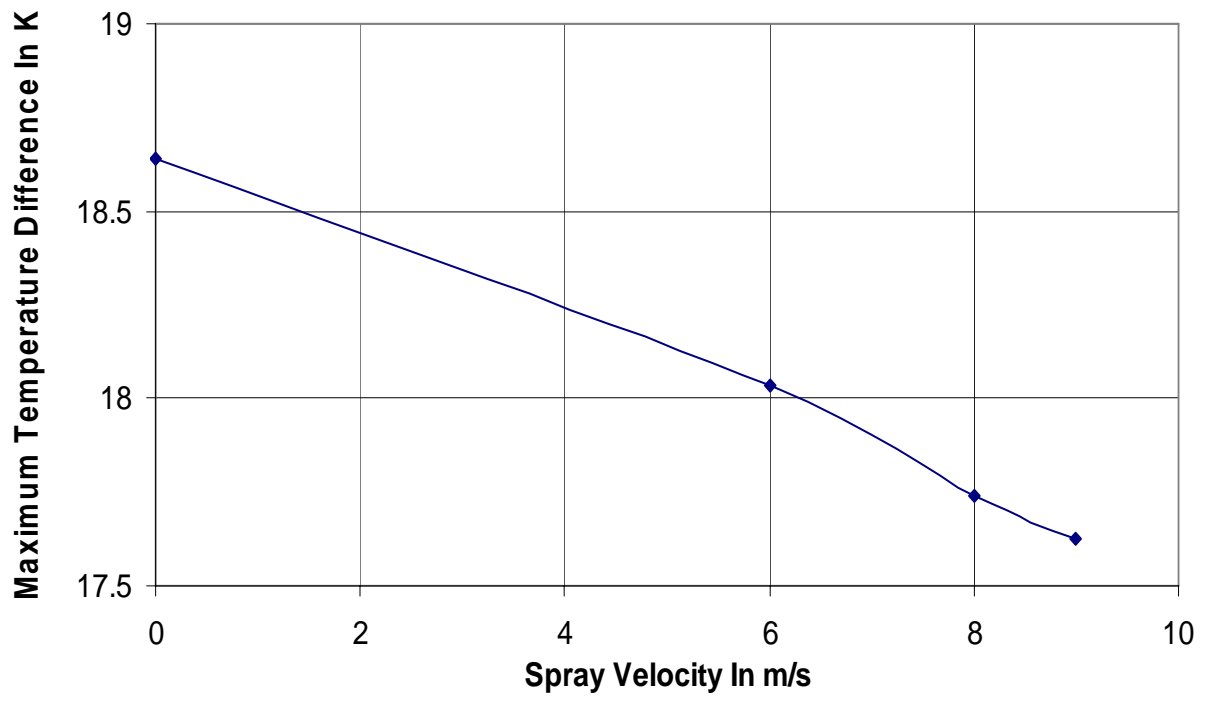

Figure 6.6 Effect of Spray Velocity on Maximum Temperature Difference (Water, $d=200$ microns, $U=1.0 \mathrm{~m} / \mathrm{s}, q^{\prime \prime}=150 \mathrm{~kW} / \mathrm{m}^{2}$ ).

The layer velocity was then lowered to see its effect on the temperature profile. A $0.5 \mathrm{~m} / \mathrm{s}$ value was used for the horizontal velocity. A significant difference in the temperature profile was observed when the spray velocity magnitudes were varied between 5 and $8 \mathrm{~m} / \mathrm{s}$. The dimensional results are shown in Figure 6.7. The plot of Nusselt number based on the same simulations is shown in Figure 6.8. In this figure the Nusselt number was higher for higher spray velocity. For the same flow parameters, the maximum difference in temperature as function of spray velocity is shown in Figure 6.9. It was again found that the cooling is higher for higher spray velocity, as would be expected. 

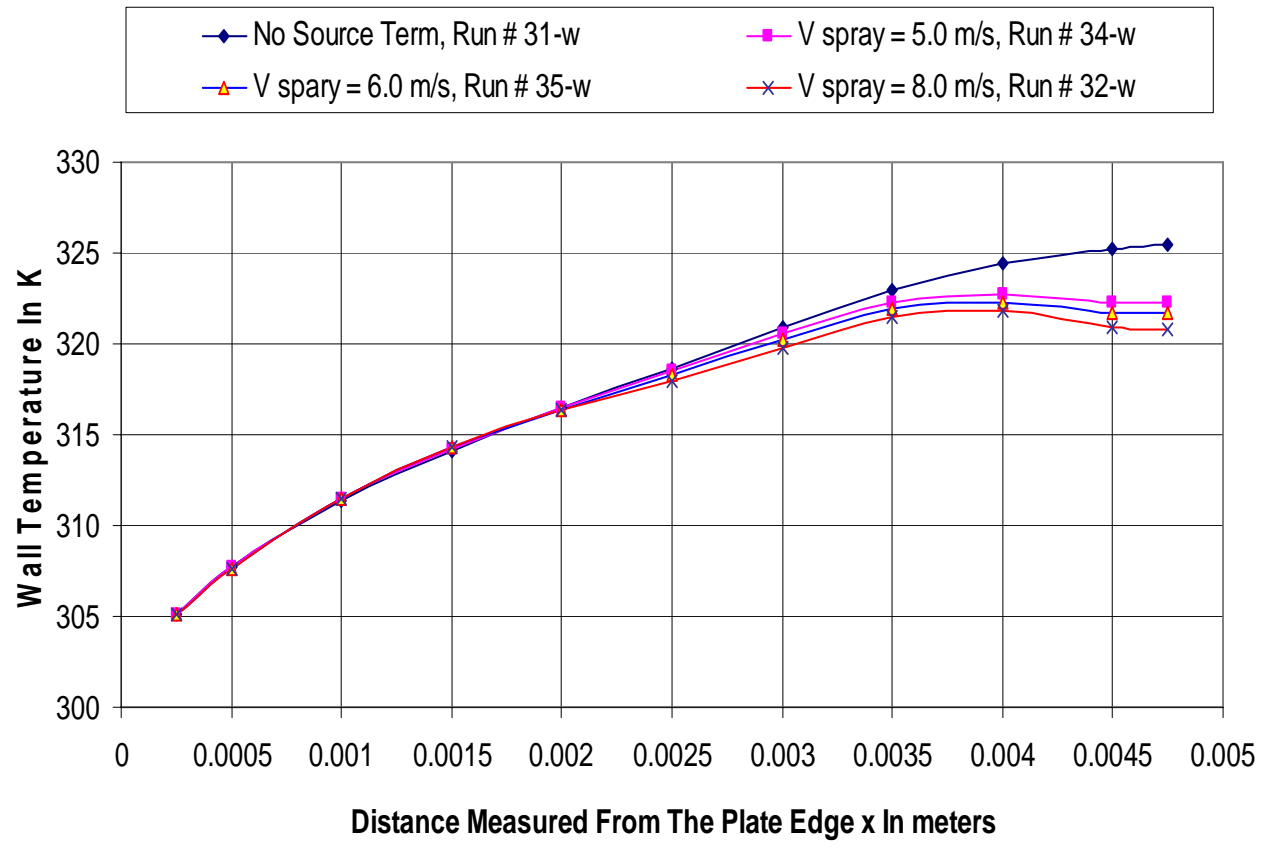

Figure 6.7 Effect of Spray Velocity on Wall Temperature Profile (Water, $d=200$ microns, $U=0.5 \mathrm{~m} / \mathrm{s}, q^{\prime \prime}=150 \mathrm{~kW} / \mathrm{m}^{2}$ ).

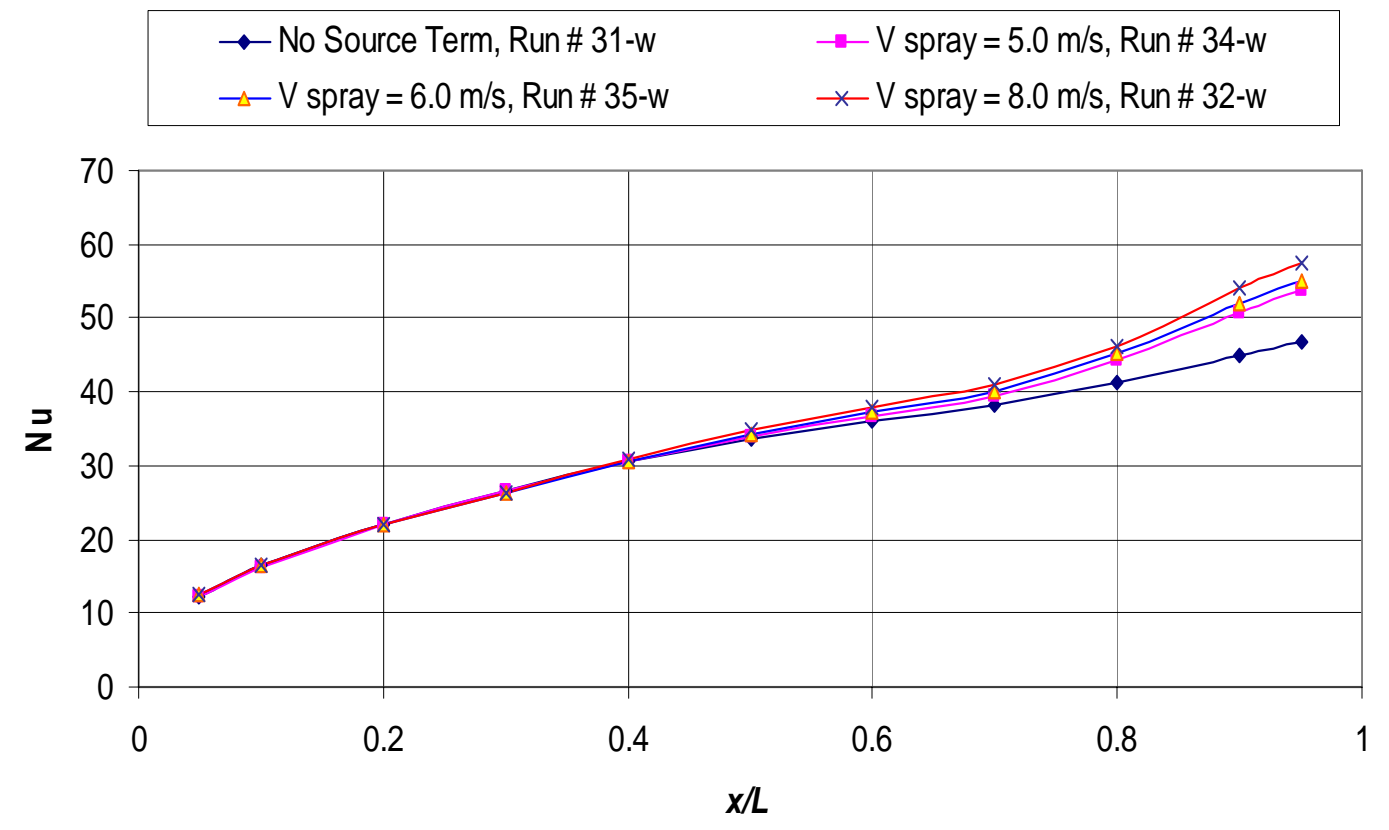

Figure 6.8 Effect of Spray Velocity on Nusselt Number (Water, $d=200$ microns, $U=0.5 \mathrm{~m} / \mathrm{s}, q^{\prime \prime}=150 \mathrm{~kW} / \mathrm{m}^{2}$ ). 


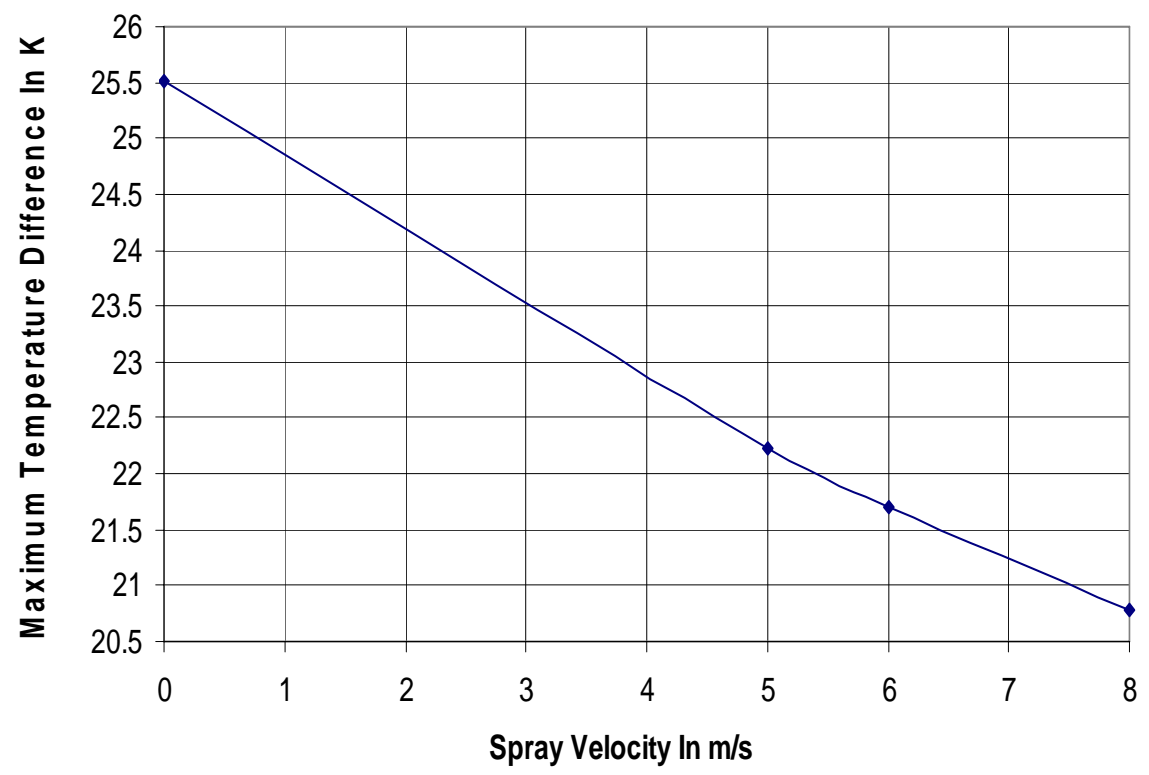

Figure 6.9 Effect of Spray Velocity on Maximum Temperature Difference (Water, $d=200$ microns, $U=0.5 \mathrm{~m} / \mathrm{s}, q^{\prime \prime}=150 \mathrm{~kW} / \mathrm{m}^{2}$ ).

It was important to know if the layer thickness would have an effect on the temperature. A thinner layer of 100 microns thickness was used for another set of simulations. The layer horizontal velocity was $0.5 \mathrm{~m} / \mathrm{s}$ and all other parameters was the same as before. Figure 6.10 shows the effect of the spray velocity on the computed wall temperature profile. As shown in the figure the wall temperature decreases as the spray velocity increases. The Nusselt number and the maximum difference in temperature as function of spray velocity are plotted in Figures 6.11 and 6.12 respectively. From Figure 6.11 it is seen that the Nusselt number increases as the spray velocity increases, while Figure 6.12 shows that the larger drop in the heater surface temperature was again found at higher spray velocity. 

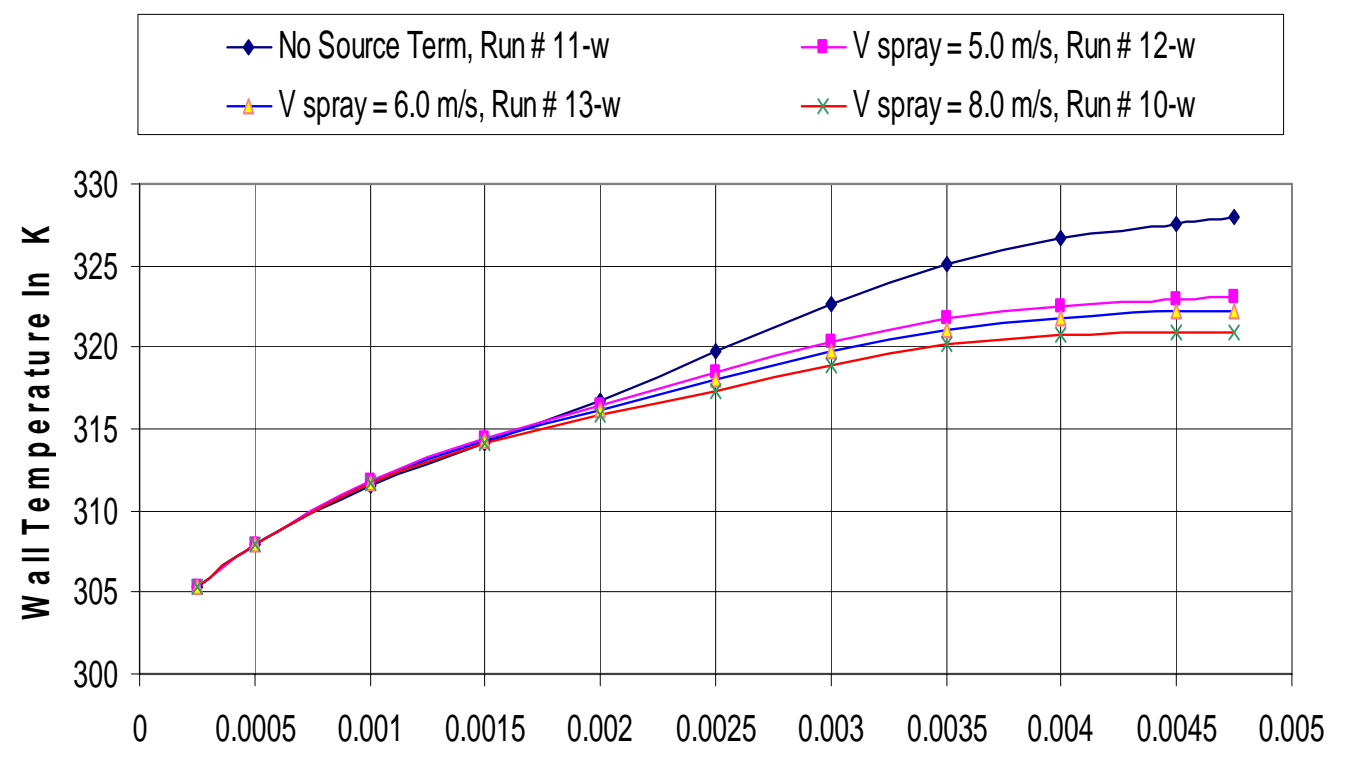

Distance Measured From The Plate Edge x In meters

Figure 6.10 Effect of Spray Velocity on Wall Temperature Profile (Water, $d=100$ microns, $U=0.5 \mathrm{~m} / \mathrm{s}, q^{\prime \prime}=150 \mathrm{~kW} / \mathrm{m}^{2}$ ).
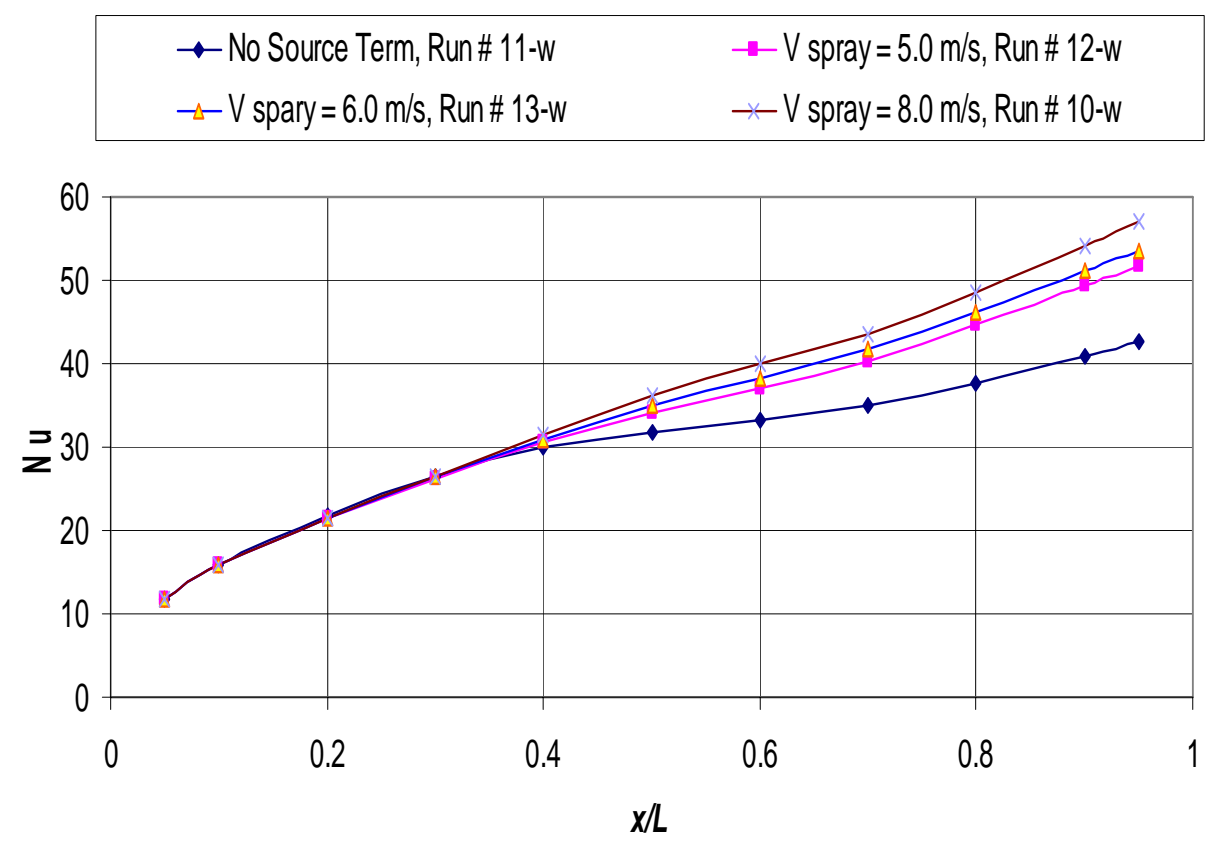

Figure 6.11 Effect of Spray Velocity on Nusselt Number (Water, $d=100$ microns, $U=0.5 \mathrm{~m} / \mathrm{s}, q^{\prime \prime}=150 \mathrm{~kW} / \mathrm{m}^{2}$ ). 


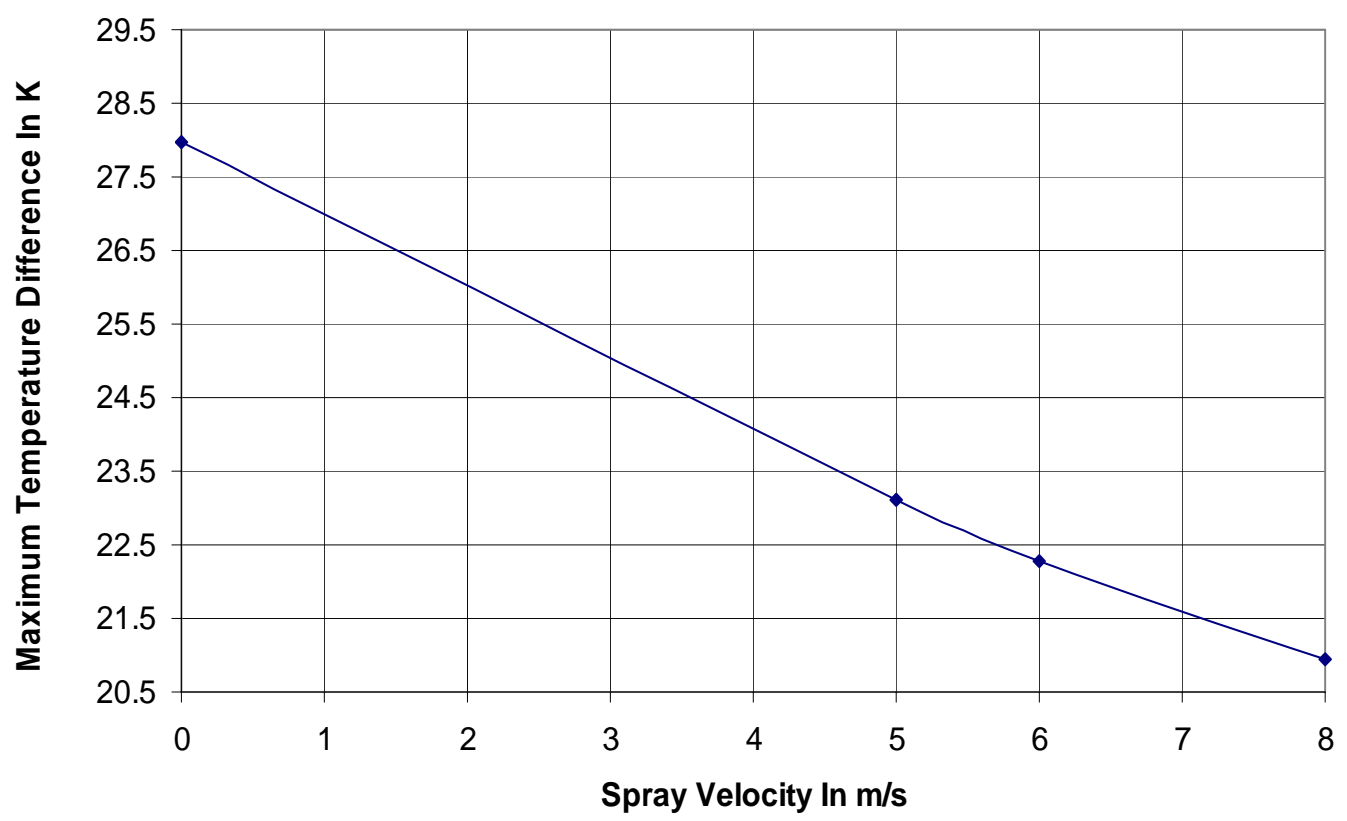

Figure 6.12 Effect of Spray Velocity on Maximum Temperature Difference (Water, $\boldsymbol{d}=100$ microns, $U=0.5 \mathrm{~m} / \mathrm{s}, q^{\prime \prime}=150 \mathrm{~kW} / \mathrm{m}^{2}$ ).

Another working fluid was used to demonstrate the effect of the spray velocity on the temperature profile and Nusselt number. In many spray cooling applications FC-72 is used as working fluid. So FC-72 was used with a 100 micron layer thickness and a 0.5 $\mathrm{m} / \mathrm{s}$ layer horizontal velocity. However because of the low boiling temperature of FC-72 which is $57{ }^{\circ} \mathrm{C}$, a $25 \mathrm{~kW} / \mathrm{m}^{2}$ constant heat flux was applied at the heater surface. The reason for decreasing the wall heat flux was to avoid boiling as the current study focuses only on single phase heat transfer. It was found that the spray velocity has a significant effect on the temperature profile and Nusselt number as shown in Figures 6.13 and 6.14 respectively. The maximum difference in temperature as function of spray velocity for the above flow parameters is shown in Figure 6.15. It was also found that by increasing the spray velocity the drop on the surface temperature is higher in comparison the lower spray velocity $(5 \mathrm{~m} / \mathrm{s})$. 


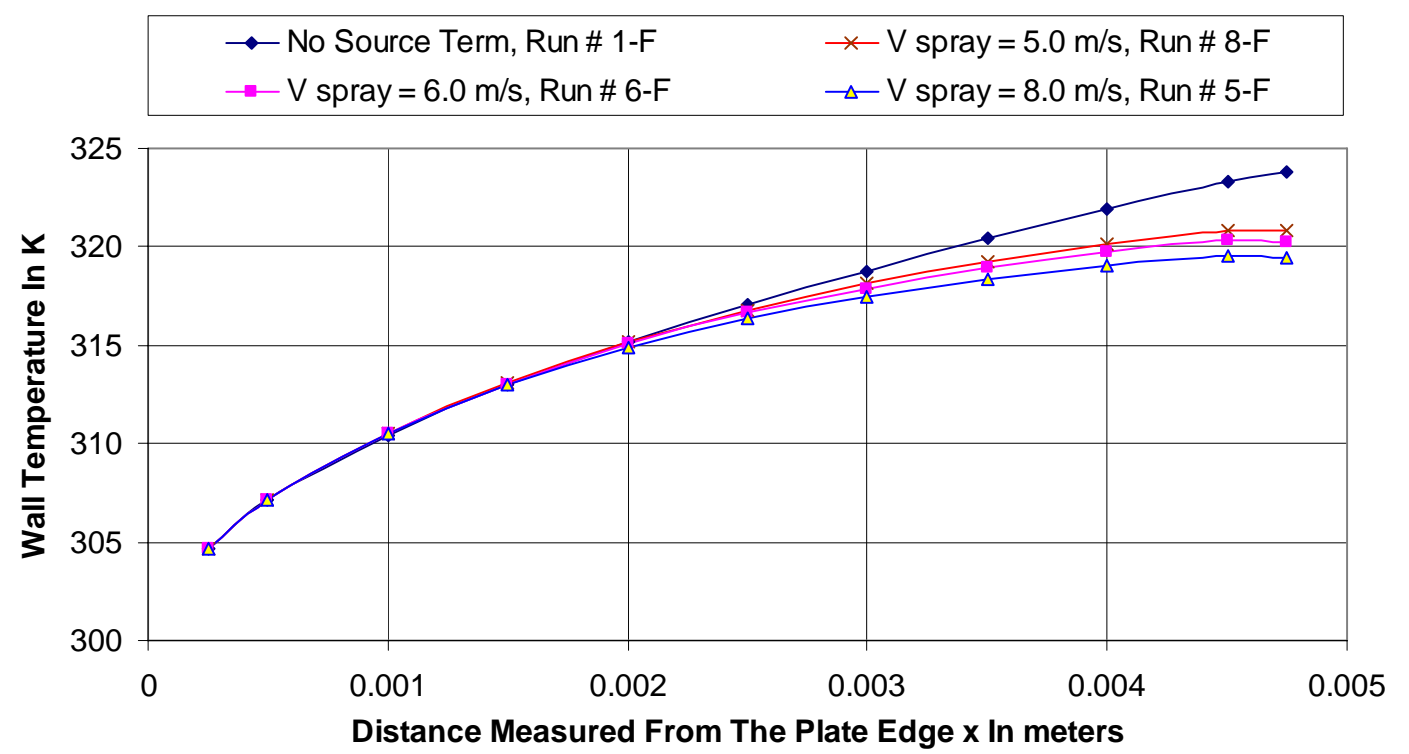

Figure 6.13 Effect of Spray Velocity on Wall Temperature Profile (FC-72, $d=100$ microns, $U=0.5 \mathrm{~m} / \mathrm{s}, q^{\prime \prime}=25 \mathrm{~kW} / \mathrm{m}^{2}$ ).

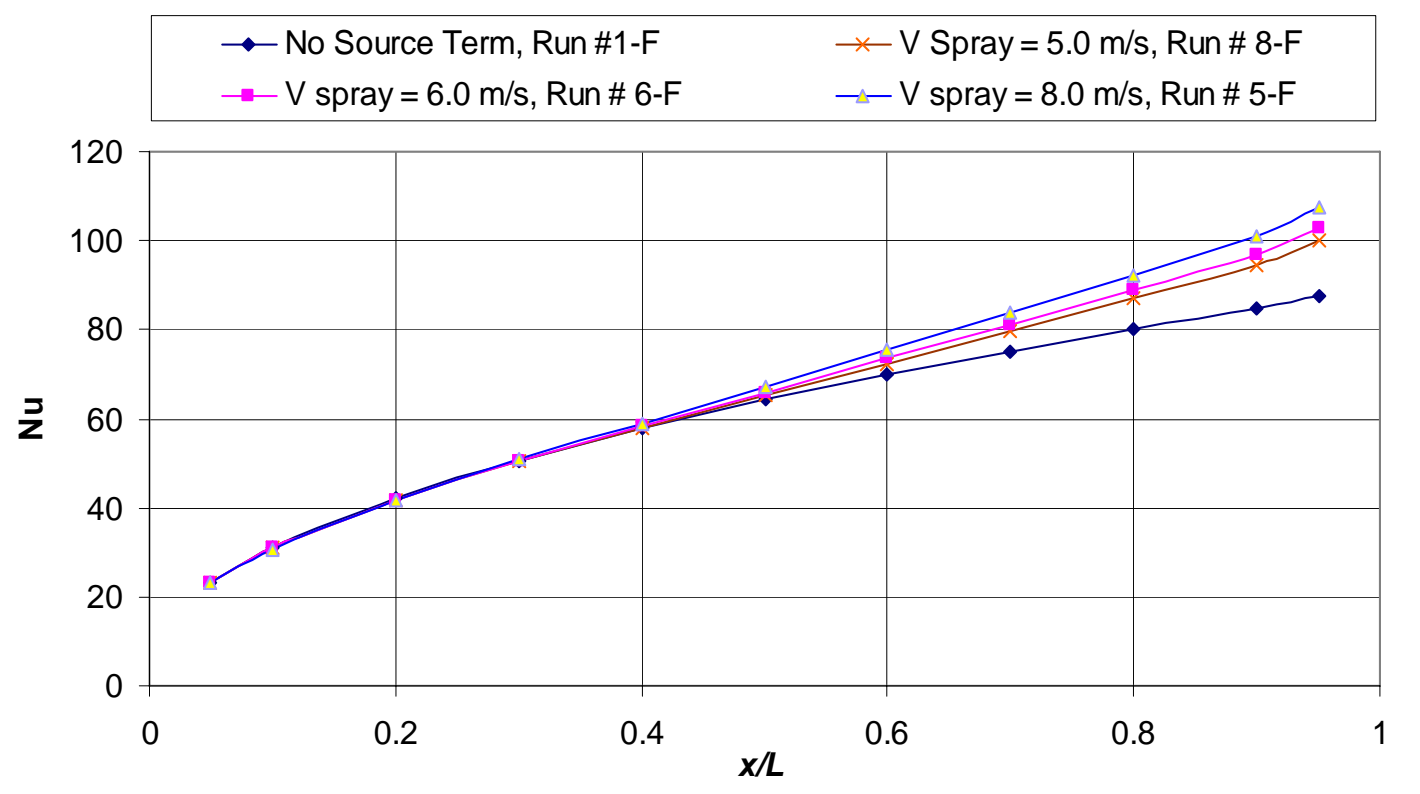

Figure 6.14 Effect of Spray Velocity on Nusselt Number (FC-72, $d=100$ microns, $U=0.5 \mathrm{~m} / \mathrm{s}, q^{\prime \prime}=25 \mathrm{~kW} / \mathrm{m}^{2}$ ). 


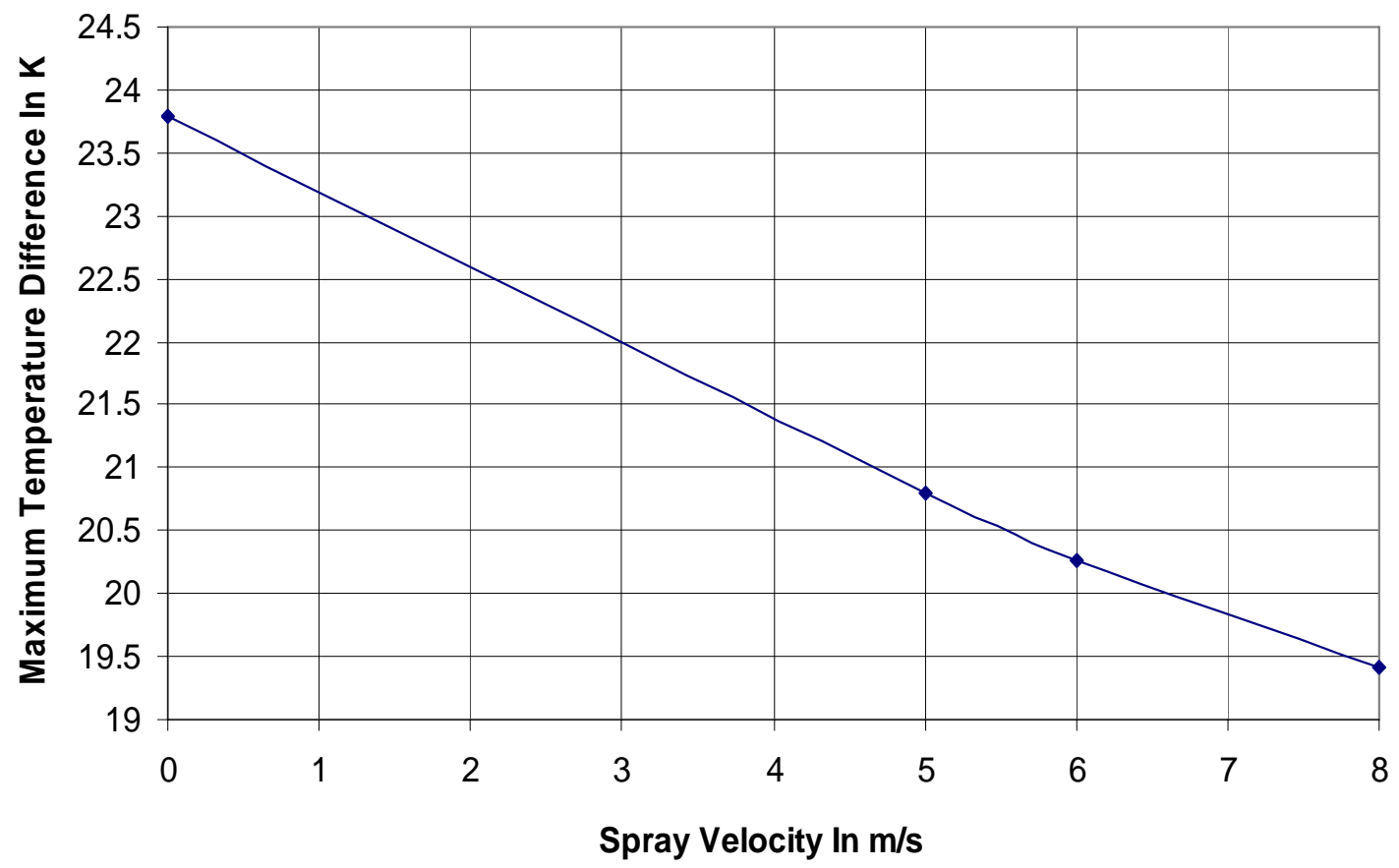

Figure 6.15 Effect of Spray Velocity on Maximum Temperature Difference (FC-72, $d=100$ microns, $U=0.5 \mathrm{~m} / \mathrm{s}, q^{\prime \prime}=25 \mathrm{~kW} / \mathrm{m}^{2}$ ).

HFE-7000 which is also used in many spray cooling applications was also simulated. However due to its lower boiling temperature, $37^{\circ} \mathrm{C}$, in comparison with water and FC-72, the wall heat flux was set equal to $10 \mathrm{~kW} / \mathrm{m}^{2}$. It was lowered for the same reason mentioned before which is the desire to avoid boiling. The same flow parameters were used as before. However because of the lower heat flux applied on the wall, the difference in the wall surface temperature after adding the source term was not more than $2^{\circ} \mathrm{C}$. It was also found that the higher the spray velocity the better the heat transfer. These results are shown in Figures 6.16 and 6.17 for the temperature profile and Nusselt number respectively, while the maximum difference in temperature as function of spray velocity is shown in Figure 6.18. 

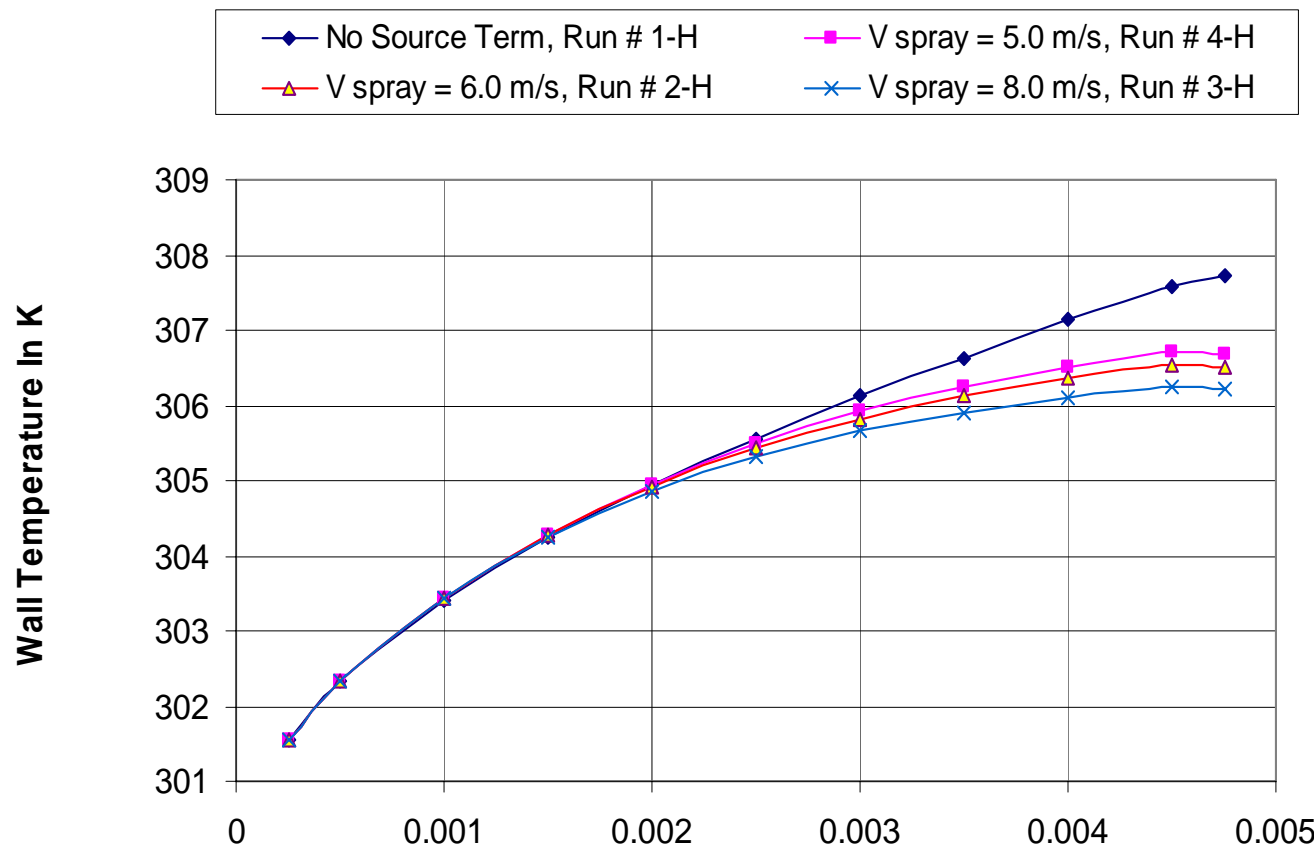

Distance Measured From The Plate Edge x In meters

Figure 6.16 Effect of Spray Velocity on Wall Temperature Profile

(HFE-7000, $d=100$ microns, $U=0.5 \mathrm{~m} / \mathrm{s}, q^{\prime \prime}=10 \mathrm{~kW} / \mathrm{m}^{2}$ ).

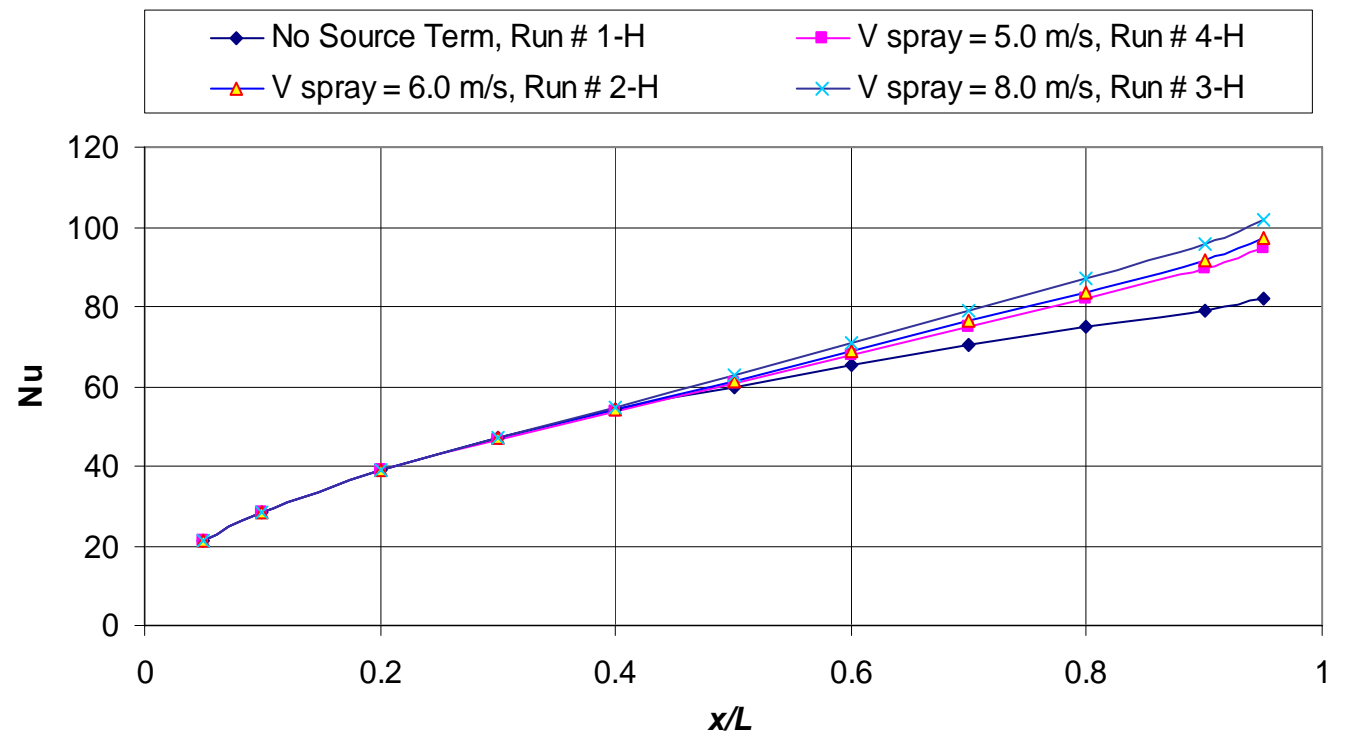

Figure 6.17 Effect of Spray Velocity on Nusselt Number (HFE-7000, $d=100$ microns, $U=0.5 \mathrm{~m} / \mathrm{s}, q^{\prime \prime}=10 \mathrm{~kW} / \mathrm{m}^{2}$ ). 


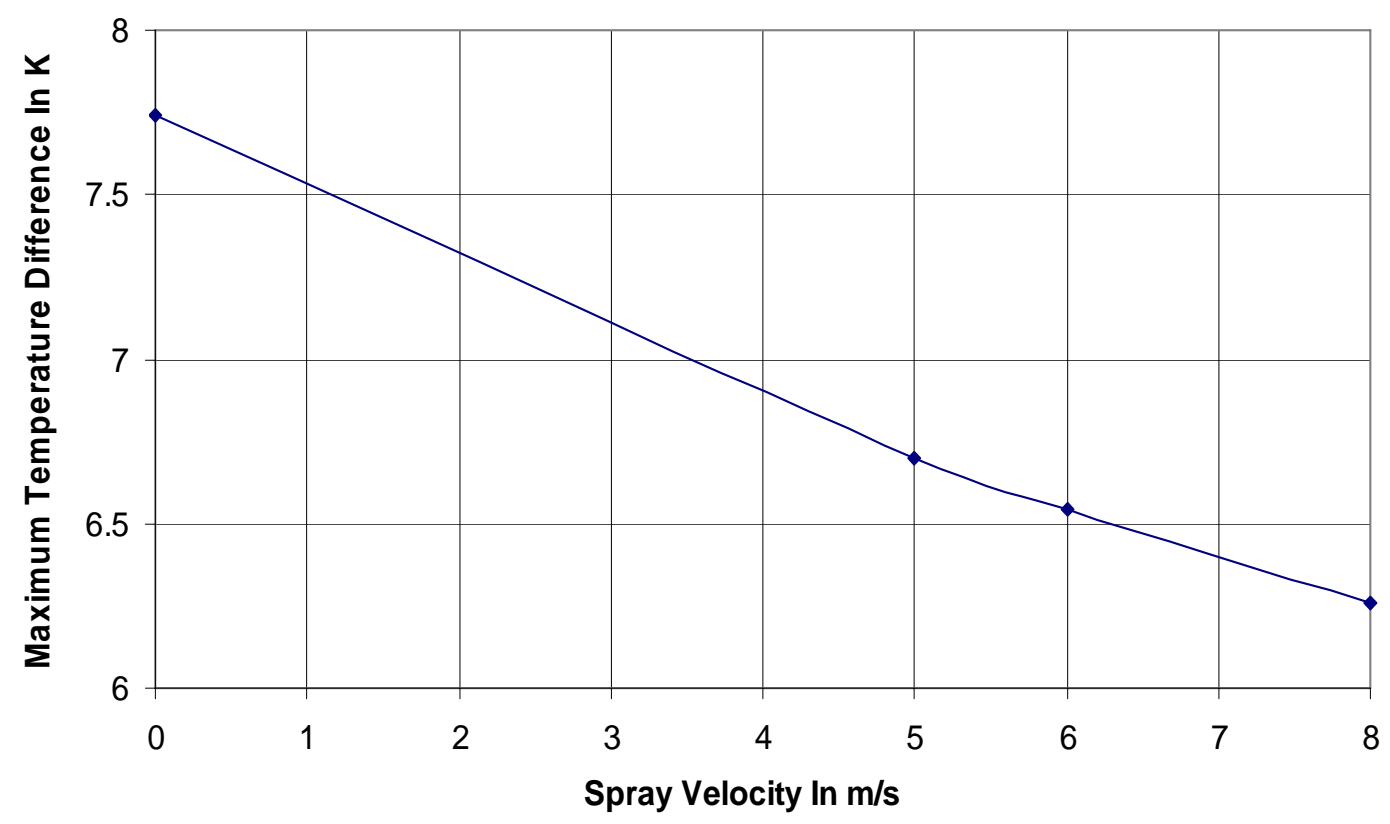

Figure 6.18 Effect of Spray Velocity on Maximum Temperature Difference (HFE-7000, $d=100$ microns, $U=0.5 \mathrm{~m} / \mathrm{s}, q^{\prime \prime}=10 \mathrm{~kW} / \mathrm{m}^{2}$ ).

In order to determine the maximum drop in the heater temperature due to the spray with no phase change, it was necessary to allow a higher heat flux at the heater surface. So, the properties of FC-72 were used except the boiling temperature was set to $90^{\circ} \mathrm{C}$. This liquid is called a hypothetical fluid.

A higher drop in temperature was observed when a $50 \mathrm{~kW} / \mathrm{m}^{2}$ constant heat flux was applied at the heater surface. Also, by increasing the spray velocity both the temperature profile and Nusselt number are higher as shown in Figures 6.19 and 6.20 respectively. Figure 6.21 shows the maximum difference in temperature as function of spray velocity. As was seen previously, it was found that the cooling is enhanced by increasing the spray velocity. 


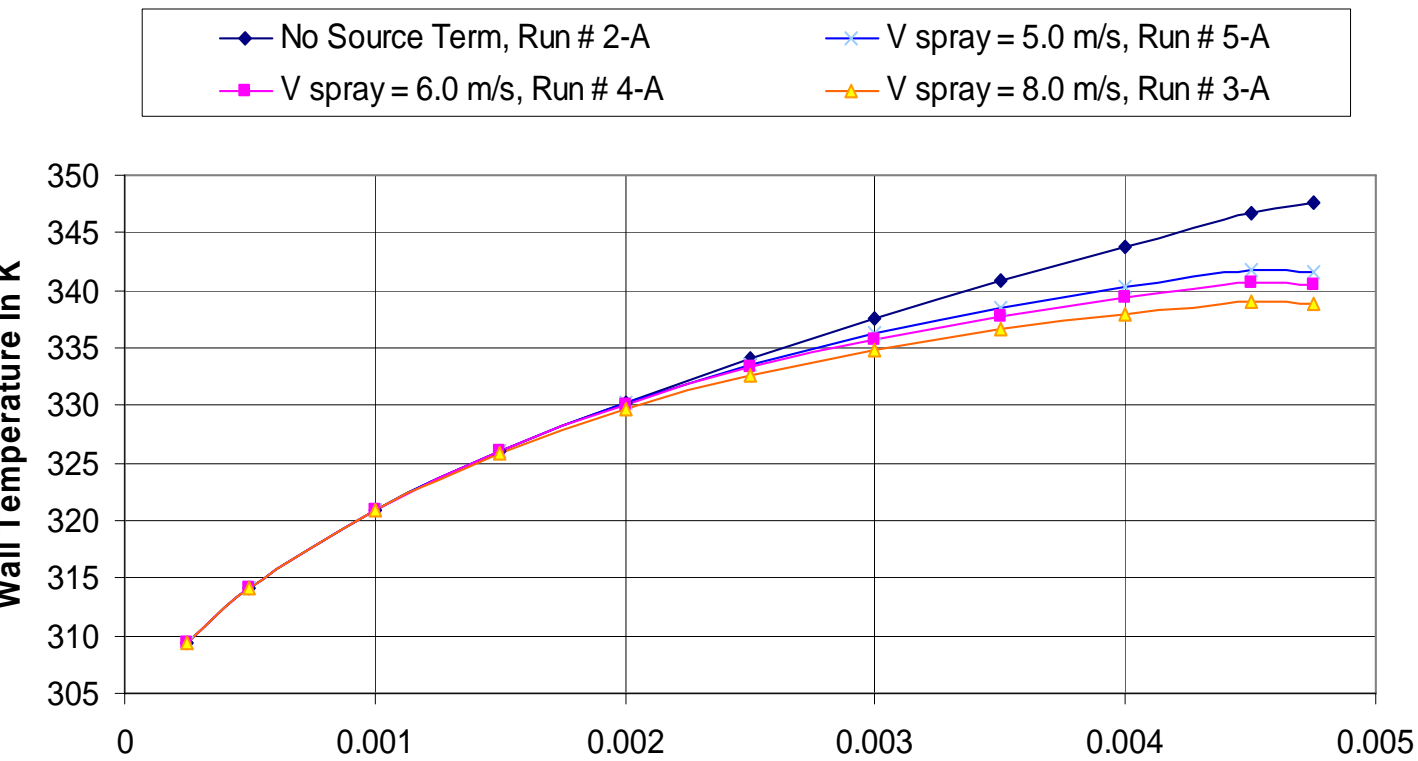

Distance Measured From The Plate Edge $\mathrm{x}$ In meters

Figure 6.19 Effect of Spray Velocity on Wall Temperature Profile (Hypothetical Fluid, $d=100$ microns, $U=0.5 \mathrm{~m} / \mathrm{s}, q^{\prime \prime}=50 \mathrm{~kW} / \mathrm{m}^{2}$ ).

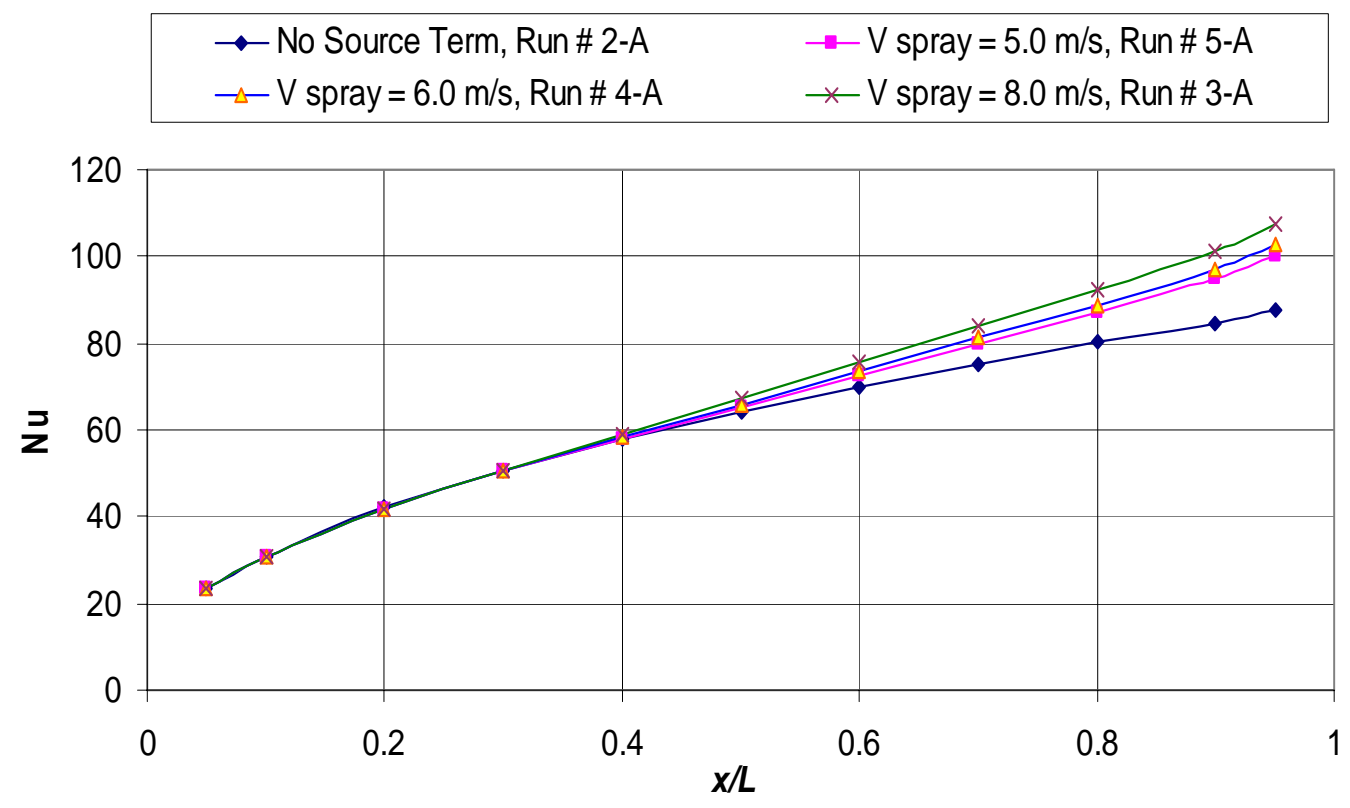

Figure 6.20 Effect of Spray Velocity on Nusselt Number (Hypothetical Fluid, $\boldsymbol{d}=100$ microns, $U=0.5 \mathrm{~m} / \mathrm{s}, q^{\prime \prime}=50 \mathrm{~kW} / \mathrm{m}^{2}$ ). 


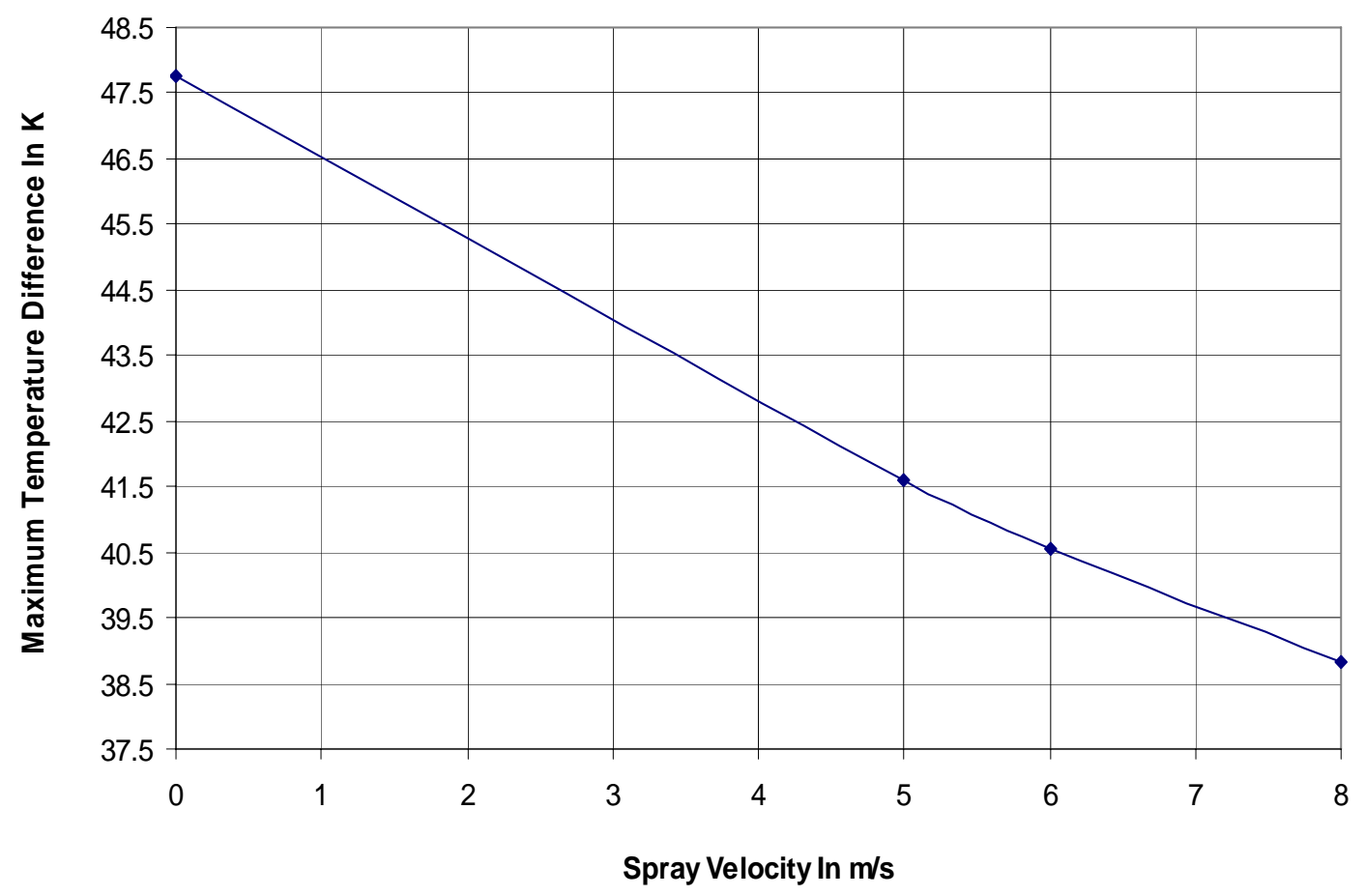

Figure 6.21 Effect of Spray Velocity on Maximum Temperature Difference (Hypothetical Fluid, $d=100$ microns, $U=0.5 \mathrm{~m} / \mathrm{s}, q^{\prime \prime}=50 \mathrm{~kW} / \mathrm{m}^{2}$ ).

\subsubsection{Effect of Spray Nozzle Spacing.}

The second parameter which was investigated in this study is the nozzle spacing. This parameter is the vertical distance between the heater surface and the spray injector. However in all cases it was assumed that the heater surface would be totally covered by the spray regardless of how far is the injector from the heater surface. The mass flow rate was the same as shown in Tables 6.2 to 6.5.

Three values for the nozzle spacing were used which are $0.01,0.013$ and $0.015 \mathrm{~m}$. These values were taken from Hunnell [47]. However the spray angle will not be the same for different nozzle spacing and the same heater length as shown in Figure 6.2. The effect of the nozzle spacing was studied for the four working fluids used before. 
Figure 6.22 shows the effect of nozzle spacing on the wall temperature profile using water as working fluid. A 200 micron layer thickness is used with a horizontal velocity of $0.5 \mathrm{~m} / \mathrm{s}$ and a heat flux of $150 \mathrm{~kW} / \mathrm{m}^{2}$ applied to the heater.

It was found that the closer the nozzle is to the heater surface, the better the heat transfer. For the same runs Nusselt number is plotted against $x / L$ in Figure 6.23 while the maximum difference in temperature as function of nozzle spacing is shown in Figure 6.24. It is shown in these figures that decreasing the distance between the nozzle injector and the heater surface increase the cooling.

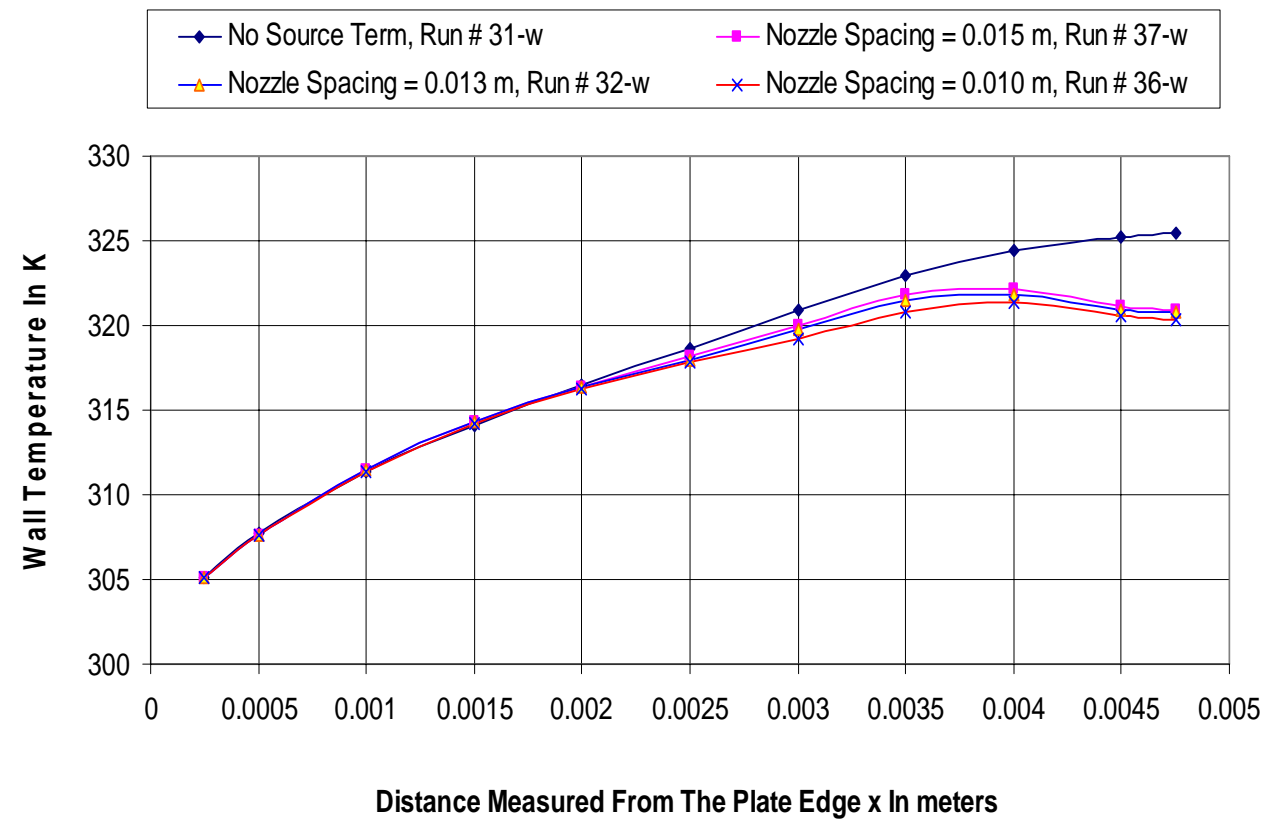

Figure 6.22 Effect of Nozzle Spacing on Wall Temperature Profile (Water, $\boldsymbol{d}=200$ microns, $\boldsymbol{U}=0.5 \mathrm{~m} / \mathrm{s}, q^{\prime \prime}=150 \mathrm{~kW} / \mathrm{m}^{2}$ ). 


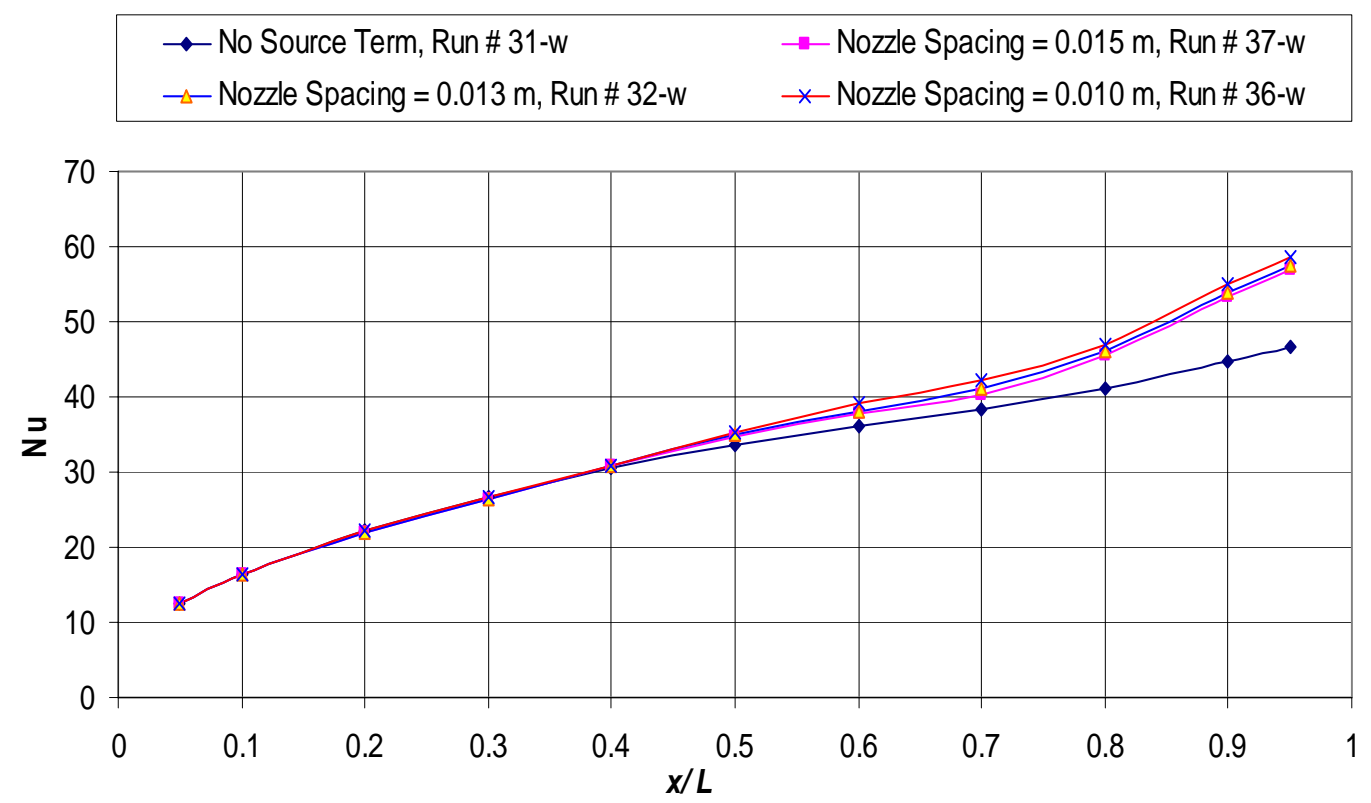

Figure 6.23 Effect of Nozzle Spacing on Nusselt Number (Water, $\boldsymbol{d}=200$ microns, $U=0.5 \mathrm{~m} / \mathrm{s}, q^{\prime \prime}=150 \mathrm{~kW} / \mathrm{m}^{2}$ ).

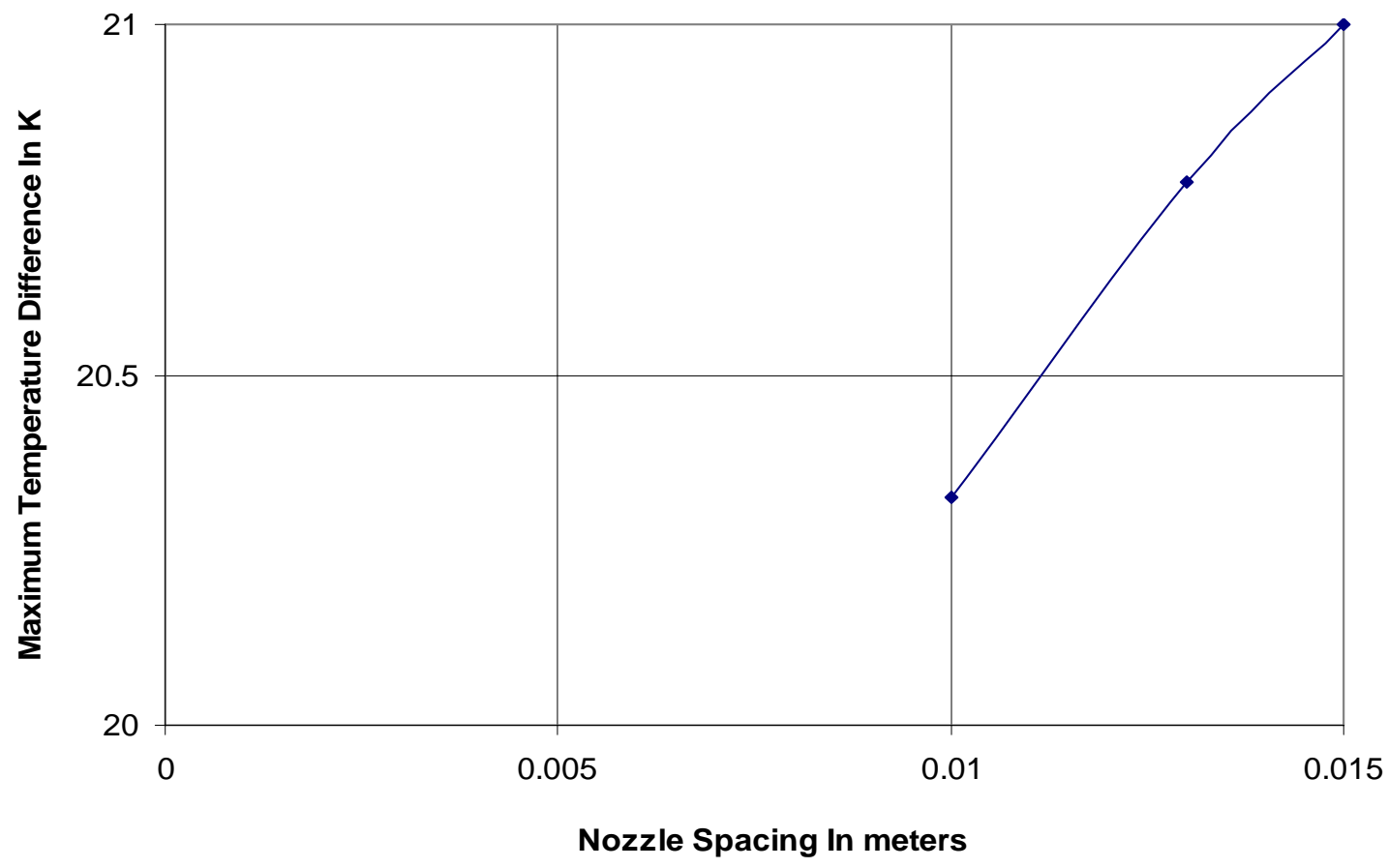

Figure 6.24Effect of Nozzle Spacing on Maximum Temperature Difference (Water, $\boldsymbol{d}=200$ microns, $U=0.5 \mathrm{~m} / \mathrm{s}, q^{\prime \prime}=150 \mathrm{~kW} / \mathrm{m}^{2}$ ). 
At a layer thickness of 100 microns, it was also found that as the nozzle spacing decreases the heat transfer increases as shown in Figures 6.25 and 6.26 for the temperature profile and Nusselt number respectively. It was found also that by decreasing the nozzle spacing the cooling is higher than that of the 200 microns layer, which means more heat can be absorbed from the heater surface. The maximum difference in temperature as function of nozzle spacing is shown in Figure 6.27. It was found that the cooling is better for smaller nozzle spacing.

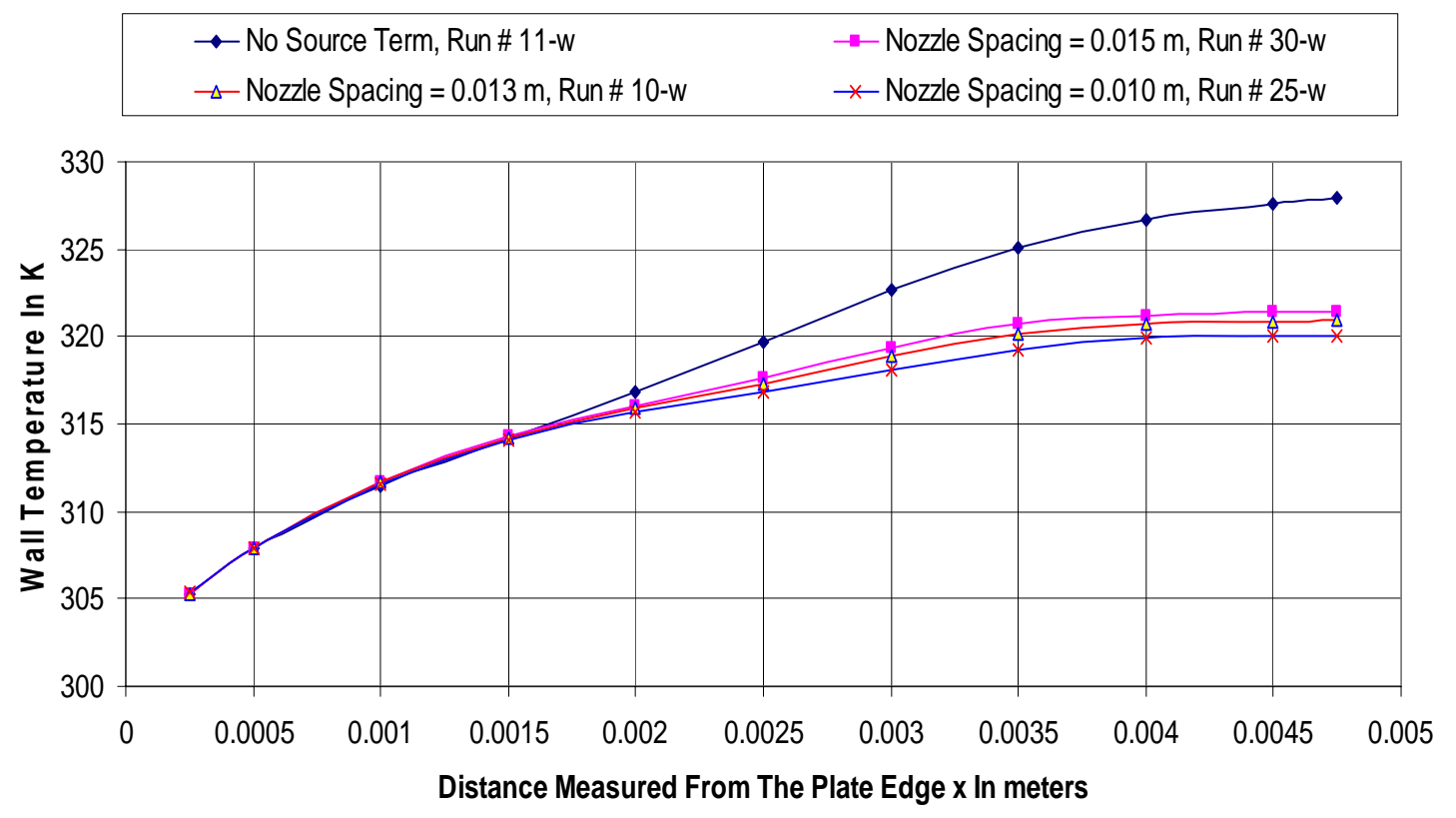

Figure 6.25 Effect Nozzles Spacing on Wall Temperature Profile (Water, $\boldsymbol{d}=100 \mathrm{microns}, \boldsymbol{U}=0.5 \mathrm{~m} / \mathrm{s}, q^{\prime \prime}=150 \mathrm{~kW} / \mathrm{m}^{2}$ ). 


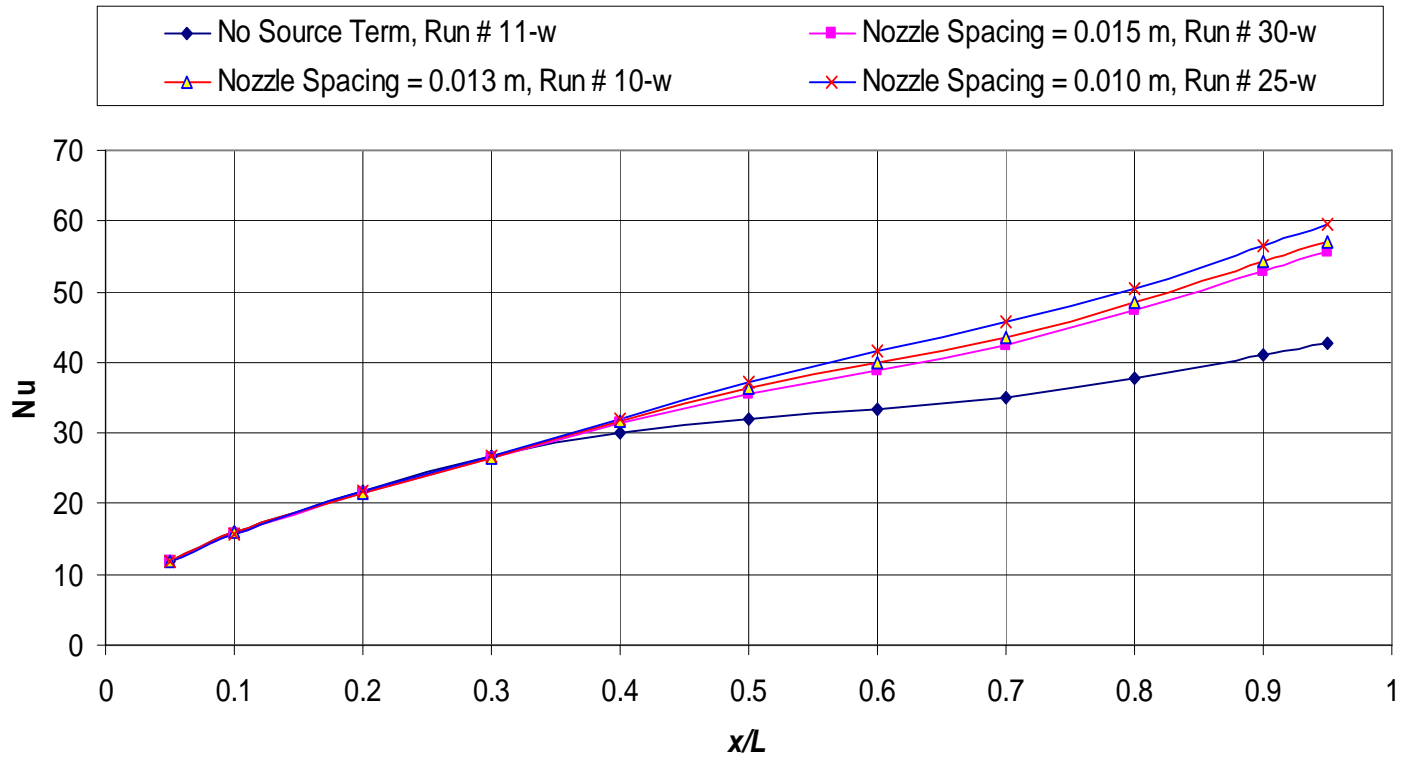

Figure 6.26 Effect of Nozzle Spacing on Nusselt Number (Water, $\boldsymbol{d}=100$ microns, $U=0.5 \mathrm{~m} / \mathrm{s}, q^{\prime \prime}=150 \mathrm{~kW} / \mathrm{m}^{2}$ ).

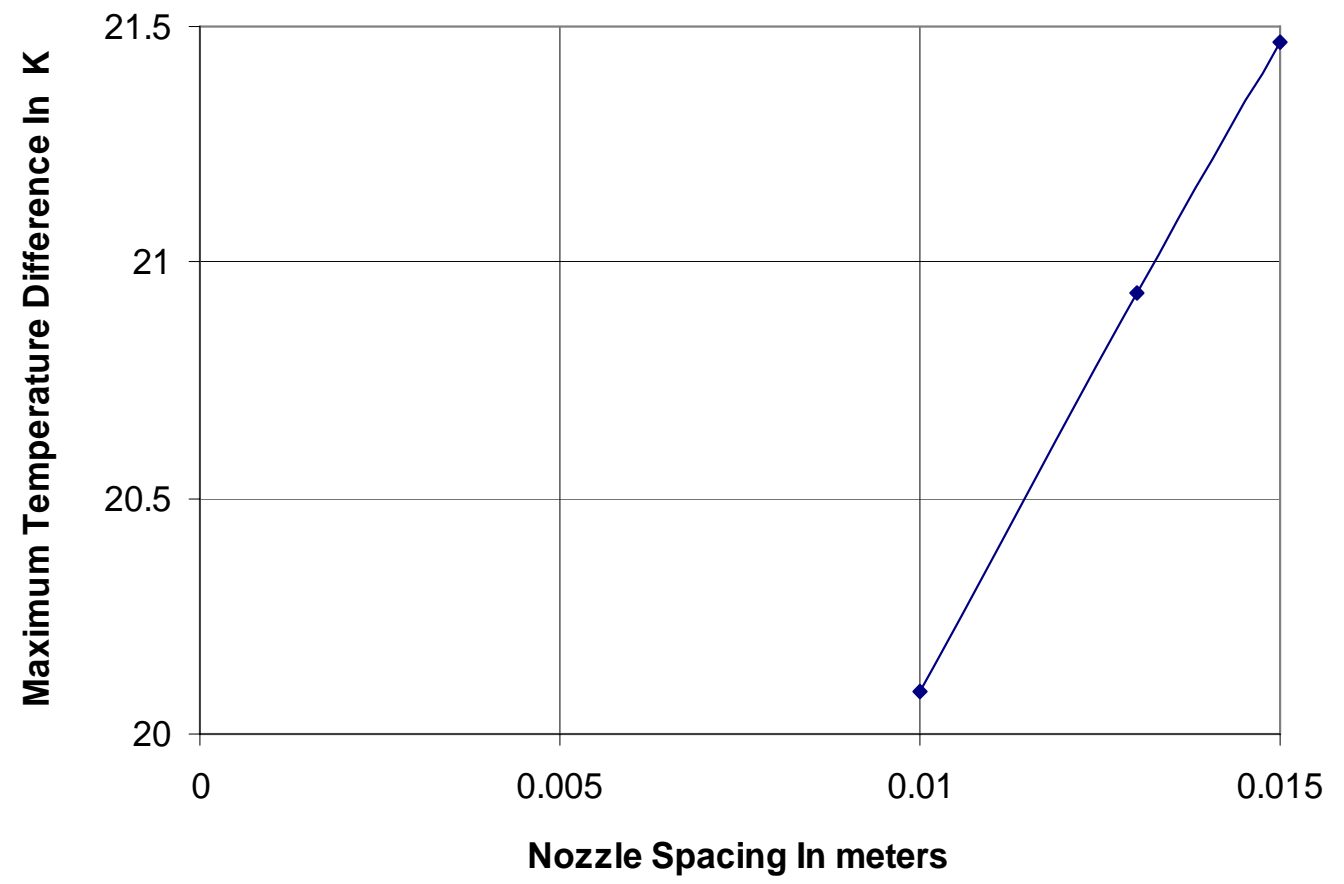

Figure 6.27 Effect of Nozzle Spacing on Maximum Temperature Difference (Water, $\boldsymbol{d}=100$ microns, $\boldsymbol{U}=0.5 \mathrm{~m} / \mathrm{s}, q^{\prime \prime}=150 \mathrm{~kW} / \mathrm{m}^{2}$ ). 
FC-72 was used as a second working fluid and the wall heat flux was reduced to $25 \mathrm{~kW} / \mathrm{m}^{2}$ to avoid boiling. The same layer horizontal velocity was used as before because it was the most effective value. However the only layer thickness used for these simulations is the 100 micron layer thickness, because it is also more effective. The same trends for both temperature profile and Nusselt number were observed as before. The results are shown in Figures 6.28 and 6.29 respectively. It was also found that the closer the nozzle the better the heat transfer. The maximum difference in temperature as function of nozzle spacing is shown in Figure 6.30.

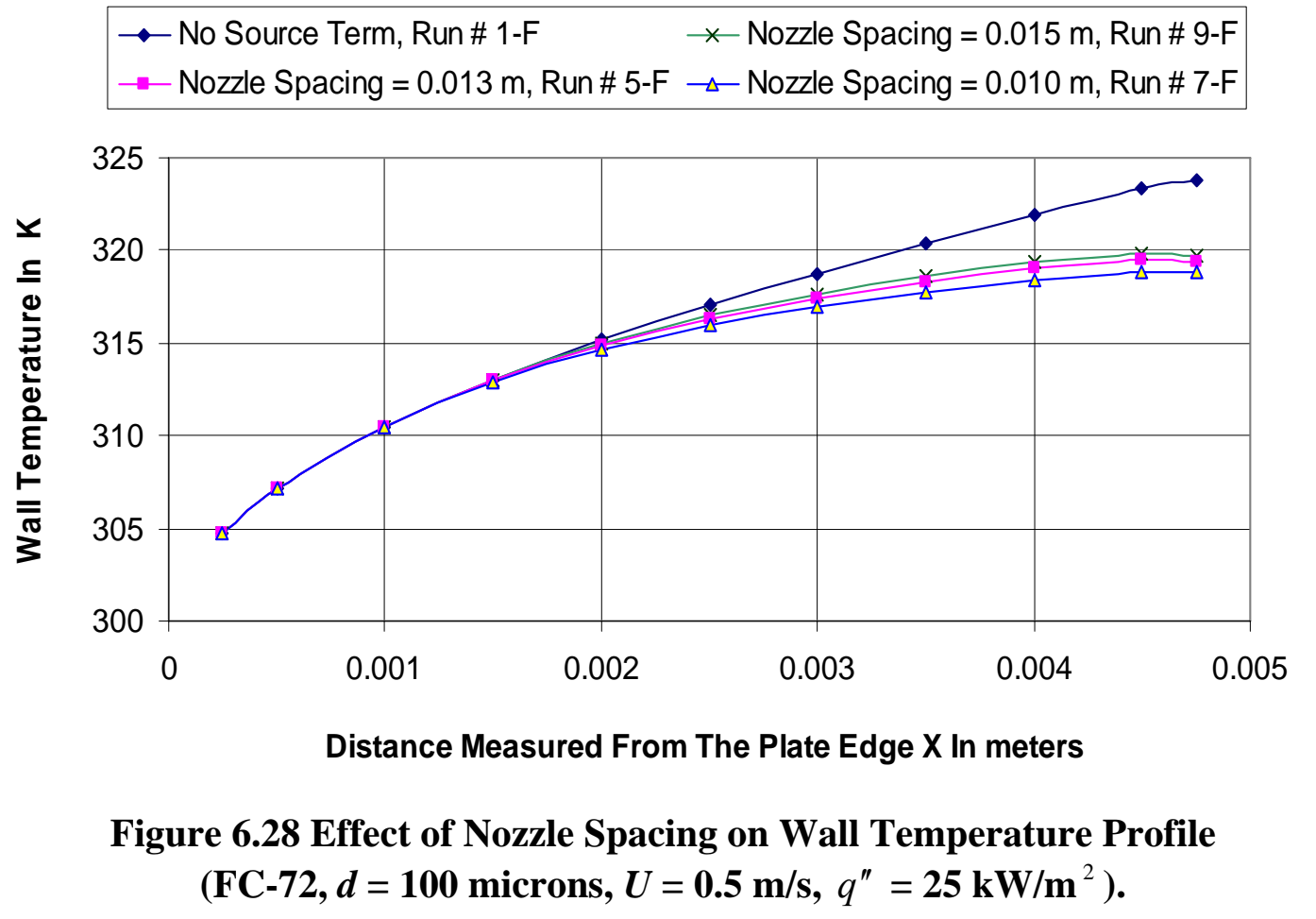




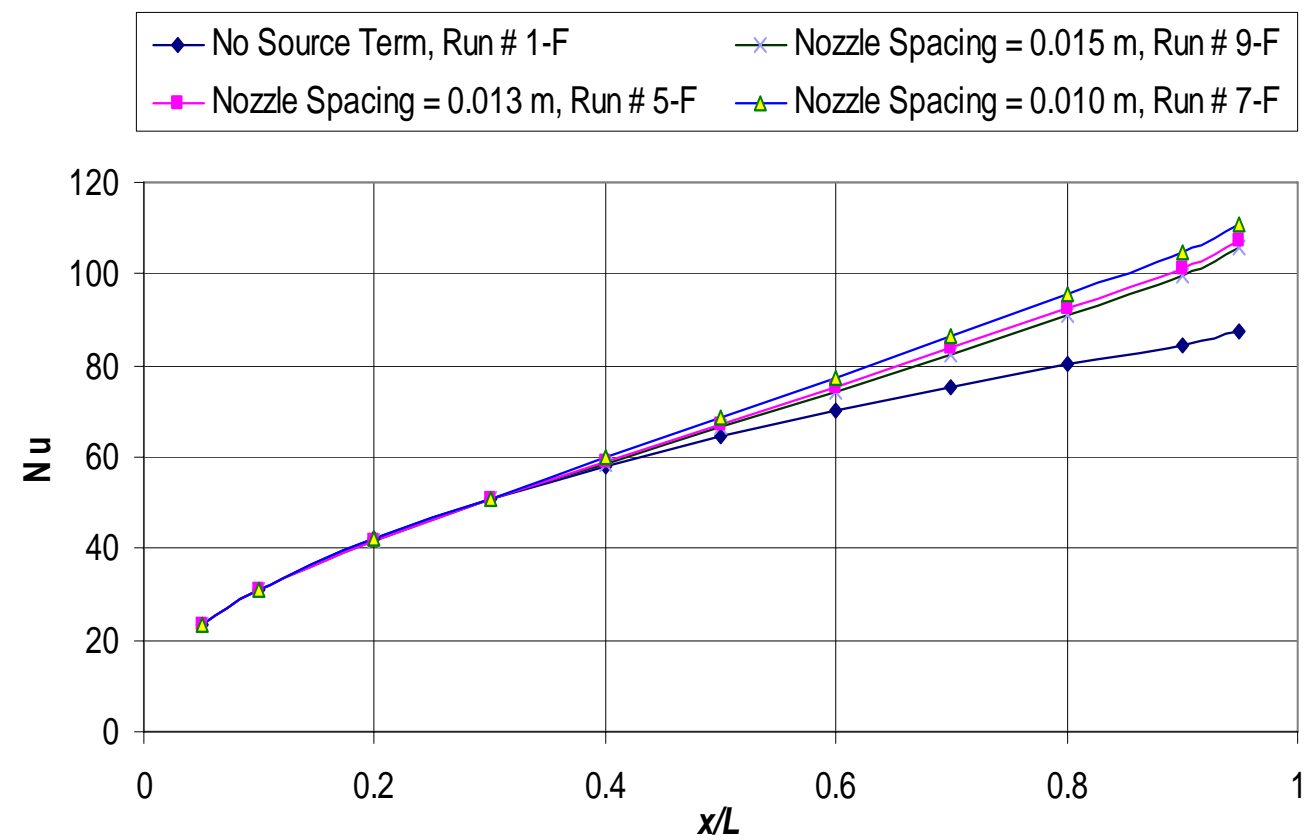

Figure 6.29 Effect of Nozzle Spacing on Nusselt Number (FC-72, $\boldsymbol{d}=100$ microns, $\boldsymbol{U}=0.5 \mathrm{~m} / \mathrm{s}, q^{\prime \prime}=25 \mathrm{~kW} / \mathrm{m}^{2}$ ).

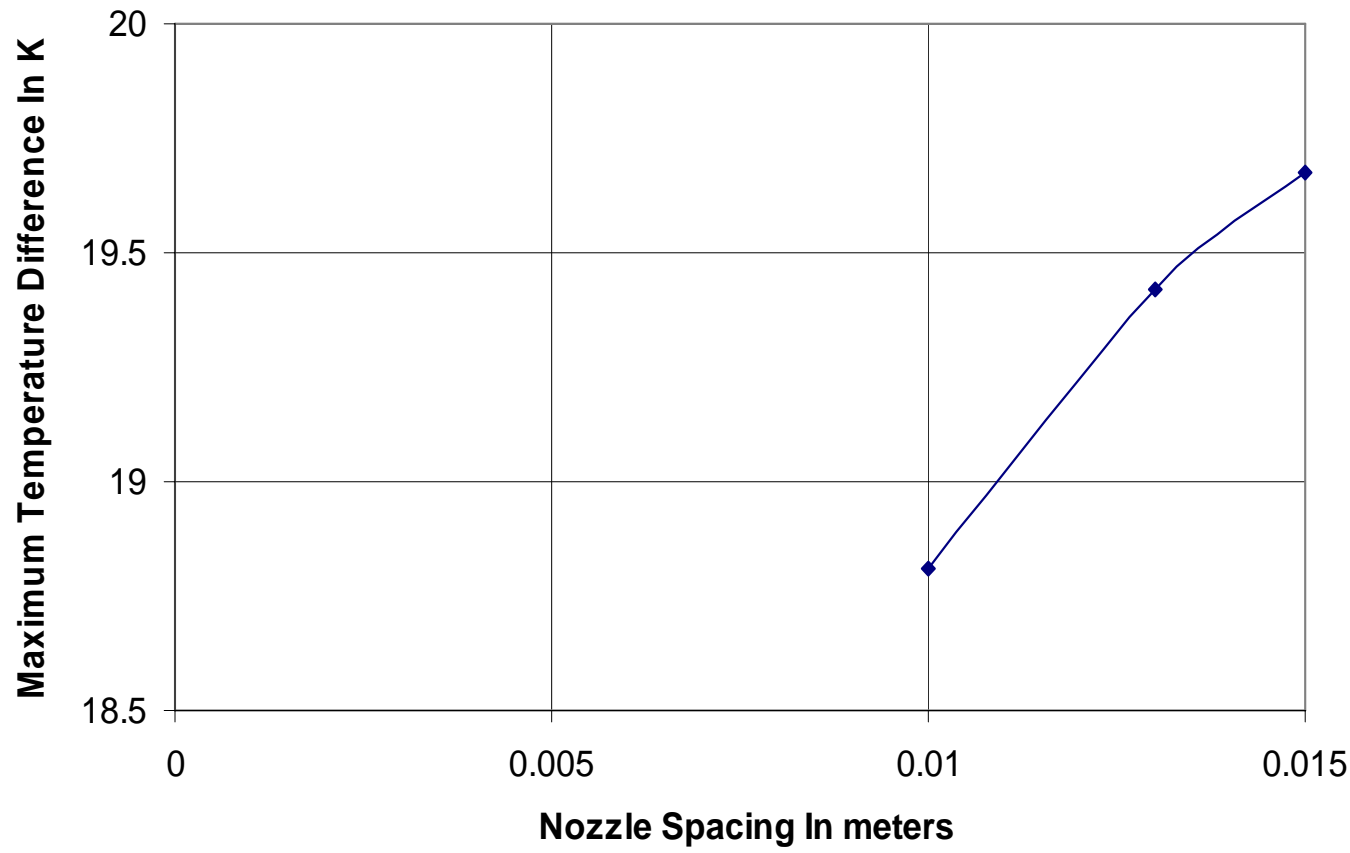

Figure 6.30 Effect of Nozzle Spacing on Maximum Temperature Difference (FC-72, $d=100$ microns, $U=0.5 \mathrm{~m} / \mathrm{s}, q^{\prime \prime}=25 \mathrm{~kW} / \mathrm{m}^{2}$ ). 
The computed effect of the nozzle spacing on the temperature profile and Nusselt number using HFE-7000 as working fluid for layer thickness of 100 microns and a horizontal velocity of $0.5 \mathrm{~m} / \mathrm{s}$ is plotted in Figures 6.31 and 6.32 respectively. The same trend was observed as in water and FC-72. Figure 6.33 shows the maximum difference in temperature as function of nozzle spacing for HFE-7000 using same parameters. In these figures it is seen that the cooling is higher for smaller nozzle spacings.

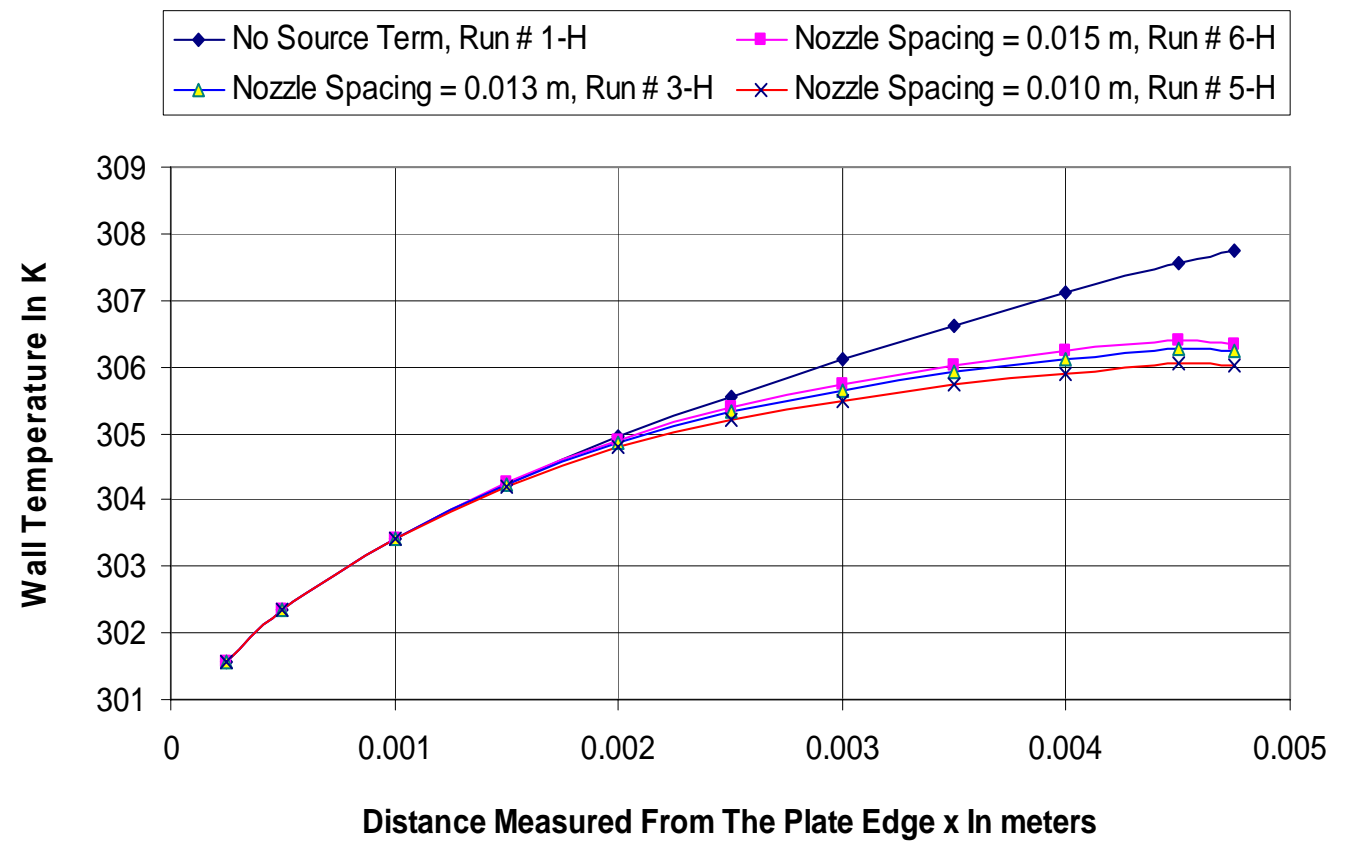

Figure 6.31 Effect of Nozzle Spacing on Wall Temperature Profile (HFE-7000, $d=100$ microns, $U=0.5 \mathrm{~m} / \mathrm{s}, q^{\prime \prime}=10 \mathrm{~kW} / \mathrm{m}^{2}$ ). 


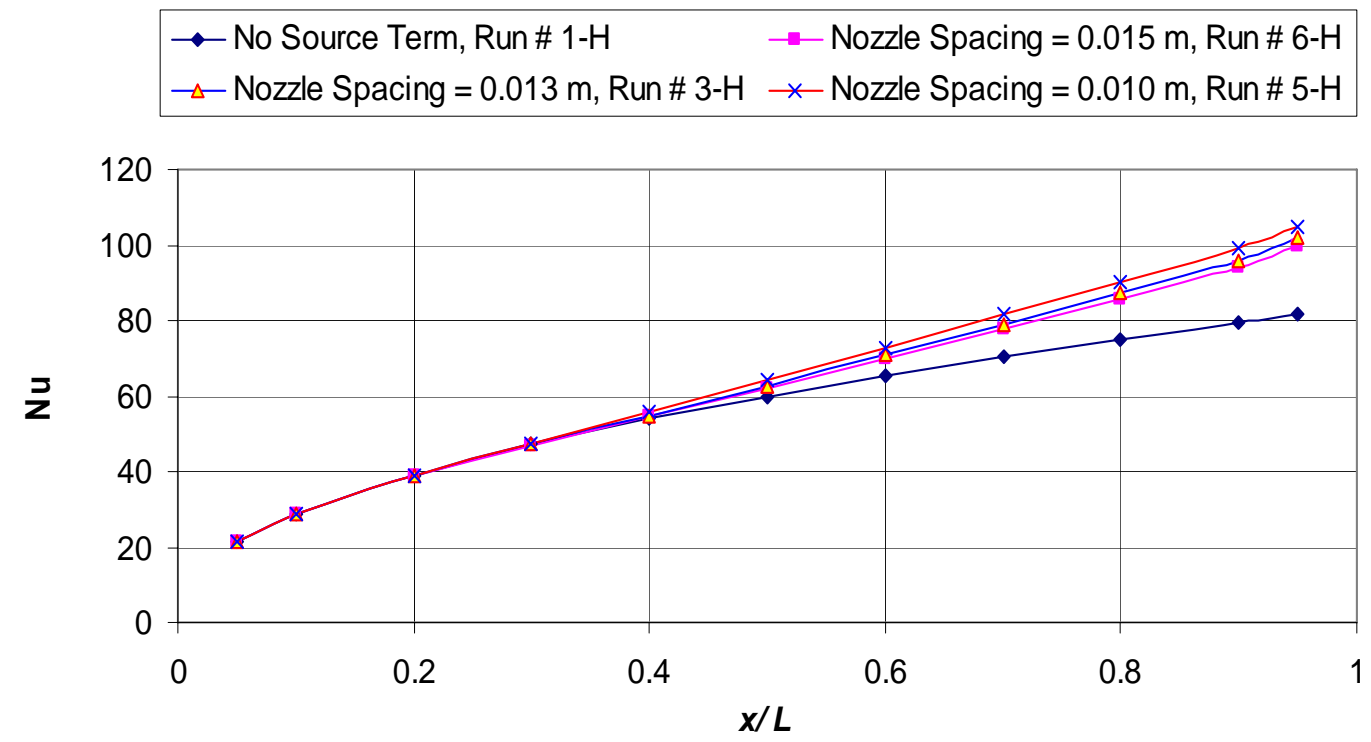

Figure 6.32 Effect of Nozzle Spacing on Nusselt Number

(HFE-7000, $d=100$ microns, $U=0.5 \mathrm{~m} / \mathrm{s}, q^{\prime \prime}=10 \mathrm{~kW} / \mathrm{m}^{2}$ ).

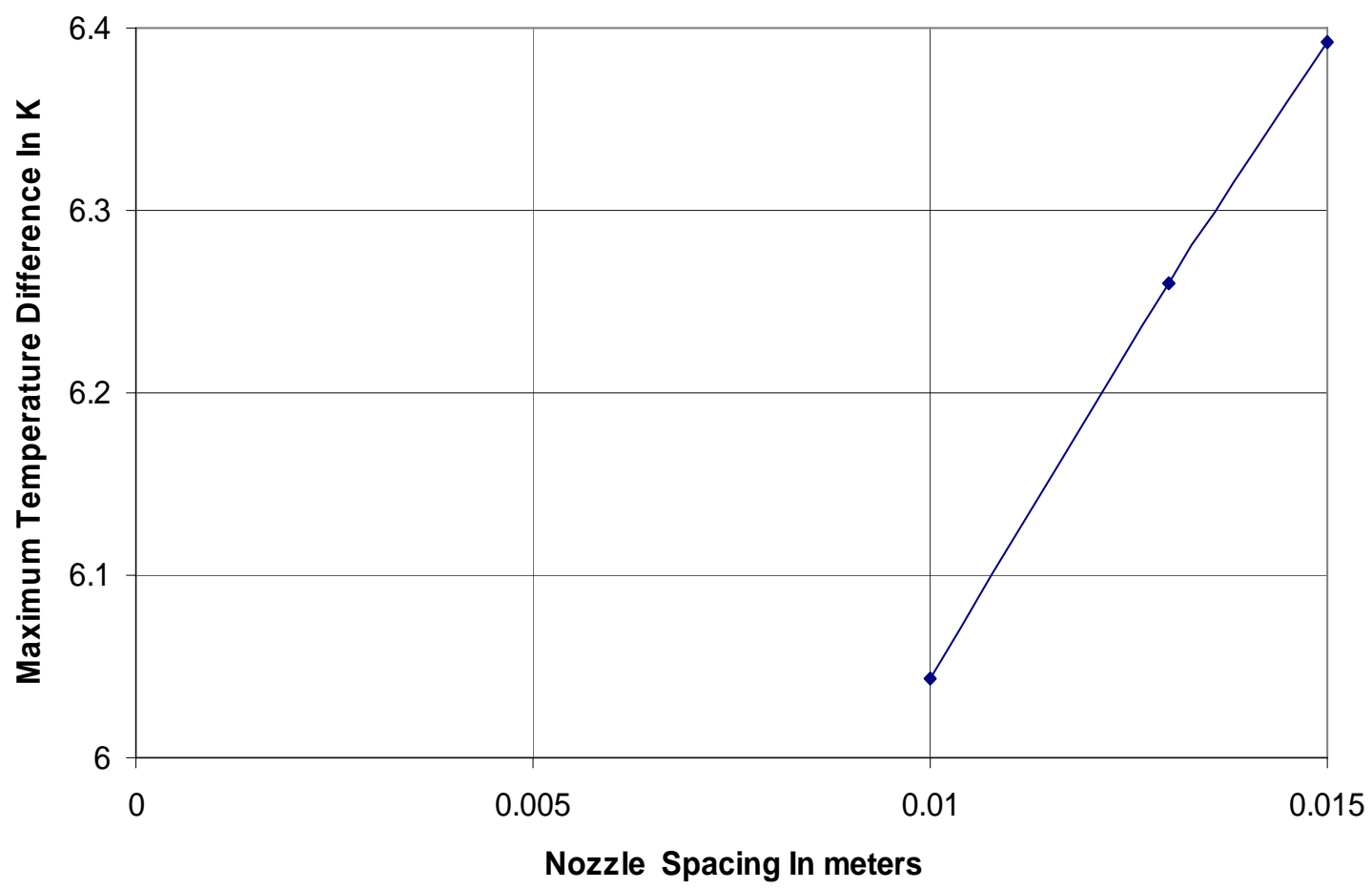

Figure 6.33 Effect of Nozzle Spacing on Maximum Temperature Difference (HFE-7000, $d=100$ microns, $U=0.5 \mathrm{~m} / \mathrm{s}, q^{\prime \prime}=10 \mathrm{~kW} / \mathrm{m}^{2}$ ). 
The same effect was observed when a hypothetical fluid with FC-72 properties but with higher boiling temperature was used as working fluid. In this case the wall heat flux was raised to $50 \mathrm{~kW} / \mathrm{m}^{2}$. The temperature profile and Nusselt number distributions are shown in Figures 6.34 and 6.35 respectively. The maximum difference in temperature as a function of nozzle spacing is shown in Figure 6.36. It is clear from these figures that the cooling is again higher for smaller nozzle spacings.

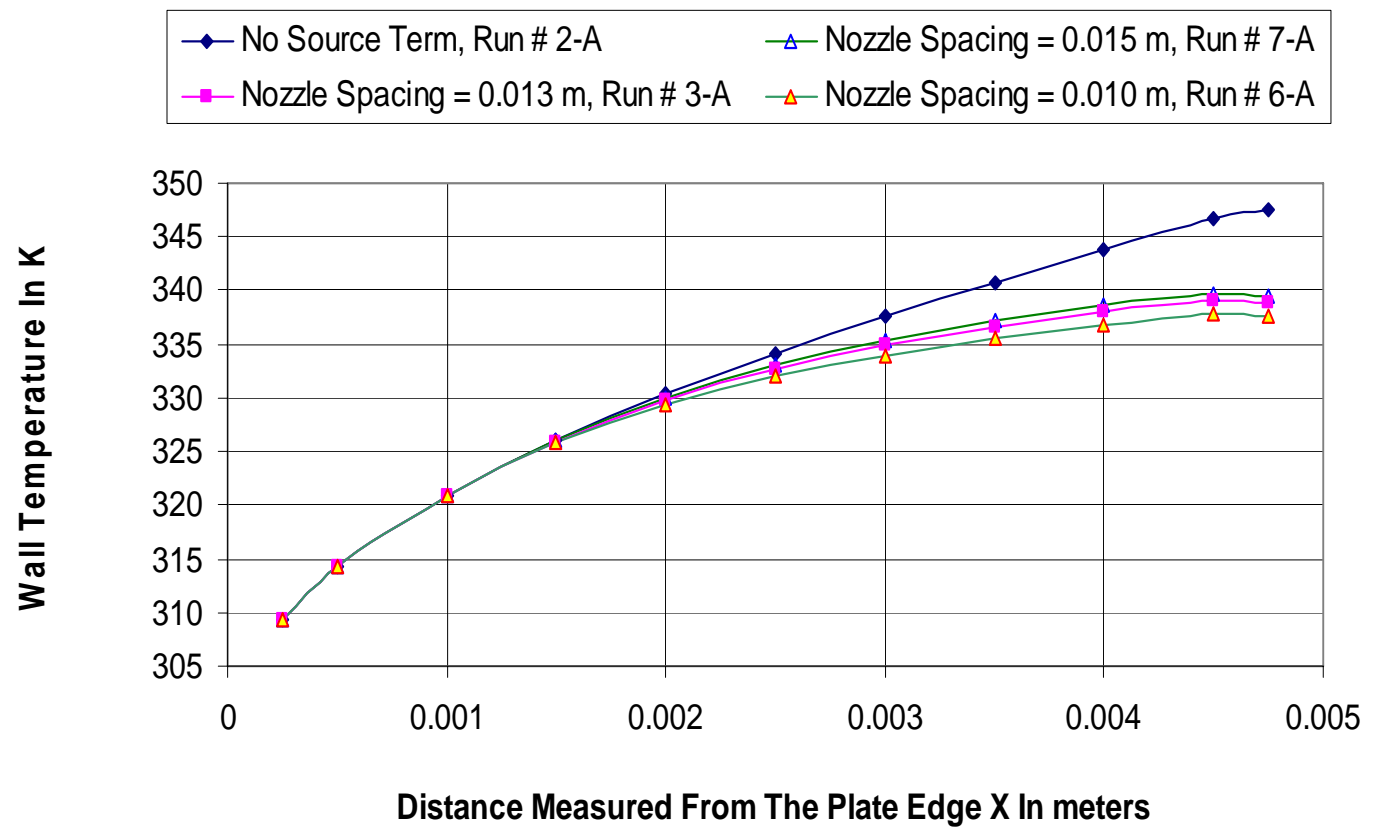

Figure 6.34 Effect of Nozzle Spacing on Wall Temperature Profile (Hypothetical Fluid, $d=100$ microns, $U=0.5 \mathrm{~m} / \mathrm{s}, q^{\prime \prime}=50 \mathrm{~kW} / \mathrm{m}^{2}$ ). 


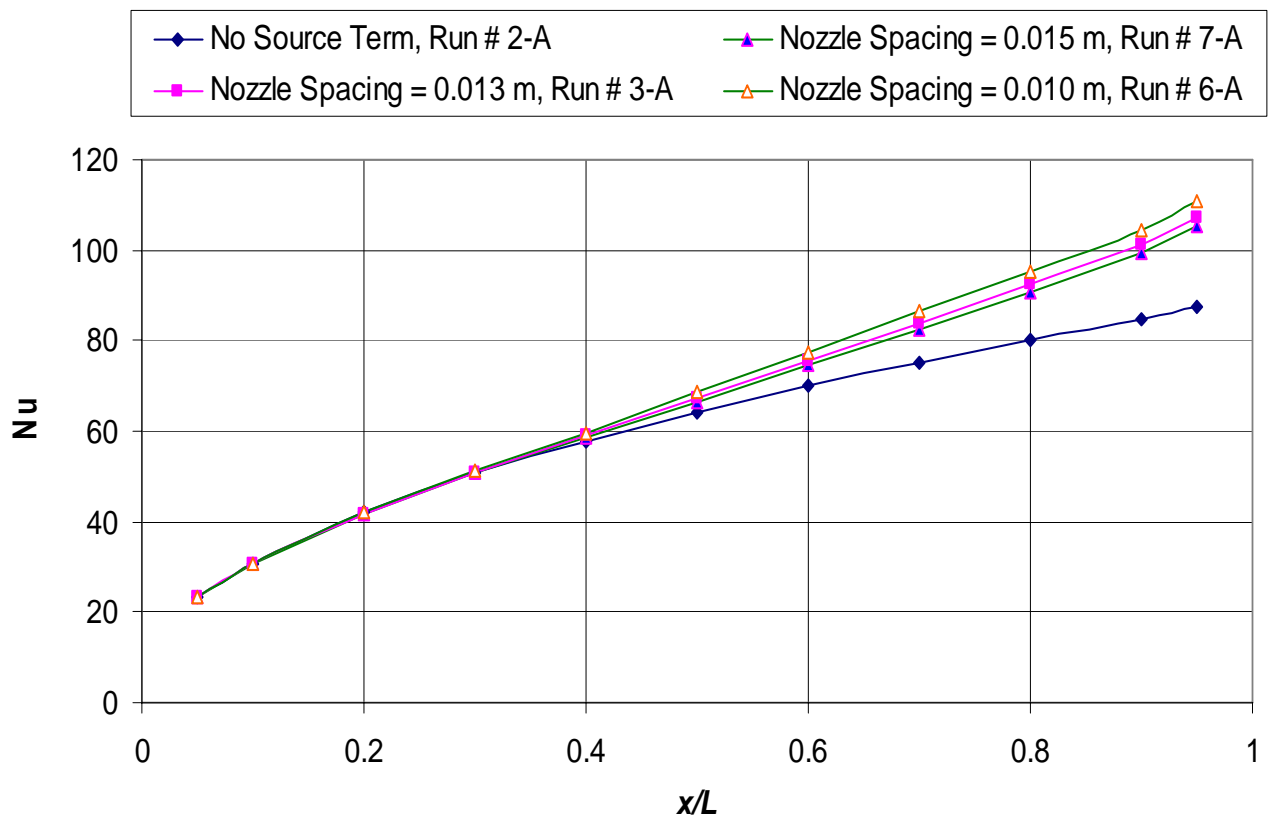

Figure 6.35 Effect of Nozzle Spacing on Nusselt Number (Hypothetical Fluid, $\boldsymbol{d}=100 \mathrm{microns}, \boldsymbol{U}=\mathbf{0 . 5} \mathrm{m} / \mathrm{s}, q^{\prime \prime}=50 \mathrm{~kW} / \mathrm{m}^{2}$ ).

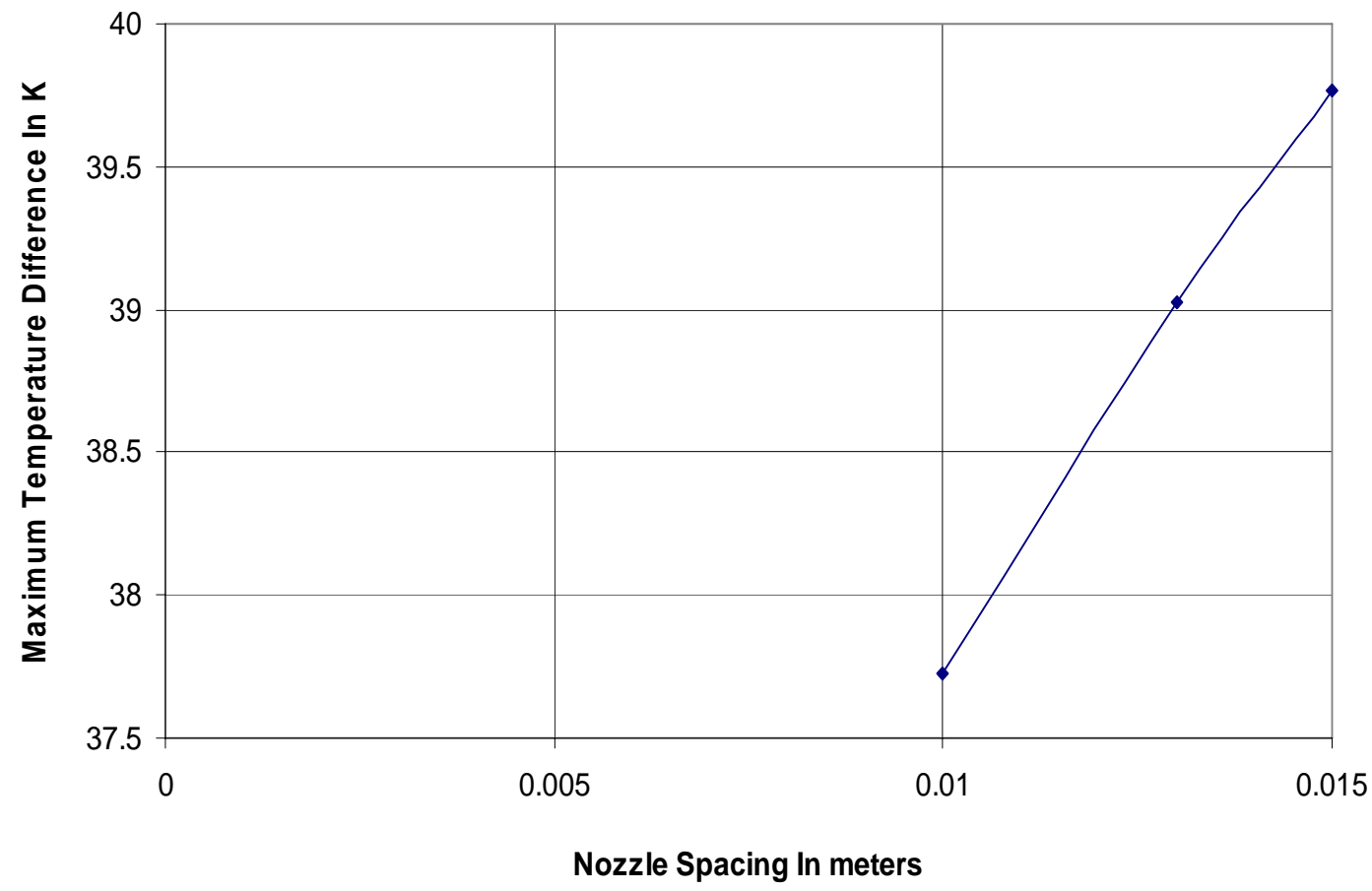

Figure 6.36 Effect of Nozzle Spacing on Maximum Temperature Difference (Hypothetical Fluid, $\boldsymbol{d}=100 \mathrm{microns}, \boldsymbol{U}=\mathbf{0 . 5} \mathrm{m} / \mathrm{s}, q^{\prime \prime}=50 \mathrm{~kW} / \mathrm{m}^{2}$ ). 
Horacek et al. [30] also found that the heat transfer across the surface increased significantly with decreasing nozzle-to-heater spacing. However, in their experiment phase change was involved.

\subsubsection{Effect of Spray Mass Flow Rate.}

The spray mass flow rate was added as a source term to the upper surface of the liquid layer. The total mass flow rate was divided by the number of cells in the upper half of the liquid layer and was allowed to vary in the horizontal $x$ direction. Closer from the nozzle center more mass was added and further from the nozzle center less mass was added. This was because the mass was added as a function of the cosine of the injecting angle. It was mentioned earlier that the mass source term was varied as a function of the drop trajectory angle, which is consequently a function of the horizontal distance $\mathrm{x}$ as shown in Figure 6.2. Three values were used which were 4.8 E-03, 7.0 E-03 and 9.8 E$03 \mathrm{~kg} / \mathrm{s}$.

Both 100 and 200 micron layers were simulated using water as the working fluid. Figure 6.37 shows the computed effect of the spray mass flow rate using water as the working fluid and a layer of 200 micron thickness and a horizontal velocity of $0.5 \mathrm{~m} / \mathrm{s}$,

while the heater heat flux was held fixed at $150 \mathrm{~kW} / \mathrm{m}^{2}$. The nozzle spacing for these runs was set equal to $0.013 \mathrm{~m}$ as shown in Table 6.2. It was found that by increasing the spray mass flow rate the maximum wall temperature increase is less. The Nusselt number profile is plotted in Figure 6.38 for the same simulation. The maximum difference in temperature as function of spray mass flow rate is shown in Figure 6.39. It was found that the cooling is higher for higher spray mass flow rates. 


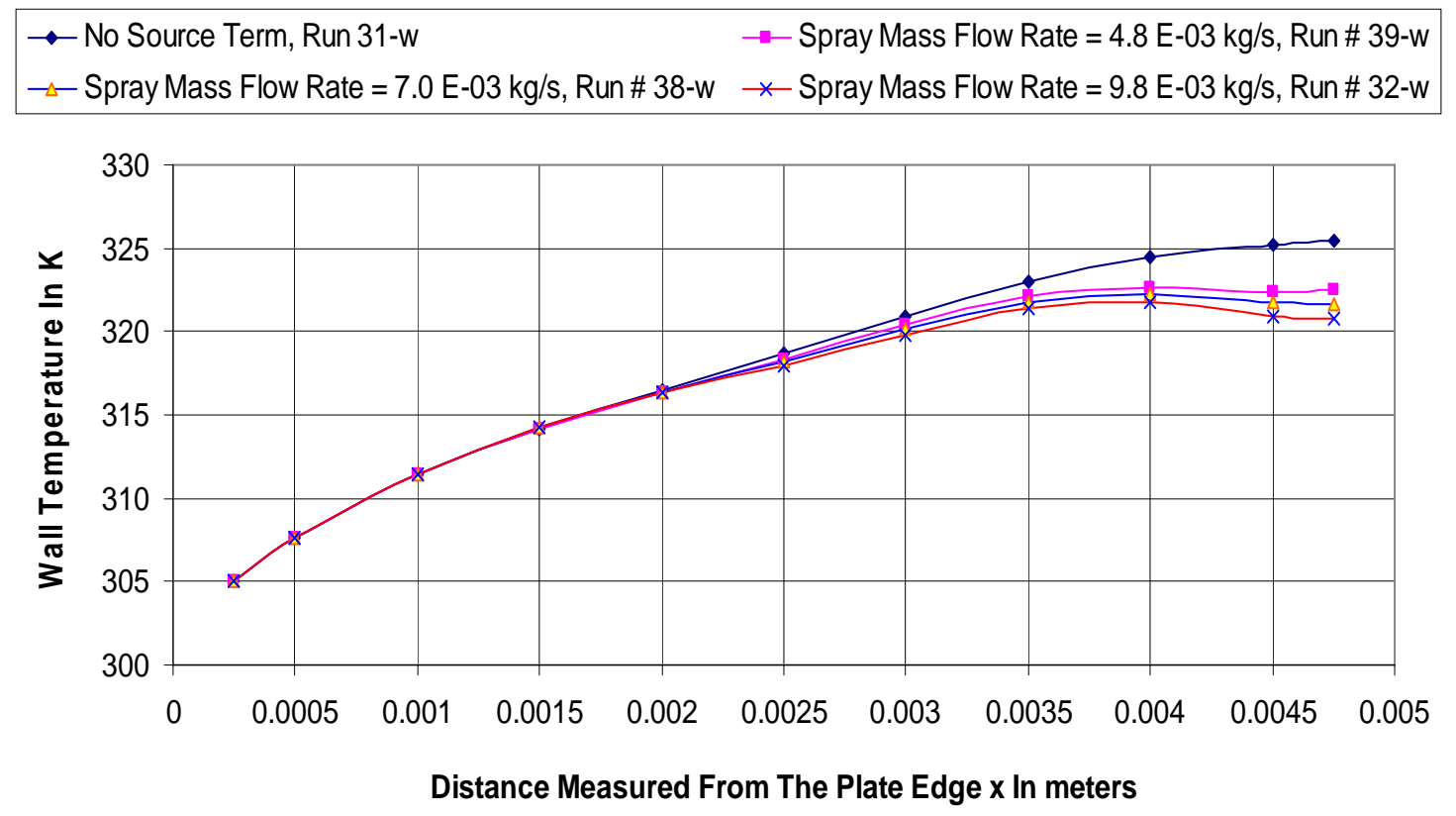

Figure 6.37 Effect of Spray Mass Flow Rate on Wall Temperature Profile (Water, $d=200$ microns, $U=0.5 \mathrm{~m} / \mathrm{s}, q^{\prime \prime}=150 \mathrm{~kW} / \mathrm{m}^{2}$ ).

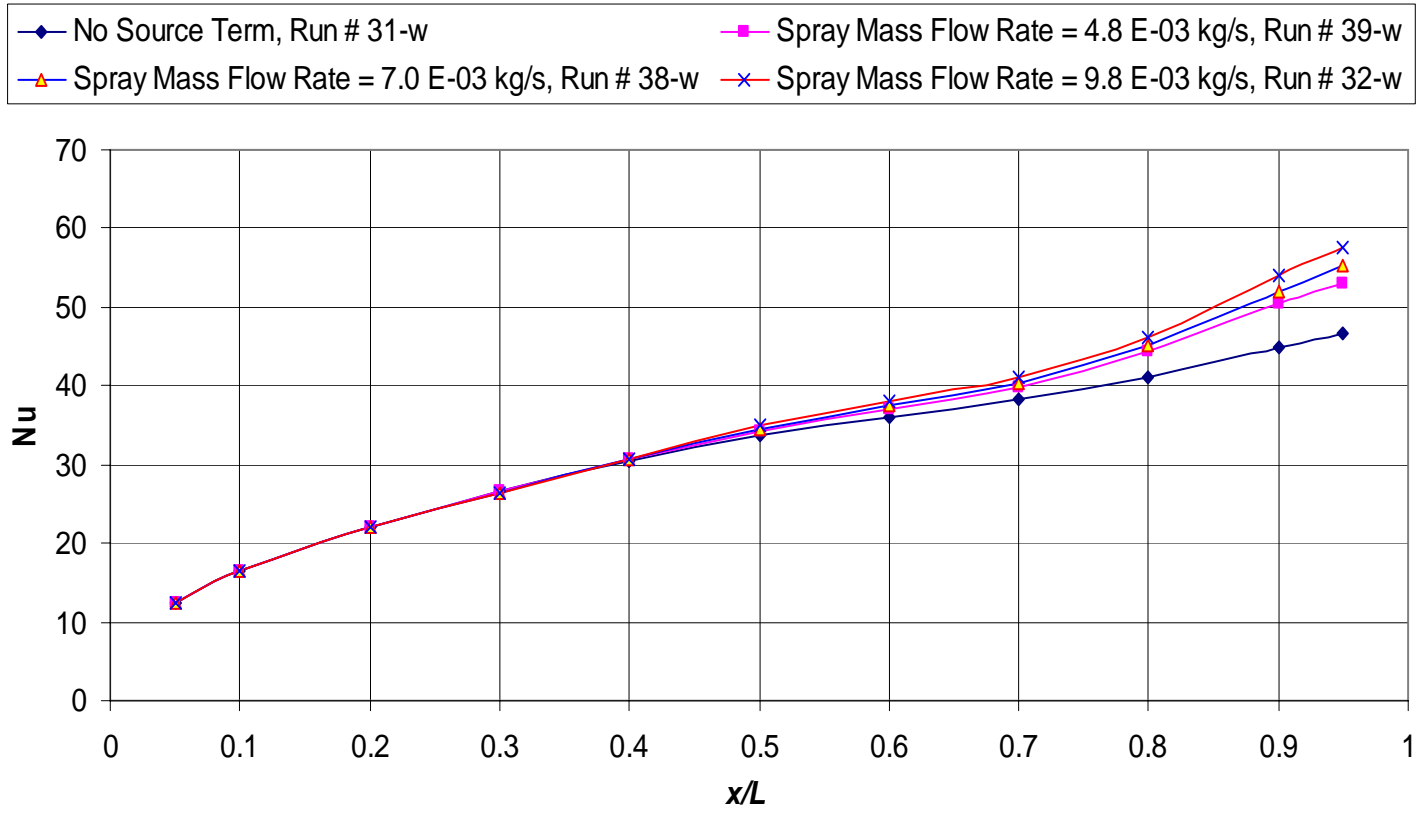

Figure 6.38 Effect of Spray Mass Flow Rate on Nusselt Number (Water, $d=200$ microns, $U=0.5 \mathrm{~m} / \mathrm{s}, q^{\prime \prime}=150 \mathrm{~kW} / \mathrm{m}^{2}$ ). 


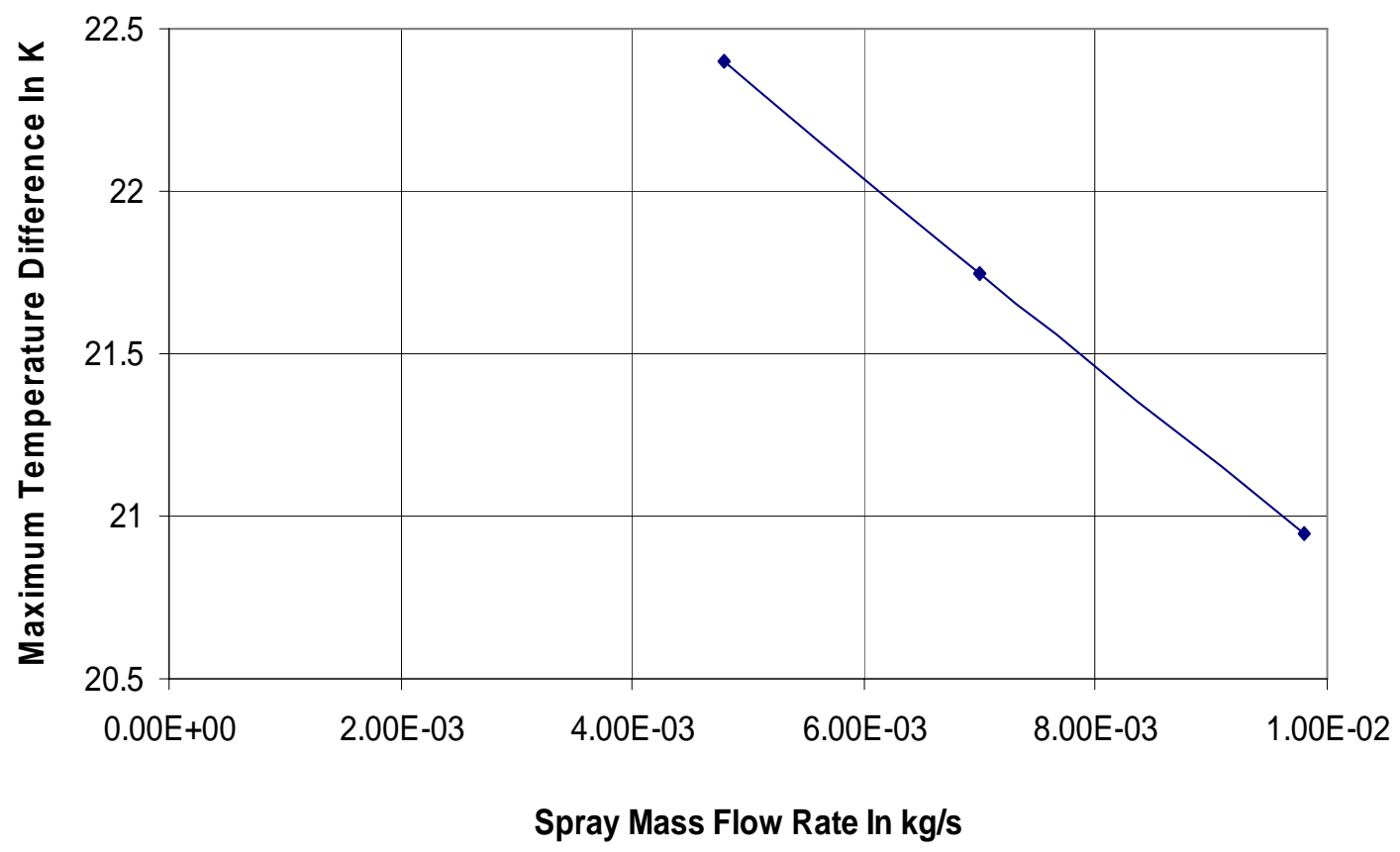

Figure 6.39 Effect of Spray Mass Flow Rate on Maximum Temperature Difference (Water, $\boldsymbol{d}=200$ microns, $U=0.5 \mathrm{~m} / \mathrm{s}, q^{\prime \prime}=150 \mathrm{~kW} / \mathrm{m}^{2}$ ).

By decreasing the layer thickness to 100 microns the heat transfer was improved. The effect of the spray mass flow rate on the wall temperature profile and Nusselt number for this layer thickness is plotted in Figures 6.40 and 6.41 respectively. The maximum difference in temperature as function of spray mass flow rate is shown in Figure 6.42. In these figures the cooling again was higher for higher spray mass flow rates. 


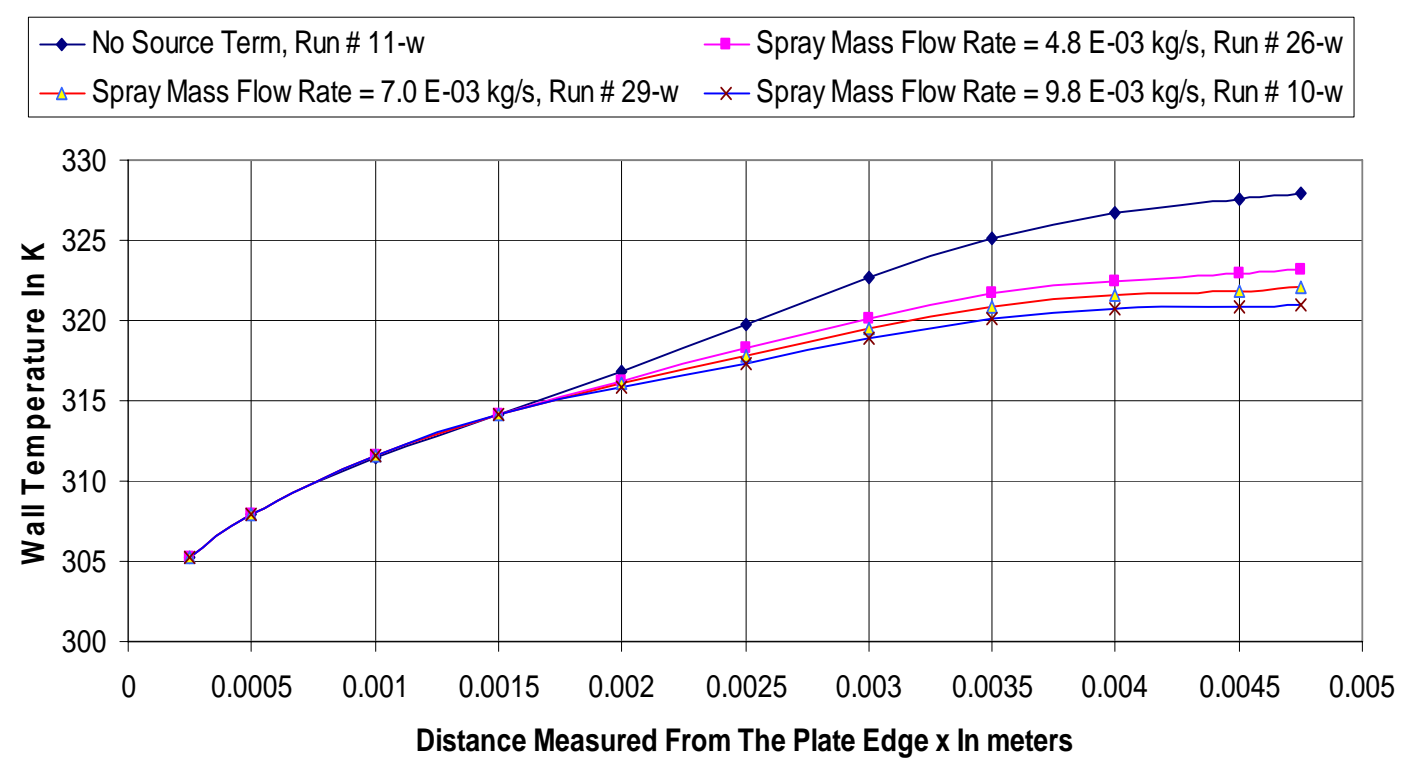

Figure 6.40 Effect of Spray Mass Flow Rate on Wall Temperature Profile (Water, $d=100$ microns, $U=0.5 \mathrm{~m} / \mathrm{s}, q^{\prime \prime}=150 \mathrm{~kW} / \mathrm{m}^{2}$ ).

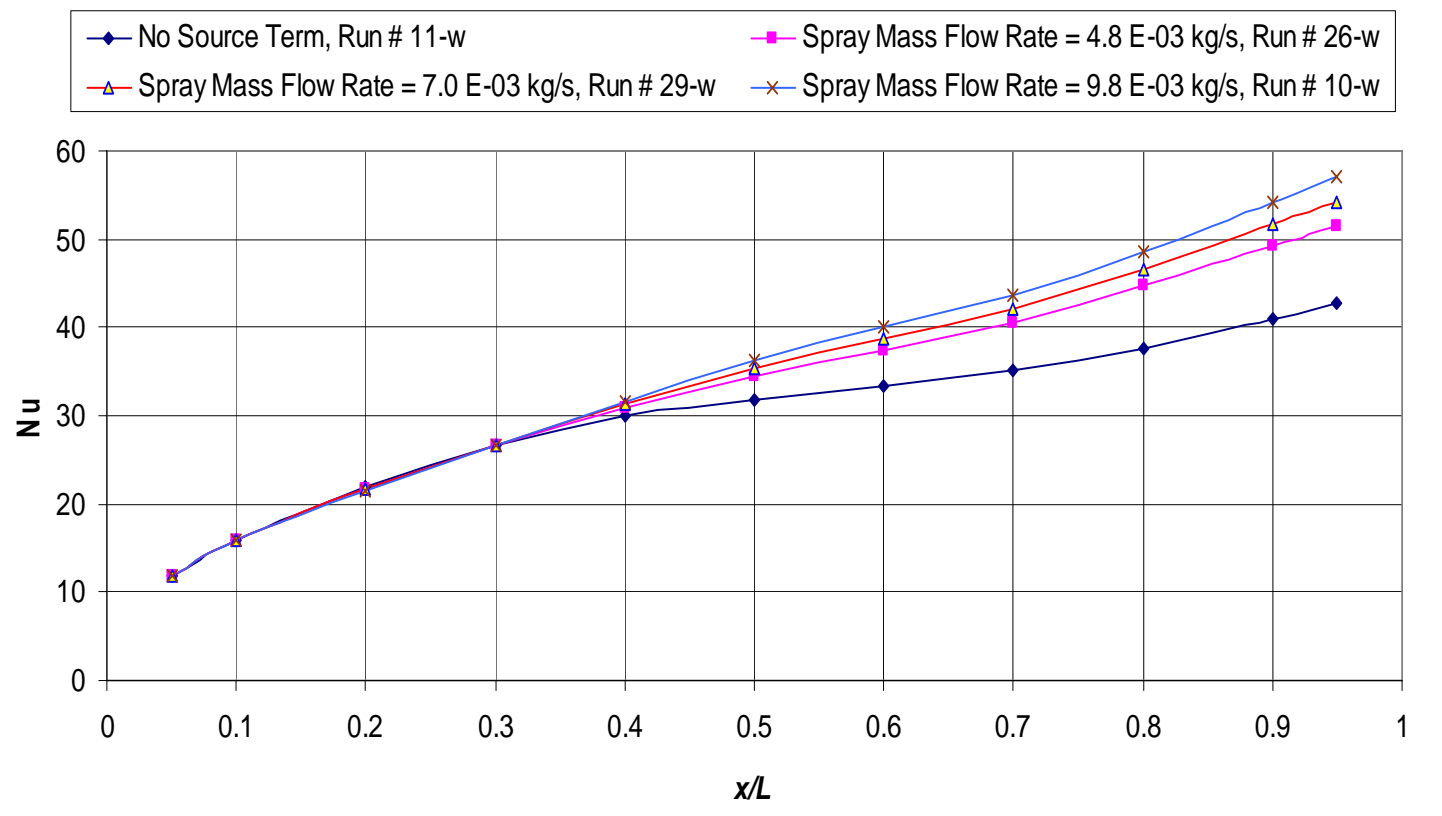

Figure 6.41 Effect of Spray Mass Flow Rate on Nusselt Number (Water, $d=100$ microns, $U=0.5 \mathrm{~m} / \mathrm{s}, q^{\prime \prime}=150 \mathrm{~kW} / \mathrm{m}^{2}$ ). 


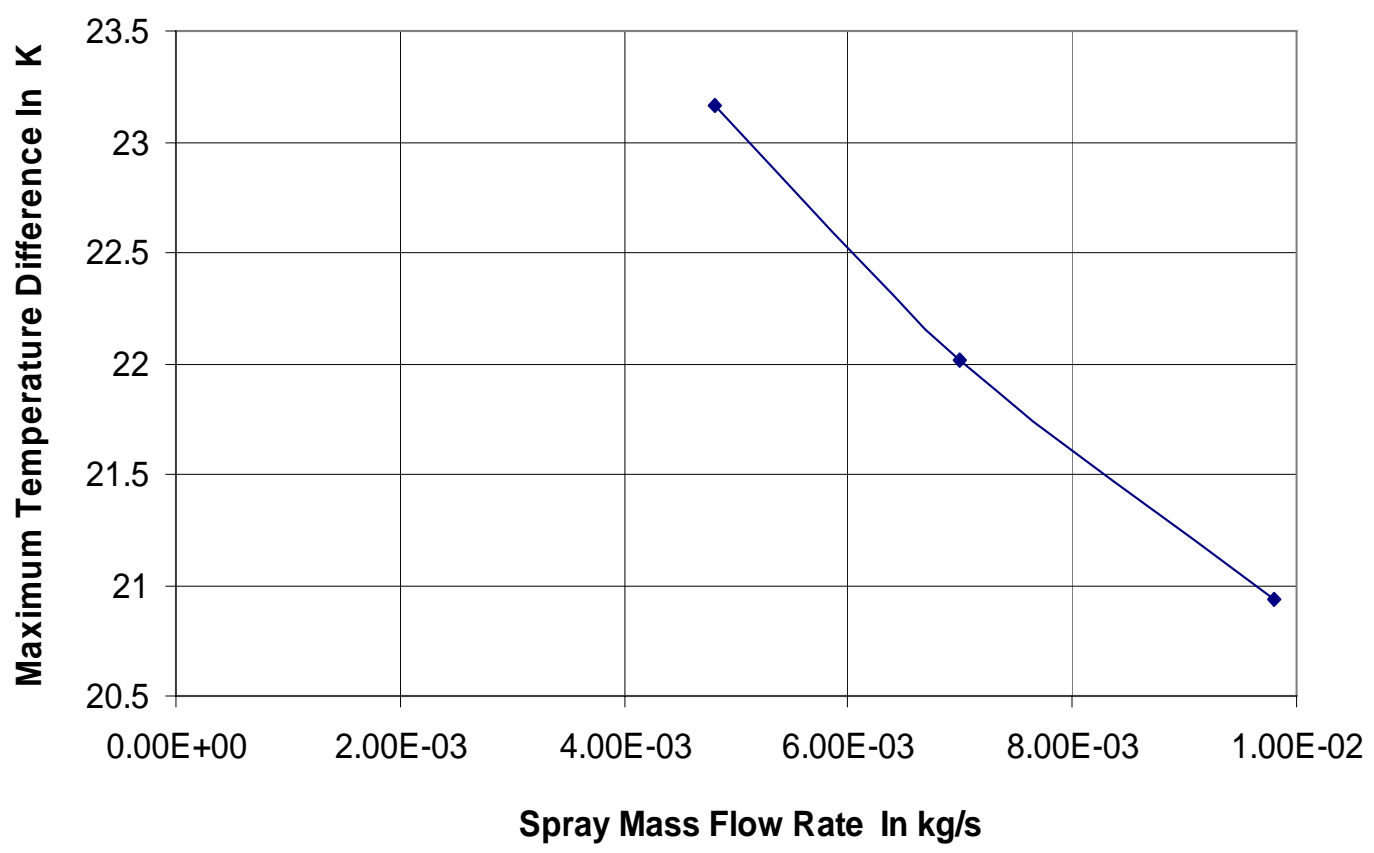

Figure 6.42 Effect of Spray Mass Flow Rate on Maximum Temperature Difference (Water, $d=100$ microns, $U=0.5 \mathrm{~m} / \mathrm{s}, q^{\prime \prime}=150 \mathrm{~kW} / \mathrm{m}^{2}$ ).

Figure 6.43 shows the computed effect of the spray mass flow rate on the wall temperature profile using FC-72 as working fluid for a 100 micron layer thickness and an inlet velocity of $0.5 \mathrm{~m} / \mathrm{s}$, where the heat flux is $25 \mathrm{~kW} / \mathrm{m}^{2}$. The Nusselt number profile is shown in Figure 6.44 for the same simulations. The same trends were observed as before. The maximum difference in temperature as function of spray mass flow rate is shown in Figure 6.45. It was found that the cooling increases by increasing the spray mass flow rate. 


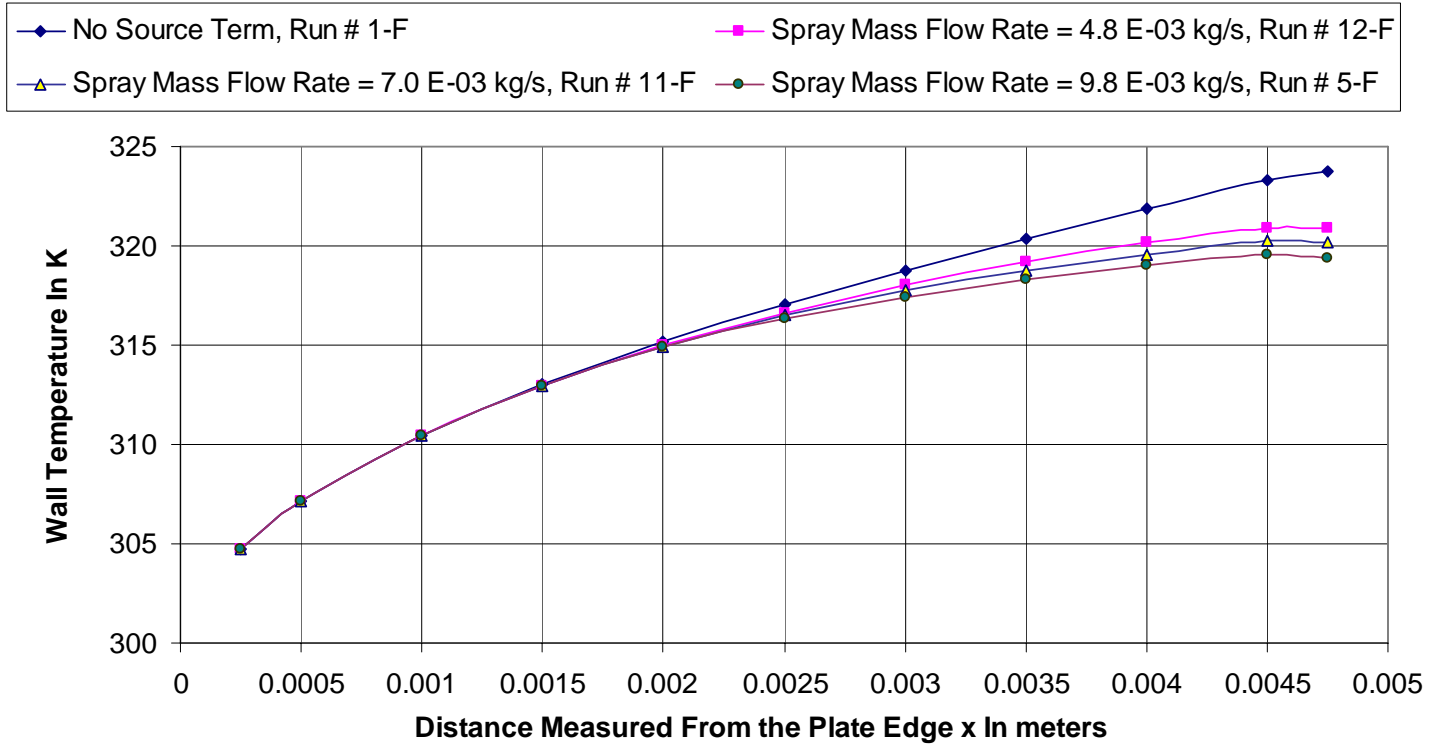

Figure 6.43 Effect of Spray Mass Flow Rate on Wall Temperature Profile (FC-72, $d=100$ microns, $U=0.5 \mathrm{~m} / \mathrm{s}, q^{\prime \prime}=25 \mathrm{~kW} / \mathrm{m}^{2}$ ).

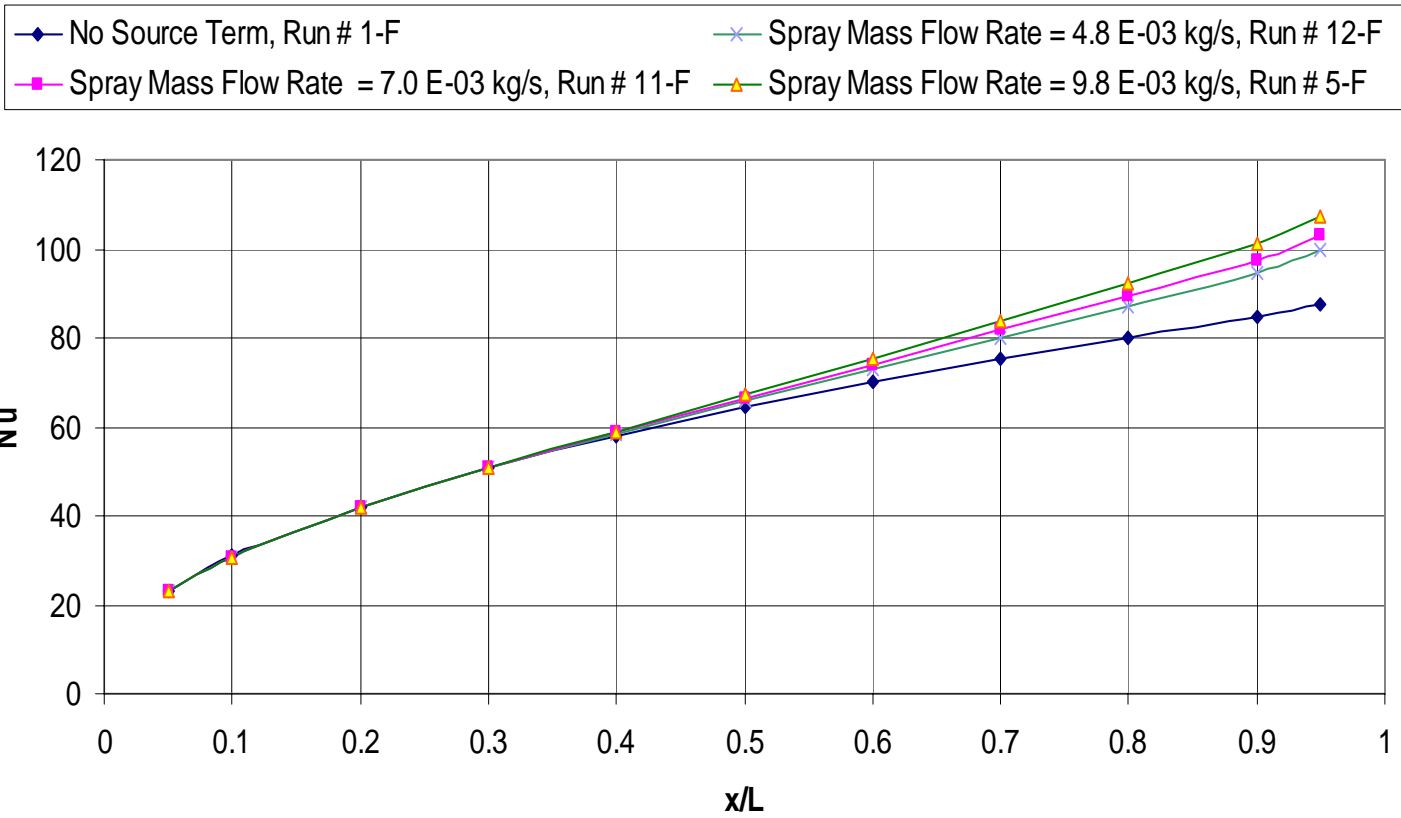

Figure 6.44 Effect of Spray Mass Flow Rate on Nusselt Number (FC-72, $d=100$ microns, $U=0.5 \mathrm{~m} / \mathrm{s}, q^{\prime \prime}=25 \mathrm{~kW} / \mathrm{m}^{2}$ ). 


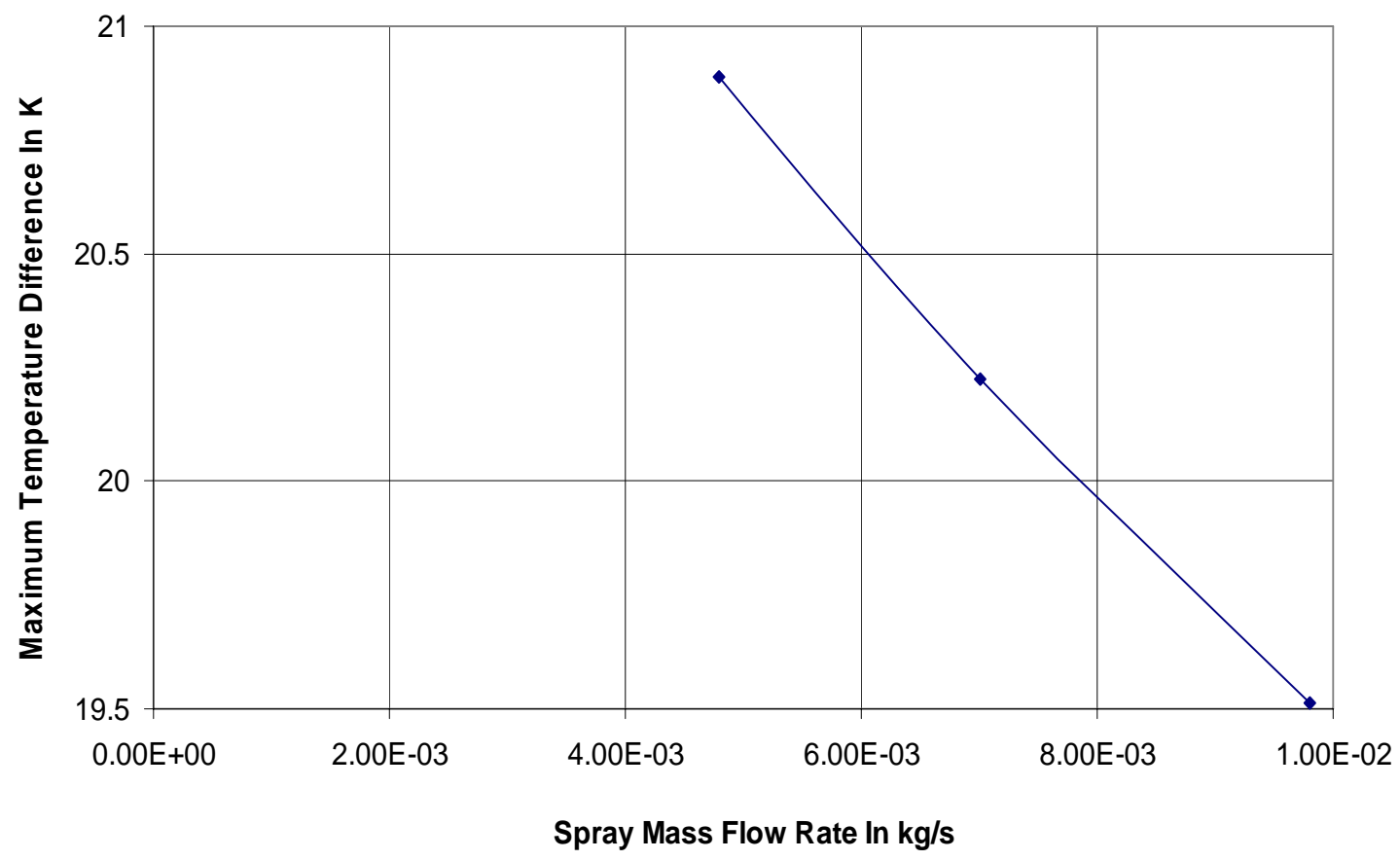

\section{Figure 6.45 Effect of Spray Mass Flow Rate on Maximum Temperature Difference (FC-72, $d=100$ microns, $U=0.5 \mathrm{~m} / \mathrm{s}, q^{\prime \prime}=25 \mathrm{~kW} / \mathrm{m}^{2}$ ).}

From the above simulations it was found that the cooling efficiency improved as the spray mass flow rate was increased for water and FC-72. However, the magnitude of the maximum wall temperature increase was not the same for different fluids. These results agree with the experimental results. Kim et al. [37], found that the spray cooling heat transfer that interferes with the liquid film flow is significantly enhanced as the spray droplet amount increases. Rybicki and Mudawar [33], concluded that the volumetric flux is a key hydrodynamic parameter that influences spray cooling performance for both single phase and two-phase flow. Toda [24], and Monde [34], as reported by [33], both found that the cooling performance is enhanced by increasing the spray volumetric flux, while Kim [36] found that the heat transfer increases with increasing spray flow rate. 


\subsubsection{Effect of Adding Mass and Momentum Source Terms on Liquid Layer Thickness and Velocity.}

The 100 micron initial layer thickness with water as working fluid was selected to demonstrate the effect of the source terms on the liquid layer thickness and the liquid layer surface velocity. The reason for this is that an observable difference was found as a result of adding the source term incomparison with 200 micron layer thickness .The same trends were found with other working fluids. The wall heat flux was set equal to 150 $\mathrm{kW} / \mathrm{m}^{2}$ and the initial liquid layer velocity was $0.5 \mathrm{~m} / \mathrm{s}$.

The effect of the spray velocity, nozzle spacing and spray mass flow rate on the liquid layer thickness and surface velocity were investigated. It was found that by increasing the spray velocity the layer thickness decreases for $x / l>0.4$, which is expected, as shown in Figure 6.46. It was found also that the layer surface velocity is increased by increasing the spray velocity as shown in Figure 6.47.

The second parameter which was investigated was the effect of the nozzle spacing on the liquid layer thickness and surface velocity. The liquid layer thickness was found to be lower for smaller nozzle spacing for $x / l>0.4$. As nozzle spacing decreased from $0.013 \mathrm{~m}$ to $0.01 \mathrm{~m}$ the layer thickness decreased as shown in Figure 6.48. It was also found that the layer surface velocity is increased by decreasing the nozzle spacing as shown in Figure 6.49.

The third parameter which was investigated was the effect of the spray mass flow rate on the liquid layer thickness and surface velocity. As the spray mass flow rate increased from $4.8 \mathrm{E}-03 \mathrm{~kg} / \mathrm{m}^{3}$ to $9.8 \mathrm{E}-03 \mathrm{~kg} / \mathrm{m}^{3}$ the layer thickness decreases for $x / l>0.4$ as shown in Figure 6.50. It was also found that by increasing the spray mass flow rate the layer surface velocity is increased as shown in Figure 6.51. 


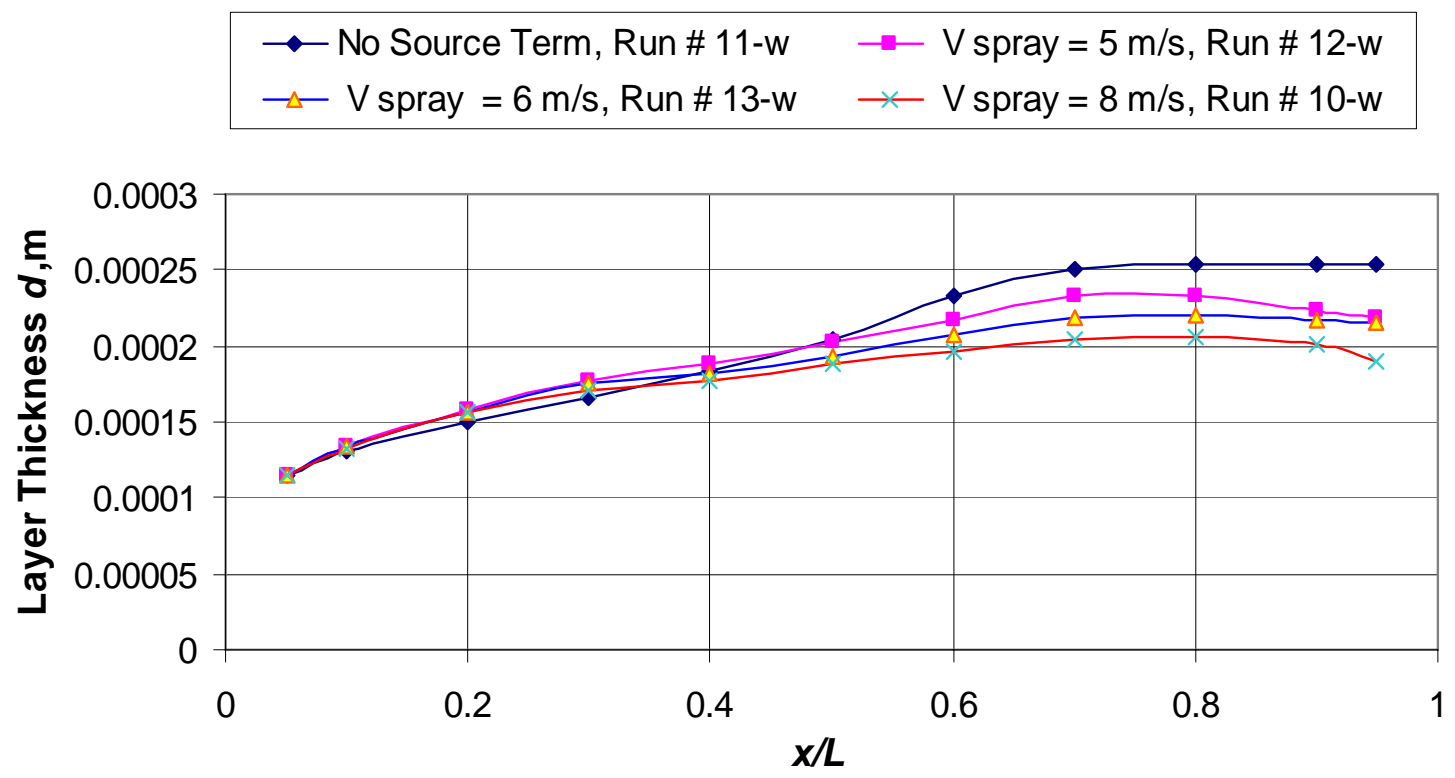

Figure 6.46 Effect of Spray Velocity on Layer Thickness (Water, $d=100$ microns, $U=0.5 \mathrm{~m} / \mathrm{s}, q^{\prime \prime}=150 \mathrm{~kW} / \mathrm{m}^{2}$ ).
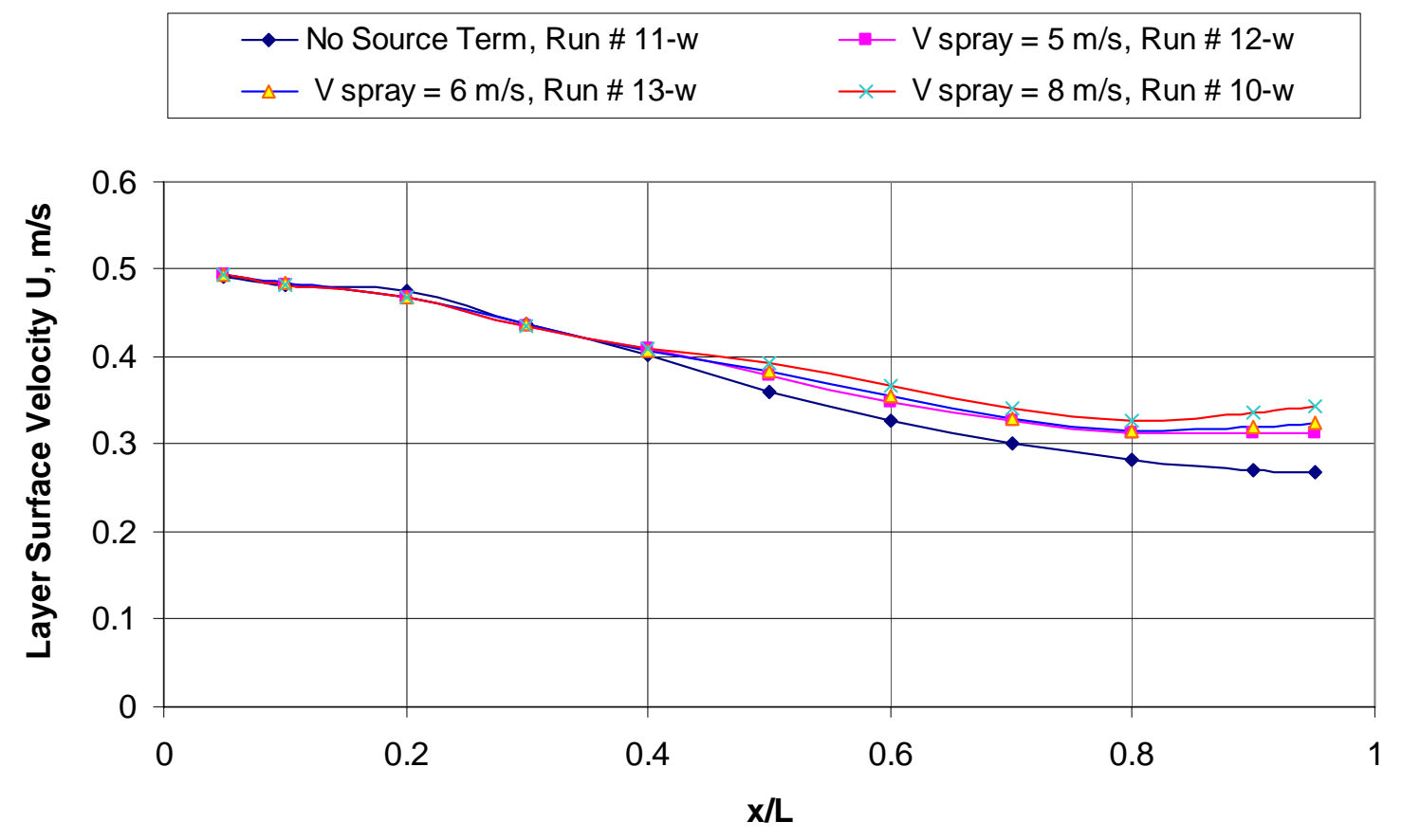

Figure 6.47 Effect of Spray Velocity on Layer Surface Velocity (Water, $d=100$ microns, $U=0.5 \mathrm{~m} / \mathrm{s}, q^{\prime \prime}=150 \mathrm{~kW} / \mathrm{m}^{2}$ ). 


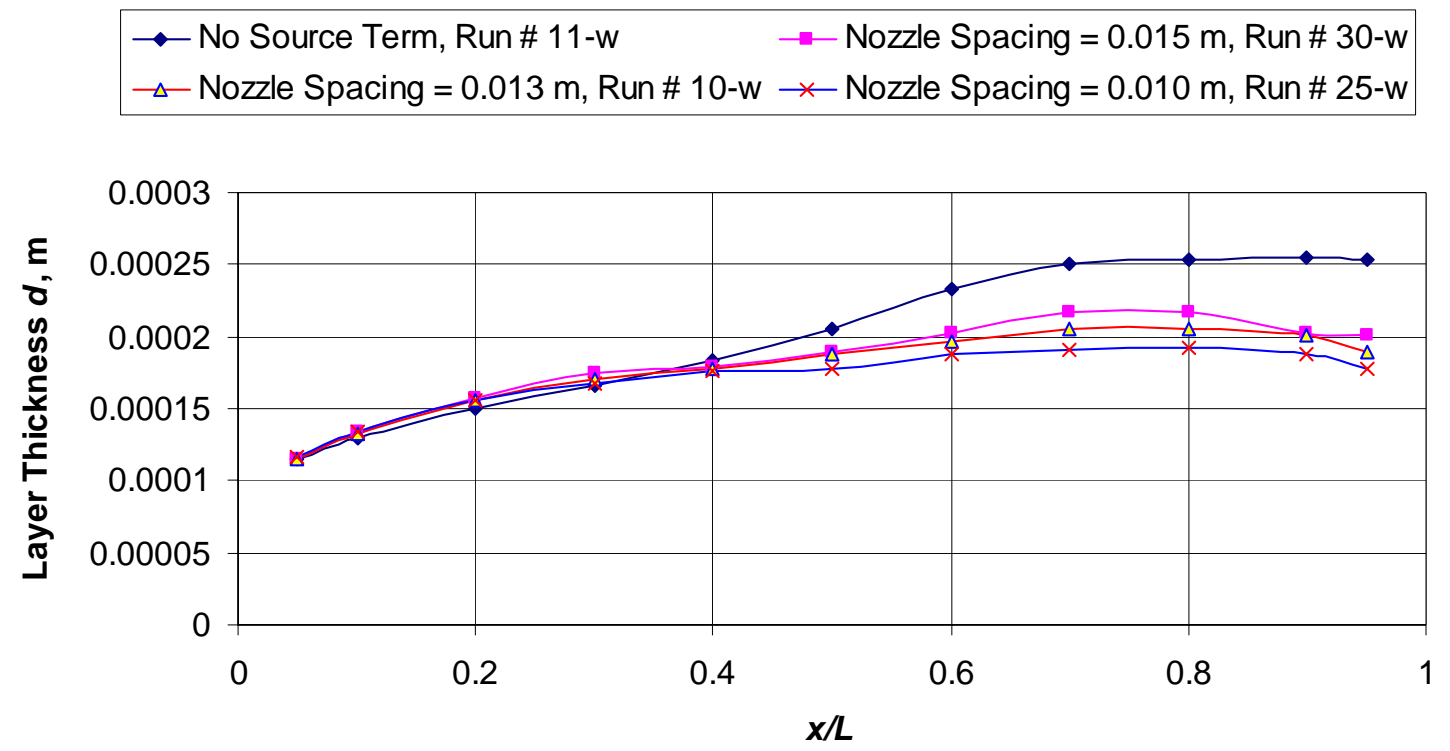

Figure 6.48 Effect of Nozzle Spacing on Layer Thickness (Water, $\boldsymbol{d}=100$ microns, $U=0.5 \mathrm{~m} / \mathrm{s}, q^{\prime \prime}=150 \mathrm{~kW} / \mathrm{m}^{2}$ ).

$\rightarrow-$ No Source Term, Run \# 11-w $\quad \rightarrow$ Nozzle Spacing $=0.015 \mathrm{~m}$, Run \# 30-w
$\triangle-$ Nozzle Spacing $=0.013 \mathrm{~m}$, Run \# 10-w $\rightarrow$ Nozzle Spacing $=0.010 \mathrm{~m}$, Run \# 25-w

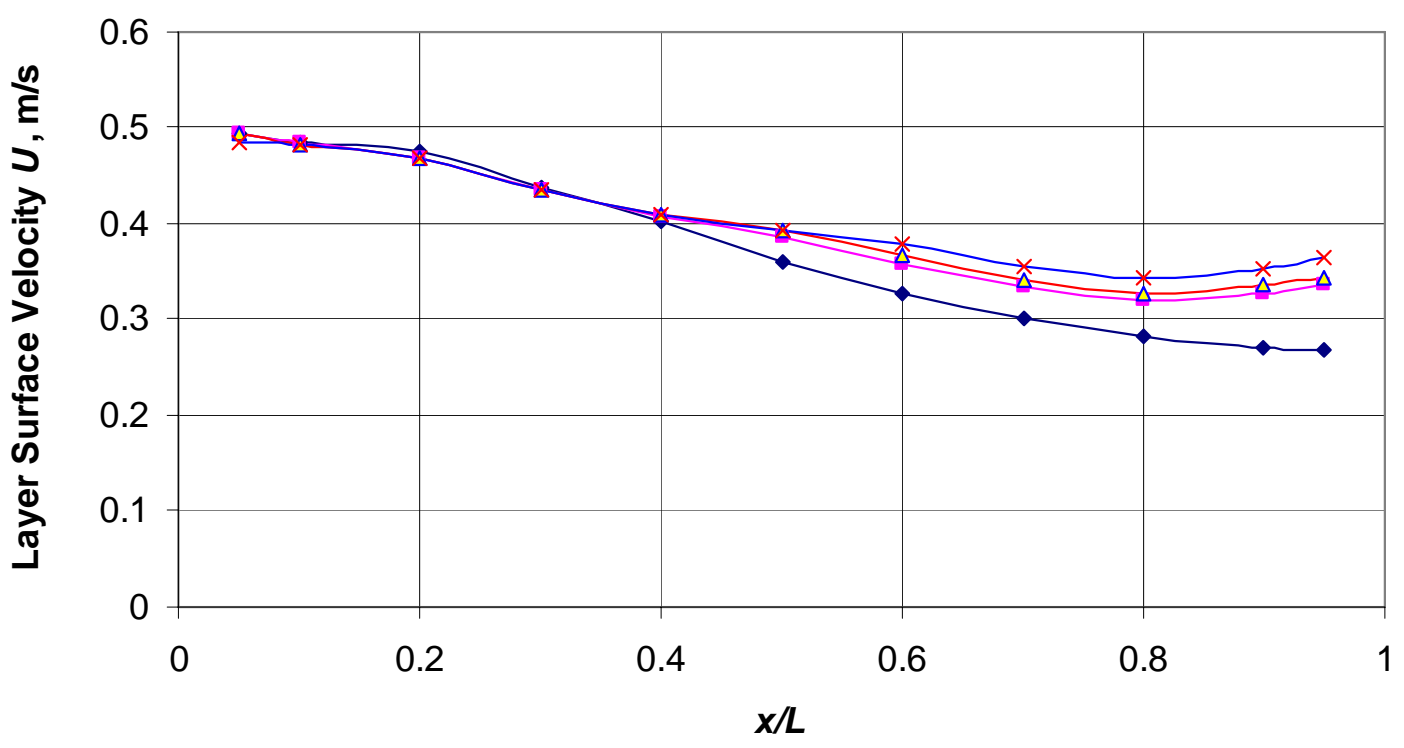

Figure 6.49 Effect of Nozzle Spacing on Layer Surface Velocity (Water, $\boldsymbol{d}=100$ microns, $U=0.5 \mathrm{~m} / \mathrm{s}, q^{\prime \prime}=150 \mathrm{~kW} / \mathrm{m}^{2}$ ). 


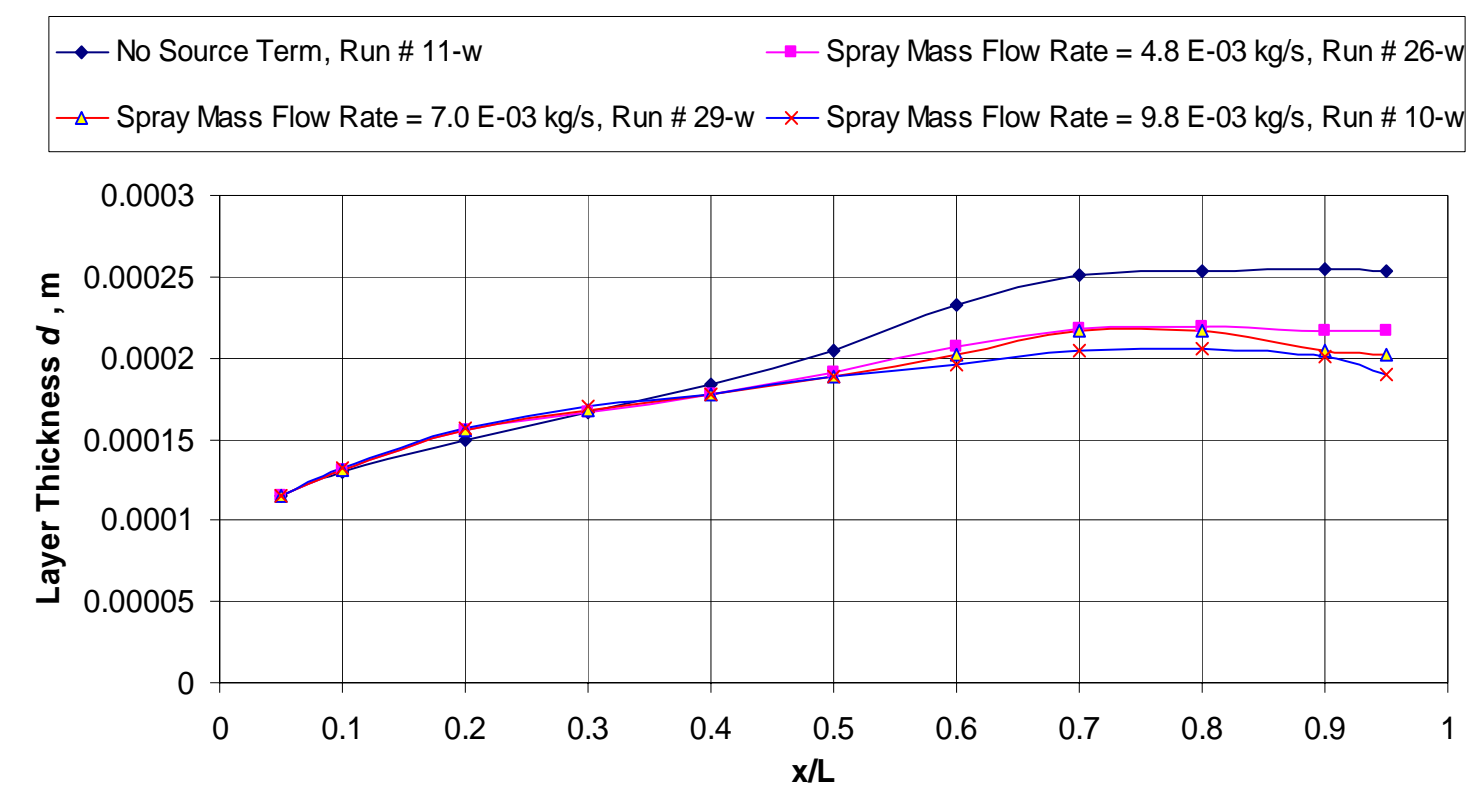

Figure 6.50 Effect of Spray Mass Flow Rate on Layer Thickness (Water, $\boldsymbol{d}=100$ microns, $U=0.5 \mathrm{~m} / \mathrm{s}, q^{\prime \prime}=150 \mathrm{~kW} / \mathrm{m}^{2}$ ).

$\rightarrow-$ No Source Term, Run \# 11-w $\rightarrow$ Spray Mass Flow Rate $=4.8$ E-03 kg/s, Run \# 26-w
$\rightarrow-$ Spray Mass Flow Rate $=7.0$ E-03 kg/s, Run \# 29-w $\rightarrow$ Spray Mass Flow Rate $=9.8$ E-03 kg/s, Run \# 10-w

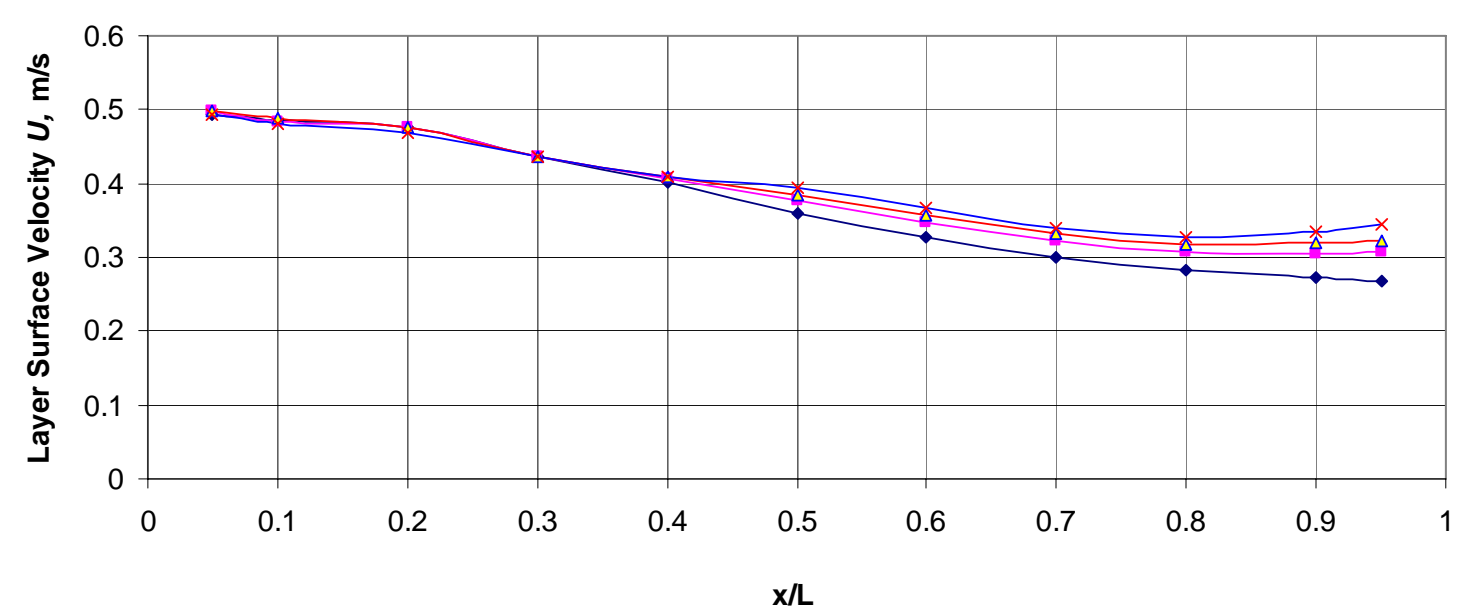

Figure 6.51 Effect of Spray Mass Flow Rate on Layer Surface Velocity (Water, $d=100$ microns, $U=0.5 \mathrm{~m} / \mathrm{s}, q^{\prime \prime}=150 \mathrm{~kW} / \mathrm{m}^{2}$ ). 


\section{Chapter 7}

\section{Conclusions and Recommendations for Future Work}

\subsection{Summary and Conclusions}

The objective of this dissertation was to study spray cooling using a commercial multiphysics numerical model and how to improve its efficiency. However, from the literature survey it was found that spray cooling is very complex. It was found that as a result of spray impinging on a wall a liquid layer is formed. Numerically it was not possible to study the spray and the liquid layer together. So, a new technique was developed in which one can model the effect of the spray on the liquid layer. This was done by adding the spray mass and momentum as source terms to the liquid layer. The commercial code CFD-ACE+ was used in this study. CFD-ACE+ allows one to change the main code through using user subroutines which run as part of the code. This was done by developing a series of user subroutines for mass and momentum source terms.

The first step in any numerical simulation is to have a grid independent solution. So, a grid dependency study was made to see what should be the best grid resolution without excessive simulation time due to a finer grid.

The second step was to validate the code before using it in the simulations. Because the focus in this study was the heat transfer to the liquid layer, it was necessary to validate the modules used in this study. So, the Flow, Heat transfer and Volume of Fluid modules of CFD-ACE+ were each validated. The Flow module was validated by comparing the numerical solution with the Blasius solution. The results were found to be within a reasonable difference.

The Heat module was validated by comparing the simulation results of a laminar flow moving parallel to heated flat plate with the integral solution for laminar boundary 
layer as shown in Bejan [46]. Two different cases were validated; in one of them air was used as working fluid and in the other one water was used as working fluid. It was found that the numerical solution had the same trends as the integral solution. However a shift was found between the two solutions. The reason is that the numerical solution is not 100 $\%$ accurate; also the integral solution is not the exact solution.

The third module which was validated is the VOF module. This was done through using the mass source term subroutine. The test case was the addition of mass at a constant rate to a tank containing fluid and calculating what should be the total mass after a certain period of time. The numerical results were compared with the calculation and it was found to be the same.

For the main study a two dimensional planar model has been built which consists of three volume conditions. The two bottom volume conditions represent the liquid layer which was given a uniform initial velocity. The upper volume condition contains the air which was given the same uniform initial velocity as the liquid layer in the horizontal direction. The spray mass and momentum source terms were added to the middle volume condition, which represents the upper surface of the liquid layer. The source term was a function of the drop trajectory angle. Both the mass and momentum source terms were varied as functions of the cell location in the upper liquid layer.

The literature survey revealed many contradictions about which parameters contribute to the cooling efficiency. It was difficult experimentally to change one parameter at a time and fix all other parameters. However, with this numerical model it was possible to change one parameter at a time and fix all other parameters. The spray velocity, nozzle spacing and the spray mass flow rate were among the parameters which were independently studied. Four working fluids were used in this study. Three of them are among the most efficient cooling fluids: water, FC-72 and HFE-7000. The fourth working fluid was a hypothetical fluid having same properties as FC-72 except for a higher boiling temperature. Different values for the horizontal velocity of the liquid layer were tested to see which one would give the best cooling. Different values for the layer 
horizontal velocity were tested. However only two values were considered which were the most efficient, these two were 0.5 and $1.0 \mathrm{~m} / \mathrm{s}$. Values of the layer thickness were varied from 50 to 500 microns. However, from the literature survey it was found that the layer thickness is expected to be between 100 and 200 microns, which were used in this study. The focus in this study was on single phase heat transfer cooling; because of this the heater heat flux was selected in such a way that no phase changes occurred. These values were varied from 10 to $150 \mathrm{~kW} / \mathrm{m}^{2}$. The model was built such that the spray covered the heater surface completely regardless of the nozzle position which was varied vertically between 0.01 to $0.015 \mathrm{~m}$. The spray velocities were varied between 5 to $9 \mathrm{~m} / \mathrm{s}$ and the spray mass flow rate was varied between 4.8 E-03 to 9.8 E-03 kg/s.

It was found from the numerical simulations that the cooling is improved by increasing the spray velocity. The reason for this was due to the increase in the momentum of the liquid layer imparted by the spray. It is obvious that the momentum should increase by increasing the spray velocity. It was also found from the numerical simulations that the cooling improves by decreasing the distance between the nozzle and the heater surface. This was also due to the increase in the momentum. The third parameter which was studied was the spray mass flow rate; it was found that increasing the spray mass flow rate improves the heat transfer. This was also clear because the mass of the spray was added as a source term into the continuity and momentum equations of the liquid layer. It is known that increasing the mass will result an increase in the momentum and consequently increase the heat transfer.

As was mentioned earlier in this chapter there often were contradictions in the experimental results regarding the parameters which control the spray cooling performance. This study resolves most of these contradictions, at least for the singlephase cases. For example, it was found numerically that the spray cooling is improved by decreasing the nozzle spacing, while experimentally their were two opinions: one agreeing with the numerical results and the other not. So the answer is that by decreasing the nozzle spacing the cooling efficiency is increased. One reason to explain the anomalous experimental results is the difficulty in controlling one parameter without 
changing others. The other reason is that due to the small scale of the physics involved in this application it is difficult to obtain very accurate results experimentally, which means very small layer thickness and heater surface area. The same explanation should work with other parameters.

\subsection{Recommendations for Future Work}

A two dimensional model was used in this study, but for more realistic results and for better comparison with the experimental results a three dimensional model is needed to simulate the spray cooling. Using a single processor it will be very difficult to achieve this goal, so a parallel computation is needed using more than one processor.

This study focused on single-phase spray cooling, however, some practical applications of spray cooling involve phase change. So the next step will be studying this phenomenon with phase change which will require the chemistry module of CFD-ACE+ to be used using the same code.

The effect of the gravity force on the cooling efficiency may be studied by using different values for the gravity force.

The heater was assumed to have a constant heat flux. The case of an isothermal heater surface should also be investigated. 


\section{References}

[1] Website, www.pitek.us.

[2] Website, www.lps.umd.edu, Laboratory for Physical Sciences, University of Maryland.

[3] Website, www.meecc.com, G. Pautsch, "Thermal Challenges in the Next Generation of Supercomputers,” CoolCon, May 17, 2005.

[4] Website, www.valcompanies.com, VAL-CO USA \& CANADA.

[5] K. Oliphant, B.W. Webb, M.Q. McQuay, “An experimental comparison of liquid jet array and spray impingement cooling in the non-boiling regime,” Experimental Thermal and Fluid Science, 18, 1-10,1998.

[6] R. H. Pereira, S. L. Barga, J. A. R. Parise, “Comparing single phase heat transfer to arrays of impinging jets and sprays,” in: Proceedings of IMECE2002, New Orleans, LA, USA, Paper IMECE2002-32531, 2002.

[7] L. Lin, R. Ponnappan, "Heat transfer characteristics of spray cooling in a closed loop,” International Journal of Heat and Mass Transfer, 46, 20, 3737-3746, 2003.

[8] A. G. Pautsch, T.A. Shedd, "Spray Impingement Cooling with Single- and MultipleNozzle Arrays Part I: Heat Transfer Data Using FC-72,” International Journal of Heat and Mass Transfer, 48 31675-3175, 2005.

[9] K. A. Estes, I. Mudawar, “Comparison of two-phase electronic cooling using free jets and sprays,” Transactions of the ASME-Journal of Electronic Packaging, 117, 323-332, 1995. 
[10] L. Lin, R. Ponnappan, K. Yerkes, B. Hager, "Large area spray cooling," in: 42nd AIAA Aerospace Sciences Meeting and Exhibit, Reno, Nevada, U.S.A., pp. 1083810843, 2004.

[11] B. Horacek, K. T. Kiger, J. Kim, "Single nozzle spray cooling heat transfer mechanisms,” International Journal of Heat and Mass Transfer, 48, 1425-1438, 2005.

[12] M. R. Pais, L. C. Chow, E. T. Mahefkey, "Surface roughness and its effect on the heat transfer mechanism in spray cooling,” J. Heat Transfer, 114,211-219, 1992.

[13] D. P. Rini, R. H. Chen, L. C. Chow, "Bubble behavior and nucleate boiling heat transfer in saturated FC-72 spray cooling,” J. Heat Transfer, 124, 1, 63-72, 2002.

[14] J. Yang, L. C. Chow, M. R. Pais, “Nucleate boiling heat transfer in spray cooling,” J. Heat Transfer, 118 , 668- 671,1996.

[15] A. G. Pautsch, "Heat Transfer and Film Thickness Characteristics of Spray Cooling with Phase Change," Master of Science, Mechanical Engineering, University of Wisconsin-Madison, 2004.

[16] K. A. Estes, I. Mudawar, "Correlation of Sauter mean diameter and critical heat flux for spray cooling of small surfaces,” Int. J. Heat Mass Transfer, Vol. 38, No. 16, pp. 2985-2996, 1995.

[17] C.O. Peterson, "An experimental study of the dynamic behavior and heat transfer characteristic of water impinging upon a heated surface," International Journal of Heat and Mass Transfer, Vol. 13, pp.369-381, 1970.

[18] M. Fabbri, S. Jiang, V. K Dhir., "Experimental investigation of a micro jets - based cooling package for electronic applications," Proceeding of $12^{\text {th }}$ International Heat Transfer Conference, Grenoble, France, August 2002. 
[19] C. Bonacina, S. Del Giudice, G. Comini, “Dropwise evaporation,” ASME Journal of Heat Transfer, Vol. 101, pp.441-446, 1979.

[20] G. P. Celata, M. Cumo, C. Lombardo, A. Mariani, L. Saraceno, “Experimental result on rewetting of hot surfaces by droplet impingement,” Experimental Thermal and Fluid Science, 29, 275-285, 2005.

[21] C. Bonacina, G. Comini, S. Del Giudice, "Evaporation of atomized liquids on hot surfaces,” Letters in Heat and Mass Transfer, 2, 401, 1975.

[22] Y. C. Kim, S. Nishio, H. Ohkubo, "Heat transfer in a high temperature region of spray cooling interacting with liquid film flow,” Heat Transfer-Japanese Research, 26, 4, 1997.

[23] R-H. Chen , L. C. Chow, J. E. Navedo, "Effects of spray characteristics on critical heat flux in subcooled water spray cooling,” International Journal of Heat and Mass Transfer, 45, 4033-4043, 2002.

[24] S. Toda, “A study of mist cooling, 1st report: investigation of mist cooling," Heat Transfer - Jpn. Res., 1, 39-50, 1972.

[25] K. A. Estes, I. Mudawar, “Correlation of Sauter mean diameter and critical heat flux for spray cooling of small surfaces,” Int. J. Heat Mass Transfer, 38, 2985-2996, 1995.

[26] M. S. Sehmbey, L. C. Chow, O. J. Hahn, M. R. Pais, "Spray cooling of power electronics at cryogenic temperatures,” AIAA J. Thermophys. Heat Transfer, 9, 123-128, 1995. 
[27] S-S. Hsieh, T-C. Fan, H-H. Tsai, "Spray cooling characteristics of water and R-134a.

Part I: nucleate boiling,” International Journal of Heat and Mass Transfer, 47, 57035712, 2004.

[28] K. J. Choi, S. C. Yao, "Mechanism of film boiling heat transfer of normally impacting spray,” International Journal of Heat and Mass Transfer, 30, 311-318, 1987.

[29] K. Yoshida,Y. Abe, T. Oka, Y.H. Mori, A. Nagashima, "Spray cooling under reduced gravity condition,” ASME J. Heat Transfer, 123, 309-318, 2001.

[30] B. Horacek. J. Kim, K. T. Kiger, "Spray cooling using multiple nozzles: Visualization and wall heat transfer measurements," in: S. Gopalakrishnan, R. M. Manglik, J. Plawsky (Eds.), Proceedings of 2004 ASME Heat Transfer/ Fluids Engineering Summer Conference, Charlotte, North Carolina, U.S.A, Paper 56163, 2004.

[31] L. C. Chow, M. S. Sehmbey, M. R. Pais, “High-heat-flux spray cooling,” Ann. Rev. Heat Transfer, 8, pp. 291-318, 1997.

[32] K. A. Estes , I. Mudawar, "Comparison of two-phase electronic cooling using free jets and sprays,” J. Electron. Packag., vol. 117, pp. 323-332, 1995.

[33] J. R. Rybicki, I. Mudawar, "Single-phase and two-phase cooling characteristics of upward-facing and downward-facing sprays,” International Journal of Heat and Mass Transfer, 49, 5-16, 2006.

[34] M. Monde, "Critical heat flux in saturated forced convection boiling with an impinging droplet,” Trans. JSME, 46, 1146-1155, 1980.

[35] I. Mudawar, W.S. Valentine, "Determination of the local quench curve for spray cooled metallic surfaces,” J. Heat Treating, 7, 107-121,1989. 
[36] J. Kim, “Spray Cooling Heat Transfer: The State of the Art,” ECI International Conference on Boiling Heat Transfer, Spoleto, 7-12 May 2006.

[37] Y-C. Kim, S. Nishio, H. Ohkubo, "Heat transfer in a high temperature region of spray cooling interacting with liquid film flow,” Heat Transfer-Japanese Research, 26-4, 1997.

[38] J. Yang, L. C. Chow, M. R. Pais, and A. Ito, "Liquid film thickness and topography determination using Fresnel difraction and holography,” Experimental Heat Transfer, 5-4, 239-252, 1992.

[39] A. G. Pautsch, T. A. Shedd, “Adiabatic and diabatic measurements of the liquid film thickness during spray cooling with FC-72,” International Journal of Heat and Mass Transfer 49, 2610-2618, 2006.

[40] R. P. Selvam, L. Lin and R. Ponnappan, "Computational Modeling of Spray Cooling: Current Status and Future Challenge,” CP746, Space Technology and applications international forum-STAIF, 2005.

[41] T. Glatzel, "Hydrodynamics in Rotating Systems," Diploma Thesis, Institute of Microsystem Technology, IMTEK, Albert-Ludwings-University Freiburg, Germany, 2003.

[42] CFD-ACE + Manual, 2006.

[43] Suhas V. Patankar, Numerical Heat Transfer and Fluid Flow, Hemisphere Publishing Corporation, 1980.

[44] F. M. White, Viscous Fluid Flow, McGraw-Hill, Second edition, 1991. 
[45] W. M. Rohsenow and J. P. Hartnett, Handbook of Heat Transfer, McGraw-Hill, 1973.

[46] A. Bejan, Heat Transfer, John Wiley and Sons, Inc, 1993.

[47] C. A. Hunnell, "Design, Construction and Initial Testing of Experimental Test Package for Convective Spray Cooling in Terrestrial Gravity Condition”, Department of Mechanical and Aerospace Engineering, West Virginia University, 2005. 


\section{! Appendix A-1 Parabolic Initial Condition Subroutine !}

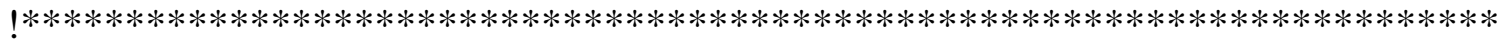

MODULE cfdrc_user

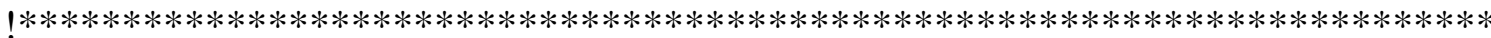

IMPLICIT NONE

INTEGER, PARAMETER :: int_p = SELECTED_INT_KIND(8)

INTEGER, PARAMETER :: string_length $=80$

INTEGER, PARAMETER :: real_p = SELECTED_REAL_KIND(8)

INTEGER, PARAMETER $::$ XDIR $=1$, YDIR $=2$, ZDIR $=3$

! Utility parameters.

REAL(real_p), PARAMETER :: zero $=0.0 \mathrm{~d} 0$, one $=1.0 \mathrm{~d} 0$, two $=2.0 \mathrm{~d} 0, \&$

$\&$ three $=3 . \mathrm{d} 0$, four $=4.0 \mathrm{~d} 0, \mathrm{pi}=3.1415926535898 \mathrm{~d} 0$

! Declare global variables

! USER CODE BEGIN

! these variables will be set during the first iteration

REAL(real_p), DIMENSION(:), ALLOCATABLE ::Su_Fluid2, Sp_Fluid2

REAL(real_p), DIMENSION(:), ALLOCATABLE ::Su_V,Sp_V,Su_U,Sp_U

REAL(real_p), DIMENSION(:), ALLOCATABLE ::Su_H, Sp_H

REAL(real_p), DIMENSION(:), ALLOCATABLE :: Ux,Vy

INTEGER(int_p) :: Fluid2_index,U_index,V_index, \&

$\&$ vol_index,H_index,XC_index, $\mathrm{n} \_$cells

LOGICAL :: first_iter $=$.TRUE.

INTEGER(int_p) :: ind_u, ind_inlet

! USER CODE END

END MODULE cfdrc_user

! $* * * * * * * * * * * * * * * * * * * * * * * * * * * * * * * * * * * * * * * * * * * * * * * * * * * * * * * * * * * * * * * * * * * * * * *$

SUBROUTINE uinit(var_index, vcindex)

!DEC\$ ATTRIBUTES DLLEXPORT :: uinit

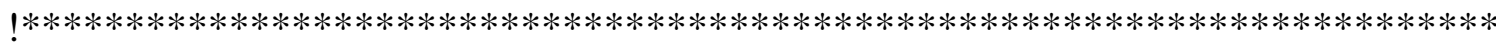

! copyright (c) 1998 cfd research corp. all rights reserved.

! 
! purpose : To allow user to set specialized initial conditions.

!

! Arguments:

! Input : IVAR is an integer flag indicating which independent

! variable this routine is called for.

! vc_name is a volume condition name defined for the zone

! for which initial conditions are to be set.

!

! This routine is called for each variable requested in the INITIAL

! CONDITIONS section of the GUI.

!

! The integer flag 'var_index' can be used to distinguish which variable this

! routine has been called for and character string 'vc_name' can be used

! to distinguish zone.

!

! This routine is called on for each volume condition(VC) where user-defined

! initial conditions are specified. The user has to specify initial values for

! all the cells in the volume condition. User can use following user access

! routines to get the cell related data such as cell index, number of cells

! in VC, and VC index.

! get_vc_index(vcname, vc_index, error)

! get_cells_vc(vc_index,ncells, error)

!

! User has to run cell loop 1 to ncells and set the values of corresponding ! variables for each cell.

!

! get_cell_index_from_vc(icell,vc_index,ind_cell,error)

! One may use get_value_one_cell to obtain values of various dependent

! variables such as temperature, velocity, Volume etc. using cell index !

! To set the initial conditions use the following user access routine ! set_value_vc(vc_index,var_index,ncells,ic_val,error)

! vc_index is the current volume condition index, var_index is the current

! variable index (for which uinit is called), ncells is the number of cells

! in current volume (can be available from get_cells_vc), ic_val is a real

! array of size ncells, contains the initial values for the current variable, ! and error is the logical variable indicates if there is an error in the ! subroutine.

! Include required global variables declared in cfdrc_user module.

USE cfdrc_user, ONLY : int_p,real_p,string_length

!******* DO NOT REMOVE FOLLOWING LINE FOR MS WINDOWS OS $* * * * * * * *$

INCLUDE 'cfdrc_include'

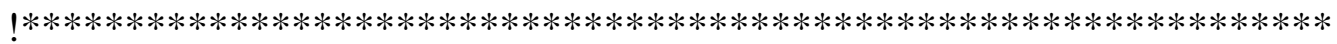

IMPLICIT NONE 
INTEGER(int_p), INTENT(IN) :: var_index, vcindex

! Declare required local variables here.

! USER CODE BEGIN

REAL(real_p):: y_coord, y_max,U_Max

REAL(real_p), ALLOCATABLE,DIMENSION(:):: velocity

INTEGER(int_p) :: volume_index, U_index, N, n_cells, cell_index, Y_index

LOGICAL :: error

CHARACTER(len=string_length):: volume_name = 'air', U_name = 'U', Y_name = 'YC'

\section{! USER CODE END}

! Start writing code here.

! USER CODE BEGIN

OPEN (UNIT = 8, FILE = 'init.txt', STATUS = 'REPLACE')

! given vc name, get vc index

CALL get_vc_index(volume_name, volume_index, error)

! given variable name, get variable index

CALL get_var_index(U_name, U_index, error)

! given variable name, get variable index

CALL get_var_index(Y_name, Y_index, error)

IF (volume_index == vcindex .AND. U_index == var_index) THEN

! given vc index, get the total number of cells in volume

CALL get_cells_vc(volume_index, n_cells, error)

ALLOCATE(velocity(n_cells))

! Loop over the cells of the VC to get the $\mathrm{x}$-coordinate of the cells and calculate $\mathrm{U}=\mathrm{x}^{*} \mathrm{x}$

DO N = 1, n_cells

CALL get_cell_index_from_vc(N, volume_index, cell_index, error)

IF (error) THEN

ENDIF

write $(8, *)$ 'Error: get_cell_index_from_vc' 
CALL get_value_one_cell(Y_index, cell_index, y_coord, error)

IF (error) THEN

write $\left(8,{ }^{*}\right)$ 'Error: get_value_one_cell' ENDIF

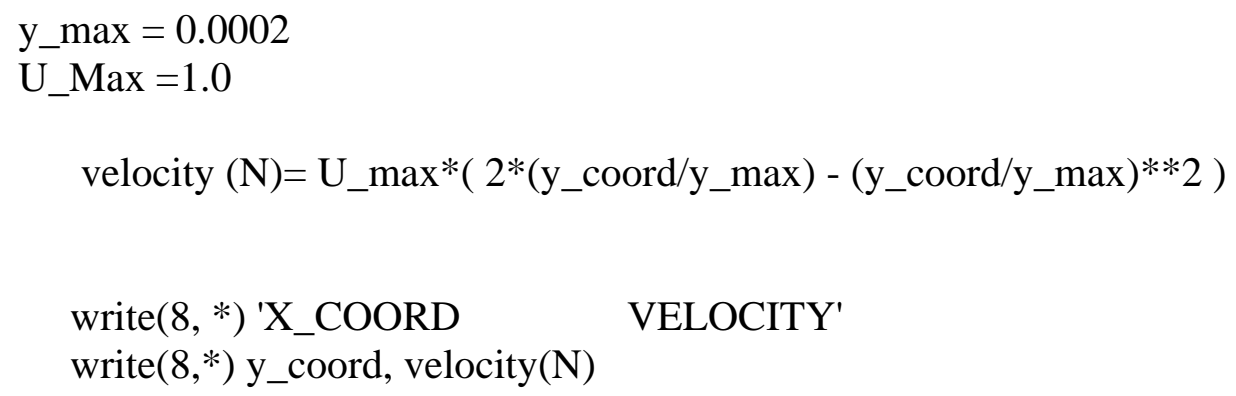

\section{ENDDO}

! Set the value of the velocity in the Volume Condition called 'air'.

CALL set_value_vc(volume_index,U_index,n_cells,velocity,error)

write $\left(8,{ }^{*}\right)$ error

ENDIF

! USER CODE END

RETURN

END SUBROUTINE uinit 
MODULE cfdrc_user

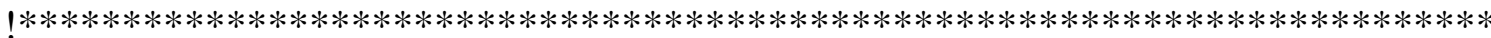

IMPLICIT NONE

INTEGER, PARAMETER :: int_p = SELECTED_INT_KIND(8)

INTEGER, PARAMETER :: string_length $=80$

INTEGER, PARAMETER :: real_p = SELECTED_REAL_KIND(8)

INTEGER, PARAMETER $::$ XDIR $=1$, YDIR $=2$, ZDIR $=3$

! Utility parameters.

REAL(real_p), PARAMETER :: zero $=0.0 \mathrm{~d} 0$, one $=1.0 \mathrm{~d} 0$, two $=2.0 \mathrm{~d} 0, \&$

$\&$ three $=3 . \mathrm{d} 0$, four $=4.0 \mathrm{~d} 0, \mathrm{pi}=3.1415926535898 \mathrm{~d} 0$

! Declare global variables

! USER CODE BEGIN

! these variables will be set during the first iteration

REAL(real_p), DIMENSION(:), ALLOCATABLE ::Su_Fluid2, Sp_Fluid2

REAL(real_p), DIMENSION(:), ALLOCATABLE ::Su_V,Sp_V,Su_U,Sp_U

REAL(real_p), DIMENSION(:), ALLOCATABLE ::Su_H, Sp_H

REAL(real_p), DIMENSION(:), ALLOCATABLE :: Ux,Vy

INTEGER(int_p) :: Fluid2_index,U_index,V_index, \&

$\&$ vol_index,H_index,XC_index, $\mathrm{n} \_$cells

LOGICAL :: first_iter $=$.TRUE.

INTEGER(int_p) :: ind_u, ind_inlet

! USER CODE END

END MODULE cfdrc_user

$! * * * * * * * * * * * * * * * * * * * * * * * * * * * * * * * * * * * * * * * * * * * * * * * * * * * * * * * * * * * * * * * * * * * * * * * * *$

SUBROUTINE ubound(bc_index, var_index, face_index, xfc, yfc, zfc)

!DEC\$ ATTRIBUTES DLLEXPORT :: ubound !******* DO NOT REMOVE ABOVE LINE FOR MS WINDOWS OS *************

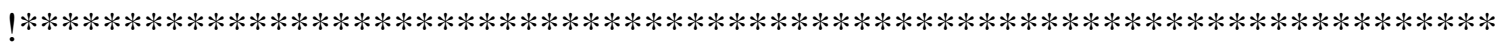
! copyright (c) 1998 cfd research corp. all rights reserved. ! 
! purpose : set boundary value of the current boundary variable.

!

! inputs : bc_index Integer, global boundary index.

! $\quad$ var_index Integer, global variable index.

! face_index, global boundary face index.

! $\quad$ xfc Real, $\mathrm{x}$ coordinate of boundary face center.

! yfc Real, y coordinate of boundary face center.

! zfc Real, z coordinate of boundary face center.

!

! This routine is called face by face basis for each bc record. Use

! get_var_index, get_bc_index and get_active_cell to get the variable

! index, boundary index and active cell index respectively.

!

! Use get_value_one_cell to get the values of different variables

! in a cell associated to face.

!

! Use set_bc() to set the value of current variable(var_index) at

! current face(face_index) along boundary(bc_index).

! Include required global variables declared in cfdrc_user module.

USE cfdrc_user, ONLY : int_p, real_p, string_length

USE cfdrc_user, ONLY : ind_u, ind_inlet, first_iter

!******* DO NOT REMOVE FOLLOWING LINE FOR MS WINDOWS OS $* * * * * * * * *$

INCLUDE 'cfdrc_include'

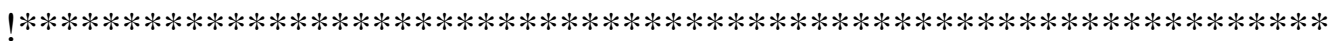

\section{IMPLICIT NONE}

! Declaration of arguments of this subroutine.

REAL(real_p), INTENT(IN) :: xfc, yfc, zfc

INTEGER(int_P), INTENT(IN) :: bc_index, var_index, face_index

! Declare required local variables here.

! USER CODE BEGIN

INTEGER(int_p) :: ierror

REAL(real_p) :: velocity, y_max,U_Max

LOGICAL :: error

CHARACTER(len=string_length) $::$ var_name, inlet_name

! USER CODE END

! Start writing code here.

! USER CODE BEGIN 
! In the first iteration, get the variable index for $\mathrm{U}$

! and the bc index for the boundary (or boundaries) of

! interest. Do this only on the first iteration as these

! values will never change.

OPEN (UNIT=8, FILE='SOURCE.TXT', STATUS='REPLACE', IOSTAT=ierror)

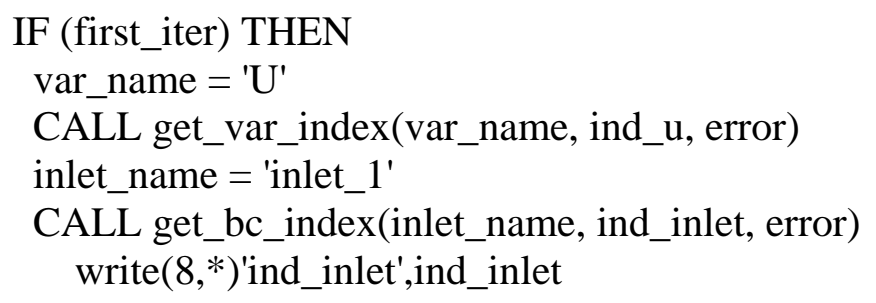

first_iter $=$.FALSE.

\section{ENDIF}

! If the current bc_index matches the index of the ! boundary of interest, then calculate the value and ! set the bc. (Useful for multiple bc's defined via ! ubound.) Same idea for variable (ie: velocity, ! temperature).

IF (bc_index == ind_inlet .AND. var_index == ind_u) THEN

! Duct geometry is such that the inlet is at $\mathrm{x}=0$

! and varies from $y=0$ to $y=2$. To impose a parabolic

! profile for $U$ in the $+x$ direction: $U=y \_m a x \wedge 2-y^{\wedge} 2$.

! Note that yfc, the boundary face coordinate, is

! passed into UBOUND for you.

y_max $=0.0002$

U_Max $=1.0$

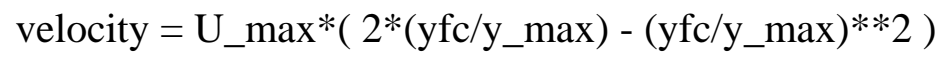

write $(8, *)$ 'velocity',velocity

write $(8, *) ' y f c ', y f c$ 
! Set the value for the boundary face. UBOUND loops

! over all boundary faces for you

CALL set_bc(velocity, error)

ENDIF

! USER CODE END

RETURN

END SUBROUTINE ubound 


\section{! Appendix A-3 Mass Source Term Subroutine !}

$\mid * * * * * * * * * * * * * * * * * * * * * * * * * * * * * * * * * * * * * * * * * * * * * * * * * * * * * * * * * * * * * * * * * * * * * * *$

MODULE cfdrc_user

$! * * * * * * * * * * * * * * * * * * * * * * * * * * * * * * * * * * * * * * * * * * * * * * * * * * * * * * * * * * * * * * * * * * * * * * * *$

IMPLICIT NONE

INTEGER, PARAMETER :: int_p = SELECTED_INT_KIND(8)

INTEGER, PARAMETER :: string_length $=80$

INTEGER, PARAMETER :: real_p = SELECTED_REAL_KIND(8)

INTEGER, PARAMETER $::$ XDIR = 1, YDIR = 2, ZDIR = 3

! Utility parameters.

REAL(real_p), PARAMETER $::$ zero $=0.0 \mathrm{~d} 0$, one $=1.0 \mathrm{~d} 0$, two $=2.0 \mathrm{~d} 0, \&$

$\&$ three $=3 . \mathrm{d} 0$, four $=4.0 \mathrm{~d} 0$, $\mathrm{pi}=3.1415926535898 \mathrm{~d} 0$

! Declare global variables

! USER CODE BEGIN

! these variables will be set during the first iteration

REAL(real_p), DIMENSION(:), ALLOCATABLE ::Su_Fluid2, Sp_Fluid2

REAL(real_p), DIMENSION(:), ALLOCATABLE :: Ux,Vy

REAL(real_p), DIMENSION(:), ALLOCATABLE :: XC,YC

REAL(real_p), DIMENSION(:), ALLOCATABLE :: Theta

INTEGER(int_p) :: Fluid2_index, vol_index, \&

\& XC_index , n_cells, YC_index

LOGICAL : : first_iter = .TRUE.

INTEGER(int_p) :: ind_u, ind_inlet

! USER CODE END

END MODULE cfdrc_user

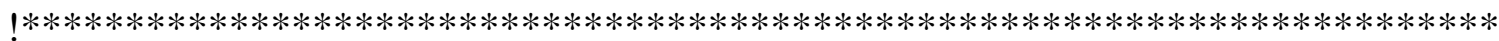




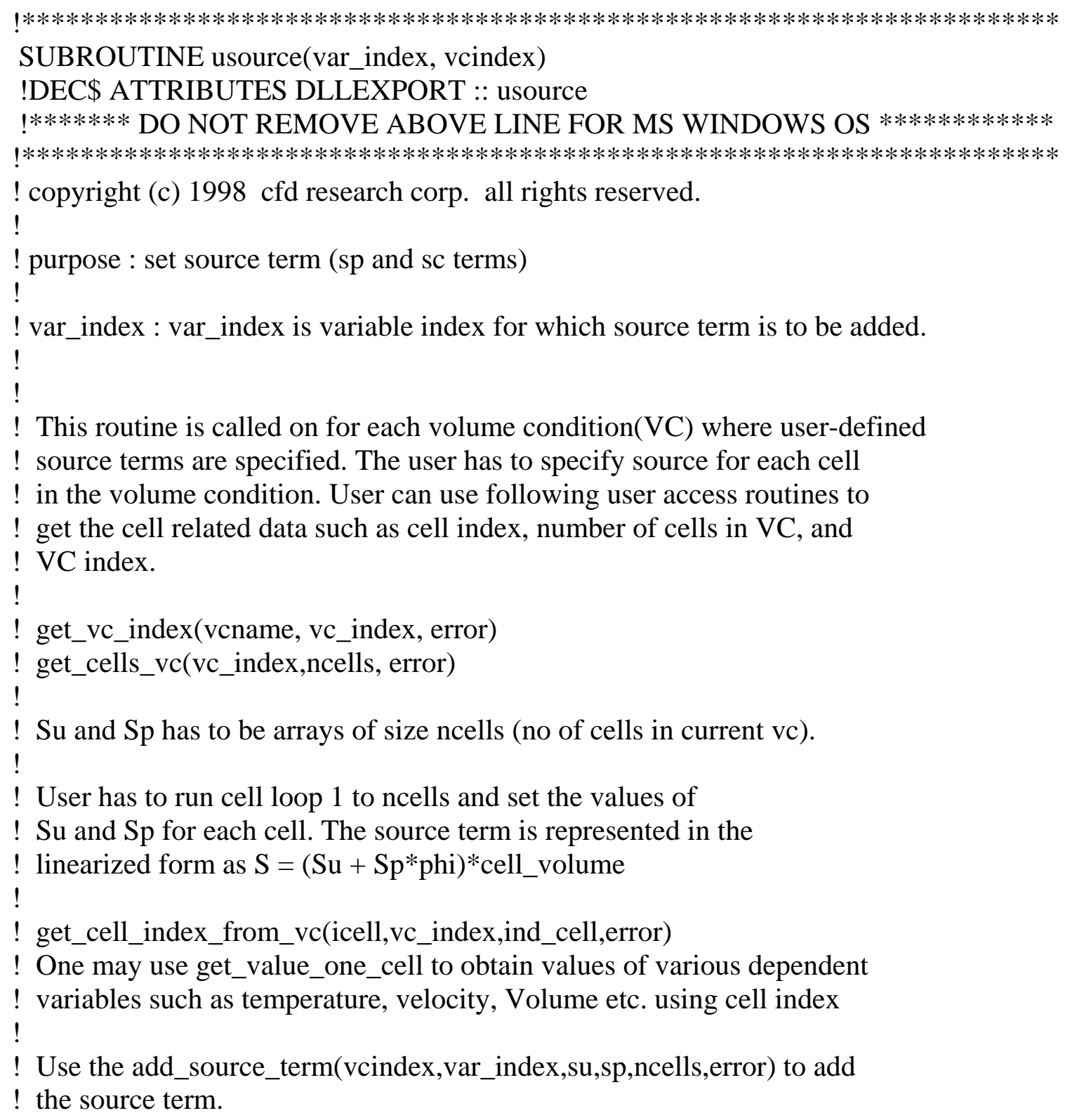

! Include required global variables declared in cfdrc_user module.

USE cfdrc_user, ONLY : int_p, real_p, string_length

! global variables are used to store information that must

! be retained from one iteration to the next.

USE cfdrc_user, ONLY : Su_Fluid2, Sp_Fluid2,Fluid2_index,\&

\& vol_index, XC_index ,n_cells, \&

\& Ux, Vy,YC_index,XC,YC,Theta 
INCLUDE 'cfdrc_include'

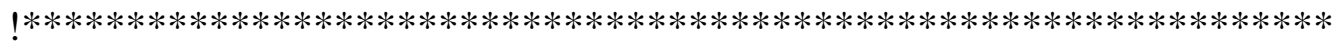

IMPLICIT NONE

INTEGER(int_p), INTENT(IN) :: var_index, vcindex

! Declare required local variables here.

! USER CODE BEGIN

INTEGER(int_p) :: N, ierror, n_steps,cell_index,n_cell

LOGICAL :: error , first_iter $=$.TRUE.

CHARACTER(len=string_length) :: Fluid2_name = 'VOF_FLUID2', \&

\& vol_name $=$ 'air',U_name $=$ 'U', \&

$\& V \_$name $=$'V',Xc_name $=$'XC',yc_name ='YC'

! USER CODE END

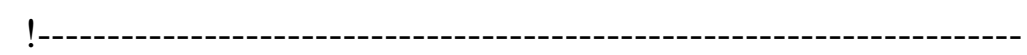

! Start writing code here.

! USER CODE BEGIN

! USER CODE BEGIN

OPEN (UNIT=8, FILE='SOURCE.TXT', STATUS='REPLACE', IOSTAT=ierror)

! Allocate arrays and get information that does not change during

! simulation: n_cells, volume index, variable indices, index of

! mass source cell

IF (first_iter) THEN

CALL get_vc_index('air', vol_index, error) 
! JVC addition to protect against problems in multi-vc models.

IF (vcindex .ne. vol_index) RETURN

CALL get_cells_vc(vol_index, n_cells, error)

WRITE(8,*)'vol_index=',vol_index

CALL get_var_index('VOF_FLUID2', Fluid2_index, error)

WRITE $(8, *)$ 'Fluid2_index=',Fluid2_index

CALL get_var_index('XC', XC_index, error)

WRITE $(8, *)^{\prime}$ XC_index=',XC_index

CALL get_var_index('YC', YC_index, error)

WRITE $(8, *)^{\prime} Y C \_$index=',YC_index

! Memory Allocation

ALLOCATE(Su_Fluid2(n_cells))

ALLOCATE(Sp_Fluid2(n_cells))

ALLOCATE(XC(n_cells))

ALLOCATE(YC(n_cells))

ALLOCATE(Theta(n_cells)) 
! Now that memory is allocated, calculate the things that do not change....

WRITE $(8, *)$ 'Completed allocation'

DO N=1,n_cells

CALL get_cell_index_from_vc(N, vol_index, cell_index, error)

CALL get_value_one_cell(XC_index, cell_index,XC(N), error)

IF (error) THEN

WRITE $\left(8,{ }^{*}\right)$ 'error getting x coordinate'

ENDIF

CALL get_value_one_cell(YC_index, cell_index,YC(N), error)

IF (error) THEN

WRITE $(8, *)$ 'error getting y coordinate'

ENDIF

first_iter $=$.FALSE.

WRITE $\left(8,{ }^{*}\right)$ 'Completed initialization'

\section{ENDDO}

ENDIF 
IF (vol_index == vcindex) THEN

DO N=1,n_cells

! We have to divide the total mass flow rate by the

! number of cells in this geometry in the upper liquid layer

$$
\begin{aligned}
& \operatorname{Theta}(\mathrm{N})=\operatorname{ATAN}(\mathrm{XC}(\mathrm{N}) / 0.013) \quad \text { ! spray Injecting angle } \\
& \operatorname{Vy}(\mathrm{N})=-8.0 * \operatorname{COS}(\operatorname{Theta}(\mathrm{N})) \quad \text { ! spray vertical component } \\
& \mathrm{Ux}(\mathrm{N})=8.0 * \operatorname{SIN}(\operatorname{Theta}(\mathrm{N})) \quad \text { ! Spray horizontal component }
\end{aligned}
$$

Su_Fluid2(N) $=5.799658273 d-6 * \operatorname{COS}(\operatorname{Theta}(\mathrm{N}))$

Sp_Fluid2(N) $=0.0$

\section{ENDDO}

IF (var_index==Fluid2_index) THEN

error)

CALL add_source_term(vol_index,Fluid2_index, Su_Fluid2,Sp_Fluid2,n_cells, 
!

ENDIF

ENDIF

! USER CODE END

RETURN

END SUBROUTINE usource 


\section{! Appendix A-4 U Momentum Source Term Subroutine!}

! $* * * * * * * * * * * * * * * * * * * * * * * * * * * * * * * * * * * * * * * * * * * * * * * * * * * * * * * * * * * * * * * * * * * * * * *$

MODULE cfdrc_user

$! * * * * * * * * * * * * * * * * * * * * * * * * * * * * * * * * * * * * * * * * * * * * * * * * * * * * * * * * * * * * * * * * * * * * * * *$

IMPLICIT NONE

INTEGER, PARAMETER :: int_p = SELECTED_INT_KIND(8)

INTEGER, PARAMETER :: string_length $=80$

INTEGER, PARAMETER :: real_p = SELECTED_REAL_KIND(8)

INTEGER, PARAMETER $::$ XDIR = 1, YDIR = 2, ZDIR = 3

! Utility parameters.

REAL(real_p), PARAMETER $::$ zero $=0.0 \mathrm{~d} 0$, one $=1.0 \mathrm{~d} 0$, two $=2.0 \mathrm{~d} 0, \&$

$\&$ three $=3 . \mathrm{d} 0$, four $=4.0 \mathrm{~d} 0, \mathrm{pi}=3.1415926535898 \mathrm{~d} 0$

! Declare global variables

! USER CODE BEGIN

! these variables will be set during the first iteration

REAL(real_p), DIMENSION(:), ALLOCATABLE ::Su_Fluid2, Sp_Fluid2

REAL(real_p), DIMENSION(:), ALLOCATABLE ::Su_U,Sp_U

REAL(real_p), DIMENSION(:), ALLOCATABLE :: Ux

REAL(real_p), DIMENSION(:), ALLOCATABLE :: XC,YC

REAL(real_p), DIMENSION(:), ALLOCATABLE :: Theta

INTEGER(int_p) :: Fluid2_index,U_index,vol_index,\&

\& vol_index,XC_index ,n_cells,YC_index

LOGICAL :: first_iter = .TRUE.

INTEGER(int_p) :: ind_u, ind_inlet

! USER CODE END

END MODULE cfdrc_user 


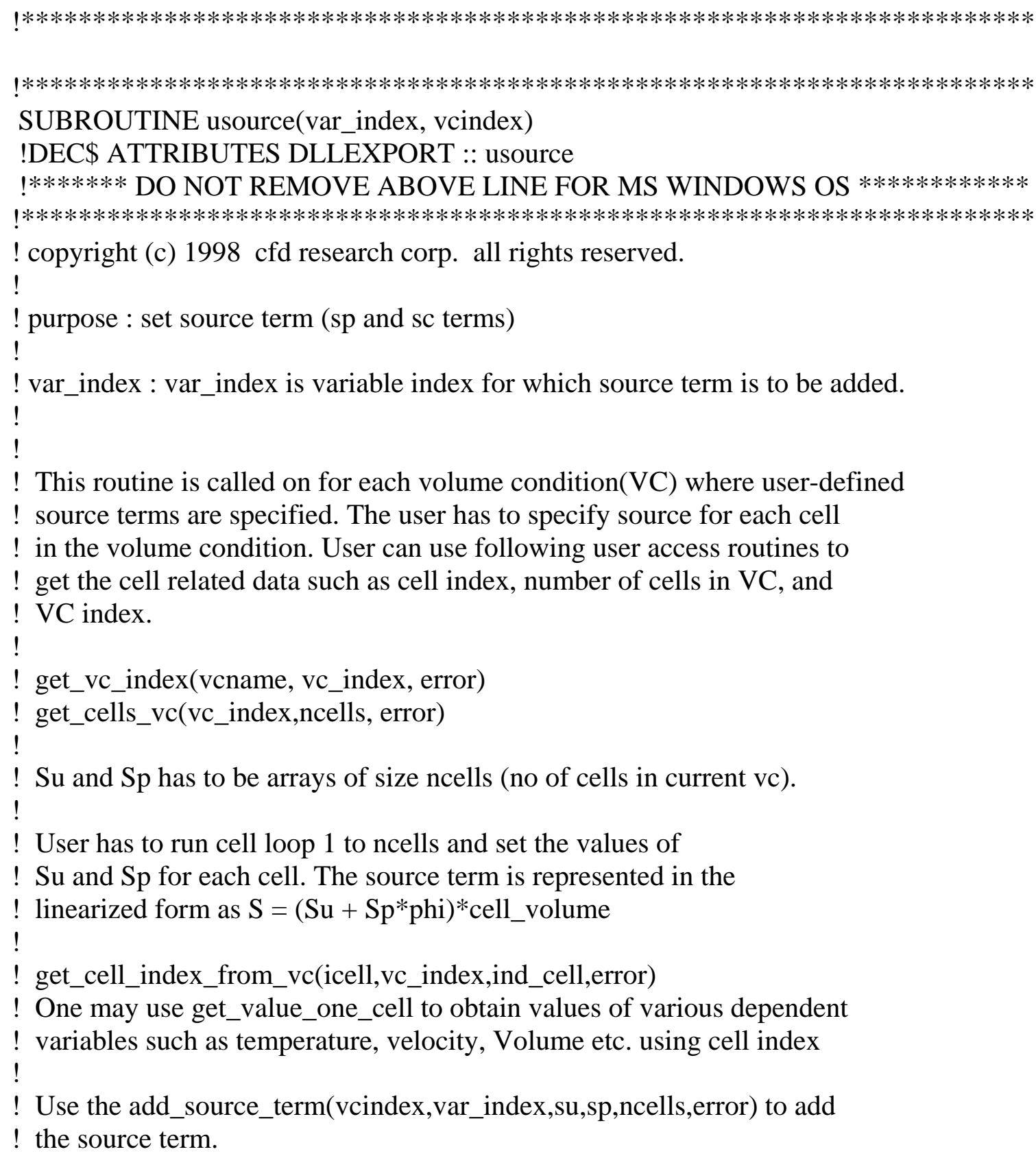

! Include required global variables declared in cfdrc_user module.

USE cfdrc_user, ONLY : int_p, real_p, string_length

! global variables are used to store information that must

! be retained from one iteration to the next.

USE cfdrc_user, ONLY : Su_Fluid2, Sp_Fluid2,Fluid2_index,\& \& Su_U, Sp_U, U_index,\& 
\& vol_index, XC_index,n_cells,\&

\& Ux,YC_index,XC,YC,Theta

!******* DO NOT REMOVE FOLLOWING LINE FOR MS WINDOWS OS ********

INCLUDE 'cfdrc_include'

! $* * * * * * * * * * * * * * * * * * * * * * * * * * * * * * * * * * * * * * * * * * * * * * * * * * * * * * * * * * * * * * *$

IMPLICIT NONE

INTEGER(int_p), INTENT(IN) :: var_index, vcindex

! Declare required local variables here.

! USER CODE BEGIN

INTEGER(int_p) :: N, ierror, n_steps,cell_index,n_cell

LOGICAL :: error , first_iter $=$.TRUE.

CHARACTER(len=string_length) :: Fluid2_name = 'VOF_FLUID2', \&

\& vol_name $=$ 'air', U_name $=$ 'U', \&

$\& \mathrm{xc} \_$name $=$'XC',yc_name $=$'YC'

! USER CODE END

!-

! Start writing code here.

! USER CODE BEGIN

! USER CODE BEGIN

OPEN (UNIT=8, FILE='SOURCE.TXT', STATUS='REPLACE', IOSTAT=ierror)

! Allocate arrays and get information that does not change during

! simulation: n_cells, volume index, variable indices, index of

! mass source cell 
IF (first_iter) THEN

CALL get_vc_index('air', vol_index, error)

! JVC addition to protect against problems in multi-vc models.

! not sure if necessary...

IF (vcindex .ne. vol_index) RETURN

CALL get_cells_vc(vol_index, n_cells, error)

WRITE $\left(8,{ }^{*}\right)^{\prime}$ vol_index=',vol_index

CALL get_var_index('VOF_FLUID2', Fluid2_index, error)

WRITE(8,*)'Fluid2_index=',Fluid2_index

CALL get_var_index('U', U_index, error)

WRITE(8, *)'U_index=',U_index

CALL get_var_index('XC', XC_index, error)

WRITE $\left(8,{ }^{*}\right)$ 'XC_index=',XC_index

CALL get_var_index('YC', YC_index, error)

WRITE $\left(8,{ }^{*}\right)^{\prime} Y C \_$index=',YC_index

! Memory Allocation

ALLOCATE(Su_Fluid2(n_cells))

ALLOCATE(Sp_Fluid2(n_cells)) 
ALLOCATE(Su_U(n_cells))

ALLOCATE(Sp_U(n_cells))

ALLOCATE(Ux(n_cells)) ～!Memory allocation for U velocity

ALLOCATE(XC(n_cells))

ALLOCATE(YC(n_cells))

ALLOCATE(Theta(n_cells))

! Now that memory is allocated, calculate the things that do not change....

WRITE $(8, *)$ 'Completed allocation'

DO N=1,n_cells

CALL get_cell_index_from_vc(N, vol_index, cell_index, error)

CALL get_value_one_cell(XC_index, cell_index,XC(N), error)

IF (error) THEN

WRITE $(8, *)$ 'error getting x coordinate'

ENDIF

CALL get_value_one_cell(YC_index, cell_index,YC(N), error)

IF (error) THEN

WRITE $\left(8,{ }^{*}\right)$ 'error getting y coordinate'

ENDIF 
first_iter $=$.FALSE.

WRITE $\left(8,{ }^{*}\right)$ 'Completed initialization'

\section{ENDDO}

\section{ENDIF}

IF (vol_index == vcindex) THEN

DO N=1,n_cells

! We have to divide the total mass flow rate by the

! number of cells in this geometry is in the upper liquid layer

$$
\begin{array}{ll}
\text { Theta }(\mathrm{N})=\operatorname{ATAN}(\mathrm{XC}(\mathrm{N}) / 0.013) & \text { ! Spray injecting angle } \\
\operatorname{Vy}(\mathrm{N})=-8.0 * \operatorname{COS}(\operatorname{Theta}(\mathrm{N})) & \text { ! Spray vertical component } \\
\mathrm{Ux}(\mathrm{N})=8.0 * \operatorname{SIN}(\operatorname{Theta}(\mathrm{N})) & \text { ! Spray horizontal component }
\end{array}
$$

Su_Fluid2 $(\mathrm{N})=5.799658273 \mathrm{~d}-6 * \operatorname{COS}($ Theta $(\mathrm{N}))$

Sp_Fluid2 $(\mathrm{N})=0.0$ 


\section{ENDDO}

IF (var_index==Fluid2_index) THEN

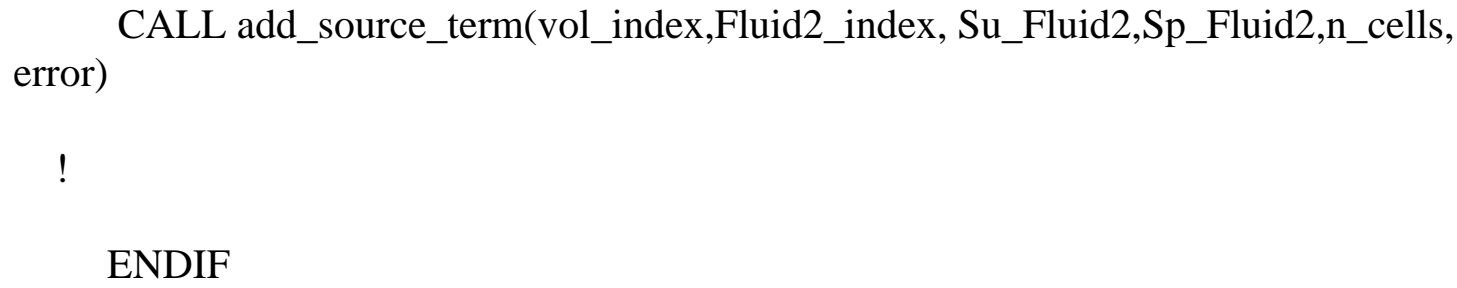

CALL add_source_term(vol_index,Fluid2_index, Su_Fluid2,Sp_Fluid2,n_cells, error)

!

ENDIF

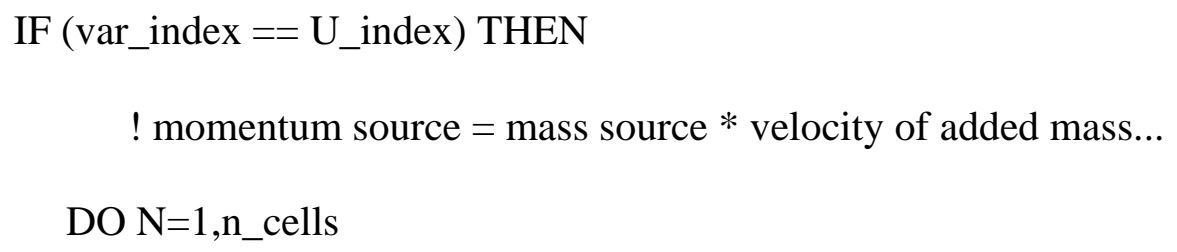

Sp_U(N) $=0.0$

$\mathrm{Su} \_\mathrm{U}(\mathrm{N})=\mathrm{Ux}(\mathrm{N}) * \mathrm{Su} \_$Fluid2$(\mathrm{N})$

ENDDO

CALL add_source_term(vol_index, U_index, Su_U, Sp_U, n_cells, error) ENDIF

ENDIF 
! USER CODE END

RETURN

END SUBROUTINE usource 


\section{! Appendix A-5 V Momentum Source Term Subroutine !}

! $* * * * * * * * * * * * * * * * * * * * * * * * * * * * * * * * * * * * * * * * * * * * * * * * * * * * * * * * * * * * * * * * * * * * * * *$

MODULE cfdrc_user

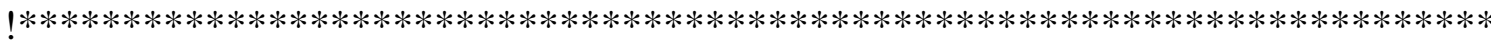

IMPLICIT NONE

INTEGER, PARAMETER :: int_p = SELECTED_INT_KIND(8)

INTEGER, PARAMETER :: string_length $=80$

INTEGER, PARAMETER :: real_p = SELECTED_REAL_KIND(8)

INTEGER, PARAMETER $::$ XDIR $=1$, YDIR $=2$, ZDIR $=3$

! Utility parameters.

REAL(real_p), PARAMETER :: zero $=0.0 \mathrm{~d} 0$, one $=1.0 \mathrm{~d} 0$, two $=2.0 \mathrm{~d} 0, \&$

$\&$ three $=3 . \mathrm{d} 0$, four $=4.0 \mathrm{~d} 0, \mathrm{pi}=3.1415926535898 \mathrm{~d} 0$

! Declare global variables

! USER CODE BEGIN

! these variables will be set during the first iteration

REAL(real_p), DIMENSION(:), ALLOCATABLE ::Su_Fluid2, Sp_Fluid2

REAL(real_p), DIMENSION(:), ALLOCATABLE ::Su_V,Sp_V

REAL(real_p), DIMENSION(:), ALLOCATABLE :: Vy

REAL(real_p), DIMENSION(:), ALLOCATABLE :: XC,YC

REAL(real_p), DIMENSION(:), ALLOCATABLE :: Theta

INTEGER(int_p) :: Fluid2_index,V_index, \&

\& vol_index,XC_index,n_cells,YC_index

LOGICAL :: first_iter $=$.TRUE.

INTEGER(int_p) :: ind_u, ind_inlet

! USER CODE END

END MODULE cfdrc_user

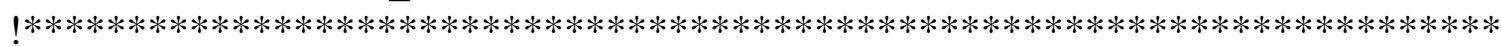




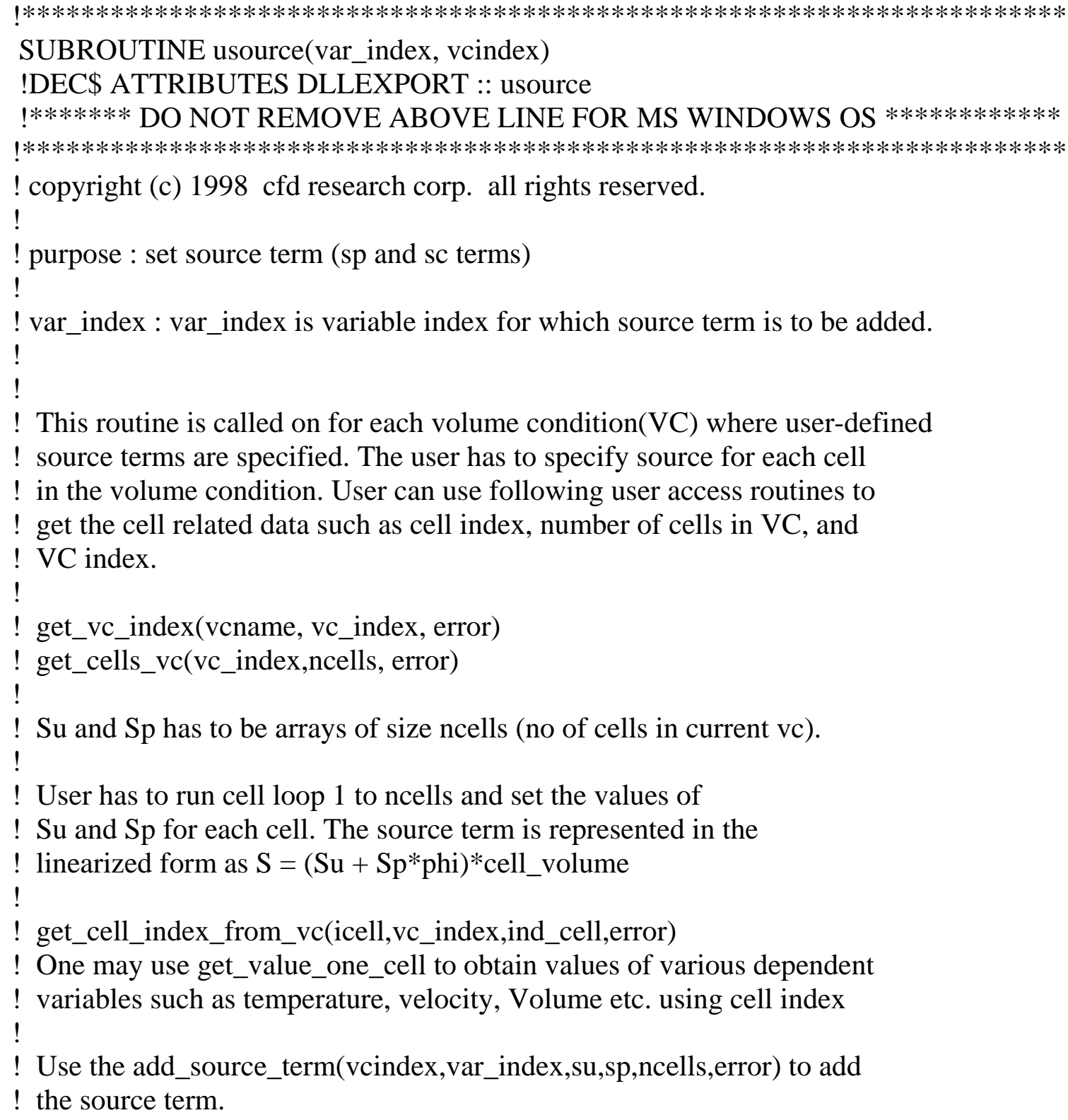

! Include required global variables declared in cfdrc_user module.

USE cfdrc_user, ONLY : int_p, real_p, string_length

! global variables are used to store information that must ! be retained from one iteration to the next.

USE cfdrc_user, ONLY : Su_Fluid2, Sp_Fluid2,Fluid2_index,\&

$\&$ Su_V, Sp_V ,V_index,\&

\& vol_index, XC_index ,n_cells, \& 
\& Vy,YC_index,XC,YC,Theta

!******* DO NOT REMOVE FOLLOWING LINE FOR MS WINDOWS OS ********

INCLUDE 'cfdrc_include'

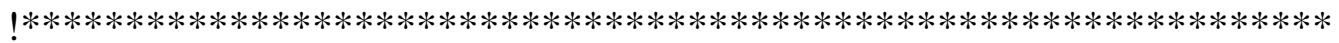

IMPLICIT NONE

INTEGER(int_p), INTENT(IN) :: var_index, vcindex

! Declare required local variables here.

! USER CODE BEGIN
\end{abstract}

INTEGER(int_p) :: N, ierror, n_steps,cell_index,n_cell

LOGICAL :: error , first_iter $=$.TRUE.

CHARACTER(len=string_length) $::$ Fluid2_name = 'VOF_FLUID2', \&

\& vol_name $=$ 'air', $\mathrm{V} \_$name $=$' $\mathrm{V}$ ', \&

$\& \mathrm{xc} \_$name $=$'XC',yc_name $=$'YC'

! USER CODE END

\& ${ }^{\prime}$ _name $=' X C, y c \_n a m e=' Y C '$

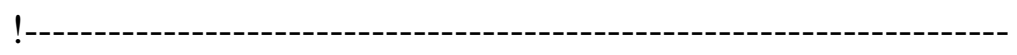

! Start writing code here.

! USER CODE BEGIN

! USER CODE BEGIN

OPEN (UNIT=8, FILE='SOURCE.TXT', STATUS='REPLACE', IOSTAT=ierror)

! Allocate arrays and get information that does not change during

! simulation: n_cells, volume index, variable indices, index of

! mass source cell

IF (first_iter) THEN 
CALL get_vc_index('air', vol_index, error)

! JVC addition to protect against problems in multi-vc models.

IF (vcindex .ne. vol_index) RETURN

CALL get_cells_vc(vol_index, n_cells, error)

WRITE $(8, *)^{\prime}$ vol_index=',vol_index

CALL get_var_index('VOF_FLUID2', Fluid2_index, error)

WRITE(8,*)'Fluid2_index=',Fluid2_index

CALL get_var_index('V', V_index, error)

WRITE $\left(8,{ }^{*}\right)^{\prime} \mathrm{V} \_$index $=$',V_index

CALL get_var_index('XC', XC_index, error)

WRITE $(8, *)^{\prime}$ XC_index=',XC_index

CALL get_var_index('YC', YC_index, error)

WRITE $\left(8, *{ }^{*}\right.$ 'YC_index=',YC_index

! Memory Allocation

ALLOCATE(Su_Fluid2(n_cells))

ALLOCATE(Sp_Fluid2(n_cells))

ALLOCATE(Su_V(n_cells)) 
ALLOCATE(Sp_V(n_cells))

ALLOCATE(Vy(n_cells)) !Memory allocation for V velocity

ALLOCATE(XC(n_cells))

ALLOCATE(YC(n_cells))

ALLOCATE(Theta(n_cells))

! Now that memory is allocated, calculate the things that do not change....

WRITE $(8, *)$ 'Completed allocation'

DO N=1,n_cells

CALL get_cell_index_from_vc(N, vol_index, cell_index, error)

CALL get_value_one_cell(XC_index, cell_index,XC(N), error) IF (error) THEN

WRITE $(8, *)$ 'error getting x coordinate' ENDIF

CALL get_value_one_cell(YC_index, cell_index,YC(N), error) IF (error) THEN

WRITE $\left(8,{ }^{*}\right)$ 'error getting y coordinate'

ENDIF

first_iter $=$.FALSE. 
WRITE $(8, *)$ 'Completed initialization'

ENDDO

ENDIF

IF (vol_index == vcindex) THEN

DO N=1,n_cells

! We have to divide the total mass flow rate by the

! number of cells in this geometry is in the upper liquid layer

$$
\begin{aligned}
& \operatorname{Theta}(\mathrm{N})=\operatorname{ATAN}(\mathrm{XC}(\mathrm{N}) / 0.013) \quad \text { ! spray Injecting angle } \\
& \operatorname{Vy}(\mathrm{N})=-8.0 * \operatorname{COS}(\operatorname{Theta}(\mathrm{N})) \quad \text { ! spray vertical component } \\
& \mathrm{Ux}(\mathrm{N})=8.0 * \operatorname{SIN}(\operatorname{Theta}(\mathrm{N}))
\end{aligned}
$$

Su_Fluid2 $(\mathrm{N})=5.799658273 \mathrm{~d}-6 * \operatorname{COS}($ Theta $(\mathrm{N}))$

Sp_Fluid2 $(\mathrm{N})=0.0$

ENDDO 
IF (var_index==Fluid2_index) THEN

\begin{abstract}
CALL add_source_term(vol_index,Fluid2_index, Su_Fluid2,Sp_Fluid2,n_cells, error)

!

ENDIF
\end{abstract}

IF (var_index == V_index) THEN

DO N=1,n_cells

Su_V(N) $=\mathrm{Vy}(\mathrm{N}) * \mathrm{Su} \_$Fluid $2(\mathrm{~N})$

$\mathrm{Sp}_{-} \mathrm{V}(\mathrm{N})=0.0$

ENDDO

CALL add_source_term(vol_index, V_index, Su_V, Sp_V, n_cells, error)

ENDIF

ENDIF

! USER CODE END

RETURN

END SUBROUTINE usource 


\section{Biographical Sketch}

Rageey Mounir Youssef was born in Alexandria, Egypt to Kawkab and Mounir Youssef on March 11, 1968. He graduated from Shedwan High School in 1985.

Mr. Youssef attended Alexandria University and recived his Bachelor Degree in Mechanical Engineering in 1990. He also got his Diploma in Mechancial Engineering in 1995 from the same university. In 2000 Mr. Youssef earned the dgree of Master in Mechanical Engineering from Alexandria University.

Mr. Youssef Joined West Virginia University in 2002 and earned his Master of

Science in Civil and Environmental Engineering. He is a Member of the American Institute of Hydrology.

In 2002 Mr. Youssef married Sozan Gamil Kras. They have two children: Jessica Youssef and Andrew Youssef. 